UNIVERSIDADE DE BRASÍLIA

INSTITUTO DE GEOCIÊNCIAS

PROGRAMA DE PÓS-GRADUAÇÃo EM GEOLOGIA

\title{
TAXONOMIA, PALEOECOLOGIA E BIOESTRATIGRAFIA DE OSTRACODES DA FORMAÇÃO RIACHUELO, BACIA DE SERGIPE-ALAGOAS, NORDESTE DO BRASIL
}

\author{
Tese de Doutorado \\ $\mathrm{N}^{\mathrm{o}} 121$
}

Lucas Silveira Antonietto

Brasília, Março de 2015. 


\title{
TAXONOMIA, PALEOECOLOGIA E BIOESTRATIGRAFIA DE OSTRACODES DA FORMAÇÃO RIACHUELO, BACIA DE SERGIPE-ALAGOAS, NORDESTE DO BRASIL
}

\begin{abstract}
Tese submetida à Coordenação do Programa de Pós-graduação em Geologia, Universidade de Brasília, como requisito parcial para obtenção de grau de Doutor em Geologia.
\end{abstract}

Área de Concentração: Geologia Regional

\author{
Orientadores: \\ Professor Doutor Dermeval A. Do Carmo (Orientador - IG/UnB) \\ Doutor Gene Hunt (Coorientador - NHMRM/Smithsonian) \\ Comissão examinadora: \\ Professor Doutor Dermeval A. Do Carmo (UnB - Brasília) \\ Professor Doutor Carlos Jorge de Abreu (UnB - Brasília) \\ Professor Doutor Ricardo Lourenço Pinto (UnB - Brasília) \\ Professor Doutor Gerson Fauth (UNISINOS - São Leopoldo) \\ Professor Doutor Cristianini Trecastro Bergue (UNISINOS - São Leopoldo)
}

Brasília, Março de 2015. 


\title{
TAXONOMIA, PALEOECOLOGIA E BIOESTRATIGRAFIA DE OSTRACODES DA FORMAÇÃO RIACHUELO, BACIA DE SERGIPE-ALAGOAS, NORDESTE DO BRASIL
}

Tese submetida à Coordenação do Programa de Pós-Graduação em Geologia, Universidade de Brasília, como requisito parcial para obtenção de grau de Doutor em Geologia.

\author{
Área de Concentração: Geologia Regional. \\ Orientador: Professor Doutor Dermeval Aparecido do Carmo. \\ Coorientador: Doutor Gene Hunt.
}

\section{Banca examinadora:}
Professor Doutor Dermeval Aparecido do Carmo (Orientador)
Universidade de Brasília (UnB)

Professor Doutor Carlos Jorge de Abreu

Universidade de Brasília (UnB)

Professor Doutor Ricardo Lourenço Pinto

Universidade de Brasília (UnB)

Professor Doutor Gerson Fauth

Universidade do Vale do Rio dos Sinos (UNISINOS)

Professor Doutor Cristianini Trecastro Bergue

Universidade do Vale do Rio dos Sinos (UNISINOS)

$$
\text { Brasília - DF }
$$

Aprovada em 28/04/2015. 
Esta tese é dedicada à Professora Emérita Maria Léa Salgado-Labouriau, colega de trabalho e eterna fonte de inspiração pessoal, intelectual e, principalmente, profissional. 


\section{AGRADECIMENTOS}

Meus sinceros agradecimentos a todos os que contribuíram para a conclusão deste trabalho, direta ou indiretamente. Espero que esta tese seja digna do esforço e paciência de todos os que me acompanharam durante a épica jornada até aqui.

A Edriana e Leonardo, por todo o apoio e compreensão durante esses anos fantásticos. Aos meus pais, Aldo e Tereza, e irmãs, Laís e Ana Tereza, pelos muitos anos de convivência. Aos meus queridos avós, Aparecida, Irotides e Aldemário; meus padrinhos, Márcia e José Augusto; meu afilhado, Matheus; e todos os tios, primos e sobrinhos que participaram positivamente desta caminhada. Aos amigos, Rodolpho, Murilo, Eliecer, Daniela, Stella, José Mendes, Graham, Cláudia, Mariano e Tito, pelo sempre excelente tempo compartilhado.

Ao Professor Doutor Dermeval Aparecido do Carmo, pela orientação durante o curso deste Doutorado. A conclusão deste trabalho obviamente não seria possível sem toda a estrutura e cooperação oferecidas. Ao Doutor Gene Hunt, coorientador durante meu Doutorado Sandwich no National Museum of Natural History do Smithsonian Institute. A Carlita Sanford, da mesma instituição, por todo o esforço com os desdobramentos do presente trabalho. Aos colegas de laboratório, Matheus, Evelyn, Christian, Simone e Guilherme, pelo convívio sempre amigável.

Ao Doutor Gilles Miller, do Natural History Museum, pela acolhida durante visita às coleções de ostracodes do museu. Aos pesquisadores Marta Claudia Viviers, João Villar Queiroz Neto, Jeanine de Lacerda Grillo, Oscar Strohschoen Junior e ao Técnico em Microscopia Eletrônica Rogério da Silva Martins da Costa, pelo apoio fundamental durante as atividades realizadas no CENPES. Ao Doutor Wagner de Souza-Lima (CENPES) e ao Professor Doutor Mario Luis Assine (UNESP - Rio Claro), pelos apoios logístico e teórico nos estágios iniciais.

Ao Instituto de Geociências da Universidade de Brasília e seus professores, Doutor Bernhard Manfred Buhn, Doutor Carlos Jorge de Abreu, Doutor Elton Luiz Dantas, João Carlos Coimbra, Doutor Ricardo Lourenço Pinto, Doutor Massimo Matteini e Doutor Roberto Ventura Santos, pelas disciplinas cursadas nestes últimos quatro anos. Aos coordenadores, Doutor Nilson Francisquini Botelho e Doutor Valmir da Silva Souza, pelos auxílios acadêmico e financeiro. Aos secretários e demais funcionários, pelo suporte nas atividades diárias. Por fim, à PETROBRAS S.A., a FINATEC, a CAPES, o CNPq e o Smithsonian Institute, pelo suporte financeiro para a realização de diversas atividades durante o Doutorado, incluindo o Projeto OSTRAKi, o Doutorado Sandwich e simpósios nacionais e internacionais. 
I've looked under chairs

Eu olhei embaixo das cadeiras

I've looked under tables

Eu olhei embaixo das mesas

I've tried to find the key

Eu tenho tentado achar a chave

To fifty million fables

Pra cinquenta milhões de fábulas

They call me the seeker

Eles me chamam o investigador

I've been searching low and high

$\mathrm{Eu}$ tenho procurado por toda parte

(Pete Townshend) 


\section{SUMÁRIO}

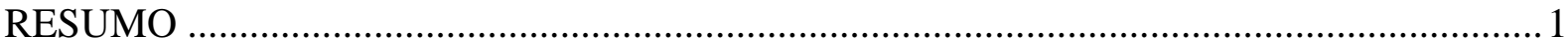

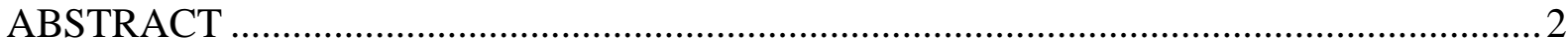

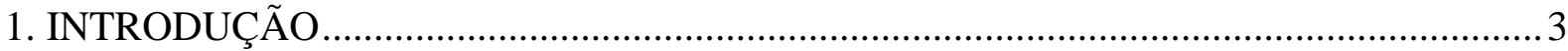

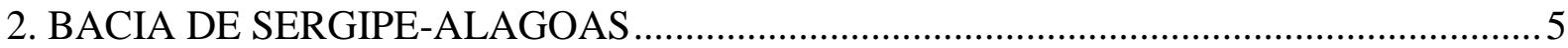

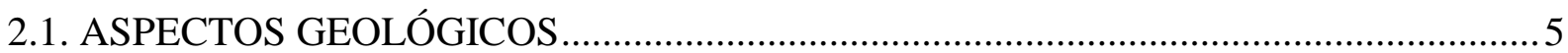

2.2. OSTRACODES DA BACIA DE SERGIPE-ALAGOAS .............................................. 10

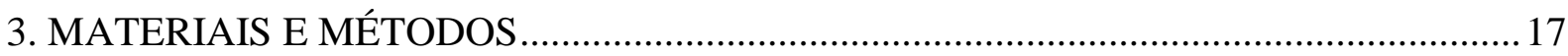

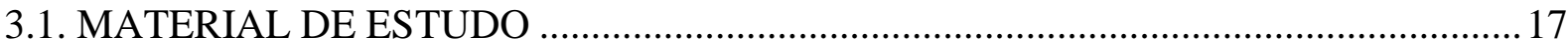

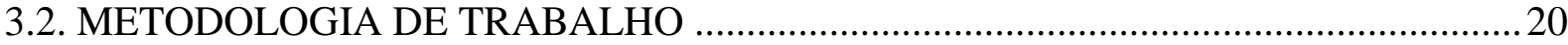

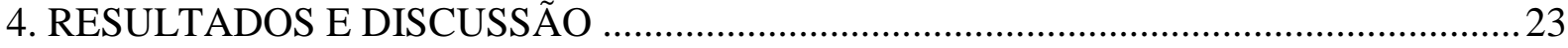

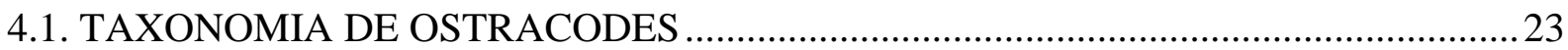

4.2. BIOESTRATIGRAFIA DO APTIANO SUPERIOR-ALBIANO DA FORMAÇÃO

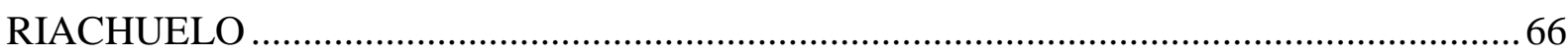

4.2.1. Revisão bioestratigráfica da Zona Aracajuia benderi (OSE-1) ....................................67

4.3. PALEOZOOGEOGRAFIA DO ALBIANO-EOCENOMANIANO DO PROTO-

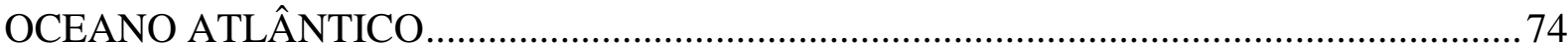

5. CONCLUSÃO

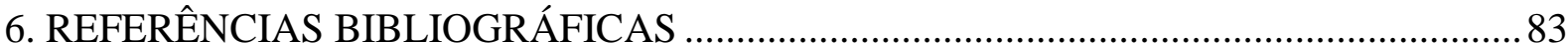




\section{LISTA DE FIGURAS}

Figura 1. Localização da bacia de Sergipe-Alagoas, Nordeste do Brasil. 3

Figura 2. Carta estratigráfica da bacia de Sergipe-Alagoas, Nordeste do Brasil, com ênfase na Formação Riachuelo (Neoalagoas-Coniaciano) (Campos Neto et al., 2007). 7

Figura 3. Seção geológica transversal da bacia de Sergipe-Alagoas, Nordeste do Brasil, com localização aproximada dos afloramentos e perfurações estudados. (A) Estado de Sergipe; (B) Estado de Alagoas (Campos Neto et al., 2007).

Figura 4. Litoestratigrafia e bioestratigrafia integrada da Formação Riachuelo (NeoalagoasEocenomaniano), bacia de Sergipe-Alagoas, Nordeste do Brasil (Koutsoukos \& Bengtson, 1993; Viviers et al., 2000).

Figura 5. Localização dos afloramentos e perfurações amostrados no presente trabalho, bacia de Sergipe-Alagoas, Nordeste do Brasil.

Figura 6. Litologia e amostragem dos afloramentos Fazenda Santa Bárbara (A), Penha (B), ESTRE (C), P384 (D), Porto dos Barcos 3 (E), Massapê (F) e São José 1 (G), bacia de Sergipe-Alagoas, Nordeste do Brasil.

Figura 7. Ostracodes da Formação Riachuelo, bacia de Sergipe-Alagoas, Nordeste do Brasil, Albiano. A-C, Cytherella besrineensis (Bischoff, 1964); A, CP-669, vista lateral direita, B, C, CP-668, B, vista lateral esquerda, C, vista dorsal. D-F, Conchoecia? sp. 1; D, E, LBP 10, D, vista lateral direita, E, vista lateral esquerda, F, LBP 11, vista dorsal. G-I, Cytherelloidea btaterensis Bischoff, 1964; G, CP-671, vista lateral direita, H, CP-672, vista lateral esquerda, I, CP-673, vista dorsal. J, Cytherella icknieldensis? (Weaver, 1982); CP-756, vista lateral direita. K, Cytherella sp. 1, CP-670, vista lateral. L, Bairdoppilata pseudoseptentrionalis Mertens, 1956; CP-676, vista lateral direita. M, Bairdoppilata sp. 1, CP-678, vista lateral direita. N-P, Bairdoppilata comanchensis (Alexander, 1929); CP-674, N, vista lateral direita, O, vista lateral esquerda, P, vista dorsal. Q-S, Bairdoppilata sp. 2; CP-757, Q, vista lateral direita, R, vista lateral esquerda, $\mathrm{S}$, vista dorsal. Escala $=100 \mu \mathrm{m}$.

Figura 8. Ostracodes da Formação Riachuelo, bacia de Sergipe-Alagoas, Nordeste do Brasil, Neoalagoas-Albiano. A, Robsoniella falklandensis Dingle, 1984; CP-733, vista lateral direita. B, Cetacella sp. 1; CP-734, vista lateral direita. C, Paracypris eniotmetos Nicolaidis \& Piovesan, 2013 in Piovesan et al., 2013; CP-679, vista lateral direita. D, Liasina sp. 1; CP682, vista lateral direita. E, Harbinia crepata Do Carmo et al., 2013; CP-681, vista lateral direita. F, Harbinia sinuata? (Krömmelbein \& Weber, 1971); LBP 9, vista lateral direita. G-J, Praebythoceratina deltalata sp. nov.; G, CP-683, vista lateral direita, H, CP-684, vista lateral 
esquerda, I, CP-759, vista dorsal, J, CP-758, vista dorsal. K-M, Praebythoceratina reducta (Gründel, 1964); K, CP-692, vista lateral esquerda, L, CP-691, vista lateral direita, M, CP690, vista dorsal. N-P, Praebythoceratina amsittenensis Andreu-Boussut, 1991; N, CP-687, vista lateral direita, O, CP-769, vista lateral esquerda, P, CP-689, vista dorsal. Q-S, Patellacythere shimonensis (Rosenfeld \& Raab, 1983); Q, CP-685, vista lateral direita, R, CP686, vista lateral esquerda, S, CP-760, vista dorsal. T, Patellacythere parva? (Weaver, 1982); CP-694, vista lateral direita. U, Xestoleberis? sp. 1; CP-761, vista lateral direita. V, Aracajuia benderi Krömmelbein, 1967; CP-711, vista lateral direita. Escala $=100 \mu \mathrm{m}$. .35

Figura 9. Ostracodes da Formação Riachuelo, bacia de Sergipe-Alagoas, Nordeste do Brasil, Albiano. A-C, Xestoleberis? sp. 2, CP-697; A, vista lateral direita, B, vista lateral esquerda, C, vista dorsal. D-H, Apatocythere? sp. 1; D-E, CP-763, D, vista lateral direita, E, vista dorsal, FH, CP-762, F, vista lateral direita, G, vista lateral esquerda, H, vista dorsal. I-N, Gabonorygma sergipana gen. et sp. nov.; I, CP-698, vista lateral direita, J, CP-700, vista lateral esquerda, K, CP-701, vista dorsal, L, CP-703, vista dorsal, M, CP-699, vista lateral direita, N-R, CP-702, N, vista interna esquerda, $\mathrm{O}$, detalhe da charneira na valva esquerda, $\mathrm{P}$, interpretação das estruturas da charneira na valva esquerda, Q, detalhe das cicatrizes musculares central e anterior, $\mathrm{R}$, interpretação das cicatrizes musculares central e anterior. $\mathrm{S}$, Aracajuia fragilis (Piovesan \& Nicolaidis, 2013) in Piovesan et al., 2013; CP-764, vista lateral esquerda. T, Microceratina? sp. 1; CP-714, vista lateral esquerda. U, Algeriana? sp. 1; CP-727, vista lateral esquerda. Escala $=100 \mu \mathrm{m}$.

Figura 10. Ostracodes da Formação Riachuelo, bacia de Sergipe-Alagoas, Nordeste do Brasil, Albiano. A, B, Neocythere pseudovanveeni Gründel, 1966; A, CP-705, vista lateral direita, B, CP-706, vista lateral esquerda. C, D, Neocythere tenuis (Kaye, 1965); C, CP-707, vista lateral direita, D, CP-708, vista lateral esquerda. E, F, Quasihermanites? sp. 1; E, CP-766, vista lateral direita, F, CP-715, vista lateral esquerda. G-I, Aracajuia antiqua (Rosenfeld \& Raab, 1983); G, I, CP-709, G, vista lateral direita, I, vista dorsal, H, CP-710, vista lateral esquerda. J-L, Eocytheropteron sp. 1; CP-765, J, vista lateral direita, K, vista lateral esquerda, L, vista dorsal. M-O, Metacytheropteron sp. 1; CP-712, M, vista lateral direita, N, vista lateral esquerda, O, vista dorsal. P-R, Microceratina azazoulensis Andreu \& Colin, 2005 in Colin et al., 2005; CP-713, P, vista lateral direita, Q, vista lateral esquerda, R, vista dorsal. Escala = $100 \mu \mathrm{m}$

Figura 11. Ostracodes da Formação Riachuelo, bacia de Sergipe-Alagoas, Nordeste do Brasil, Albiano. A, Sergipella viviersae Do Carmo et al., 2012; CP-728, vista lateral direita. B-D, Veenia guianensis Swain, 1976; CP-732, B, vista lateral direita, C, vista lateral esquerda, D, 
vista dorsal. E-P, Reticulocosta edrianae sp. nov.; E, CP-716, vista lateral direita, F, CP-718, vista lateral esquerda, G, CP-719, vista dorsal, H, I, CP-717, H, vista lateral direita, I, vista dorsal, J, K, CP-768, J, vista dorsal, I, interpretação das estruturas da charneira na valva direita, L-P, CP-720, L, vista interna esquerda, M, detalhe da charneira na valva esquerda, N, interpretação das estruturas da charneira na valva esquerda, $O$, detalhe das cicatrizes musculares central e anterior, P, interpretação das cicatrizes musculares central e anterior. QV, Brachycythere smithsoniana sp. nov.; Q, CP-721, vista lateral direita, R, CP-723, vista lateral esquerda, S, CP-724, vista dorsal, T, CP-726, vista dorsal, U, CP-722, vista lateral direita, V, CP-725, vista interna esquerda. Escala $=100 \mu \mathrm{m}$.

Figura 12. Correlação (A) e seção esquemática bioestratigráfica (B) da Formação Riachuelo nos afloramentos e perfurações estudados no presente trabalho, bacia de Sergipe-Alagoas, Nordeste do Brasil. 68

Figura 13. Revisão da bioestratigrafia do Aptiano superior-Albiano da Formação Riachuelo juntamente com a distribuição temporal das espécies do intervalo, bacia de Sergipe-Alagoas, Nordeste do Brasil. Espécies em vermelho correspondem a espécies guia.

Figura 14. Paleozoogeografia de espécies com ocorrência na Formação Riachuelo, bacia de Sergipe-Alagoas, Nordeste do Brasil, e litologias coevas, concomitantes (símbolo cheio) ou não (símbolo vazio), entre o Albiano (A, Eoalbiano; B; Mesoalbiano; C, Neoalbiano) e o Eocenomaniano (D). Paleomapas adaptados de ODSN (2011).

Figura 15. Distribuição estratigráfica e paleozoogeografia da Subfamília Brachycytherinae Puri, 1954, desde sua possível origem no Neoaptiano até o fim do Albiano. Linhas cheias indicam rotas prováveis de dispersão, enquanto as tracejadas representam rotas possíveis. Paleomapa adaptado de ODSN (2011). 78

Figura 16. Paleozoogeografia e rotas de migração de Aracajuia Krömmelbein de 1967 durante o Tithoniano-Barremiano (A) e o Barremiano-Turoniano (B) (modificado de Smith et al., 1994)

Figura 17. Paleozoogeografia e rotas de migração de Aracajuia Krömmelbein de 1967 durante o Turoniano-Santoniano (modificado de Smith et al., 1994). 80 


\section{LISTA DE TABELAS}

Tabela 1. Espécies de ostracodes mencionados na literatura como ocorrentes na bacia de Sergipe-Alagoas, Nordeste do Brasil

Tabela 2. Perfurações e profundidades das amostras da PETROBRAS S.A utilizadas no presente trabalho, bacia de Sergipe-Alagoas, Nordeste do Brasil.

Tabela 3. Distribuição estratigráfica por amostra das espécies de ostracodes identificadas no afloramento Penha, Município de Riachuelo, Estado de Sergipe, Brasil; Formação Riachuelo, bacia de Sergipe-Alagoas. Espécies guia para as zonas e subzonas identificadas se encontram sombreadas. 105

Tabela 4. Distribuição estratigráfica por amostra das espécies de ostracodes identificadas no afloramento Fazenda Santa Bárbara, Município de Rosário do Catete, Estado de Sergipe, Brasil; Formação Riachuelo, bacia de Sergipe-Alagoas. Espécies guia para as zonas e subzonas identificadas se encontram sombreadas.

Tabela 5. Distribuição estratigráfica por amostra das espécies de ostracodes identificadas no afloramento ESTRE, Município de Rosário do Catete, Estado de Sergipe, Brasil; Formação Riachuelo, bacia de Sergipe-Alagoas. Espécies guia para as zonas e subzonas identificadas se encontram sombreadas. 106

Tabela 6. Distribuição estratigráfica por amostra das espécies de ostracodes identificadas no afloramento P384, Município de Riachuelo, Estado de Sergipe, Brasil; Formação Riachuelo, bacia de Sergipe-Alagoas. Espécies guia para as zonas e subzonas identificadas se encontram sombreadas.

Tabela 7. Distribuição estratigráfica por amostra das espécies de ostracodes identificadas no afloramento Porto dos Barcos 3, Município de Riachuelo, Estado de Sergipe, Brasil; Formação Riachuelo, bacia de Sergipe-Alagoas. Espécies guia para as zonas e subzonas identificadas se encontram sombreadas.

Tabela 8. Distribuição estratigráfica por amostra das espécies de ostracodes identificadas no afloramento Massapê, Município de Riachuelo, Estado de Sergipe, Brasil; Formação Riachuelo, bacia de Sergipe-Alagoas. Espécies guia para as zonas e subzonas identificadas se encontram sombreadas.

Tabela 9. Distribuição estratigráfica por amostra das espécies de ostracodes identificadas no afloramento São José 1, Município de Riachuelo, Estado de Sergipe, Brasil; Formação Riachuelo, bacia de Sergipe-Alagoas. Espécies guia para as zonas e subzonas identificadas se encontram sombreadas. 
Tabela 10. Distribuição estratigráfica por amostra das espécies de ostracodes identificadas na perfuração 1-CPB-1, Município de Carmópolis, Estado de Sergipe, Brasil. Espécies guia para as zonas e subzonas identificadas se encontram sombreadas.

Tabela 11. Distribuição estratigráfica por amostra das espécies de ostracodes identificadas na perfuração 1-US-1, Município de Laranjeiras, Estado de Sergipe, Brasil. Espécies guia para as zonas e subzonas identificadas se encontram sombreadas. 114

Tabela 12. Distribuição estratigráfica por amostra das espécies de ostracodes identificadas na perfuração 7-CP-252, Município de Santo Amaro das Brotas, Estado de Sergipe, Brasil. Espécies guia para as zonas e subzonas identificadas se encontram sombreadas. 120 


\section{LISTA DE ANEXOS}

Anexo I. Tabelas de distribuição estratigráfica por amostra das espécies de ostracodes identificadas nos afloramentos e perfurações do presente trabalho. 104

Anexo II. Artigo intitulado Taxonomy, biostratigraphy and paleozoogeography of Amphicytherura Butler and Jones, Aracajuia Krömmelbein and Dinglecythere Antonietto et al., n. gen. (Crustacea, Ostracoda), publicado no periódico Marine Micropaleontology..... 125 Anexo III. Artigo intitulado Taxonomy of limnic Ostracoda (Crustacea) from the Alagamar Formation, middle-upper Aptian, Potiguar basin, Northeastern Brazil, publicado no periódico Journal of Paleontology 126

Anexo IV. Manuscrito intitulado Biostratigraphic and paleozoogeographic review of the uppermost Alagoas-Albian Ostracods of Riachuelo Formation, Sergipe-Alagoas basin, Northeastern Brazil, aceito com correções pela Revista Brasileira de Paleontologia 127

Anexo V. Resumo intitulado Taxonomic, biostratigraphic e palaeozoogeographic aspects of Amphicytherura Butler \& Jones, 1957 e Aracajuia Krömmelbein, 1967 (Cytheridae, Schizocytherinae), apresentado no $17^{\text {th }}$ International Symposium on Ostracoda (ISO), realizado em Roma, Itália. 128

Anexo VI. Resumo intitulado Insights on taxonomy, paleozoogeography and biostratigraphy of Albian Ostracoda (Crustacea) from the Sergipe-Alagoas basin, Brazil, apresentado no $4^{\text {th }}$ International Palaeontological Congress (IPC), realizado em Mendoza, Argentina 


\section{RESUMO}

A bacia de Sergipe-Alagoas, localizada na região Nordeste do Brasil, tem sido alvo de diversos trabalhos em estratigrafia, geoquímica e paleontologia. A Formação Riachuelo, do Aptiano superior-Cenomaniano inferior, corresponde aos primeiros estágios de invasão do proto-oceano Atlântico Sul nesta bacia. A presente revisão da taxonomia de 39 espécies de ostracodes da formação levou à descrição de um novo gênero - Gabonorygma - quatro espécies novas - Praebythoceratina deltalata, Gabonorygma sergipana, Reticulocosta edrianae e Brachycythere smithsoniana. Esta revisão também permitiu a expansão das interpretações paleozoogeográficas e bioestratigráficas atuais sobre a formação, correlacionando-a aos demais ambientes tropicais atlânticos do fim do Eocretáceo. Um novo gênero, Gabonorygma, também é aqui proposto. O estudo taxonômico do Gênero Aracajuia Krömmelbein, 1967 comparado a Amphicytherura Butler \& Jones, 1957 e Sondagella Dingle, 1969, bem como de sua espécie tipo, Aracajuia benderi Krömmelbein, 1967, levou a uma detalhada revisão da paleozoogeografia e estratigrafia daquele gênero. Aracajuia foi comum em ambientes marinhos subtropicais, onde teve origem, a tropicais, principalmente em Gondwana, durante o Eocretáceo, onde atingiu sua máxima diversidade no Albiano, ao longo das atuais África, América do Sul e Ásia (Oriente Médio). Novas inferências também são feitas quando comparadas a Província Brasil-África Ocidental Central, onde se insere a presente bacia, às demais regiões ao longo do proto-oceano Atlântico no Eocretáceo. Houve intercâmbio faunístico considerável entre aquela província e regiões no norte de Megatétis a partir do Eoalbiano. Também foram observados influxos limitados ao longo da cordilheira de Walvis, divisa entre os domínios Austral e central do proto-oceano Atlântico Sul. Estes movimentos se deram em ambos os sentidos, tanto de sul para norte (Albiano) quanto em direção contrária (Eocenomaniano). A presença de espécies de Brachycytherinae na Província Brasil-África Ocidental Central, logo no Aptiano, representa uma nova origem geográfica para esta subfamília, e ao mesmo tempo ajuda a explicar a presença do mesmo tanto em regiões austrais e no norte de Megatétis durante o Albiano. O arcabouço estratigráfico baseado em ostracodes do Albiano da bacia também foi reavaliado, e uma série de mudanças nomenclaturais e de zoneamento foi proposta: a Zona OSE-1, bem como as subzonas OSE1.1, OSE-1.3 e OSE-1.4 tiveram seus nomes alterados, tanto para espécie guia quanto para codificação (respectivamente, MSA-0, MSA-0.1, MSA-0.3 e MSA-0.4); as duas últimas também foram alteradas em sua extensão e definição do contato. A Subzona OSE-1.2 teve seu estratótipo definido, limite inferior modificada (Albiano inferior para Aptiano superior) e código alterado para MSA-0.2, enquanto OSE-1.5 foi apenas renomeada MSA-0.5. Uma nova zona diferencial superior, Aracajuia antiqua (MSA-1), posicionada no Albiano mais superior, foi criada a partir da revisão taxonômica da espécie guia da Subzona OSE-1.6. 


\begin{abstract}
The Sergipe-Alagoas basin, located in northeastern Brazil, has been subject of several studies in stratigraphy, geochemistry and paleontology. The Riachuelo Formation, upper Aptian-lower Cenomanian, corresponds to the first stages of the southern proto-Atlantic ocean invasion in that basin. The present taxonomic review of 39 ostracods species of the formation led to the description of a new genus - Gabonorygma - and four new species Praebythoceratina deltalata, Gabonorygma sergipana, Reticulocosta edrianae and Brachycythere smithsoniana. This review also heped to expand the current paleozoogeographic and biostratigraphic interpretations of the formation, correlating it to the other Atlantic tropical environments from the end of the Early Cretaceous. A new genus, Gabonorygma, is also herein proposed. The taxonomic study of the genus Aracajuia Krömmelbein 1967 compared to Amphicytherura Butler \& Jones, 1957 and Sondagella Dingle, 1969, as well as its type species, Aracajuia benderi Krömmelbein, 1967 led to a detailed review of that genus' paleozoogeography and stratigraphy. Aracajuia was common in subtropical, where it originated, marine environments to tropical, especially in Gondwana during the Early Cretaceous, where it reached its maximum diversity in the Albian, along the current Africa, South America and Asia (Middle East) continents. New inferences are also made when comparing the Brazil-Central West Africa Province, which includes this basin, to other regions along the proto-Atlantic Ocean in the Early Cretaceous. There was considerable faunal exchange between that province and regions in northern Megatethys, starting in the Early Albian. Limited inflows were also observed along the Walvis ridge, which separates austral from central areas of the Southern proto-Atlantic Ocean. These migrations took place in both directions, both from south to north (Albian) and in the opposite direction (Early Cenomanian). The presence of Brachycytherinae species in Brazil-Central West Africa Province, already in the Aptian, sets a new geographical origin for this subfamily, while helping to explain their presence in both southern and northern regions of Megatethys during the Albian. The stratigraphic framework based on ostracods of the Albian of the basin was also reassessed, and some nomenclatural changes and new zones were proposed: the OSE-1 Zone and the OSE-1.1, OSE-1.3 and OSE- 1.4 sub-zones had their names changed, both their guide species and codification (MSA-0, MSA-0.1, MSA-0.3 and MSA-0.4, respectively); the last two were also altered in its extent and contact definition. The OSE-1.2 Subzone had its code changed for MSA-0.2; also, a stratotype was stablished for it, and its lower limit repositioned in time (from early Albian to upper Aptian). The OSE-1.5 Subzone was solely renamed MSA-0.5. A new latest occurrence interval zone, Aracajuia antiqua (MSA-1), from the uppermost Albian interval, was created after taxonomic review of the OSE-1.6 Subzone guide species.
\end{abstract}




\section{INTRODUÇÃO}

O presente trabalho tem como objetivo o ampliar o conhecimento a respeito da diversidade taxonômica de Ostracoda da Formação Riachuelo da bacia de Sergipe-Alagoas. Adicionalmente contribuir para o estudo da evolução paleozoogeográfica e da bioestratigrafia do Aptiano superior-Cenomaniano inferior da formação. Com estes resultados, espera-se contribuir para refinar a bioestratigrafia dos ostracodes dos andares Alagoas e Albiano da bacia de Sergipe-Alagoas. Ao mesmo tempo, permite-se correlacionar seções da bacia com camadas coevas nas bacias marginais brasileiras e de regiões próximas ao longo do oceano Atlântico.

No campo da paleozoogeografia, o autor pretende expandir o âmbito das interpretações atuais sobre a Formação Riachuelo, adicionando contribuições ao entendimento da biodiversidade dos ambientes tropicais do fim do Cretáceo Inferior, como a Província BrasilÁfrica Ocidental Central e o domínio de Megatétis. A integração destes tópicos é fundamental para caracterização da viabilidade econômica da bacia de Sergipe-Alagoas, uma vez que a Formação Riachuelo está em contato direto com importantes reservas de petróleo e gás da bacia de Sergipe-Alagoas, tanto em áreas onshore quanto offshore.

A bacia de Sergipe-Alagoas (fig. 1) é uma bacia marginal localizada na região Nordeste do Brasil, entre as latitudes de $9^{\circ}$ e $11^{\circ} 30^{\prime} \mathrm{S}$, e longitudes de $37^{\circ}$ e $35^{\circ} 30^{\prime} \mathrm{W}$. A bacia possui entre 16 e $50 \mathrm{~km}$ de comprimento e $170 \mathrm{~km}$ de largura, cobrindo uma área total onshore e

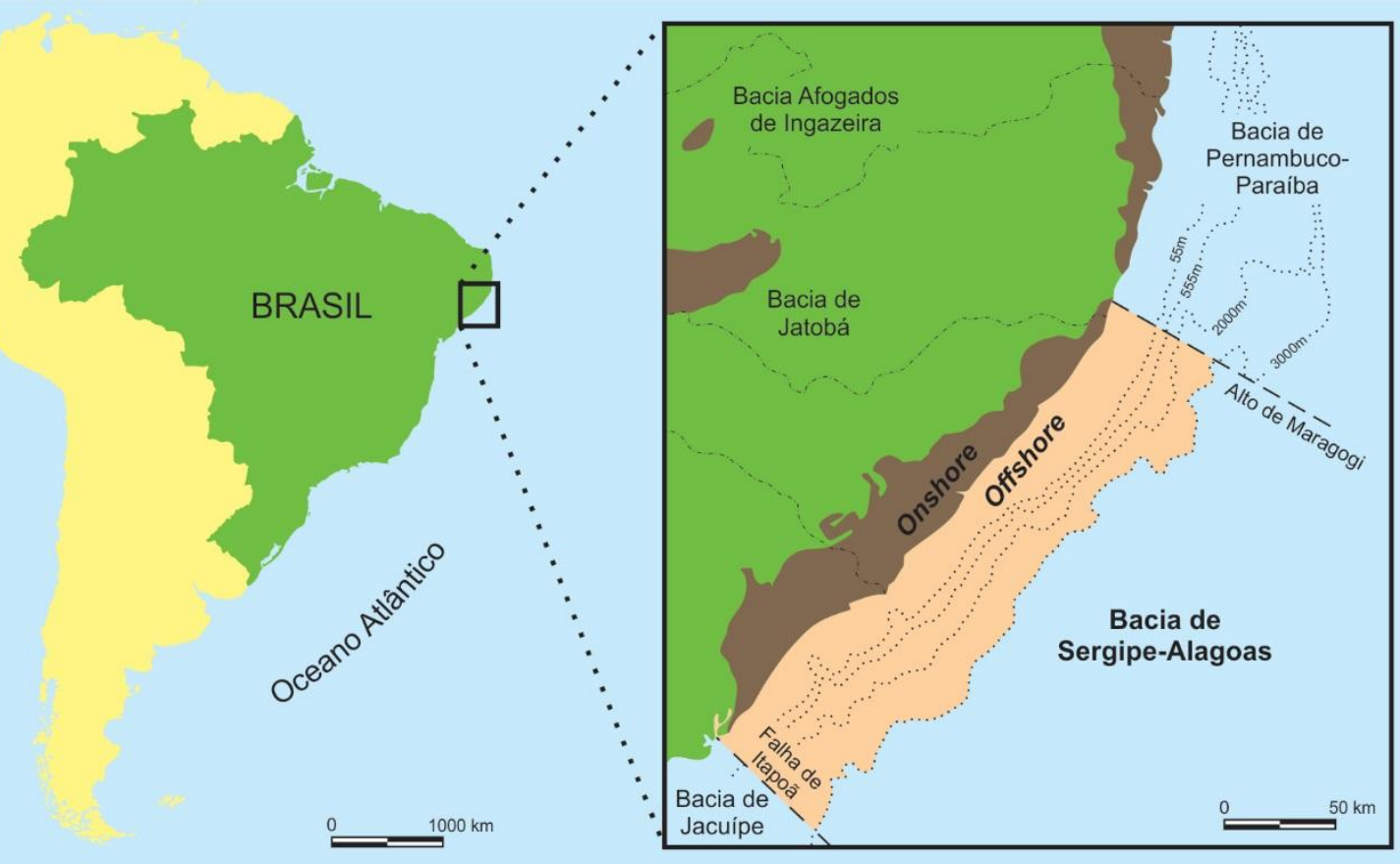

Figura 1. Localização da bacia de Sergipe-Alagoas, Nordeste do Brasil. 
offshore de aproximadamente $11000 \mathrm{~km}^{2}$ (Feijó, 1994). Seus limites incluem a bacia de Pernambuco-Paraíba a nordeste (ao longo do alto de Maragogi) (Souza-Lima et al., 2002; Campos Neto et al., 2007) e a bacia do Jacuípe a sudoeste (falha de Itapuã) (Graddi et al., 2007).

Esta bacia tem sido alvo de diversos trabalhos em estratigrafia, geoquímica e paleontologia, devido à quantidade de dados adquiridos através de perfurações, linhas sísmicas, levantamentos gravimétricos e magnetométricos, etc. Além de um vasto acervo de informações de perfurações, a bacia possui vários afloramentos, o que contribui muito para um melhor entendimento de sua evolução. Entre todas as bacias brasileiras, esta é a que provavelmente possui o mais completo registro tectono-sedimentar. A maior parte dos estudos realizados é direcionada aos intervalos produtores de óleo e gás, uma vez que ocorrem reservas significativas no embasamento fraturado (Proterozoico), no campo de Carmópolis (Jurássico Superior-Aptiano) e na Formação Calumbi (Santoniano-Cenozoico) (Marques, 1965; Mendes, 1994; Campos Neto et al., 2007). 


\section{BACIA DE SERGIPE-ALAGOAS}

O nome "bacia de Sergipe-Alagoas" foi originalmente introduzido por Schaller (1969). Entretanto, Feijó (1994), em trabalho de revisão estratigráfica, considerou a mesma como um conjunto de duas bacias individualizadas, respectivamente denominadas de bacia de Sergipe e bacia de Alagoas e limitadas pelo alto de Japoatã-Penedo. Diversos trabalhos anteriores e posteriores a este adotam a mesma definição (Benson, 1984; Bengtson \& Nordlund, 1987; Koutsoukos \& Hart, 1990; Koutsoukos, 1992; Mohriak et al., 1997; Silva et al., 1997; Seeling \& Bengtson, 1999, 2003; Viviers et al., 2000; Nogueira et al., 2003; Carvalho, 2004; Carvalho et al., 2005; Ferreira et al., 2005; Hessel, 2005).

Todavia, a maioria dos autores utiliza a nomeação original (Ojeda \& Fugita, 1976; Bandeira Júnior, 1978, Feijó, 1980; Rand \& Mabesoone, 1982; Tambareau, 1982; Bertani \& Carozzi, 1985; Lana, 1985; Petri, 1987; Assine, 1992, 1994, 2007; Koutsoukos \& Bengtson, 1993; Cesero \& Ponte, 1997; Garcia et al., 1998; Cainelli \& Mohriak, 1999; Gonçalves, 2001; Coimbra et al., 2002; Fauth, 2002; Lana \& Carvalho, 2002; Borba et al., 2003; Magnavita et al., 2003; Mendonça et al., 2003; Souza-Lima \& Hamsi Junior, 2003a, b; Valença et al., 2003; Bueno, 2004; Dias, 2004; Oliveira et al., 2004; Chiossi, 2005; Fauth et al., 2005; Martins Neto, 2005). Atualmente, a abordagem das sub-bacias de Sergipe e Alagoas como uma única bacia é preferido em relação à divisão (Córdoba et al., 2007; Graddi et al., 2007; Lana \& Beurlen, 2007; Milani et al., 2007; Silva et al., 2007; Do Carmo et al., 2008, 2012, 2013; Mohriak et al., 2008; Rodrigues et al., 2012). Em sua mais recente revisão, Campos Neto et al. (2007) revalidaram o senso comum ao não considerar o Alto de Japoatã-Penedo um divisor, visto que o mesmo não é observado em toda a extensão da bacia de SergipeAlagoas.

\subsection{ASPECTOS GEOLÓGICOS}

A bacia de Sergipe-Alagoas constitui-se de 23 formações, correlacionáveis aos estágios evolutivos que culminaram com a formação do oceano Atlântico Sul: sinéclise, pré-rifte, rifte, golfo e drifte (Ponte \& Asmus, 1976; Feijó, 1994). O embasamento, de idade proterozoica, é formado pelas rochas metamórficas de baixo grau dos grupos Miaba e Vaza-Barris e metassedimentos possivelmente cambrianos do Grupo Estância, depositados por sistemas alúvio-fluviais, deltaicos e de marés (Silva Filho et al., 1978). Também são identificadas as rochas de composição granítica do maciço Pernambuco-Alagoas. O preenchimento sedimentar e o estilo tectônico na bacia variam nos estados de Sergipe e Alagoas (Campos 
Neto et al., 2007) (figs 2 e 3).

Sobre o embasamento, foram depositadas as sequências do Carbonífero (Formação Batinga) e do Permiano (Formação Aracaré). Estas representam o registro sedimentar de sinéclises paleozoicas que cobriam extensas áreas do continente Gondwana (Campos Neto et $a l .$, 2007). Rochas siliciclásticas depositadas em ambiente glacial subaquoso compõem a Formação Batinga, onde dois membros são reconhecidos: Mulungu (conglomerados e diamictitos resultantes do retrabalhamento dos sedimentos glaciais por fluxos de detritos) e Boacica (conglomerados, arenitos, siltitos e folhelhos provenientes de leques deltaicos). A Formação Aracaré corresponde a ambientes desérticos, litorâneos e deltaicos, depositados retrabalhados por ventos e ondas. Essa sucessão é caracterizada por um ciclo transgressivoregressivo, no qual os folhelhos pretos são recobertos por arenitos, calcarenitos associados a sílex e lâminas algálicas (Schaller, 1969; Campos Neto et al., 2007).

Ao longo do Neojurássico-Eocretáceo, a bacia de Sergipe-Alagoas fez parte da chamada depressão afro-brasileira. Nessa fase de estabilidade tectônica, depositaram-se os folhelhos vermelhos lacustres da Formação Bananeiras e os arenitos fluviodeltaicos da Formação Candeeiro. Posteriormente, sistemas fluviais entrelaçados com retrabalhamento eólico recobriram esse registro com os arenitos da Formação Serraria. O estabelecimento da fase rifte na bacia de Sergipe-Alagoas ocorreu no Berriasiano, com a sedimentação da Formação Feliz Deserto, uma sucessão de folhelhos esverdeados com delgadas intercalações areníticas de origem provavelmente lacustre. Em segmentos da borda da bacia, registra-se a sedimentação arenosa alúvio-fluvial da Formação Penedo (Ponte \& Asmus, 1976; Campos Neto et al., 2007).

Durante o primeiro pulso tectônico da fase rifte, ocorreu a deposição dos conglomerados aluviais da Formação Rio Pitanga e dos arenitos da Formação Penedo, enquanto nas porções distais, prevalecia a sedimentação deltaica-lacustre da Formação Barra de Itiúba (Schaller, 1969). O nível máximo desse lago ocorreu no Barremiano, quando se depositaram folhelhos do Andar Buracica (Barremiano superior-Aptiano), os quais foram colmatados pelos sedimentos alúvio-fluviais das formações Rio Pitanga e Penedo. Durante períodos de baixo aporte sedimentar, formaram-se os níveis de coquinas de bivalves e ostracodes da Formação Morro do Chaves (Campos Neto et al., 2007; Do Carmo et al., 2008).

No Eoaptiano da bacia, observa-se alta taxa de sedimentação, em virtude de processos de subsidência. Na parte proximal, predominavam os conglomerados aluviais das formações Rio Pitanga e Poção e os carbonatos e folhelhos da Formação Morro do Chaves. Nas porções distais a sedimentação era alúvio-deltaica-lacustre, com os arenitos e da Formação Coqueiro 


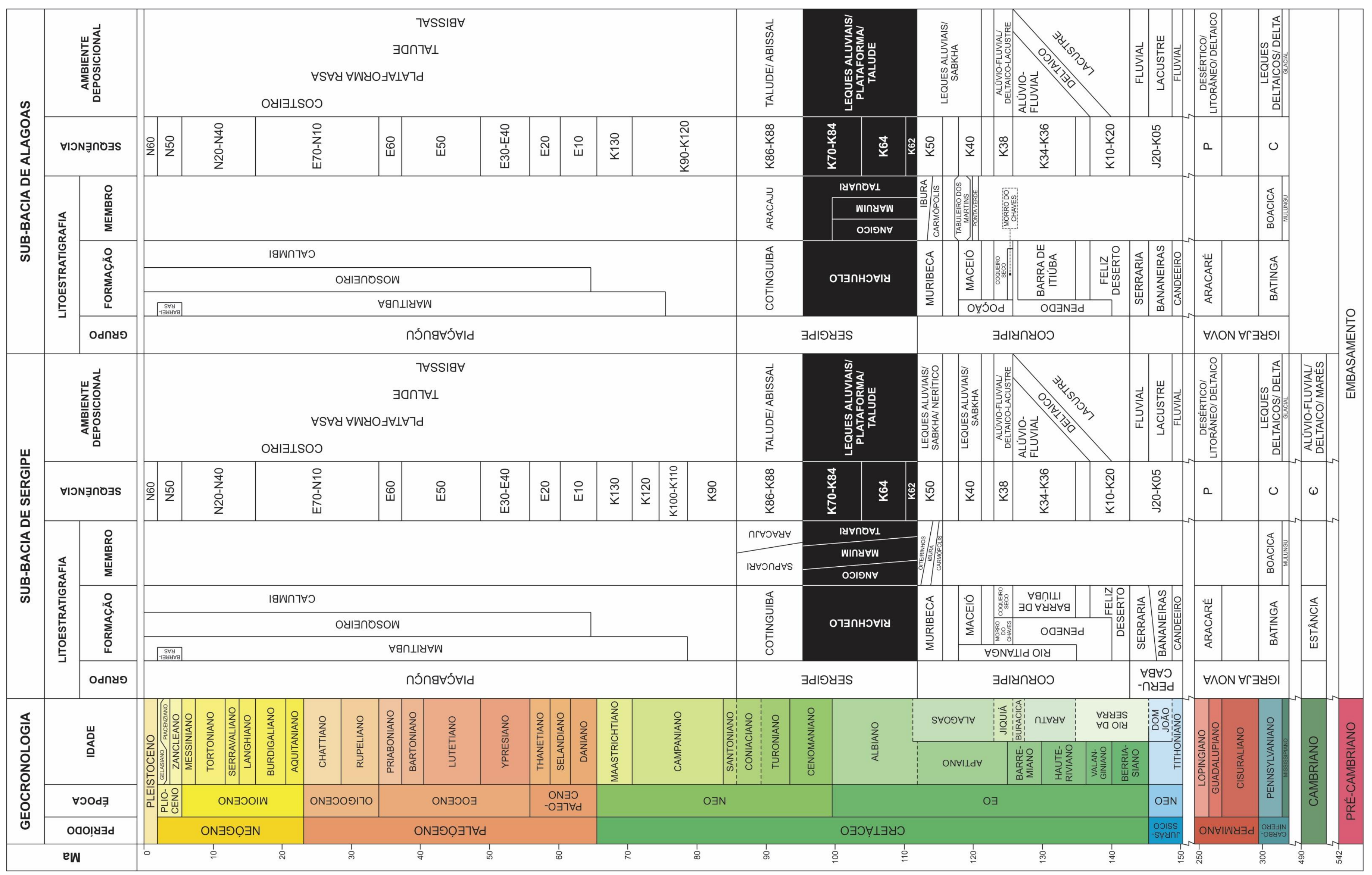

Figura 2. Carta estratigráfica da bacia de Sergipe-Alagoas, Nordeste do Brasil, com ênfase na Formação Riachuelo (Neoalagoas-Coniaciano) (Campos Neto et al., 2007). 


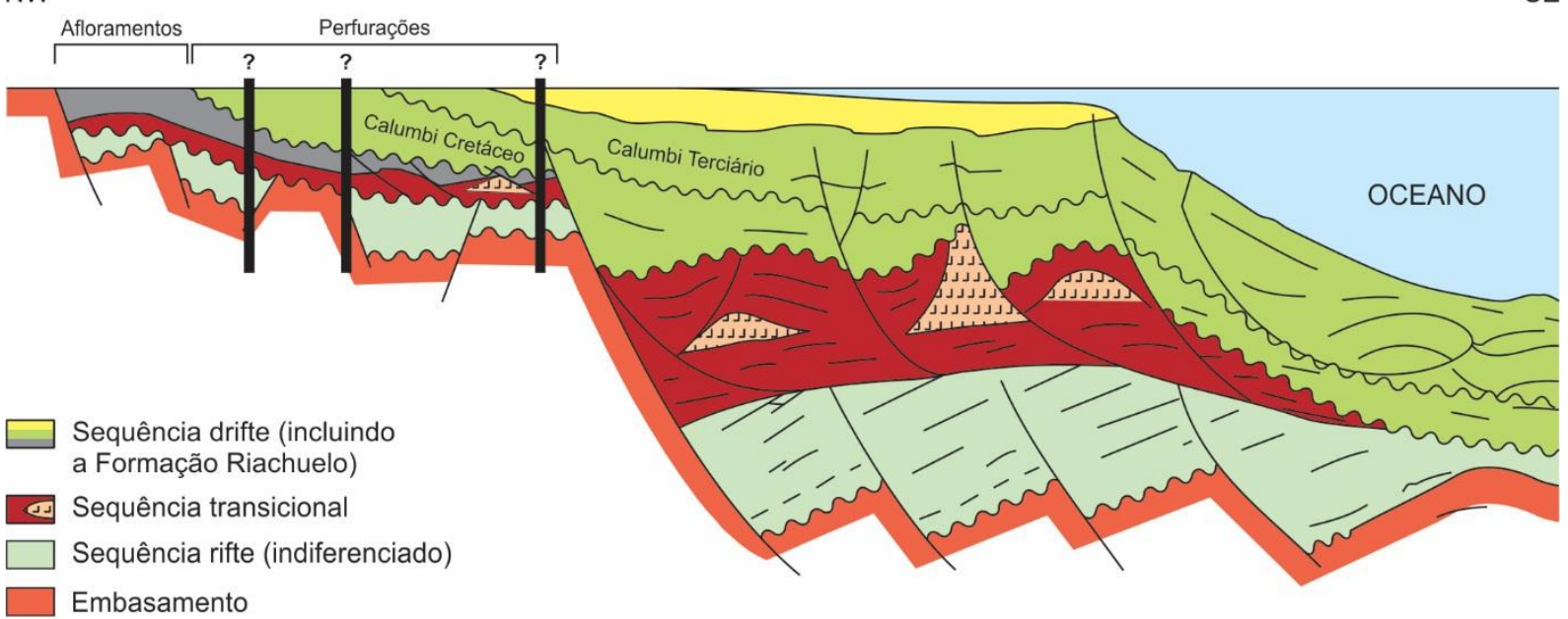

(B)

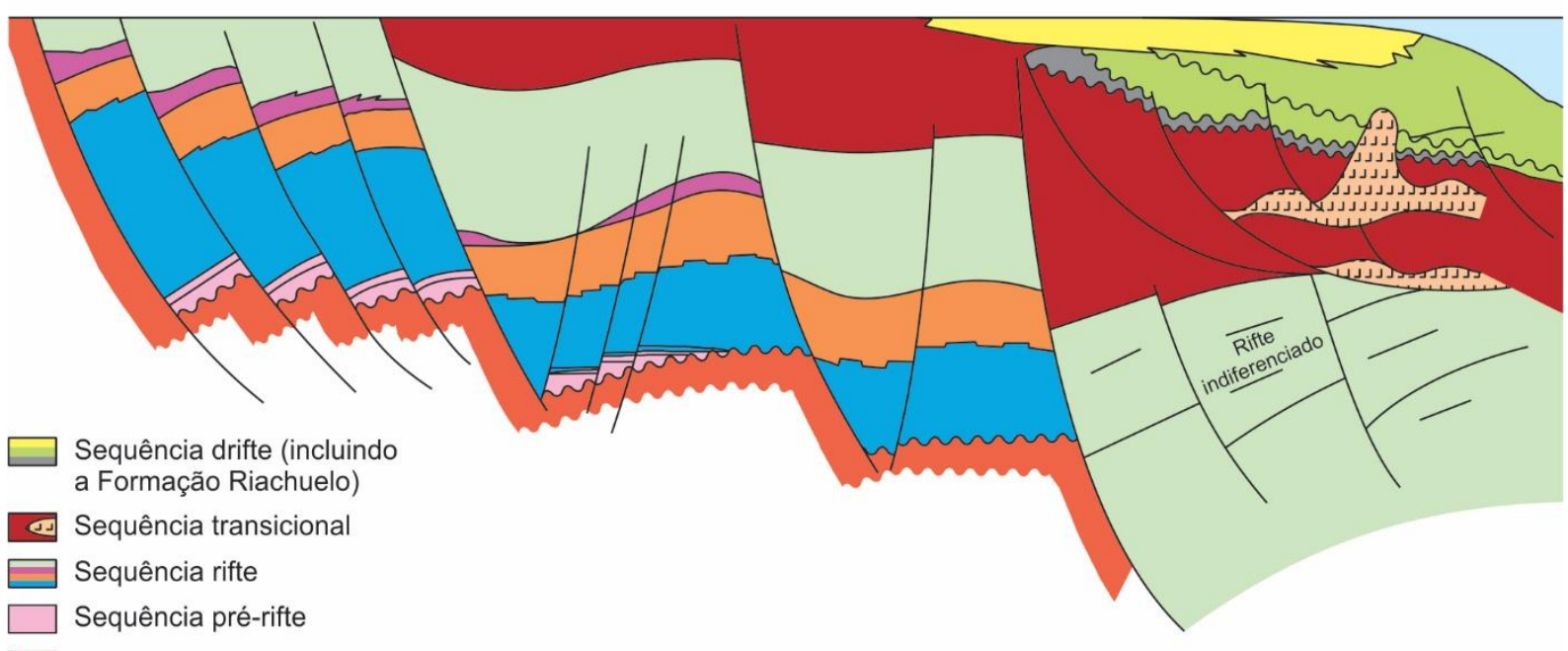

Embasamento

Figura 3. Seção geológica transversal da bacia de Sergipe-Alagoas, Nordeste do Brasil, com localização aproximada dos afloramentos e perfurações estudados. (A) Estado de Sergipe; (B) Estado de Alagoas (Campos Neto et al., 2007).

Seco. Uma sucessão de folhelhos betuminosos e evaporitos no intervalo intermediário dessa formação representam a primeira incursão marinha na bacia de Sergipe-Alagoas (Campos Neto et al., 2007).

A partir do Eoaptiano ocorreu um intenso tectonismo na bacia, causando soerguimento que restringiu a sedimentação a porções isoladas da bacia (Campos Neto et al., 2007). Desse intervalo datam evaporitos interpretados como um ambiente marinho com influência continental (Florêncio, 1996). Estes evidenciam as transgressões ocorridas nestas localidades 
durante o Eoalagoas, ao contrário das condições continentais das demais bacias próximas (Dias, 2004). Além das formações Rio Pitanga e Poção, pertencem a esta sequência os arenitos, folhelhos, evaporitos e calcilutitos da Formação Maceió, correspondentes a tratos de sistemas transgressivos formados em períodos de clima úmido e grande aporte sedimentar. Em climas mais áridos, predominavam folhelhos e calcilutitos algálicos, e no máximo de aridez, evaporitos estabelecidos em ambientes do tipo sabkha (Arienti, 1996).

O início da fase de golfo, durante o Neoaptiano-Albiano, é marcado pela primeira grande incursão marinha na bacia e o estabelecimento da margem passiva observada até os dias atuais. Este evento implicou na deposição da Formação Muribeca, compreendendo os sedimentos siliciclásticos grossos do Membro Carmópolis, evaporitos, carbonatos microbiais e folhelhos do Membro Ibura e intercalações de folhelhos e calcilutitos do Membro Oiteirinhos. Os depósitos do Membro Carmópolis constituem tratos de sistemas de mar baixo e transgressivo, enquanto o Membro Ibura representa tratos de sistemas de mar alto, caracterizados por ambientes marinhos rasos com influência de marés (Campos Neto et al., 2007).

$\mathrm{Na}$ fase drifte, depósitos inicialmente marinhos restritos evoluem posteriormente para aqueles característicos de mar aberto. No Eoalbiano, em consequência de uma transgressão, estabeleceu-se a sedimentação marinha franca da Formação Riachuelo (Koutsoukos, 1989). Nas bordas da bacia e nos blocos rebaixados depositaram-se em leques deltaicos as rochas siliciclásticas grossas do Membro Angico. Nas áreas de menor aporte sedimentar desenvolveu-se a rampa carbonática com bancos parcialmente dolomitizados de oólitos e oncólitos do Membro Maruim, e nas lagunas e no talude, os calcilutitos e folhelhos do Membro Taquari (Mendes, 1994; Falconi, 2006). Duas sequências de terceira ordem, caracterizadas por um intervalo basal argiloso de alto teor orgânico e padrão de empilhamento retrogradacional, são interpretadas como trato de sistemas transgressivo. Uma terceira, com depósitos predominantemente de carbonatos e com padrão progradacional, equivale a trato de sistemas de mar alto (Mendes, 1994).

Do Neocenomaniano ao Coniaciano ocorreu um evento transgressivo com ápice no Eoturoniano, resultando nos sedimentos carbonáticos da Formação Cotinguiba (Koutsoukos, 1989). Na parte proximal da rampa depositaram-se calcilutitos maciços e brechóides do Membro Sapucarí, enquanto no talude e na plataforma são visualizados os folhelhos, margas e calcilutitos do Membro Aracaju. No final do Coniaciano houve rebaixamento do nível do mar seguido de transgressão com máximo no Eocampaniano, responsável pela sucessão de folhelhos da Formação Calumbi. Com o maior aporte sedimentar e a progradação do 
empilhamento rochoso, formaram-se nas porções proximais da bacia as areias costeiras e plataformais da Formação Marituba. Nas partes distais persistiu a Formação Calumbi, com folhelhos e eventuais intercalações de arenito. Do Neocampaniano ao Maastrichtiano, o padrão da sedimentação continuou progradante, com a ampliação da planície costeira e da plataforma arenosa da Formação Marituba (Campos Neto et al., 2007).

Durante o Paleoceno (Daniano), o padrão de empilhamento continuou progradacional. Entretanto, na borda da Formação Marituba, foram acumulados os calcarenitos bioclásticos da Formação Mosqueiro (Feijó, 1994). O ápice deste evento ocorreu no Eoceno, enquanto no Oligoceno houve rebaixamento no nível do mar, seguido de nova transgressão no Mioceno. Até o fim desse período, o padrão de sedimentação foi agradacional, com a deposição das formações Marituba, Mosqueiro e Calumbi. No Plioceno, outro evento regressivo deu origem aos depósitos costeiros da Formação Barreiras na porção terrestre da bacia (Campos Neto et al., 2007).

Em águas profundas e ultraprofundas da bacia de Sergipe-Alagoas ocorrem corpos magmáticos interpostos às rochas sedimentares. Os truncamentos e as deformações provocadas nas reflexões sísmicas permitem atribuir a esses eventos idades albiana e turoniana (Feijó, 1994; Mohriak et al., 1995). Entretanto, não são descartadas reativações mais jovens, talvez paleogênicas (Cainelli, 1992; Gomes, 2000). Na transição da crosta continental para crosta oceânica, feições magmáticas são frequentes (Mohriak et al., 1995; Gomes, 2000; Hamsi Júnior et al., 2006). Essas rochas estão relacionadas com o magmatismo resultante da formação da crosta oceânica do Atlântico Sul (Campos Neto et al., 2007).

\subsection{OSTRACODES DA BACIA DE SERGIPE-ALAGOAS}

Os estudos em ostracodes da bacia de Sergipe-Alagoas tiveram início nas décadas de 1960 e 1970, inicialmente de caráter taxonômico (tab. 1), e progredindo logo em seguida para diversos campos de atuação. A primeira menção aos mesmos na bacia foi feita por Krömmelbein (1962), ao abordar diversas espécies do Gênero Paracypridea Swain, 1946 no nordeste brasileiro. Este trabalho determinou que a distribuição geográfica do gênero supracitado incluísse a "bacia costeira de Alagôas-Sergipe". Entretanto, não se especificou quais seriam as espécies presentes nessa bacia, uma vez que somente os materiais tipos das espécies estudadas, todos sem exceção advindos da "Série Bahia" (Neojurássico-Aptiano) da bacia do Recôncavo, foram posicionados geograficamente.

Krömmelbein (1964a) descreveu a primeira espécie descoberta na bacia, Brachycythere (Brachycythere) sapucariensis Krömmelbein, 1964a. Os espécimes tipo foram coletados na 
Tabela 1. Espécies de ostracodes mencionados na literatura como ocorrentes na bacia de Sergipe-Alagoas, Nordeste do Brasil.

\begin{tabular}{|c|c|c|}
\hline Unidade litológica & Época(s)/Andar(es) & Espécie \\
\hline \multirow{36}{*}{ Indeterminada } & \multirow{9}{*}{ Rio da Serra } & "Metacypris” longisulcata Schaller, 1969 n.n. ${ }^{1}$ \\
\hline & & Candona? condensa Krömmelbein, $1962^{1}$ \\
\hline & & Cypridea (Morininoides) barnesi Schaller, 1969 n.n. ${ }^{1}$ \\
\hline & & Cypridea (Morininoides) candeiensis Krömmelbein, $1962^{1}$ \\
\hline & & Cypridea (Morininoides) grekoffi Krömmelbein, $1965^{1}$ \\
\hline & & Cypridea (Morininoides) hadronodosa Krömmelbein, $1962^{1}$ \\
\hline & & Cypridea ambigua Krömmelbein, $1962^{1}$ \\
\hline & & Paracypridea brasiliensis Krömmelbein, $1961^{1}$ \\
\hline & & Tucanocypris camposi Krömmelbein, $1965^{1}$ \\
\hline & \multirow{4}{*}{ Rio da Serra-Aratu } & Paracypridea elegans Krömmelbein, $1962^{1}$ \\
\hline & & Paracypridea langdoni Krömmelbein, $1961^{1}$ \\
\hline & & Paracypridea obovata obovata Krömmelbein, $1961^{1}$ \\
\hline & & Paracypridea similis Krömmelbein, $1961^{1}$ \\
\hline & \multirow{7}{*}{ Aratu } & Cypridea (Morinina?) bibullata bibullata Wicher, $1959^{1}$ \\
\hline & & Cypridea (Morinina?) bibullata tribullata \\
\hline & & Krömmelbein, $1962^{1}$ \\
\hline & & Paracypridea rhomboidalis Wicher, $1959^{1}$ \\
\hline & & Reconcavona bythrocyproides Schaller, 1969 n.n. ${ }^{1}$ \\
\hline & & Reconcavona striatula Swain, $1946^{1}$ \\
\hline & & Reconcavona triebeli Krömmelbein, $1964 b^{1}$ \\
\hline & Aratu-Buracica & Paracypridea quadrirugosa weberi Krömmelbein, $1961^{1}$ \\
\hline & \multirow{5}{*}{ Buracica-Jiquiá } & "Metacypris" postangularis Swain, $1946{ }^{1 "}$ \\
\hline & & Cypridea (Sebastianites) devexa Krömmelbein, $1962^{1}$ \\
\hline & & Cypridea (Sebastianites) fida Krömmelbein, $1962^{1}$ \\
\hline & & Cypridea (Sebastianites) sostensis Krömmelbein, $1962^{1}$ \\
\hline & & Petrobrasia marfinensis Krömmelbein, $1962^{1}$ \\
\hline & \multirow{10}{*}{ Jiquiá } & Candona? centroimpressa Weber, 1964 n.n. ${ }^{*}$ \\
\hline & & Candona? são-franciscoensis (sic) Weber, 1964 n.n. ${ }^{1}{ }^{*}$ \\
\hline & & Cypridea (Pseudocypridina) faveolata Moura, $1972^{1}$ \\
\hline & & Cypridea benderi Weber, 1964 n.n. ${ }^{1}{ }^{*}$ \\
\hline & & Cypridea jequiensis Krömmelbein \& Weber, $1971^{1}$ \\
\hline & & Cypridea luzi Moura, $1972^{1}$ \\
\hline & & Cypridea nodoreticulata Weber, 1964 n.n. ${ }^{1 *}$ \\
\hline & & Cyprideis? rugosa Weber, 1964 n.n. ${ }^{1 *}$ \\
\hline & & Limnocypridea? subquadrata Weber, 1964 n.n. ${ }^{1 *}$ \\
\hline & & Schuleridea? immensa Weber, 1964 n.n. ${ }^{1 *}$ \\
\hline Formação Coqueiro Seco & Jiquiá superior & Cypridea africana (Krömmelbein, 1965) ${ }^{1}$ \\
\hline
\end{tabular}


Tabela 1 (continuação). Espécies de ostracodes mencionados na literatura como ocorrentes na bacia de SergipeAlagoas, Nordeste do Brasil.

\begin{tabular}{|c|c|c|}
\hline Unidade litológica & Época(s)/Andar(es) & Espécie \\
\hline Formação Maceió & Aptiano inferior & Limnocythere? troelseni Krommelbein \& Weber, $1971^{1}$ \\
\hline Formação Muribeca & Aptiano & Cypridea confluens (Krommelbein \& Weber, 1971) ${ }^{1}$ \\
\hline \multirow{7}{*}{ Formação Riachuelo } & \multirow{3}{*}{ Aptiano } & Harbinia angulata (Krömmelbein \& Weber, 1971) ${ }^{1}$ \\
\hline & & Harbinia sinuata (Krömmelbein \& Weber, 1971) ${ }^{1}$ \\
\hline & & Harbinia micropapillosa (Bate, 1972) ${ }^{2}$ \\
\hline & Aptiano superior-Albiano & Aracajuia benderi Krömmelbein, $1967^{3}$ \\
\hline & Albiano inferior & Sergipella transatlantica Krömmelbein, $1967^{4}$ \\
\hline & \multirow{2}{*}{ Albiano inferior-médio } & Sergipella viviersae Do Carmo et al., $2012^{4}$ \\
\hline & & Veenia guianensis Swain, $1976^{5}$ \\
\hline \multirow{2}{*}{ Formação Cotinguiba } & \multirow{2}{*}{ Turoniano inferior } & Brachycythere (Brachycythere) sapucariensis \\
\hline & & Krömmelbein, $1964 \mathrm{a}^{5}$ \\
\hline \multirow{26}{*}{ Grupo Piaçabuçu } & \multirow{10}{*}{ Daniano? } & Cytherella piacabucuensis Neufville, $1979^{6}$ \\
\hline & & Bairdia hiwanneensis Howe \& Lea, $1936^{6}$ \\
\hline & & in Howe \& Law (1936) \\
\hline & & Echinocythereis garretti (Howe \& McGuirt, 1935) ${ }^{6}$ \\
\hline & & in Howe (1935) \\
\hline & & Trachyleberis bermudezi (Bold, 1946) ${ }^{6}$ \\
\hline & & Costa barri Bold, $1960^{6}$ \\
\hline & & Krithe saundersi Bold, $1946^{6}$ \\
\hline & & Langiella reymenti (Neufville, 1979) ${ }^{6}$ \\
\hline & & Soudanella laciniosa triangulata Apostolescu, $1961^{6}$ \\
\hline & \multirow{2}{*}{ Daniano?-Eoceno inferior } & Cytherella sergipensis Neufville, $1979^{6}$ \\
\hline & & Cythereis? longicostata Blake, $1950^{6}$ \\
\hline & \multirow{14}{*}{ Eoceno inferior } & Cytherella harmoniensis Bold, $1960^{6}$ \\
\hline & & Bairdia cespedensis Bold, $1946^{6}$ \\
\hline & & Pontocypris dreikanter (Coryell \& Fields, 1937) ${ }^{6}$ \\
\hline & & Argilloecia faba Alexander, 1934a ${ }^{6}$ \\
\hline & & Macrocypris lanceolata Neufville, $1979^{6}$ \\
\hline & & Hemicythere bellula Howe, $1951^{6}$ \\
\hline & & Trachyleberis reticulospinosa (Bold, 1946) ${ }^{6}$ \\
\hline & & Cativella moriahensis Bold, $1960^{6}$ \\
\hline & & Kingmaina brazilensis Neufville, $1979^{6}$ \\
\hline & & Krithe mutveii Neufville, $1979^{6}$ \\
\hline & & Krithe guatemalensis Bold, $1946^{6}$ \\
\hline & & Parakrithe? ovata Bold, $1960^{6}$ \\
\hline & & Eucytherura rohri (Bold, 1958) \\
\hline & & Paracytheridea toleri Howe \& Law, $1936^{6}$ \\
\hline
\end{tabular}


Tabela 1 (continuação). Espécies de ostracodes mencionados na literatura como ocorrentes na bacia de SergipeAlagoas, Nordeste do Brasil.

\begin{tabular}{lcl}
\hline \multicolumn{1}{c}{ Unidade litológica } & Época & \multicolumn{1}{c}{ Espécie } \\
\hline \multirow{2}{*}{ Grupo Piaçabuçu } & Eoceno inferior & Loxoconcha corrugata Alexander, 1934a ${ }^{6}$ \\
& & Xestoleberis chamela Bold, 1960 \\
& Eoceno & Costa variabilicostata seminuda $($ Bold, 1958)
\end{tabular}

1- Segundo Poropat \& Colin (2012a). ${ }^{2}$ - Segundo Do Carmo et al. (2008). ${ }^{3}$ - Segundo Antonietto et al. (2013a). ${ }^{4}$ Segundo Do Carmo et al. (2012). ${ }^{5}$ - Segundo Viviers et al. (2000). ${ }^{6}$ - Segundo Neufville (1979). *- Apud Schaller, 1969.

área entre as cidades de Maruim e Aracaju e a microrregião do Baixo Cotinguiba, Estado de Sergipe, em sedimentos do Membro Sapucarí, do Turoniano Inferior. Dois novos gêneros, Aracajuia Krömmelbein, 1967 e Sergipella Krömmelbein, 1967, e suas espécies tipo, Aracajuia benderi Krömmelbein, 1967 e Sergipella transatlantica Krömmelbein, 1967 foram identificados e descritos a partir de sedimentos da Formação Riachuelo (Aptiano superiorAlbiano) (Krömmelbein, 1966a, 1967), na antiga "Usina Fortuna", próximo à cidade de Divina Pastora, Sergipe.

Krömmelbein (1966b) e Krömmelbein \& Wenger (1966) compararam ostracodes do Berriasiano-Hauteriviano das bacias de Tucano e Sergipe-Alagoas com aqueles do Gabão, no oeste da África. Em ambos os casos, foram encontradas similaridades entre as faunas das chamadas "Série Bahia" e "Série Cocobeach". Estas análises foram complementadas pelos estudos paleogeográficos de Krömmelbein (1970), em uma tentativa de estabelecer o conceito atual do supercontinente Gondwana. Schaller (1969), a partir de Viana (1966) estabeleceu o primeiro zoneamento com base em ostracodes da bacia, abrangendo os estratos entre o Tithoniano superior e o Aptiano inferior. Entretanto, do ponto de vista taxonômico, este é um trabalho em sua maioria incompleto, uma vez que várias das espécies identificadas foram descritas por R. Weber, em relatório interno da empresa Petróleo Brasileiro S.A. (PETROBRAS) de 1964, ou não receberam descrição alguma. Fazem parte desta lista Candona? centroimpressa Weber, 1964 n.n., Candona? são-franciscoensis Weber, 1964 n.n., Cypridea benderi Weber, 1964 n.n., Limnocypridea? subquadrata Weber, 1964 n.n., Cyprideis? rugosa Weber, 1964 n.n., Cypridea nodoreticulata Weber, 1964 n.n., Schuleridea? immensa Weber, 1964 n.n. "Metacypris" longisulcata Schaller, 1969 n.n., Cypridea (Morininoides) barnesi Schaller, 1969 n.n. e Reconcavona bythrocyproides Schaller, 1969 n.n.

Krömmelbein \& Weber (1971), em grande levantamento taxonômico de espécies do 
"Wealden" (Berriasiano-Aptiano) do Brasil, descreveram espécies de diversas bacias, incluindo Harbinia angulata (Krömmelbein \& Weber, 1971), Harbinia sinuata (Krömmelbein \& Weber, 1971), Cypridea confluens (Krommelbein \& Weber, 1971) e Limnocythere? troelseni Krommelbein \& Weber, 1971, da bacia de Sergipe-Alagoas. Moura (1972), em revisão das bacias do Recôncavo e Sergipe-Alagoas, oficializou algumas das espécies previamente nominadas por R. Weber (apud Schaller, 1969)e Schaller (1969), ao mesmo tempo em que propôs Cypridea (Sebastianites) fida minor Moura, 1972. Após estes trabalhos, ocorreu uma mudança no foco dos estudos, predominando os ambientes marinhos do Albiano ao Paleoceno em relação aos límnicos do Juro-Cretáceo Inferior. Estudos de grande amplitude geográfica (incluindo a bacia de Sergipe-Alagoas) foram conduzidos por Krömmelbein (1975, 1976), com os ostracodes marinhos de Gondwana, e Bertels (1977), com faunas límnicas e marinhas das bacias ao longo do Atlântico Sul.

Neufville $(1973,1979)$ apresentaram o levantamento mais detalhado até o momento das espécies do Cretáceo Superior-Paleoceno da bacia, com a descrição de diversas espécies: Bairdia itaporangaensis Neufville, 1973, Cytherella piacabucuensis Neufville 1973, Cytherella sergipensis Neufville, 1973, Langiella reymenti (Neufville, 1973) [segundo revisão em Fauth et al. (2005)], Kingmaina brazilensis Neufville, 1973, Krithe mutveii Neufville, 1973 e Macrocypris lanceolata Neufville, 1973. Em ambos também foram feitas considerações acerca da bioestratigrafia e paleozoogeografia das mesmas. Os resultados taxonômicos e paleogeográficos deste e outros trabalhos até então foram sumarizados por Tambareau (1982), com a proposta de uma bioprovíncia de ostracodes endêmica do protooceano Atlântico Central, separada do Mar de Tétis ao Norte e do proto-oceano Atlântico Austral, denominada Província Brasil-África Ocidental Central.

As pesquisas em ostracodes da bacia foram retomadas apenas nos anos 1990, com a publicação de Carbonnel (1991). Nesta, analisou-se aspectos paleozoogeográficos de Soudanella laciniosa Apostolescu, 1961, espécie do Paleoceno com distribuição ao longo de bacias das margens continentais da África e do Brasil. Dingle (1999), ao comparar faunas de regiões a sul e norte da cordilheira de Walvis durante o Cretáceo, abordou a presença de gêneros de ampla a moderada ocorrência na bacia de Sergipe-Alagoas, como Aracajuia, Sergipella, Neocythere Mertens, 1956, Brachycythere Alexander, 1933 e Soudanella Apostolescu, 1961.

Viviers et al. (2000) realizaram o último grande levantamento bioestratigráfico com base em ostracodes - iniciado por Koutsoukos \& Silva-Telles Júnior (1993) -, expandindo o zoneamento da sub-bacia de Sergipe até o Campaniano e integrando-o à bioestratigrafia com 
base em ostracodes e cefalópodes pré-existente (fig. 4). Entretanto, todas as espécies publicadas neste levantamento apresentam nomenclatura imprecisa ou em aberto. Este mesmo trabalho estabeleceu diversas correlações entre o proto-oceano Atlântico Sul e ambiente tetianos a norte, análises estas posteriormente expandidas por Fauth (2002), em revisão integrada dos ambientes do Cretáceo Superior do proto-oceano Atlântico Central.

Atualizações posteriores de algumas das espécies abordadas em Viviers et al. (2000) são apresentadas por Smith (2000) [Harbinia micropapillosa (Bate, 1972)], Do Carmo et al. (2008) [Cypridea africana (Krömmelbein, 1965)], Do Carmo et al. (2012), (Sergipella transatlantica Krömmelbein, 1967 e Sergipella viviersae Do Carmo et al., 2012) e Do Carmo et al. (2013) [Harbinia sinuata (Krömmelbein \& Weber, 1971)]. Piovesan et al. (2012) em revisão de Majungaella Grekoff, 1963, identificou exemplares de uma espécie não descrita deste gênero no Campaniano-Maastrichtiano da bacia de Sergipe-Alagoas. Poropat \& Colin (2012a, b) oferecem, respectivamente, um estudo integrado da bioestratigrafia baseada em ostracodes do Tithoniano superior-Aptiano das bacias costeiras do nordeste do Brasil e África Central Ocidental, incluindo a bacia de Sergipe-Alagoas, e uma revisão de espécies do gênero Harbinia Tsao, 1959, incluindo aquelas de ocorrência nesta bacia. 


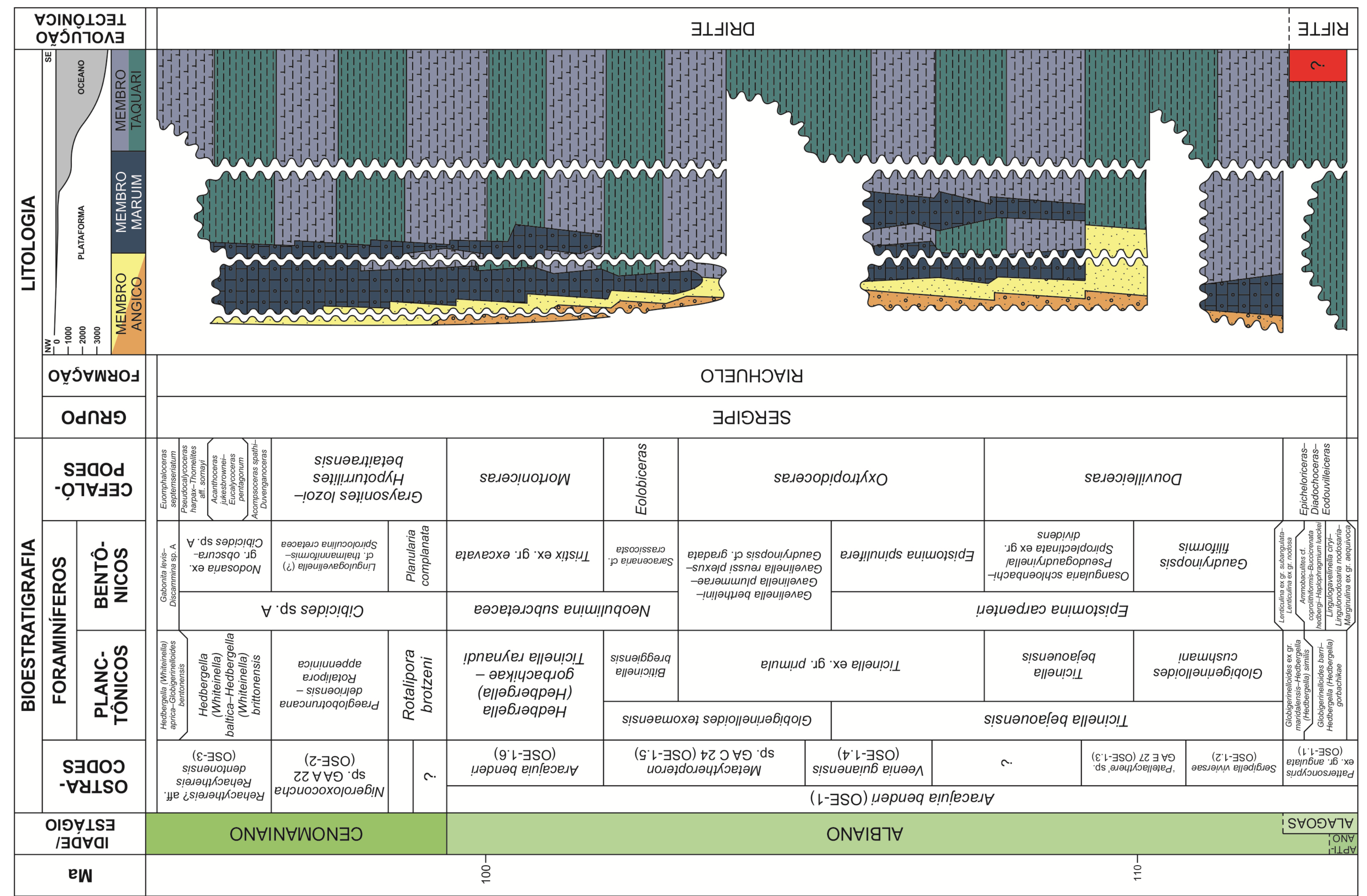

Figura 4. Litoestratigrafia e bioestratigrafia integrada da Formação Riachuelo (Neoalagoas-Eocenomaniano), bacia de Sergipe-Alagoas, Nordeste do Brasil (Koutsoukos \& Bengtson, 1993; Viviers et al., 2000). 


\section{MATERIAIS E MÉTODOS}

O trabalho de campo realizado na bacia de Sergipe-Alagoas, no Estado de Sergipe, nordeste do Brasil, entre os dias 11 e 17/09/2011, analisou 11 afloramentos, dos quais sete foram amostrados. O material de estudo compreende 147 amostras coletadas em sete destes afloramentos (fig. 5). O quadrante de referência para as coordenadas UTM destes afloramentos é o 24L, e o sistema padrão é o SAD69. Somadas àquelas, 189 amostras de testemunho de perfurações conduzidas pela PETROBRAS foram analisadas, as mesmas utilizadas no arcabouço estratigráfico da Formação Riachuelo obtido por Viviers et al. (2000). Os materiais preparados em laboratório seguiram metodologia desenvolvida pelo Laboratório de Micropaleontologia da Universidade de Brasília (LabMicro-UnB).

\subsection{MATERIAL DE ESTUDO}

Os afloramentos amostrados durante o trabalho de campo são descritos abaixo quanto à sua localidade, litologia e conteúdo fossilífero. Às margens da rodovia BR-101, no Município de Rosário do Catete, encontra-se o afloramento Fazenda Santa Bárbara (716635N/8821887L) (fig. 6A). Esta localidade é considerada seção tipo do Membro Taquari da Formação Riachuelo (Schaller, 1969). Na seção analisada, são descritos folhelhos avermelhados carbonáticos. O registro fóssil prévio está composto por moldes de gastrópodes turritellídeos (Família Turritellidae Lovén, 1847), bem como possíveis braquiópodes. O afloramento Penha (692726N/8812604L) (fig. 6B) se localiza às margens da Rodovia SE-245, próximo à Igreja da Penha, no Município de Riachuelo. O afloramento apresenta em sua base uma sequência de arenitos finos amarelos e carbonáticos, com nível de coquina de possíveis

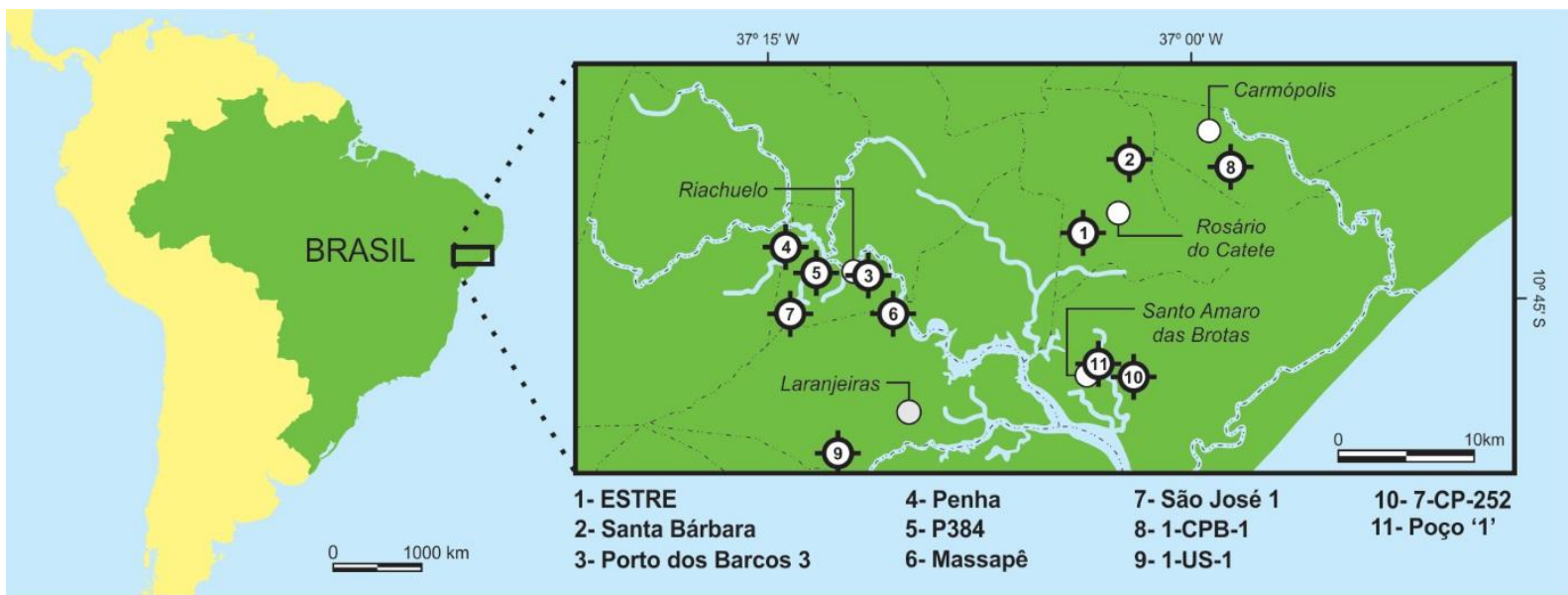

Figura 5. Localização dos afloramentos e perfurações amostrados no presente trabalho, bacia de SergipeAlagoas, Nordeste do Brasil. 
braquiópodes e esparsos fitofósseis. Acima, observa-se folhelhos cinzentos carbonáticos, seguidos de siltitos laminados amarelos carbonáticos e por fim arenitos finos laminados amarelos. Ocorrências abundantes de bivalves e equinoides também são registradas.

O afloramento ESTRE (fig. 6C), em Rosário do Catete (713561N/8816808L), está situado próximo à mina de potássio da Companhia Vale S/A. O afloramento, a partir da base, se inicia com folhelhos margosos ricos em fitofósseis, seguidos por intercalação de níveis carbonáticos e argilosos. A camada seguinte é composta por folhelhos creme bioturbados, com abundantes impregnações oleosas e concreções silicosas fossilíferas no topo. Logo acima, ocorrem folhelhos carbonáticos creme a cinza, abundantes em fitofósseis, especialmente angiospermas (Magnoliopsida?). Próximo à perfuração RO-636 (PETROBRAS S/A), em Riachuelo, está o afloramento P384 (695625N/8814175L) (fig. 6D). Na base deste afloramento são reconhecidos folhelhos laminados de cor creme e carbonáticos, com níveis de bioturbação e ricos em braquiópodes, bivalves e fitoclastos. Em seguida, depositam-se arenitos amarelados carbonáticos e siltitos creme intercalados. A seção se encerra com folhelhos laminados creme carbonáticos. Demais grupos fósseis incluem gastrópodes turritellídeos.

O afloramento Porto dos Barcos 3 (fig. 6E) está localizado em Riachuelo (699059N/8814030L). Da base para o topo, a sequência, ligeiramente saprolítica, compreende níveis de siltito carbonático creme, seguidos de siltito também carbonático, porém com alternância entre sedimentos creme e acinzentados. Em seguida ocorrem folhelhos cinzentos a amarelados; a camada se torna bastante fossilífera próximo ao topo. Sobre este folhelho, observam-se siltitos carbonáticos de cor creme, e o afloramento se encerra com folhelhos micáceos também de cor creme. O registro fóssil do afloramento "Porto dos Barcos 3" inclui espinhos de equinodermos, gastrópodes e bivalves. Uma amostra proveniente deste afloramento, MP-291, obtida durante o primeiro trabalho de campo, apresentou população abundante e excepcionalmente preservada de Aracajuia benderi, e por esse motivo foi incorporada ao grupo de trabalho.

O afloramento Massapê (700764N/881233L) (fig. 6F) se localiza à margem da Ferrovia Centro-Atlântica, próximo ao vilarejo de mesmo nome em Riachuelo. A litologia deste extenso afloramento se inicia com siltitos laminados amarelo-creme, carbonáticos e micáceos. Sobre os mesmos, ocorrem arenitos finos a muito finos amarelados, também carbonáticos e micáceos. Mais acima, são vistos, nesta ordem: intercalação de siltitos amarelos e folhelhos creme; grauvaca cinza com impregnações escuras; e por fim níveis interpostos de calcarenitos oolíticos e arenitos amarelados com grãos de quartzo fumê, oóides e bioturbações esparsos. 

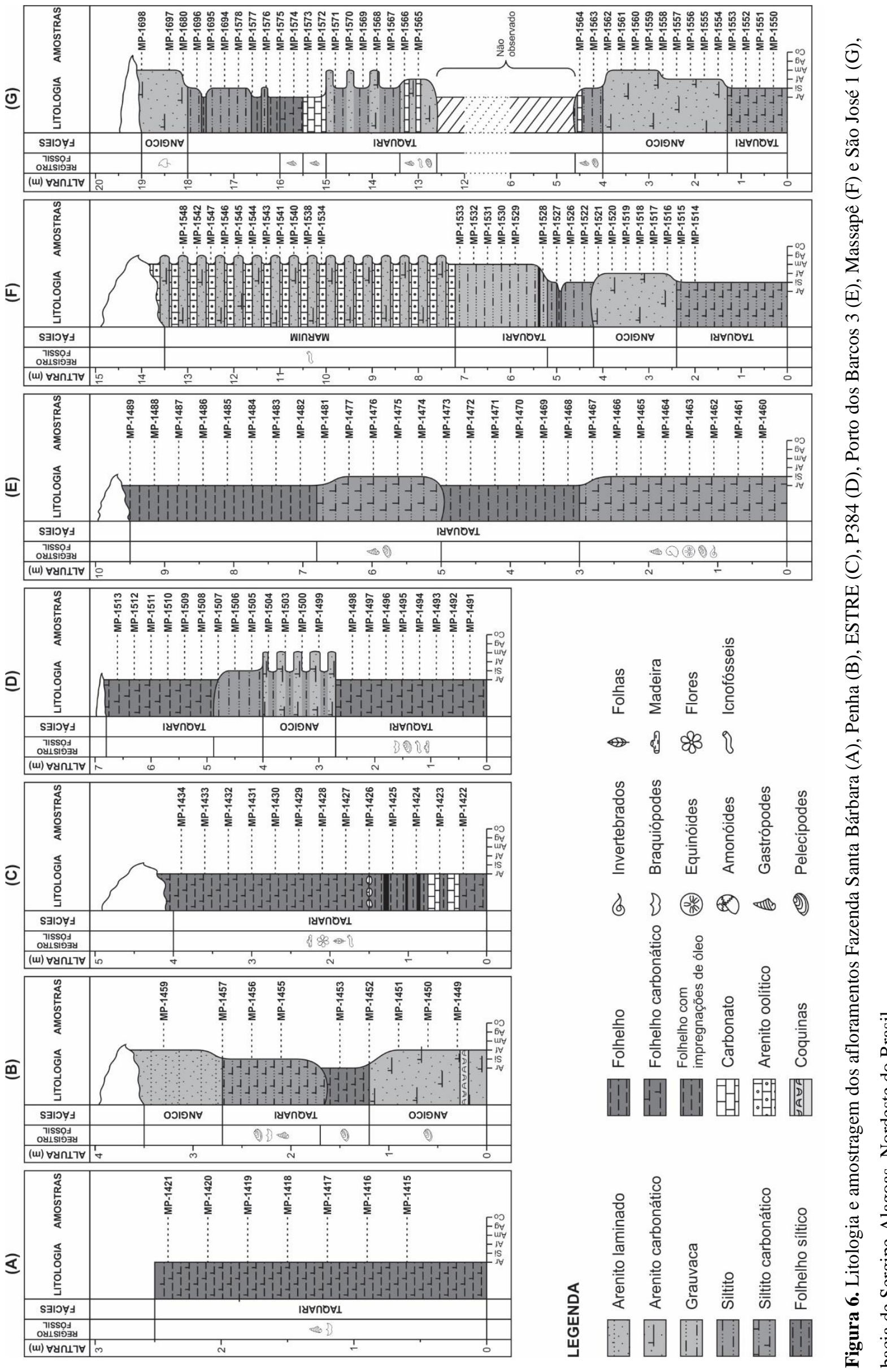
O afloramento São José 1 (693824N/8811279L) (fig. 6G), localizado em Riachuelo, apresenta a litologia mais complexa entre os afloramentos estudados. A partir da base, são encontrados siltitos com impregnações calcíferas, seguidos de arenito fino siltoso amarelo carbonático e siltitos amarelos com níveis carbonáticos. Após um intervalo não observável, aparecem arenitos amarelos interpostos com calcários maciços, abundantes em bivalves, cefalópodes e bioturbações. Em direção ao topo, ocorrem níveis margosos, com quantidades variáveis de carbonato. Na sequência, são observados calcários maciços muito fossilíferos, e logo acima uma intercalação não rítmica de marga síltica creme laminada e pelitos ricos em fósseis de turritellídeos. A seção se encerra com a deposição de arenitos médios a finos laminados creme-amarelados carbonáticos, com grande quantidade de fitofósseis.

\subsection{METODOLOGIA DE TRABALHO}

Cento e quarenta e duas amostras obtidas a partir do trabalho de campo mais a amostra MP-291 foram tombadas, preparadas e acondicionadas no LabMicro-UnB. Sessenta gramas de cada amostra foram preparados, e o restante foi acondicionado em sacos plásticos duplos, com uma ficha-catálogo, sob o prefixo "MP" (Micropaleontologia). Este material foi guardado em caixas, as quais foram encaminhadas para o armário de amostras preparadas do LabMicro-UnB.

O conteúdo separado para preparação foi tratado no LabMicro-UnB seguindo Do Carmo et al. (2004). As amostras foram tratadas com peróxido de hidrogênio $\left(\mathrm{H}_{2} \mathrm{O}_{2}\right)$ a $30 \%$, visando à desagregação das partículas da rocha. Etanol a 92GL foi adicionado para encerrar a reação entre $\mathrm{o}_{2} \mathrm{O}_{2}$ e a rocha. A separação dos grãos por tamanho foi feita, salvo exceções, com peneiras de malha de 630, 250, 160 e $80 \mu \mathrm{m}$. Para as amostras MP-1430 a MP-1434 (afloramento Estre), MP-1493, MP-1494 (afloramento P384) e MP-1578 (afloramento São José 1), substituiu-se a peneira de $80 \mu \mathrm{m}$ por uma de 90 e outra de $56 \mu \mathrm{m}$, devido ao rompimento daquela.

O material retido em cada peneira foi secado e acondicionado em potes etiquetados. Em seguida, ocorreu a triagem e a identificação dos espécimes de ostracodes. Parte dos trabalhos taxonômicos foi conduzida junto ao National Museum of Natural History (NMNH) do Smithsonian Institute, Washington, D.C., Estados Unidos. O Natural History Museum, na cidade de Londres, Reino Unido, também foi visitado com o mesmo propósito. Em ambos os museus, foram acessadas as coleções de materiais tipo, a fim de comparar os espécimes das presentes amostras com aqueles depositados nestas coleções.

Equipamentos utilizados para imageamento dos espécimes incluem: JEOL Neoscope 
JCM-5000 (LabMicro-UnB); Philips XL-30 (NMNH); e Zeiss EV040 (Centro de Pesquisas Leopoldo Américo Miguez de Mello - CENPES -, Rio de Janeiro, Brasil). Medidas de altura, comprimento e largura dos espécimes foram realizadas com o auxílio de uma lupa estereoscópica Olympus SZX12 com uma câmera Q5, através do software QCapture 7. Medições adicionais foram feitas em uma lupa estereoscópica Heerbrugg Wild M3Z e lentes de medição Leica.

As amostras de perfurações cedidas pela PETROBRAS foram obtidas a partir do cilindro central resultante das perfurações 1-CPB-1, 1-US-1 e 7-CP-252 (tab. 2). Uma amostra adicional foi retirada da perfuração "Poço 1", com o objetivo de caracterizar taxonomicamente a espécie Conchoecia? sp. 1. O material foi analisado nas instalações do CENPES, Rio de Janeiro, e as ocorrências por amostra, tanto aquelas de afloramento quanto as de perfurações, foram sumarizadas com auxílio do software Microsoft Excel (anexo I). Alterações realizadas no arcabouço estratigráfico da Formação Riachuelo obtido por Viviers et al. (2000) foram realizadas seguindo orientação do Código Brasileiro de Nomenclatura Estratigráfica (CENE/SBG, 1986). Seguindo recomendações do mesmo, um novo código foi introduzido para esta zona e suas subdivisões, baseado na sigla para ostracodes "marinhos de

Tabela 2. Perfurações e profundidades das amostras da PETROBRAS S.A utilizadas no presente trabalho, bacia de Sergipe-Alagoas, Nordeste do Brasil.

\begin{tabular}{ll}
\hline Perfuração & \multicolumn{1}{c}{ Profundidades amostradas (m) } \\
\hline 1-CPB-1 & $198,222,345.5,348,348.5,35,354.5,355.5,356.5,358.5,359.5,360.5$ e 364.5 \\
$1-U S-1$ & $0,12,30,60,90,98.5,99.5,100.5,101.1,120,150,180,210,240,246,261,270,270.05,276,291$, \\
& $300,306,321,330,336,351,360,366,381,390,396,399,399.5,400.5,411,420,426,441,450$, \\
& $456,471,480,486,501,510,516,531,540,541,546,552,552.5,553.5,554.5,555.5,561,570$, \\
& $576,591,600,606,621,630,636,651,660,666,678,679.55,681,690,696,711,720,726,741$, \\
& $750,756,771,780,786,801,804,810,816,831,840,846,861,870,876,891,900,906,921,930$, \\
& $936,951,953,953.1,960,966,981,990,996,1011,1020,1026,1041,1050,1056,1067,1067.25$, \\
& $1071,1080,1086,1101,1110,1116,1131,1139.2,1139,1140,1146,1161,1170,1200,1230$, \\
& $1260,1290,1320,1350,1380,1395,1410$ e 1425 \\
& $466,466.2,466.7,467.5,467.55,467.9,468.7,469.2,469.75,469.8,470.15,470.6,470.65,471.25$, \\
& $471.8,472.25,472.3,472.6,473.3,473.8,474.45,474.5,474.85,475.3,475.85,476.25,476.3$, \\
& $476.5,476.7,477.1,477.5,477.95,478.45,478.85,479.5,480.3,480.55,480.95,481.6,481.8$, \\
& $482.9,483.5,483.55,484.15,484.4,484.75,485.6,486.05,486.45,487,488.15,488.4,489.15$, \\
& $489.2,489.7,490,490.1,490.35,492.95,493,493.45,493.5,494.3,494.75,495.85,495.9,496.55$, \\
& $496.6,497.7,498.3,498.6,502.4,503.35,503.53,506.3,507.15,508.4,508.75,509.3,511.35$, \\
& $511.4,511.9,512.7,514,514.05,515,516,517.45,518.3,518.8,521,521.4,523.9,527.1,534.8$, \\
& $535.55,540.05,552,553.4,558.9,560.3,564.8,567.15,568.15,568.95$ e 581.35,
\end{tabular}


Sergipe-Alagoas" (MSA), em substituição ao original "OSE”.

Análises paleozoogeográficas foram realizadas tomando por base a literatura existente para espécies identificadas durante a revisão taxonômica. A distribuição de cada espécie considerada foi inferida com base na literatura disponível, obtida principalmente através das bibliotecas do LabMicro e do NMNH (NMNH Library e Benson Library). Dois tipos de rotas de migração foram estabelecidos, com base no nível de certitude quanto à localidade geográfica do ponto de origem da espécie (assumida como a localidade do registro mais antigo de cada uma): rotas possíveis de migração partiram de um ponto de origem incerto, enquanto rotas prováveis de migração tiveram um ponto de origem confiável. Identificações dúbias ou incompletas não foram consideradas, exceto aquelas incompletas mas com distribuição fora da bacia de Sergipe-Alagoas, como Conchoecia sp. 1. 


\section{RESULTADOS E DISCUSSÃO}

O estudo dos ostracodes da Formação Riachuelo aqui apresentado permitiu a melhor identificação e descrição das espécies de ostracodes do Albiano da bacia de Sergipe-Alagoas. $\mathrm{O}$ arcabouço estratigráfico baseado em ostracodes do Albiano da bacia foi reavaliado (anexos II e V), e uma série de mudanças nomenclaturais e de zoneamento é proposta para o zoneamento existente, em especial a criação da nova Zona Diferencial Superior Aracajuia antiqua (MSA-1), do Albiano mais superior. O estudo do status taxonômico do Gênero Aracajuia e sua espécie tipo, Aracajuia benderi, comparado a Amphicytherura Butler \& Jones, 1957 e Sondagella (Dingle, 1969), levou a uma detalhada revisão da paleozoogeografia e estratigrafia dos três gêneros (anexos III e VI). Da mesma forma, novas inferências paleozoogeográficas são feitas com base em outros táxons identificados, comparando a Província Brasil-África Ocidental Central às demais encontradas ao longo do proto-oceano Atlântico no Eocretáceo.

\subsection{TAXONOMIA DE OSTRACODES}

Trinta e nove espécies de 17 famílias foram recuperadas e identificadas a partir das amostras analisadas. Os espécimes tipo estão tombados na Coleção de Pesquisa do LabMicro, UnB, sob o prefixo “CP” (Coleção de Pesquisa) e numerações de 668 a 735 e 756 a 769. Material tipo adicional de outras duas espécies se encontra no CENPES, Rio de Janeiro, Brasil, perfazendo três espécimes sob prefixo ainda não designado. A classificação suprafamiliar aqui utilizada segue a revisão mais recente de Liebau (2005). A taxonomia de clados inferiores se baseou em Maddocks (1969), Hanai (1970), Gründel \& Kozur (1971), Gründel (1974a, 1976, 1977, 1978a, 1978b) e Hou et al. (2002), como indicado na seção "Discussão" de cada espécie.

A terminologia morfológica é a mesma de Sylvester-Bradley \& Benson (1971), exceto quanto ao uso do termo "costela", para o qual Kesling (1951) é seguido. A terminologia para descrever a curvatura das extremidades anterior e posterior - infracurvado, equicurvado e supracurvado - foi extraída de Lüttig (1962). A abundância populacional de cada espécie foi medida da seguinte maneira: rara, 1-5 espécimes; comum, 6-10; e abundante, mais de 10. A definição de biozonas, a fim de delimitar a distribuição das espécies na bacia de SergipeAlagoas, segue os resultados obtidos por Antonietto et al. (aceito) (anexo IV), sumarizados na seção “Bioestratigrafia do Albiano da Formação Riachuelo" do presente trabalho. 
SUBCLASSE Ostracoda Latreille, 1802

SUPERORDEM Myodocopomorpha Kozur, 1972

ORDEM Halocypridida Skogsberg, 1920

SUBORDEM Halocypridina Skogsberg, 1920

SUPERFAMÍLIA Halocypridoidea Dana, 1853

FAMÍLIA Halocyprididae Dana, 1853

GÊNERO Conchoecia Dana, 1849

Conchoecia? sp. 1

Figs 7D-F

1979 "Conchoecia" GA D 31. Grosdidier: p. 8, figs 60a-d.

1983 Gênero aff. "Conchoecia” sp. 150. Rosenfeld \& Raab: p. 113, est. 7, fig. 10.

1985 Gen. aff. "Conchoecia” sp. 150. Honigstein et al.: est. 6, fig. 150, est. 7, fig. 150.

1991 Conchoecia sp. 1. Andreu-Boussut: p. 437, est. 1, figs 1-3.

1992 Conchoecia sp. 1. Andreu: p. 296, est. 1, fig. 1.

2000 Conchoecia? sp. Se6 aff. 'C' sp. GA D 31 Grosdidier. Viviers et al.: p. 414, figs 10, 11.

Hipótipos. LBP 10 (carapaça) e LBP 11 (carapaça).

Medidas. LBP 10, comprimento $=0.63 \mathrm{~mm}$, altura $=0.49 \mathrm{~mm}$, largura $=0.38 \mathrm{~mm}$; LBP 11 , comprimento $=0.53 \mathrm{~mm}$, altura $=0.43 \mathrm{~mm}$.

Ocorrência. Nas profundidades de 876, 891 e 900m na perfuração 1-US-1, Município de Laranjeiras; e 510 a 540m na perfuração "1", Santo Amaro das Brotas; Estado de Sergipe, Brasil.

Discussão. A presença de halocypridídeos no Cretáceo Inferior do oceano Atlântico foi notada primeiramente por Pokorný (1964), ao lidar com ostracodes do Coniaciano da Tchecoslováquia. Desde então, diversos táxons tem sido provisoriamente classificados no Gênero Conchoecia Dana, 1849 por vários autores (Colin \& Andreu, 1990), embora as únicas semelhanças morfológicas entre aqueles e este gênero do Recente são a presença de um rostrum (alguns dos espécimes, mas não aqueles aqui estudados) e a ornamentação estriada. Estudos mais aprofundados das características internas dos referidos espécimes nunca foram realizados, e tampouco são possíveis com o presente material. Portanto, os autores optam por manter o status taxonômico atual, porém com dúvida, à espera de ocorrências melhor preservadas para detalhamento taxonômico.

Distribuição geográfica e estratigráfica. Formação Madiéla, bacia do Gabão, Gabão, Albiano inferior-médio (Grosdidier, 1979). Formações Talme Yafe, Yavne Shales e Hazera, bacia Levantina, Israel, Albiano-Cenomaniano inferior (Rosenfeld \& Raab, 1983). Bacia de Agadir, Marrocos, Albiano-Cenomaniano inferior (Andreu-Boussut, 1991). Membro Maruim, 


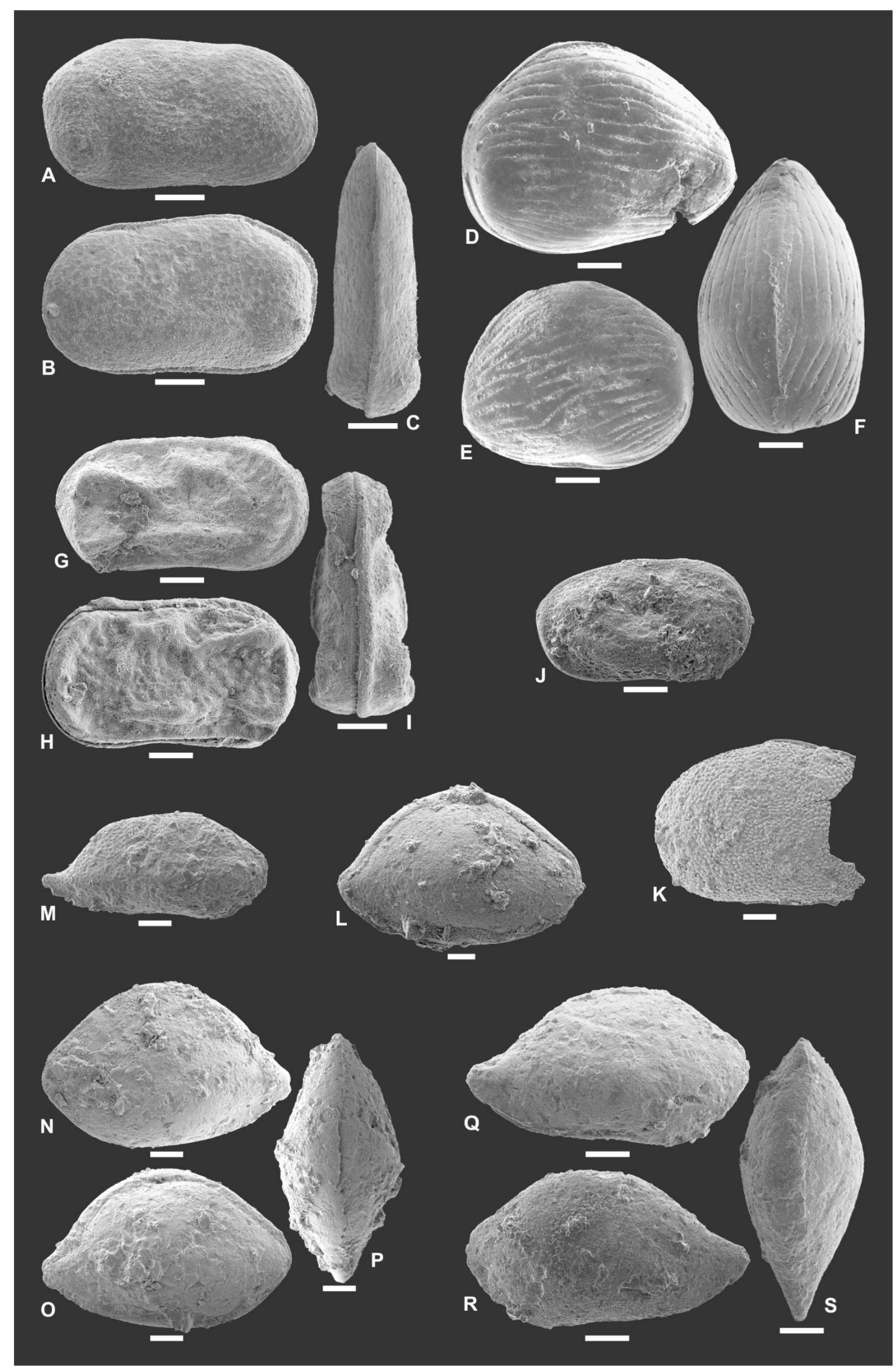


Formação Riachuelo, bacia de Sergipe-Alagoas, Brasil, Albiano superior, Zona Aracajuia benderi (MSA-0), Subzona Metacytheropteron aff. M. sp. GA C 24 (MSA-0.5) (Viviers et al., 2000).

\author{
SUPERORDEM Podocopomorpha Kozur, 1972 \\ ORDEM Platycopida Sars, 1866 \\ SUPERFAMÍLIA Cytherelloidea Sars, 1866 \\ FAMÍLIA Cytherellidae Sars, 1866 \\ GÊNERO Cytherella Jones, 1849 \\ Cytherella besrineensis (Bischoff, 1964)
}

Figs 7A-C

1964 Cytherelloidea besrineensis Bischoff: p. 15, est. 3, figs 21-22

1983 Cytherelloidea besrineensis Bischoff. Rosenfeld \& Raab: p. 92, est. 1, figs 11, 12.

1985 Cytherelloidea besrineensis Bischoff. Honigstein et al.: p. 3, est. 3, fig. 228.

2000 Cytherella sp. Se3. Viviers: p. 415, fig. 8.13.

Homótipos. CP-668 (carapaça, fêmea) e CP-669 (valva direita, fêmea).

Medidas. CP-668, comprimento $=0.56 \mathrm{~mm}$, altura $=0.30 \mathrm{~mm}$, largura $=0.20 \mathrm{~mm}$; CP-669, comprimento $=0.55 \mathrm{~mm}$, altura $=0.28 \mathrm{~mm}$.

Ocorrência. Abundante, nas amostras MP-1428 (afloramento ESTRE), Município de Rosário do Catete; MP-1460, MP-1468, MP-1469, MP-1470, MP-1471, MP-1472, MP-1481 (afloramento Porto dos Barcos 3), MP-1500, MP-1506, MP-1509, MP-1510, MP-1511, MP1512, MP-1513 (afloramento P384), MP-1518, MP-1520 (afloramento Massapê), MP-1558 e MP-1563 (afloramento São José 1), Município de Riachuelo; Estado de Sergipe, Brasil.

Discussão. Bischoff (1964) atribuiu inicialmente Cytherella besrineensis Bischoff, 1964 ao Gênero Cytherelloidea Alexander, 1929, apesar de esta não apresentar nenhuma costela em sua superfície lateral, uma característica diagnóstica deste gênero (Alexander, 1929). Por esse

\footnotetext{
Figura 7. Ostracodes da Formação Riachuelo, bacia de Sergipe-Alagoas, Nordeste do Brasil, Albiano. A-C, Cytherella besrineensis (Bischoff, 1964); A, CP-669, vista lateral direita, B, C, CP-668, B, vista lateral esquerda, C, vista dorsal. D-F, Conchoecia? sp. 1; D, E, LBP 10, D, vista lateral direita, E, vista lateral esquerda, F, LBP 11, vista dorsal. G-I, Cytherelloidea btaterensis Bischoff, 1964; G, CP-671, vista lateral direita, H, CP-672, vista lateral esquerda, I, CP-673, vista dorsal. J, Cytherella icknieldensis? (Weaver, 1982); CP-756, vista lateral direita. K, Cytherella sp. 1, CP-670, vista lateral. L, Bairdoppilata pseudoseptentrionalis Mertens, 1956; CP676, vista lateral direita. M, Bairdoppilata sp. 1, CP-678, vista lateral direita. N-P, Bairdoppilata comanchensis (Alexander, 1929); CP-674, N, vista lateral direita, O, vista lateral esquerda, P, vista dorsal. Q-S, Bairdoppilata sp. 2; CP-757, Q, vista lateral direita, R, vista lateral esquerda, S, vista dorsal. Escala $=100 \mu \mathrm{m}$.
} 
motivo, a espécie é transferida no presente trabalho para Cytherella Jones, 1849, com base em semelhanças na ornamentação.

Distribuição geográfica e estratigráfica. Formações Talme Yafe, Rama, Telamim e Yavne Shales, bacia Levantina, Israel, Aptiano-Albiano (Rosenfeld \& Raab, 1983; Honigstein et al., 1985). Bacia Levantina, Líbano, Aptiano-Albiano (Bischoff, 1964). No presente trabalho, como em Viviers et al. (2000), membros Taquari e Maruim, Formação Riachuelo, bacia de Sergipe-Alagoas, Brasil, Aptiano superior-Albiano, zonas Aracajuia benderi (MSA-0) subzonas Sergipella viviersae (MSA-0.2), Praebythoceratina amsittenensis (MSA-0.3) e Reticulocosta edrianae (MSA-0.4) - e Aracajuia antiqua (MSA-1).

Cytherella icknieldensis? (Weaver, 1982)

Fig. 7J

1982 Platella icknieldensis Weaver: p. 24, est. 3, figs 17-19.

1988 Platella icknieldensis Weaver. Wilkinson: p. 1236, est. 1, fig. 13.

1992 Platella icknieldensis Weaver. Witte et al.: p. 48, est. 1, figs 13-14.

Homótipo. CP-756 (valva direita).

Ocorrência. Rara, nas amostras MP-1422 e MP-1428 (afloramento ESTRE), Município de Rosário do Catete, Estado de Sergipe, Brasil.

Medidas. Comprimento $=0.51 \mathrm{~mm}$, altura $=0.29 \mathrm{~mm}$.

Discussão: Esta espécie é muito semelhante a Platella icknieldensis Weaver, 1982, do Cenomaniano da Inglaterra e Holanda (Weaver, 1982; Witte et al., 1992), embora um pouco menor e menos ornamentada; diagênese poderia ser a causa desta última diferença. Platella Coryell \& Fields, 1937 parece não ser um gênero válido, uma vez que foi estabelecido com base em carapaças de formas juvenis, de acordo com a Bold (1967) e Malz \& Lord (2004).

Distribuição geográfica e estratigráfica. Membros Glauconitic Marl e Cambridge Greensand, Formação West Melbury Marly Chalk; Membro Totternhoe Stone, Formação Zig Zag Chalk; e Membro Plenus Marl, Formação Holywell Nodular Chalk, bacia Anglo-Paris, Inglaterra, Cenomaniano (Weaver, 1982; Wilkinson, 1988). Holanda, Cenomaniano inferior (Witte et al., 1992). No presente trabalho, Membro Taquari, Formação Riachuelo, bacia de Sergipe-Alagoas, Brasil, Albiano médio, Zona Aracajuia benderi (MSA-0), Subzona Reticulocosta edrianae (MSA-0.4).

\section{Cytherella sp. 1}

Fig. 7K 
Hipótipo. CP-670 (valva).

Ocorrência. Rara, nas amostras MP-1427 e MP-1429 (afloramento ESTRE), Município de Rosário do Catete, Estado de Sergipe, Brasil.

Medidas. Altura $=0.51 \mathrm{~mm}$.

Discussão. Cytherella sp. 1 é comparável a várias espécies lisas de Cytherella com distribuição no Albiano (parcial ou não). Estas incluem Cytherella ovata (Roemer, 1841) (várias unidades litológicas, andares e localidades na Europa, e possivelmente regiões próximas na América, África e Ásia) (Brown, 1957; Herrig, 1966; Bassoulet \& Damotte, 1969; Swain \& Brown, 1972; Majoran, 1989; Witte, et al., 1992, El-Nady et al., 2008).; Cytherella comanchensis Alexander, 1929 (Formação Fort Worth, Estados Unidos, Albiano superior) (Alexander, 1929); e Cytherella fredericksburgensis Alexander, 1932 (Formação Goodland, Estados Unidos, Albiano) (Alexander, 1932). Por causa da ausência nas amostras atuais de espécimes bem conservados, não foi possível fornecer uma identificação mais completa de Cytherella sp. 1.

Distribuição geográfica e estratigráfica. Membro Taquari, Formação Riachuelo, bacia de Sergipe-Alagoas, Brasil, Albiano superior, Subzona Reticulocosta edrianae (MSA-0.4).

\section{GÊNERO Cytherelloidea Alexander, 1929 \\ Cytherelloidea btaterensis Bischoff, 1964}

Figs 7G-I

1964 Cytherelloidea btaterensis Bischoff: p. 17, est. 2 figs 16-17, est. 3 figs 18-19.

1972 Cytherelloidea btaterensis Bischoff. Damotte \& Saint-Marc: p. 277, est. 1, fig. 2.

1983 Cytherelloidea btaterensis Bischoff. Rosenfeld \& Raab: p. 92, est. 1, figs 14-16.

1985 Cytherelloidea btaterensis Bischoff. Honigstein et al.: p. 12, est. 3, fig. 173.

Homótipos. CP-671 (valva direita, fêmea), CP-672 (carapaça, fêmea) e CP-673 (carapaça, fêmea).

Ocorrência. Abundante, nas amostras MP-1420 (afloramento Santa Bárbara), Município de Rosário do Catete; MP-1449, MP-1452, MP-1457, MP-1459 (afloramento Penha), MP-1474, MP-1477 (afloramento Porto dos Barcos 3), MP-1500, MP-1509, MP-1510, MP-1511, MP1512, MP-1513 (afloramento P384), MP-1515, MP-1518, MP-1519, MP-1520 (afloramento Massapê), MP-1550, MP-1551, MP-1552, MP-1553, MP-1554, MP-1555, MP-1558, MP1563 e MP-1565 (afloramento São José 1), Município de Riachuelo; Estado de Sergipe, Brasil.

Medidas. CP-671, comprimento $=0.58 \mathrm{~mm}$, altura $=0.30 \mathrm{~mm} ; \mathrm{CP}-672$, comprimento $=0.59$ 
$\mathrm{mm}$, altura $=0.32 \mathrm{~mm}$, largura $=0.27 \mathrm{~mm} ;$ CP-673, comprimento $=0.54 \mathrm{~mm}$, altura $=0.30$ $\mathrm{mm}$, largura $=0.23 \mathrm{~mm}$.

Discussão. O diagnóstico segue Bischoff (1964). A presente espécie se assemelha a Cytherelloidea circumvallata Bonnema, 1941 (Albiano médio-Cenomaniano superior da Holanda) (Bonnema, 1941; Gründel, 1966), porém a última apresenta uma costela central adicional, ausente na primeira. Cytherelloidea knaptonensis Kaye, 1963, do Albiano do Líbano (Bischoff, 1964), também pode ser separada daquela espécie por sua ornamentação, que não inclui reticulações e pontuações entre as costelas; igualmente, a forma da costela posterior é notavelmente diferente, especialmente ao longo da margem dorsoposterior. Cytherelloidea kayei Weaver, 1982, do Cenomaniano médio-superior da Inglaterra (Weaver, 1982), mesmo sendo muito semelhante a Cytherelloidea btaterensis, tem costelas mais espessas em geral.

Distribuição geográfica e estratigráfica. Bacia Levantina, Líbano, Aptiano-Albiano (Bischoff, 1964; Damotte \& Saint-Marc, 1972); formações Tamun, Hidra, Rama, Yakhini, Yavne Shales e Talme Yafe, bacia Levantina, Israel, Aptiano-Albiano (Rosenfeld \& Raab, 1983; Honigstein et al., 1985); no presente trabalho, Membro Taquari, Formação Riachuelo, bacia de Sergipe-Alagoas, Brasil, Aptiano superior-Albiano, zonas Aracajuia benderi (MSA0) - subzonas Sergipella viviersae (MSA-0.2) e Praebythoceratina amsittenensis (MSA-0.3) - e Aracajuia antiqua (MSA-1).

ORDEM Podocopida Sars, 1866

SUBORDEM Bairdiocopina Gründel, 1967

SUPERFAMÍLIA Bairdioidea Sars, 1888

FAMÍLIA Bairdiidae Sars, 1888

SUBFAMÍLIA Bairdiinae Sars, 1888

GÊNERO Bairdoppilata Coryell et al., 1935

Bairdoppilata comanchensis (Alexander, 1929)

Figs $7 \mathrm{~N}-\mathrm{P}$

1929 Bairdia comanchensis Alexander: p. 63, est. 2, fig. 15; est. 3, fig. 4.

?1956 Bairdia cf. B. comanchensis Alexander. Grekoff \& Deroo: p. 217, est. 46, figs 9, 10.

1958 Bairdia comanchensis Alexander. Howe \& Laurencich: p. 66, figs sem número.

[Non] 1964 Bairdia comanchensis Alexander. Swain \& Brown: p. 12, est. 1, figs 5a-c.

?1973 Bairdia aff. comanchensis Alexander. Neufville: p. 127, est. 7.4, figs 3a, b.

[Pars] 1974 Bairdia spp. Rosenfeld \& Raab: p. 6, est. 1, fig. 14.

[Non] 1974 Bairdia spp. Rosenfeld \& Raab: p. 6, est. 1, figs 15, 16. 
?1981 Bairdia aff. comanchensis Alexander. Reyment: p. 142, figs 2a, b.

1982 Bairdia comanchensis Alexander. Moysey \& Maddocks: p. 144, est. 1, figs 2a, b, est. 4, figs 13, 14.

[Pars] 1985 Bairdia spp. Honigstein et al.: p. 3, est. 9 figs 94, 94.

1991 Bairdia pseudoseptentrionalis (Mertens, 1956). Shahin: p. 136, est. 1, figs 16, 17.

2006 Bairdoppilata aff. pseudoseptentrionalis (Mertens, 1956). Andreu \& Bilotte: p. 60, est. 1, figs 15-17.

Homótipos. CP-674 (carapaça) e CP-675 (valva direita).

Ocorrência. Abundante, nas amostras MP-1514, MP-1516, MP-1517, MP-1518, MP-1519, MP-1520, MP-1522, MP-1542, MP-1543 e MP-1546 (afloramento Massapê), Município de Riachuelo; também nas profundidades de 552, 570, 600, 810, 816 e 840m na perfuração 1US-1, Município de Laranjeiras; Estado de Sergipe, Brasil.

Medidas. CP-674, comprimento $=0.76 \mathrm{~mm}$, altura $=0.49 \mathrm{~mm}$, largura $=0.38 \mathrm{~mm} ;$ CP-675, comprimento $=0.75 \mathrm{~mm}$, altura $=0.42 \mathrm{~mm}$.

Discussão. A nova identificação de gênero para Bairdoppilata comanchensis (Alexander, 1929) segue Maddocks (1969) e Becker et al. (1989). De acordo com ambos, o Gênero Bairdia M'Coy, 1844 (ao qual esta espécie foi atribuída em um primeiro momento), é restrito ao Paleozoico. O primeiro também afirma que Bairdoppilata Coryell et al., 1935 é praticamente idêntica em vista externa a Bairdia, mas apresenta séries de dentículos à frente de ambas as extremidades da charneira em vista interna, além de estar confinada ao Cretáceo superior. A presente revisão se baseia em ambas as informações para a mudança de gênero realizada. Diversas ocorrências (incluindo algumas duvidosas) de Bairdoppilata pseudoseptentrionalis Mertens, 1956 (Shahin, 1991; Andreu \& Bilotte, 2006) são transferidas para Bairdoppilata comanchensis com base em diferenças de tamanho e formato externo geral desses espécimes em comparação àqueles designados por Mertens (1956). Um dos espécimes identificados como Bairdoppilata comanchensis em Swain \& Brown (1964, est. 1, figs 4a, 5c) pertence na verdade a Bairdoppilata rotunda (Alexander, 1929), de acordo com a revisão dos gêneros Bairdia e Bairdoppilata em Howe \& Laurencich (1958); o outro exemplar pertence a um táxon não identificado. O espécime em Neufville (1973), também figurado em Reyment (1981), possivelmente corresponde a Bairdoppilata comanchensis, apesar das diferenças de tamanho da carapaça e morfologia da margem dorsal - estas poderiam ser causadas por fossildiagênese. Um dos espécimes de Bairdia spp. em Rosenfeld \& Raab (1974, est. 1, fig. 14) também pertence a Bairdoppilata comanchensis, porém estes autores não especificam sua distribuição geográfica e estratigráfica, optando por agrupá-lo com outros identificados como Bairdia; este problema é parcialmente resolvido por Honigstein et al. (1985), o qual restringe o espécimes de Bairdoppilata comanchensis ao Cenomaniano superior-Turoniano. 
Distribuição geográfica e estratigráfica. Formações Denton, Weno (Albiano) e Walnut (Albiano médio), Estados Unidos, (Alexander, 1929; Howe \& Laurencich, 1958; Moysey \& Maddocks, 1982). Formações Raha e Abu Qada, Egito, Cenomaniano (Shahin, 1991). Formações Marnes de la Fontaine Salée e Grès de las Sals, bacia de Aquitaine, França, Cenomaniano-Turoniano (Andreu \& Bilotte, 2006). Possivelmente a camada informalmente conhecida como "Ora Shale”, parte superior do Membro 'En Yorqe'am, e Membro Avnon, Formação Hazera; Membro Yotvata; formações Negba, Mozza, Bet Hakerem, Kefar Sha'ul, 'Isfiya, Khureibe e Daliya; bacia Levantina, Israel, Cenomaniano superior-Turoniano (Rosenfeld \& Raab, 1974; Honigstein et al., 1985). No presente trabalho, Membro Maruim, Formação Riachuelo, bacia de Sergipe-Alagoas, Brasil, Albiano superior, Zona Aracajuia antiqua (MSA-1).

Bairdoppilata pseudoseptentrionalis Mertens, 1956

Fig. 7L

?1841 Cytherina subdeltoidea Münster. Roemer: p. 105, est. 16, fig. 22.

?1845 Cytherina subdeltoidea Münster. Reuss: p. 54, est. 5, fig. 38.

1849 Cythere (Bairdia) subdeltoidea (Münster). Jones: p. 23, est. 5, figs 15a-c, e, f.

[Non] 1849 Cythere (Bairdia) subdeltoidea (Münster). Jones: p. 23, est. 5, fig. 15d.

?1890 Bairdia subdeltoidea (Münster). Jones \& Hinde: p. 5, est. 2, figs 31-34.

1956 Bairdoppilata pseudoseptentrionalis Mertens: p. 182, est. 8, figs 7-10, est. 13, figs 89-90.

1958 Bairdoppilata pseudoseptentrionalis Mertens. Howe \& Laurencich: p. 82, figs sem número.

1963 Bairdia pseudoseptentrionalis (Mertens). Oertli: est. 72; 73, 1; 76.

?1965 Bairdia pseudoseptentrionalis (Mertens). Kaye: p. 223, est. 2, figs 1, 3-6.

?1966 Bairdia pseudoseptentrionalis (Mertens). Gründel: p. 15, est. 1, fig. 18.

?1971 Bairdia pseudoseptentrionalis (Mertens). Keen \& Siddiqui: p. 63, est. 1, fig. 2.

1973 Bairdia pseudoseptentrionalis (Mertens). Hart: p. 281, fig. 4.

1982 Bairdoppilata pseudoseptentrionalis Mertens. Weaver: p. 24, est. 4 figs 1-3.

?1985a Bairdia pseudoseptentrionalis (Mertens). Babinot et al.: p. 172, est. 51, fig. 1.

[Non] 1985b Bairdia gr. pseudoseptentrionalis (Mertens). Babinot et al.: p. 224, est. 55, figs 15, 16.

?1988 Bairdoppilata pseudoseptentrionalis Mertens. Jarvis et al.: p. 34, fig. 15j.

1989 Bairdia sp. Majoran: p. 9, est. 2, figs 4-7.

[Non] 2008 Bairdia pseudoseptentrionalis (Mertens). El-Nady et al.: p. 544, est. 2, fig. 6.

2013 Bairdoppilata sp. 1. Piovesan et al.: p. 244, figs 3.8a-b.

Homótipos. CP-676 (carapaça) e CP-677 (valva esquerda).

Ocorrência. Abundante, nas amostras MP-1460, MP-1468, MP-1469 (afloramento Porto dos Barcos 3), MP-1509, MP-1510, MP-1511, MP-1512, MP-1513 (afloramento P384), MP-1574, MP-1680 e MP-1697 (afloramento São José 1), Município de Riachuelo, Estado de Sergipe, 
Brasil.

Medidas. CP-676, comprimento $=0.91 \mathrm{~mm}$, altura $=0.58 \mathrm{~mm}$, largura $=0.44 \mathrm{~mm}$; CP-677, comprimento $=0.91 \mathrm{~mm}$, altura $=0.55 \mathrm{~mm}$.

Discussão: O diagnóstico segue Mertens (1956). Historicamente, Bairdoppilata pseudoseptentrionalis Mertens, 1956 tem sido confundida com Bairdoppilata subdeltoidea (Münster, 1830), uma vez que a mesma nunca foi devidamente ilustrada desde sua descrição por Münster (1830). Várias subespécies foram adicionadas à espécie durante o século 19, agravando as dificuldades em estabelecer um status taxonômico atualmente. A mais recente revisão de Bairdoppilata subdeltoidea pode ser vista em Deroo (1956), o qual a renomeou como Bairdoppilata roemeri e estabeleceu para a mesma uma distribuição estratigráfica do Cretáceo Inferior ao Paleógeno. Assumindo que a espécie ainda seja válida, deve-se considerar a necessidade de avaliar a distinção entre Bairdoppilata pseudoseptentrionalis e Bairdoppilata roemeri. Os espécimes em Kaye (1965), Gründel (1966) e Jarvis et al. (1988) apresentam a porção posterior da margem dorsal mais retilínea na valva esquerda, a qual é mais arredondada em Bairdoppilata pseudoseptentrionalis. Em Keen \& Siddiqui (1971) e Babinot et al. (1985b), os exemplares apresentam formato geral menos arredondado e maior recobrimento da valva esquerda sobre a direita, comparado àqueles em Mertens (1956).

Distribuição geográfica e estratigráfica. Bacia Anglo-Paris, França, Albiano médio (Oertli, 1963). Grupo Lower Chalk, Alemanha, Albiano-Cenomaniano (Roemer, 1841; Reuss, 1845; Mertens, 1956). Formações Gault, Greensand e Holywell Nodular Chalk (inclusive o Membro Plenus Marl), bacia Anglo-Paris, Inglaterra, Albiano-Cenomaniano (Jones, 1849; Kaye, 1965; Hart, 1973; Weaver, 1982). bacia Bordj Ghdir, Argélia, Cenomaniano inferior (Majoran, 1989). Formações Florianópolis e Guarujá, bacia de Santos, Aptiano superior-médio (Piovesan et al., 2013); no presente trabalho, Membro Taquari, Formação Riachuelo, bacia de Sergipe-Alagoas, Aptiano superior-Albiano médio, Zona Aracajuia benderi (MSA-0), subzonas Sergipella viviersae (MSA-0.2) e Praebythoceratina amsittenensis (MSA-0.3); Brasil.

\section{Bairdoppilata sp. 1}

Fig. $7 \mathrm{M}$

Hipótipo. CP-678 (valva direita).

Ocorrência. Comum, nas amostras MP-1516, MP-1518, MP-1520, MP-1545 e MP-1546 (afloramento Massapê), Município de Riachuelo, Estado de Sergipe, Brasil.

Medidas. CP-678, Comprimento $=0.69 \mathrm{~mm}$, altura $=0.32 \mathrm{~mm}$. 
Discussão. Bairdoppilata sp. 1 é notável entre as espécies de Bairdoppilata do Cretáceo inferior devido ao formato geral alongado, em especial a extremidade posterior, comparável a Bairdoppilata southerhamensis Weaver, 1982 - embora a carapaça desta espécie apresente maior altura (Weaver, 1982). Os espécimes também apresentam ornamentação pontuada como característica distintiva. Os espécimes aqui representados provavelmente correspondem a uma nova espécie; entretanto, devido à preservação ruim do material recuperado, composto unicamente por valvas, a nomenclatura da mesma é deixada em aberto.

Distribuição geográfica e estratigráfica. Membro Maruim, Formação Riachuelo, bacia de Estado de Sergipe-Alagoas, Brasil, Albiano superior, Zona Aracajuia antiqua (MSA-1).

\section{Bairdoppilata sp. 2}

Figs. 7Q-S

Hipótipo. CP-757 (carapaça).

Ocorrência. Rara, na amostra MP-1521 (afloramento Massapê), Município de Riachuelo, Estado de Sergipe, Brasil.

Medidas. Comprimento $=0.64 \mathrm{~mm}$, altura $=0.34 \mathrm{~mm}$, largura $=0.29 \mathrm{~mm}$.

Discussão. Os espécimes de Bairdoppilata sp. 2 se assemelham aos de Bairdoppilata sp. 1, embora sejam menos alongados e possuam a superfície lateral lisa. Em comparação com Bairdoppilata southerhamensis em Weaver (1982), a primeira é menos arredondada em vista lateral e mais estreita em vista dorsal do que a segunda.

Distribuição geográfica e estratigráfica. Membro Maruim, Formação Riachuelo, bacia de Sergipe-Alagoas, Brasil, Albiano superior, Zona Aracajuia antiqua (MSA-1).

FAMÍLIA Bythocyprididae (Maddocks, 1969)

GÊNERO Robsoniella Kuznetsova, 1956

Robsoniella falklandensis Dingle, 1984

Fig. 8A

?1974 Indet. sp. A. Oertli: p. 947, est. 6, figs 1-11.

1984 Robsoniella falklandensis Dingle: p. 118, figs 8c-f.

?1992 Robsoniella cf. falklandensis Dingle. Damotte: p. 826, est. 1, fig. 8.

Homótipo. CP-733 (valva direita, homótipo).

Ocorrência. Rara, nas amostras MP-1468 e MP-1470 (afloramento Porto dos Barcos 3), Município de Riachuelo, Estado de Sergipe, Brasil.

Medidas. Comprimento $=0.72 \mathrm{~mm}$, altura $=0.43 \mathrm{~mm}$. 


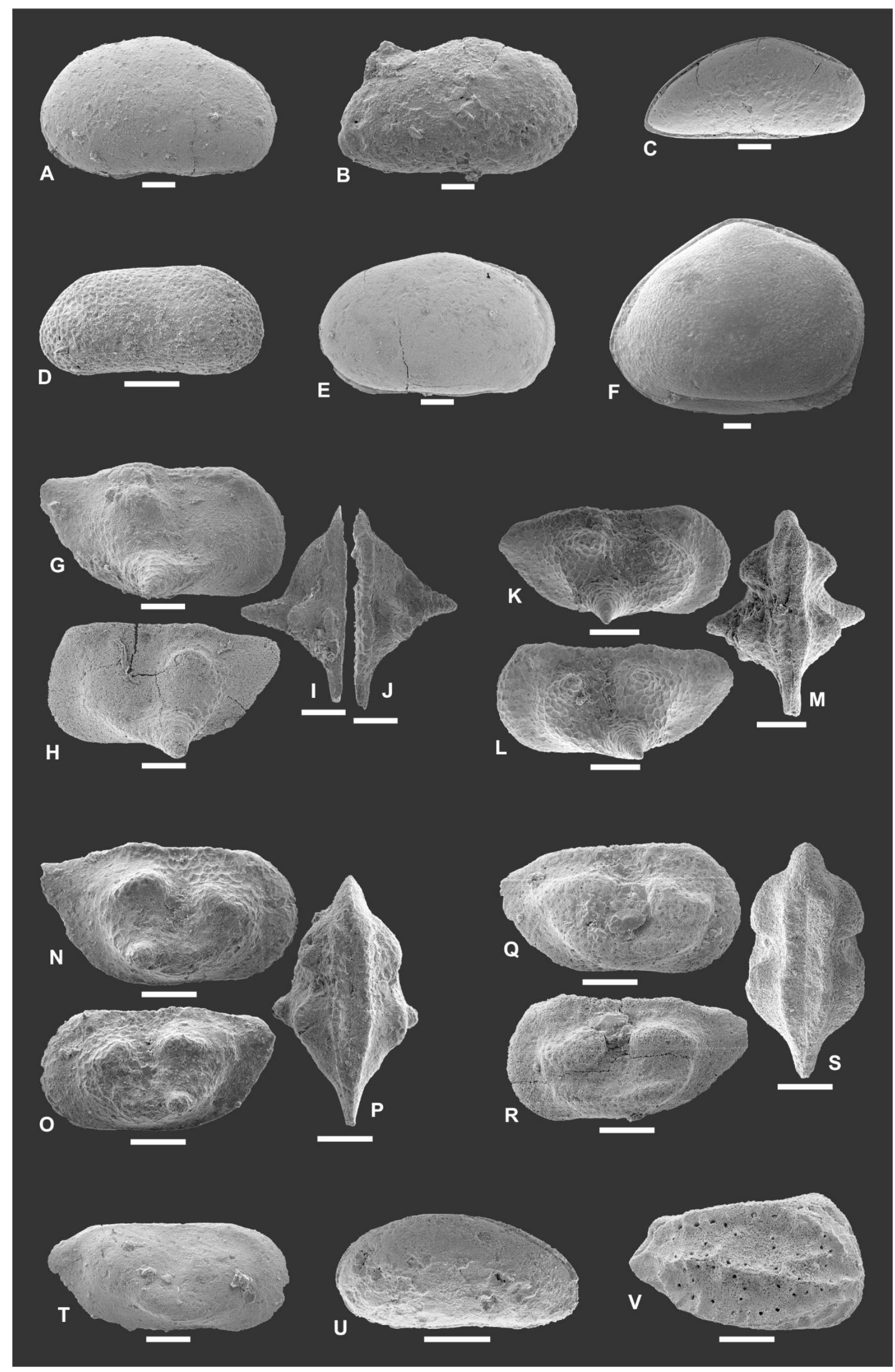


Discussão. A identificação segue Dingle (1984). O Gênero Robsoniella Kuznetsova, 1956 foi originalmente colocado na Família Healdiidae Harlton, 1933 por Kuznetsova (1956). Após a revisão por Gramm \& Kuznetsova (1970), este foi separado em sua própria família, Robsoniellidae Gramm \& Kuznetsova, 1970. Dingle (1984) foi o primeiro a notar a semelhança de Robsoniella com gêneros de outras famílias da Superfamília Bairdioidea Sars, 1888, ao classificá-lo junto à Família Bairdiidae Sars, 1888. Todavia, Robsoniella compartilha várias características morfológicas com Bythocyprididae (Maddocks, 1969), como já salientado por Babinot et al. (2009), embora o mesmo não dê mais detalhes a respeito. Bythocyprididae foi originalmente proposto por Maddocks (1969) como uma subfamília de Bairdiidae Sars, 1888, a saber, Bythocypridinae Maddocks, 1969. Seu status foi revisto por Kozur (1972), que a elevou ao nível familiar atual. Espécimes em Oertli (1974) e Damotte (1992) apresentam um layout geral muito semelhante em vista lateral a Robsoniella falklandensis Dingle, 1984 no presente trabalho, embora apenas o suficiente para estabelecer parcialmente a sinonímia entre estes.

Distribuição geográfica e estratigráfica. Formação Mzinene, África do Sul, Cenomaniano (Dingle, 1984). Membro Taquari, Formação Riachuelo, bacia de Sergipe-Alagoas, Brasil, Albiano médio, Zona Aracajuia benderi (MSA-0), Subzona Praebythoceratina amsittenensis (MSA-0.3).

\author{
SUBORDEM Cypridocopina Jones, 1901 \\ SUPERFAMÍLIA Cypridoidea Baird, 1845 \\ FAMÍLIA Candonidae Kaufmann, 1900
}

Figura 8. Ostracodes da Formação Riachuelo, bacia de Sergipe-Alagoas, Nordeste do Brasil, NeoalagoasAlbiano. A, Robsoniella falklandensis Dingle, 1984; CP-733, vista lateral direita. B, Cetacella sp. 1; CP-734, vista lateral direita. C, Paracypris eniotmetos Nicolaidis \& Piovesan, 2013 in Piovesan et al., 2013; CP-679, vista lateral direita. D, Liasina sp. 1; CP-682, vista lateral direita. E, Harbinia crepata Do Carmo et al., 2013; CP-681, vista lateral direita. F, Harbinia sinuata? (Krömmelbein \& Weber, 1971); LBP 9, vista lateral direita. GJ, Praebythoceratina deltalata sp. nov.; G, CP-683, vista lateral direita, H, CP-684, vista lateral esquerda, I, CP759, vista dorsal, J, CP-758, vista dorsal. K-M, Praebythoceratina reducta (Gründel, 1964); K, CP-692, vista lateral esquerda, L, CP-691, vista lateral direita, M, CP-690, vista dorsal. N-P, Praebythoceratina amsittenensis Andreu-Boussut, 1991; N, CP-687, vista lateral direita, O, CP-769, vista lateral esquerda, P, CP-689, vista dorsal. Q-S, Patellacythere shimonensis (Rosenfeld \& Raab, 1983); Q, CP-685, vista lateral direita, R, CP-686, vista lateral esquerda, S, CP-760, vista dorsal. T, Patellacythere parva? (Weaver, 1982); CP-694, vista lateral direita. U, Xestoleberis? sp. 1; CP-761, vista lateral direita. V, Aracajuia benderi Krömmelbein, 1967; CP-711, vista lateral direita. Escala $=100 \mu \mathrm{m}$. 


\section{SUBFAMÍLIA Cyclocypridinae Kaufmann, 1900 \\ GÊNERO Cetacella Martin, 1958 \\ Cetacella sp. 1}

Fig. 8B

1979 Cetacella GA D 25. Grosdidier: p. 8, figs 53a-c.

Hipótipo. CP-734 (valva direita).

Ocorrência. Comum, nas amostras MP-1517, MP-1534, MP-1544, MP-1545 e MP-1547 (afloramento Massapê), Município de Riachuelo; também nas profundidades de 750, 1110 e 1131m na perfuração 1-US-1, Município de Laranjeiras; Estado de Sergipe, Brasil.

Medidas. Comprimento $=0.73 \mathrm{~mm}$, altura $=0.42 \mathrm{~mm}$.

Discussão. A identificação de gênero segue Martin (1958). Cetacella GA D 25 em Grosdidier (1979) também pertence à mesma espécie. A preservação ruim dos espécimes identificados e a presença de apenas valvas no material inviabilizam o detalhamento taxonômico de Cetacella sp. 1.

Distribuição geográfica e estratigráfica. Formação Madiéla, bacia do Gabão, Gabão, Aptiano superior-Albiano inferior (Grosdidier, 1979). No presente trabalho, Membro Maruim, Formação Riachuelo, bacia de Sergipe-Alagoas, Brasil, Aptiano superior-Albiano, zonas Aracajuia benderi (MSA-0) - subzonas Sergipella viviersae (MSA-0.2) e Metacytheropteron aff. M. sp. GA C 24 (MSA-0.5) - e Aracajuia antiqua (MSA-1).

SUBFAMÍLIA Paracypridinae Sars, 1923

GÊNERO Paracypris Sars, 1866

Paracypris eniotmetos Nicolaidis \& Piovesan, 2013

Fig. 8C

2000 Paracypris sp. P3. Viviers et al.: p. 418, figs 10.10, 10.11.

2000 Paracypris aff. P. mdaouerensis Bassoullet \& Damotte, 1969. Viviers et al.: p. 418, figs 10.16, 10.21, 10.22 .

2013 Paracypris eniotmetos Nicolaidis \& Piovesan in Piovesan et al.: p. 244, figs 3.10a-e.

Homótipos. CP-679 (carapaça) e CP-680 (valva direita).

Ocorrência: Abundante, nas amostras MP-1420 (afloramento Santa Bárbara) e MP-1423 (afloramento ESTRE), Município de Rosário do Catete; MP-1449, MP-1450, MP-1451, MP1452, MP-1453, MP-1456, MP-1457, MP-1459 (afloramento Penha), MP-1460, MP-1461, MP-1462, MP-1463, MP-1464, MP-1465, MP-1466, MP-1468, MP-1469, MP-1470, MP1471, MP-1472 (afloramento Porto dos Barcos 3), MP-1497, MP-1506, MP-1511, MP-1512, 
MP-1513 (afloramento P384), MP-1514, MP-1515, MP-1517, MP-1518, MP-1519, MP-1520, MP-1521, MP-1531, MP-1545, MP-1546, MP-1547 (afloramento Massapê), MP-1550, MP1551, MP-1552, MP-1553, MP-1554, MP-1555, MP-1557, MP-1558, MP-1559, MP-1560, MP-1561, MP-1562, MP-1563, MP-1564, MP-1565, MP-1566, MP-1567, MP-1568, MP1570, MP-1571, MP-1572, MP-1573, MP-1574, MP-1575, MP-1576, MP-1577, MP-1680, MP-1695, MP-1696 e MP-1697 (afloramento São José 1), Município de Riachuelo; também nas profundidades de 300, 390, 804 e 831m na perfuração 1-US-1, Município de Laranjeiras; Estado de Sergipe, Brasil.

Medidas: CP-679, comprimento $=0.67 \mathrm{~mm}$, altura $=0.30 \mathrm{~mm}$, largura $=0.20 \mathrm{~mm} ; \mathrm{CP}-680$, comprimento $=0.58 \mathrm{~mm}$, altura $=0.24 \mathrm{~mm}$.

Discussão: A identificação segue Nicolaidis \& Piovesan (2013) in Piovesan et al. (2013), embora não tenham sido observadas formas estriadas no presente trabalho.

Distribuição geográfica e estratigráfica: Formação Jandaíra, bacia Potiguar, ConiacianoSantoniano (Viviers et al., 2000); formações Florianópolis, Juréia e Itanhaém, bacia de Santos, Albiano-Santoniano inferior; Formação São Mateus, bacia do Espírito Santo, Albiano (Piovesan et al., 2013); membros Angico e Taquari, Formação Riachuelo, bacia de SergipeAlagoas, Albiano, Zona Aracajuia benderi (MSA-0), subzonas Praebythoceratina amsittenensis (MSA-0.3) e Reticulocosta edrianae (MSA-0.4) (Viviers et al., 2000); no presente trabalho, também no Membro Maruim, Subzona Sergipella viviersae (MSA-0.2), Aptiano superior, e Zona Aracajuia antiqua (MSA-1), Albiano superior; Brasil.

FAMÍLIA Quadracyprididae Hou, 2002

SUBFAMÍLIA Quadracypridinae Hou, 2002

GÊNERO Harbinia Tsao, 1959

Harbinia sinuata? (Krömmelbein \& Weber, 1971)

Fig. 8F

1971 Hourcqia angulata sinuata Krömmelbein \& Weber: p. 35, est. 6, figs 24a-c.

?1985 “Cytheridea”? sp. gr. 201/218. Moura \& Praça: p. 407, est. 2, figs 19, 22.

?1988 “Cypridea” spp. ex. gr. 201/218. Moura: p. 1212, est. 2, figs 7, 10.

?1990 Hourcqia angulata ssp. Silva-Telles Júnior \& Viana: p. 320, est. 3, fig. 4.

[Non] 1991 Hourcqia angulata sinuata Krömmelbein \& Weber. Andreu-Boussut: p. 480, est. 1, figs 4-9.

?1997 Hourcqia gr. angulata Krömmelbein \& Weber. Colin \& Dépêche: p. 434, fig. 2.19.

?2006 Harbinia sinuata (Krömmelbein \& Weber). Ramos et al.: p. 344, figs 4I-L.

?2008 Harbinia sinuata (Krömmelbein \& Weber). Do Carmo et al.: p. 796, est. 6, fig. 10.

?2012b Pattersoncypris sinuata (Krömmelbein \& Weber). Poropat \& Colin: p. 714, fig. 4.2. 
?2013 Harbinia sinuata (Krömmelbein \& Weber). Do Carmo et al.: p. 95, figs 4.1-4.24.

Homótipo. LBP 9 (carapaça).

Ocorrência. Abundante, nas profundidades de 478.45, 478.85, 481.6, 482.9 e 484.4m na perfuração 7-CP-252, Município de Santo Amaro das Brotas; e 354.5m na perfuração 1-CPB1, Município de Carmópolis; Estado de Sergipe, Brasil.

Medidas. Comprimento $=0.93 \mathrm{~mm}$, altura $=0.76 \mathrm{~mm}$.

Discussão. A taxonomia supragenérica segue Hou et al. (2002) e a de gênero, Do Carmo et al. (2013). Todavia, os exemplares aqui observados, embora muito semelhantes aos de Harbinia sinuata (Krömmelbein \& Weber, 1971), diferem quanto ao formato da margem dorsal anterior nas adjacências da região da corcova. Em espécimes de Krömmelbein \& Weber (1971) e Do Carmo et al. (2013), esta determinada região é menos inclinada, conferindo à margem anterior um padrão morfológico mais amplo. Os exemplares do presente trabalho parecem apresentar ornamentação similar a outras espécies do gênero (Krömmelbein \& Weber, 1971, Hou, 1984; Antonietto et al., 2012; Do Carmo et al., 2013), embora muito mais discreta. Por essa razão, os atuais espécimes são identificados de maneira dúbia como Harbinia sinuata.

Distribuição geográfica e estratigráfica. Membros Crato e Ipubi, bacia do Araripe, Aptiano inferior (Colin \& Dépêche, 1997); bacia de Campos, Aptiano superior (Moura \& Praça, 1985; Moura, 1988); Formação Alagamar, bacia Potiguar, Aptiano médio-superior (Do Carmo et al., 2008, 2013); Formação Codó, bacia do Grajaú, Aptiano superior (Ramos et al., 2006); Formação Riachuelo, bacia de Sergipe-Alagoas, Aptiano superior, Zona Aracajuia benderi (MSA-0), Subzona Harbinia sinuata? (MSA-0.1) (Krömmelbein \& Weber, 1971); Brasil.

Harbinia crepata Do Carmo et al., 2013

Fig. 8E

1990 Gen. ind. sp. aff. 207. Silva-Telles Júnior \& Viana: p. 314, est. 2, figs 1, 3.

2013 Harbinia crepata Do Carmo et al.: p. 95, figs 3.9-3.18.

Hipótipo. CP-681 (valva direita, hipótipo).

Ocorrência. Rara, nas amostras MP-1423 (afloramento ESTRE), Rosário do Catete; e MP1561 e MP-1573 (afloramento São José 1), Município de Riachuelo; Estado de Sergipe, Brasil Medidas. Comprimento $=0.72 \mathrm{~mm}$, altura $=0.43 \mathrm{~mm}$.

Discussão. A identificação segue Do Carmo et al. (2013) (anexo III). Os espécimes das amostras MP-1423 e MP-1573 apresentam sinais de retrabalhamento, não sendo considerados na distribuição estratigráfica da espécie. 
Distribuição geográfica e estratigráfica. Membro Crato, Formação Santana, bacia do Araripe, Aptiano (Silva-Telles Júnior \& Viana, 1990); Formação Alagamar, bacia Potiguar, Aptiano médio a superior (Do Carmo et al., 2013); no presente trabalho, membros Angico e Taquari, Formação Riachuelo, bacia de Sergipe-Alagoas, Aptiano superior-Albiano inferior, Zona Aracajuia benderi (MSA-0), Subzona Sergipella viviersae (MSA-0.2).

\section{SUPERFAMÍLIA Pontocypridoidea Müller, 1894 \\ FAMÍLIA Pontocyprididae Müller, 1894 \\ GÊNERO Liasina Gramann, 1963 \\ Liasina sp. 1}

Fig. 8D

2000 Bythocypris? sp. Se1 aff. B.? sp. GA C 28. Viviers et al.: p. 414, figs 9.8, 9.9.

2013 Australoecia sp. 1. Piovesan et al: p. 245, figs 4.5a, b.

Hipótipo. CP-682 (valva direita).

Ocorrência. Rara, na amostra MP-1552 (afloramento São José 1), Município de Riachuelo, Estado de Sergipe, Brasil.

Medidas. Comprimento $=0.41 \mathrm{~mm}$, altura $=0.20 \mathrm{~mm}$.

Discussão. A identificação de gênero segue Gramann (1963). Liasina sp. 1 não é lisa como a maioria das espécies de Liasina Gramann, 1963, mas sim puntada em vista lateral. A quantidade muito restrita de espécimes encontrada inviabiliza a descrição completa desta espécie, a qual é provavelmente nova. Espécimes nomeados Bythocypris? sp. Se1 em Viviers et al. (2000), e Australoecia sp. 1 em Piovesan et al. (2013) também pertencem a Liasina sp. 1.

Distribuição geográfica e estratigráfica. Formações Itanhaém e Itajaí-Açú, bacia de Santos, Albiano (Piovesan et al., 2013); membros Angico (Viviers et al., 2000) e Taquari (presente trabalho), Formação Riachuelo, bacia de Sergipe-Alagoas, Aptiano superior-Albiano inferior, Zona Aracajuia benderi (MSA-0), Subzona Sergipella viviersae (MSA-0.2); Brasil.

SUBORDEM Cytherocopina Gründel, 1967

INFRAORDEM Archaeocytherinina Liebau, 1991

SUPERFAMÍLIA Bythocytheroidea Sars, 1926

FAMÍLIA Bythocytheridae Sars, 1926

SUBFAMÍLIA Bythocytherinae Sars, 1926

TRIBO Bythoceratinini Gründel \& Kozur, 1971 
GÊNERO Praebythoceratina Gründel \& Kozur, 1971 emend. Becker, 1990

Praebythoceratina deltalata sp. nov.

Figs 8G-J

?1964 Monoceratina sp. A. Donze: p. 148, est. 7, fig. 145.

Holótipo. CP-683 (valva direita).

Parátipos. CP-684 (valva esquerda), CP-758 (valva direita) e CP-759 (valva esquerda).

Localidade tipo e horizonte tipo. Amostra MP-1680, Afloramento São José 1 (693824N/8811279L, quadrante UTM 24L, sistema SAD69), Município de Riachuelo, Estado de Sergipe, Brasil, Aptiano superior-Albiano inferior, Zona Aracajuia benderi (MSA-0), Subzona Sergipella viviersae (MSA-0.2).

Ocorrência. Abundante, nas amostras MP-1551, MP-1552, MP-1554, MP-1558, MP-1559, MP-1561, MP-1564, MP-1565, MP-1567, MP-1568, MP-1570, MP-1571, MP-1572, MP1573, MP-1574, MP-1575 e MP-1576 (afloramento São José 1), Município de Riachuelo, Estado de Sergipe, Brasil.

Etimologia. do grego delta, significando "D", e do latim alata, ou "com uma asa". Praebythoceratina deltalata sp. nov. apresenta um espinho na sua região ventroposterior lembrando uma ala triangular (razão pela qual adota-se o termo delta, visto que a letra do alfabeto grego corresponde ao " $D$ " se assemelha a um triângulo).

Diagnose. Ornamentação consistindo de reticulações irregulares nas áreas posterocentral e ventroposterior, um tubérculo na área dorsocentral e um espinho irregularmente reticulado na área ventrocentral. Em vista dorsal, fortemente sagitiforme; o espinho apresenta a base alargada, formando uma ala triangular ampla que vai da área posteroventral à anteroventral.

Descrição. Carapaça de tamanho médio, subtriangular a sub-retangular, com maior altura na região posterocentral e maior comprimento na centrodorsal. Extremidade anterior arredondada, geralmente equicurvada, tornando-se ligeiramente retilínea próximo à margem dorsal, onde um ângulo cardinal obtuso é formado. Extremidade posterior aguda, supracurvada, formando um processo caudal dorsal. Margem dorsal retilínea, tornando-se ligeiramente côncava apenas na região centroposterior. Margem ventral regularmente retilínea, com leve concavidade na região oral. Ornamentação primária consistindo de um tubérculo na área dorsocentral, um espinho na área ventrocentral e uma costela marginal muito discreta percorrendo a margem dorsoposterior até a anteroventral. Sulcos S1 e S2 muito discretos. Ornamentação secundária inclui reticulações irregulares nas áreas ventroposterior e posterocentral e sobre o espinho, da metade do comprimento em diante. Tubérculo ocular arredondado, fracamente desenvolvido. Em vista dorsal, fortemente sagitiforme; o espinho 
lateral apresenta a base alargada, formando uma ala triangular ampla que vai da área posteroventral à anteroventral. A presença da costela dorsal cria uma superfície plana adjacente à linha de charneira. Em vista interna, charneira adonte, composta na valva direita por um sulco correndo ao longo da maior parte da margem dorsal. Lamela interna fracamente desenvolvida, observável ao longo da extremidade anterior e da região ventral da extremidade posterior; não observável na região oral, onde a margem da valva se invagina para dentro expressivamente.

Medidas. CP-683, comprimento $=0.56 \mathrm{~mm}$, altura $=0.29 \mathrm{~mm} ;$ CP-684, comprimento $=0.53$ $\mathrm{mm}$, altura $=0.29 \mathrm{~mm} ;$ CP-758, comprimento $=0.47 \mathrm{~mm} ;$ CP-759, comprimento $=0.45 \mathrm{~mm}$, altura $=0.23 \mathrm{~mm}$.

Discussão. As identificações subfamiliar e tribal seguem Gründel \& Kozur (1971), e a de gênero, Becker (1990). As presentes ocorrências correspondem ao primeiro registro do gênero Praebythoceratina Gründel \& Kozur, 1971, até então restrito ao Triássico-Jurássico, no Eocretáceo. A maioria dos exemplares de Praebythoceratina deltalata sp. nov foi encontrada quebrada, limitando assim a designação de espécimes tipo. Esta espécie é muito semelhante em formato geral a Bythoceratina umbonatoides (Kaye, 1964), Bythoceratina umbonata (Williamson, 1847) e Monoceratina longispina (Bosquet, 1854) do Albiano-Cenomaniano da Inglaterra (Kaye, 1964, 1965; Weaver, 1982). Entretanto, estas diferem de Praebythoceratina deltalata na posição do tubérculo dorsal (posterior nas primeiras, anterodorsal na última) e na morfologia da base do espinho posteroventral (estreito em Praebythoceratina umbonatoides). Vários táxons, incluindo Praebythoceratina amsittenensis, descrito no Albiano de Marrocos (Andreu-Boussut, 1991), Bythoceratina tamarae Rosenfeld, 1974 e Bythoceratina avnonensis Rosenfeld, 1974 do Cenomaniano superior de Israel (Rosenfeld \& Raab, 1974), podem ser separados de Praebythoceratina deltalata pelas mesmas características. Donze (1964) ilustra Monoceratina sp. A do Berriasiano da França em vista dorsal, a qual é muito semelhante à dos espécimes aqui representados. Entretanto, não são fornecidas medidas de altura, comprimento ou largura, para estes espécimes, motivo pelo qual não é possível assumir que os mesmos sejam de fato de Praebythoceratina deltalata.

Distribuição geográfica e estratigráfica. Membro Taquari, Formação Riachuelo, bacia de Sergipe-Alagoas, Brasil, Aptiano superior-Albiano inferior, Zona Aracajuia benderi (MSA$0)$, Subzona Sergipella viviersae (MSA-0.2). 
1979 "Patellacythere" GA E 27. Grosdidier: p. 8, figs 41a, 51c.

[Non] 1979 "Patellacythere" GA E 27. Grosdidier: p. 8, fig. 41b.

1991 Bythoceratina amsittenensis Andreu-Boussut: p. 496, est. 41, figs 6-11.

?2000 Bythoceratina? sp. P1. Viviers et al.: p. 411, figs 11.12-11.14.

Homótipos. CP-687 (valva direita), CP-688 (valva direita), CP-689 (carapaça) e CP-769 (valva esquerda).

Ocorrência. Abundante, nas amostras MP-1420 (afloramento Santa Bárbara) e MP-1423 (afloramento ESTRE), Município de Rosário do Catete; MP-1460, MP-1461, MP-1462, MP1463, MP-1464, MP-1468, MP-1469, MP-1470, MP-1471, MP-1472, MP-1476, MP-1477, MP-1481 (afloramento Porto dos Barcos 3), MP-1497, MP-1506, MP-1508, MP-1510, MP1511, MP-1512 e MP-1513 (afloramento P384), Município de Riachuelo; também nas profundidades de 473.8 e $475.3 \mathrm{~m}$ na perfuração 7-CP-252 e $345.5,348$ e $348.5 \mathrm{~m}$ na perfuração 1-CPB-1, Carmópolis; Estado de Sergipe, Brasil.

Medidas. $\mathrm{CP}-687$, comprimento $=0.47 \mathrm{~mm}$, altura $=0.26 \mathrm{~mm}$; CP-688, comprimento $=0.46$ $\mathrm{mm}$, altura $=0.23 \mathrm{~mm} ; \mathrm{CP}-689$, comprimento $=0.46 \mathrm{~mm}$, altura $=0.23 \mathrm{~mm}$, largura $=0.22$ $\mathrm{mm} ; \mathrm{CP}-769$, comprimento $=0.43 \mathrm{~mm}$, altura $=0.23 \mathrm{~mm}$.

Discussão. A identificação de gênero segue Becker (1990), e a de espécie, Andreu-Boussut (1991). Alguns dos espécimes do Aptiano do Gabão identificados por Grosdidier (1979) como "Patellacythere" GA E 27 pertencem a Praebythoceratina amsittenensis (Andreu-Boussut, 1991), enquanto um terceiro está relacionado a Patelacythere shimonensis (Rosenfeld \& Raab, 1983). Bythoceratina? sp. P1 em Viviers et al. (2000), provavelmente, também pertence à espécie atual, embora não seja possível confirma-lo, já que o material figurado está mal preservado. Monoceratina trinodosa Alexander, 1934b, do Albiano do Texas (Alexander, 1934b), apesar de algumas semelhanças com Praebythoceratina amsittenensis, pertence a uma espécie diferente. O holótipo mal preservado daquela apresenta diferenças no formato geral, arranjo dos espinhos e tubérculos e ornamentação mais linear (em vez de reticulada) quando comparado com esta.

Distribuição geográfica e estratigráfica. Formação Madiéla, bacia do Gabão, Gabão, Aptiano superior-Albiano inferior (Grosdidier, 1979). Formação Oued Tidsi, Marrocos, Albiano (Andreu-Boussut, 1991). Membro Taquari, Formação Riachuelo, bacia de SergipeAlagoas, Brasil, Aptiano superior-Albiano médio, Zona Aracajuia benderi (MSA-0), subzonas Sergipella viviersae (MSA-0.2) e Praebythoceratina amsittenensis (MSA-0.3). 
Figs $8 \mathrm{~K}-8 \mathrm{M}$

1964 Monoceratina nodulosa reducta Gründel: p. 857, est. 2, figs 15-16.

1966 Monoceratina nodulosa reducta Gründel. Gründel: p. 48, est. 8, figs 19-20.

Homótipos. CP-690 (carapaça), CP-691 (valva direita) CP-692 (valva esquerda) e CP-693 (valva direita).

Ocorrência. Abundante, nas amostras MP-1550, MP-1552, MP-1553, MP-1554, MP-1558, MP-1563, MP-1564, MP-1565, MP-1571, MP-1574, MP-1575 e MP-1576 (afloramento São José 1), Município de Riachuelo, Estado de Sergipe, Brasil.

Medidas. CP-690, comprimento $=0.42 \mathrm{~mm}$, altura $=0.22 \mathrm{~mm}$, largura $=0.22 \mathrm{~mm} ;$ CP-691, comprimento $=0.47 \mathrm{~mm}$, altura $=0.25 \mathrm{~mm} ; \mathrm{CP}-692$, comprimento $=0.48 \mathrm{~mm}$, altura $=0.22$ $\mathrm{mm}$; CP-693, comprimento $=0.49 \mathrm{~mm}$, altura $=0.24 \mathrm{~mm}$.

Discussão. A identificação de gênero segue Becker (1990), e a de espécie, Gründel (1964). A Família Bythocytheridae Sars, 1926 foi revisada por Gründel \& Kozur (1971) Schornikov (1990) e Schornikov \& Mikhailova (1990), os quais restringem a distribuição estratigráfica do Gênero Monoceratina Roth, 1928 a um grupo de espécies do Devoniano-Permiano com afinidade morfológica restrita com os Bythoceratinini Gründel \& Kozur, 1971. Paralelamente, Monoceratina nodulosa reducta Gründel, 1964 foi inicialmente considerada uma subespécie de Monoceratina nodulosa Gründel, 1964, junto com Monoceratina nodulosa nodulosa Gründel, 1964. Entretanto, existem diferenças morfológicas suficientes entre ambas (incluindo o tamanho, formato geral em vistas dorsal e lateral e ornamentação) para que sejam colocadas em espécies separadas. Por esse motivo, a espécie é aqui renomeada Praebythoceratina reducta (Gründel, 1964).

Distribuição geográfica e estratigráfica. Alemanha, Albiano (Gründel, 1964, 1966). No presente trabalho, Membro Taquari, Formação Riachuelo, bacia de Sergipe-Alagoas, Brasil, Aptiano superior-Albiano inferior, Zona Aracajuia benderi (MSA-0), Subzona Sergipella viviersae (MSA-0.2).

\footnotetext{
TRIBO Bythocytherini Sars, 1926

GÊNERO Patellacythere Gründel \& Kozur, 1971

Patellacythere shimonensis (Rosenfeld \& Raab, 1983)

Figs 8Q-S
}

1979 “Patellacythere” GA E 27. Grosdidier: p. 8, fig. 41 b.

1983 Monoceratina shimonensis Rosenfeld \& Raab: p. 112, est. 7, figs 4-7.

1985 Monoceratina shimonensis Rosenfeld \& Raab. Honigstein et al.: p. 2, est. 6, fig. 159.

2000 'Patellacythere'sp. GA E 27. Viviers et al.: p. 427, figs 15.14, 15.15. 
Homótipos. CP-685 (valva direita) e CP-686 (valva esquerda) e CP-760 (carapaça).

Ocorrência. Abundante, nas amostras MP-1450, MP-1451, MP-1452, MP-1453, MP-1457, MP-1459 (afloramento Penha), MP-1550, MP-1551, MP-1552, MP-1553, MP-1554, MP1555, MP-1556, MP-1557, MP-1558, MP-1560, MP-1562, MP-1565, MP-1566, MP-1567, MP-1568, MP-1569, MP-1570, MP-1572, MP-1573 e MP-1575 (afloramento São José 1), Município de Riachuelo, Estado de Sergipe, Brasil.

Medidas. CP-685, comprimento $=0.44 \mathrm{~mm}$, altura $=0.23 \mathrm{~mm} ; \mathrm{CP}-686$, comprimento $=0.44$ $\mathrm{mm}$, altura $=0.22 \mathrm{~mm} ;$ CP-760, comprimento $=0.41 \mathrm{~mm}$, altura $=0.21 \mathrm{~mm}$, largura $=0.22$ $\mathrm{mm}$.

Discussão. A identificação segue Rosenfeld \& Raab (1983). Para alterações na taxonomia do gênero Monoceratina, seguir a seção "Discussão" em Praebythoceratina reducta. Monoceratina shimonensis Rosenfeld \& Raab, 1983 é aqui renomeada Patellacythere shimonensis (Rosenfeld \& Raab, 1983), com base tanto na morfologia da carapaça quanto em distribuições estratigráficas dos gêneros Monoceratina e Patellacythere Gründel \& Kozur, 1971.

Distribuição geográfica e estratigráfica. Formação Madiéla, bacia do Gabão, Gabão, Aptiano superior-Albiano inferior (Grosdidier, 1979). Formação Talme Yafe, bacia Levantina, Israel, Albiano (Rosenfeld \& Raab, 1983). Membros Angico (Viviers et al., 2000) e Taquari (presente trabalho), Formação Riachuelo, bacia de Sergipe-Alagoas, Brasil, Aptiano superiorAlbiano inferior, Zona Aracajuia benderi (MSA-0), Subzona Sergipella viviersae (MSA-0.2).

\section{Patellacythere parva? Weaver, 1982}

Fig. 8T

?1982 Patellacythere parva Weaver: p. 44, est. 7, figs 8-10.

?1992 Patellacythere parva Weaver. Witte et al.: p. 57, est. 3, fig. 13.

Homótipo. CP-694 (valva direita).

Ocorrência. Rara, na amostra MP-1468 (afloramento Porto dos Barcos 3), Município de Riachuelo, Estado de Sergipe, Brasil.

Medidas. Comprimento $=0.55 \mathrm{~mm}$, altura $=0.24 \mathrm{~mm}$.

Discussão. O diagnóstico segue Weaver (1982). O espécime figurado Witte et al. (1992) está incompleto, tendo perdido a maior parte de sua extremidade posterior, e sua atribuição a Patellacythere parva Weaver, 1982 é incerta. O único exemplar encontrado nas presentes amostras não apresenta o entumescimento lateral em forma de " $U$ " característico dos espécimes tipo de Patellacythere parva, embora a superfície lateral daquele espécime seja 
ligeiramente inflada, lembrando a ornamentação observada nesta espécie. Por esse motivo, o espécime atual foi dubiamente identificado como Patellacythere parva?.

Distribuição geográfica e estratigráfica. Possivelmente nas formações Grey Chalk e Holywell Nodular Chalk (incluindo o Membro Plenus Marl), bacia Anglo-Paris, Inglaterra, Cenomaniano (Weaver, 1982). Possivelmente na bacia da Baixa Saxônia, Holanda, Cenomaniano inferior (Witte et al., 1992). No presente trabalho, Membro Taquari, Formação Riachuelo, bacia de Sergipe-Alagoas, Brasil, Albiano médio, Zona Aracajuia benderi (MSA0), Subzona Praebythoceratina amsittenensis (MSA-0.3).

\section{SUPERFAMÍLIA Xestoleberidoidea Sars, 1928 \\ FAMÍLIA Xestoleberididae Sars, 1928 \\ GÊNERO Xestoleberis Sars, 1866 \\ Xestoleberis? sp. 1}

Fig. 8U

\section{Hipótipo. CP-761 (carapaça).}

Ocorrência. Abundante, nas amostras MP-1518, MP-1534, MP-1544, MP-1545 e MP-1547 (afloramento Massapê), Município de Riachuelo; também nas profundidades de 480, 552, 554.5, 1080 e 1086m na perfuração 1-US-1, Município de Laranjeiras; Estado de Sergipe, Brasil.

Medidas. Comprimento $=0.37 \mathrm{~mm}$, altura $=0.17 \mathrm{~mm}$.

Discussão. Os presentes espécimes compartilham da morfologia típica do Gênero Xestoleberis Sars, 1866, ou seja, uma carapaça pequena e lisa, com maior largura posterodorsal. Nenhum dos espécimes coletados se encontra desarticulado, ou seja, nenhuma de suas características internas foi observada De acordo com Kempf (1986), mais de 300 espécies são descritas como ou atribuídas a Xestoleberis, apesar da morfologia da carapaça bastante comum e do fato de este gênero ter sido originalmente descrito com base na morfologia das partes moles (Puckett et al., 2012). Diversos trabalhos prévios descrevem ou identificam, com ou sem dubiedade, espécies de Xestoleberis no Cretáceo (Veen, 1936; Bonnema, 1941; Schmidt, 1948, Benson \& Tatro, 1964; Bold, 1964; Holden, 1964; Crane, 1965; Herrig, 1966; Rosenfeld \& Raab, 1974; Dingle, 1980; Weaver, 1982; Damotte \& Fleury, 1987; Ismail \& Soliman, 1997; Gebhardt, 1999; Morsi et al., 2008; Piovesan et al., 2009, 2013; Tesakova, 2010; Babinot \& Colin, 2011; Puckett et al., 2012). Por estas razões, os exemplares observados na Formação Riachuelo são mantidos em nomenclatura de gênero aberta como Xestoleberis? sp. 1. 
Distribuição geográfica e estratigráfica. Membro Maruim, Formação Riachuelo, bacia de Sergipe-Alagoas, Brasil, Albiano superior, Zona Aracajuia antiqua (MSA-1).

\section{Xestoleberis? sp. 2}

Figs 9A-C

Hipótipos. CP-697 (carapaça) e CP-735 (valva esquerda).

Ocorrência. Rara, nas amostras MP-1423 (afloramento ESTRE), Município de Rosário do Catete; e MP-1460 (afloramento Porto dos Barcos 3), Município de Riachuelo; também na profundidade de 861m na perfuração 1-US-1, Município de Laranjeiras; Estado de Sergipe, Brasil.

Medidas. CP-697, comprimento $=0.52 \mathrm{~mm}$, altura $=0.28 \mathrm{~mm}$, largura $=0.25 \mathrm{~mm} ; \mathrm{CP}-735$, comprimento $=0.58 \mathrm{~mm}$, altura $=0.30 \mathrm{~mm}$.

Discussão. Para incertezas na identificação do Gênero Xestoleberis, seguir a seção "Discussão" em Xestoleberis? sp. 1. Xestoleberis? sp. 2 difere da anterior por ser maior e mais robusta, tanto em vista lateral quanto dorsal.

Distribuição geográfica e estratigráfica. Membro Taquari, Formação Riachuelo, bacia de Sergipe-Alagoas, Brasil, Albiano médio, Zona Aracajuia benderi (MSA-0), Subzona Praebythoceratina amsittenensis (MSA-0.3).

INFRAORDEM Nomocytherinina Liebau, 1991

SUPERFAMÍLIA Cytherideoidea Sars, 1925

FAMÍLIA Cytherideidae Sars, 1925

SUBFAMÍLIA Schulerideinae Mandel'shtam, 1960

TRIBO Schulerideini Mandel'shtam, 1960

GÊNERO Apatocythere Triebel, 1940

Apatocythere? sp. 1

Figs 9D-H

Hipótipo. CP-762 (carapaça, fêmea, hipótipo) e CP-763 (carapaça, macho, hipótipo).

Ocorrência. Comum, nas amostras MP-1511, MP-1512 e MP-1513 (afloramento P384).. Município de Riachuelo, Estado de Sergipe, Brasil.

Medidas. CP-762, comprimento $=0.60 \mathrm{~mm}$, altura $=0.36 \mathrm{~mm}$, largura $=0.30 \mathrm{~mm} ; \mathrm{CP}-763$, comprimento $=0.66 \mathrm{~mm}$, altura $=0.35 \mathrm{~mm}$; largura $=0.31 \mathrm{~mm}$.

Discussão. A identificação supragenérica segue Neale (1982). Nenhuma característica interna foi observável nos presentes espécimes, embora o formato geral e tamanho destes lembrem os 


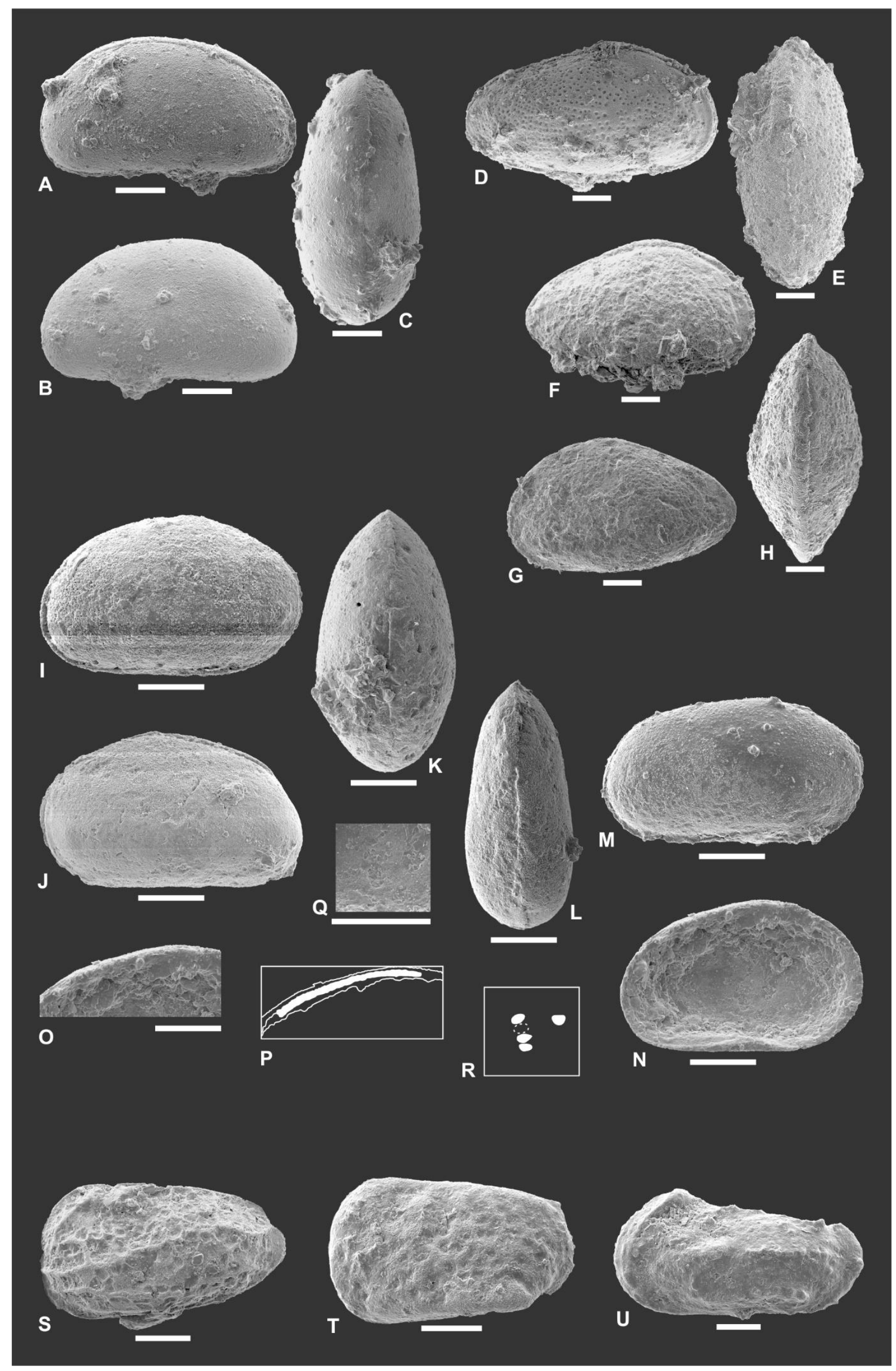


de espécies de Apatocythere Triebel, 1940 em Triebel (1940). Por causa disso, o presente autor propõe a atribuição de gênero duvidosa de Apatocythere? sp. 1.

Distribuição geográfica e estratigráfica. Membro Taquari, Formação Riachuelo, bacia de Sergipe-Alagoas, Brasil, Albiano médio, Zona Aracajuia benderi (MSA-0), Subzona Praebythoceratina amsittenensis (MSA-0.3).

FAMÍLIA Krithidae Mandel'shtam, 1960

SUBFAMÍLIA Cuneocytherinae Mandel'shtam, 1960

TRIBO Dicrorygmini? Gründel \& Kozur, 1975

GÊNERO Gabonorygma n. gen.

Espécie tipo. Dicrorygma (Orthorygma) brotzeni Christensen, 1965.

Etimologia. Do latim Gabon, ou "Gabão", país onde espécimes do gênero são bastante comuns em estratos do Cretáceo Inferior; e do grego orygma, significando "túnel", uma referência ao fato do novo gênero pertencer à tribo Dicrorygmini? Gründel \& Kozur de 1975.

Diagnose. Carapaça sub-arredondada a sub-retangular com margem dorsal convexa e arredondada, ornamentação lisa ou puntada, elementos da linha de charneira fracamente desenvolvidos, zona marginal e lamelas anterior e posterior estreitas e valvas altamente encurvadas para dentro na região oral, por vezes obliterando parcialmente a visualização da lamela interna e da selvage nesta região.

Discussão. As identificações tribal e subfamiliar seguem Gründel (1978b). Dicrorygmini? Gründel \& Kozur, 1975 é uma pequena tribo de ostracodes composta pelos seguintes gêneros: Archeocuneocythere Mandel'shtam, 1947, Dicrorygma Poag, Jr. 1962, Orthorygma (Christensen, 1965) (= Oertliana Kilenyi, 1965), aqui elevado ao nível de gênero, e Gabonorygma n. gen. Oertli et al. (1961) propôs o gênero Cytherideinarum Oertli et al.,

Figura 9. Ostracodes da Formação Riachuelo, bacia de Sergipe-Alagoas, Nordeste do Brasil, Albiano. A-C, Xestoleberis? sp. 2, CP-697; A, vista lateral direita, B, vista lateral esquerda, C, vista dorsal. D-H, Apatocythere? sp. 1; D-E, CP-763, D, vista lateral direita, E, vista dorsal, F-H, CP-762, F, vista lateral direita, G, vista lateral esquerda, H, vista dorsal. I-N, Gabonorygma sergipana gen. et sp. nov.; I, CP-698, vista lateral direita, J, CP700, vista lateral esquerda, K, CP-701, vista dorsal, L, CP-703, vista dorsal, M, CP-699, vista lateral direita, NR, CP-702, N, vista interna esquerda, O, detalhe da charneira na valva esquerda, P, interpretação das estruturas da charneira na valva esquerda, Q, detalhe das cicatrizes musculares central e anterior, R, interpretação das cicatrizes musculares central e anterior. S, Aracajuia fragilis (Piovesan \& Nicolaidis, 2013) in Piovesan et al., 2013; CP-764, vista lateral esquerda. T, Microceratina? sp. 1; CP-714, vista lateral esquerda. U, Algeriana? sp. 1; CP-727, vista lateral esquerda. Escala $=100 \mu \mathrm{m}$. 
1961, mas este não é incluído na presente lista, uma vez que não foi formalmente descrito.

Gabonorygma é um gênero de poucas espécies, possivelmente por apresentar um formato geral de carapaça negligenciado por taxonomistas, ou seja, pequeno, arredondado e liso, sem estruturas morfológicas expressivas. Espécies deste gênero até o momento incluem Gabonorygma brotzeni (Christensen, 1965), do Tithoniano-Kimmeridgiano inferior da Dinamarca, e Gabonorygma sergipana gen. et sp. nov. Cytherideinarum gen. sp. nov. 2 em Oertli et al. (1961), do Valanginiano-Barremiano da Dinamarca, também pertence a Gabonorygma, assim como Pattersoncypris? sp. 1 em Piovesan et al. (2013), caso devidamente revista.

Gabonorygma sergipana gen. et sp. nov.

Figs 9I-N

1979 "Asciocythere" GA E 26. Grosdidier: p. 8, figs 58a-c.

2000 Ovocytheridea aff. O. reniformis Bold, 1964. Viviers et al.: p. 8, figs 14.3, 14.4.

Holótipo. CP-698 (carapaça, fêmea).

Alótipo. CP-699 (carapaça, macho).

Parátipos. CP-700 (carapaça, fêmea), CP-701 (carapaça, fêmea), CP-702 (valva, fêmea) e CP-703 (carapaça, macho).

Localidade tipo e horizonte tipo. Amostra MP-1472, Afloramento Porto dos Barcos 3 (699059N/8814030L, quadrante UTM 24L, sistema SAD69), Município de Riachuelo, Estado de Sergipe, Brasil, Albiano Médio, Zona Aracajuia benderi (MSA-0), Subzona Praebythoceratina amsittenensis (MSA-0.3).

Ocorrência. Abundante, nas amostras MP-1419 (afloramento Santa Bárbara), Município de Rosário do Catete; MP-1450, MP-1451, MP-1452, MP-1459 (afloramento Penha), MP-1460, MP-1461， MP-1463， MP-1465， MP-1468， MP-1469， MP-1470， MP-1471， MP-1472 (afloramento Porto dos Barcos 3), MP-1550, MP-1551, MP-1552, MP-1553, MP-1554, MP1555, MP-1556, MP-1557, MP-1558, MP-1559, MP-1560, MP-1561, MP-1562, MP-1563, MP-1564 e MP-1565 (afloramento São José 1), Município de Riachuelo; também nas profundidades de 512.7m na perfuração 7-CP-252 e 399, 450, 1011, 1020 e 1080m na perfuração 1-US-1, Município de Laranjeiras; Estado de Sergipe, Brasil.

Etimologia. Do português Sergipe, Estado do Brasil de onde vem os materiais tipo desta espécie, acrescido do sufixo latino -ana.

Diagnose. Carapaça com maior altura na região anterocentral e maior largura centroposterior; extremidade posterior arredondada, ligeiramente infracurvada; e lamela interna pouco 
desenvolvida, não visualizável na região oral, onde a margem da valva se invagina para dentro de forma expressiva.

Descrição. Carapaça sub-arredondada a sub-retangular, com maior altura na região anterocentral e maior comprimento na região central. Valva esquerda maior que a direita, ligeiramente sobrepondo esta na margem ventral e na extremidade posterior. Extremidade anterior arredondada, tornando-se ligeiramente retilínea próximo à margem dorsal, onde um ângulo cardinal obtuso é formado. extremidade posterior arredondada, ligeiramente infracurvada; ângulo posterior cardinal obtuso. Margem dorsal ligeiramente retilínea a côncava. Margem ventral retilínea. Superfície lateral lisa. Em vista dorsal, elíptica, com maior largura centroposterior. Em vista interna, charneira adonte, composta na valva esquerda por uma barra lisa. Lamela interna fracamente desenvolvida, não visualizável na região oral, onde a margem da valva se invagina para dentro de forma expressiva. Selvage visível ao longo da margem livre. Cicatriz muscular central consistindo de pelo menos três cicatrizes adutoras elípticas, orientadas no seu maior eixo da margem anteroventral para a posterodorsal, e uma cicatriz frontal elíptica. Dimorfismo sexual discreto: as fêmeas são mais sub-arredondadas e largas em vista dorsal que os machos.

Medidas. CP-698, comprimento $=0.40 \mathrm{~mm}$, altura $=0.23 \mathrm{~mm}$, largura $=0.21 \mathrm{~mm}$; CP-699, comprimento $=0.40 \mathrm{~mm}$, altura $=0.22 \mathrm{~mm}$, largura $=0.17 \mathrm{~mm} ; \mathrm{CP}-700$, comprimento $=0.38$ $\mathrm{mm}$, altura $=0.22 \mathrm{~mm}$, largura $=0.20 \mathrm{~mm} ; \mathrm{CP}-701$, comprimento $=0.40 \mathrm{~mm}$, altura $=0.23$ $\mathrm{mm}$, largura $=0.21 \mathrm{~mm} ;$ CP-702, comprimento $=0.37 \mathrm{~mm}$, altura $=0.22 \mathrm{~mm} ;$ CP-703, comprimento $=0.38 \mathrm{~mm}$, altura $=0.20 \mathrm{~mm}$, largura $=0.17 \mathrm{~mm}$.

Discussão. Gabonorygma sergipana gen. et sp. nov. difere de Gabonorygma brotzeni pelo formato arredondado da extremidade posterior, maior altura mais anteriormente posicionada e maior comprimento mais central. Espécimes em Grosdidier (1979) e Viviers et al. (2000) também pertencem a esta espécie, conforme consta na lista sinonímica proposta.

Distribuição geográfica e estratigráfica. Formação Madiéla, bacia do Gabão, Gabão, Albiano inferior-médio (Grosdidier, 1979). Angico (Viviers et al., 2000) e Taquari (presente trabalho) membros, Riachuelo Formação, Sergipe-Alagoas bacia, Aptiano superior-Albiano, zonas Aracajuia benderi (MSA-0) e Aracajuia antiqua (MSA-1); Brasil.

FAMÍLIA Progonocytheridae Sylvester-Bradley, 1948

SUBFAMÍLIA Progonocytherinae Sylvester-Bradley, 1948

TRIBO Majungaellini Krömmelbein, 1974

GÊNERO Neocythere Mertens, 1956 
Neocythere pseudovanveeni Gründel, 1966

Figs 10A, B

1966 Neocythere? pseudovanveeni Gründel: p. 33, est. 6, figs 1, 2.

1967 Neocythere (n. subgen.?) pseudovanveeni Gründel. Gründel: p. 638, est. 2, figs 14, 15.

1979 Neocythere GA B 21 Grosdidier: p. 8, figs 38a-c.

2013 Perissocytheridea? sp. 1. Piovesan et al.: p. 240, figs 5.4a, b.

Homótipos. CP-705 (valva direita) e CP-706 (valva esquerda).

Ocorrência. Abundante, nas amostras MP-1514, MP-1515, MP-1517, MP-1518, MP-1519, MP-1520, MP-1521, MP-1522, MP-1534, MP-1538, MP-1541, MP-1543, MP-1545, MP1546 e MP-1547 (afloramento Massapê), Município de Riachuelo; também na profundidade de 222m na perfuração 1-CPB-1, Carmópolis; Estado de Sergipe, Brasil.

Medidas. CP-705, comprimento $=0.48 \mathrm{~mm}$, altura $=0.30 \mathrm{~mm} ; \mathrm{CP}-706$, comprimento $=0.49$ $\mathrm{mm}$, altura $=0.28 \mathrm{~mm}$.

Discussão. A identificação supragenérica segue Gründel (1977) e Liebau (2005), enquanto a de espécie é baseada em Gründel $(1966,1967)$. Quanto ao nível de subgênero, os distintos subgêneros de Neocythere Mertens, 1956 descritos por Kaye (1963) não são considerados no presente trabalho, dada a similaridade morfológica entre estes. Espécimes identificados como (Gründel, 1966, 1967). Formação Madiéla, bacia do Gabão, Gabão, Albiano superiorCenomaniano (Grosdidier, 1979). Formação Guarujá, bacia de Santos, Albiano inferior-médio (Piovesan et al., 2013); no presente trabalho, Membro Maruim, Formação Riachuelo, bacia de Sergipe-Alagoas, Albiano superior, Zona Aracajuia antiqua (MSA-1); Brasil.

Neocythere tenuis Kaye, 1965

Figs $10 \mathrm{C}, \mathrm{D}$

1965 Neocythere (Physocythere) tenuis Kaye: p. 245, est. 6, figs 14-17

1978 Neocythere (Physocythere) tenuis Kaye. Neale: p. 352, est. 10, fig. 10.

2000 Neocythere sp. GA B 21 Grosdidier. Viviers et al.: p. 427, figs 15.20-15.22.

Homótipos. CP-707 (valva direita) e CP-708 (valva esquerda).

Ocorrência. Rara, nas amostras MP-1423, MP-1426 e MP-1429 (afloramento ESTRE), Município de Rosário do Catete, Estado de Sergipe, Brasil.

Medidas. $\mathrm{CP}-707$, comprimento $=0.43 \mathrm{~mm}$, altura $=0.25 \mathrm{~mm}$; CP-708, comprimento $=0.44$ $\mathrm{mm}$, altura $=0.24 \mathrm{~mm}$.

Discussão. Para uma discussão sobre a taxonomia supra e subgenérica do Gênero Neocythere, consultar a seção "Discussão" em Neocythere pseudovanveeni Gründel, 1966. A identificação de espécie segue Kaye (1965). A espécie aqui identificada é a mesma denominada em Viviers 

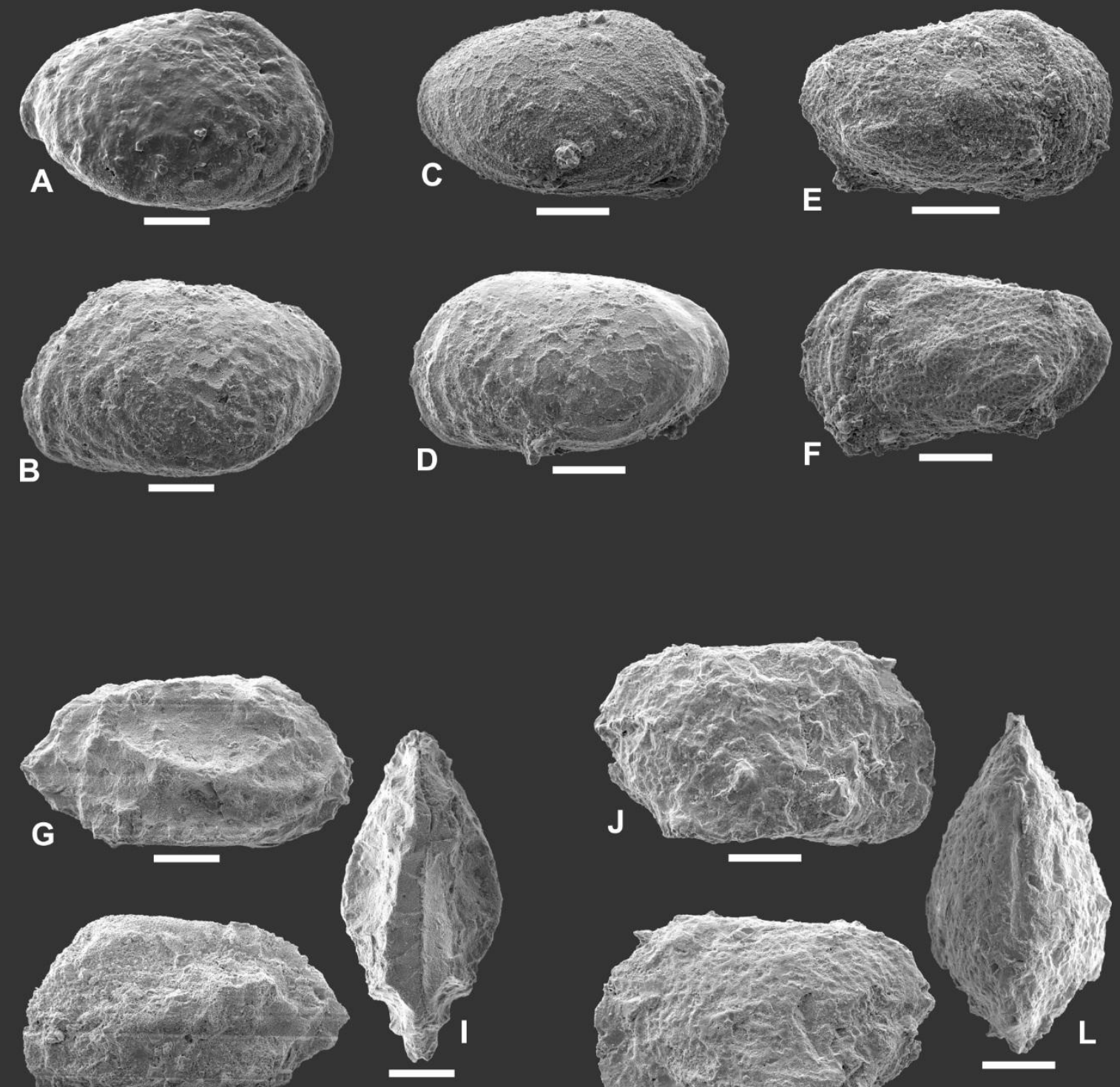

H
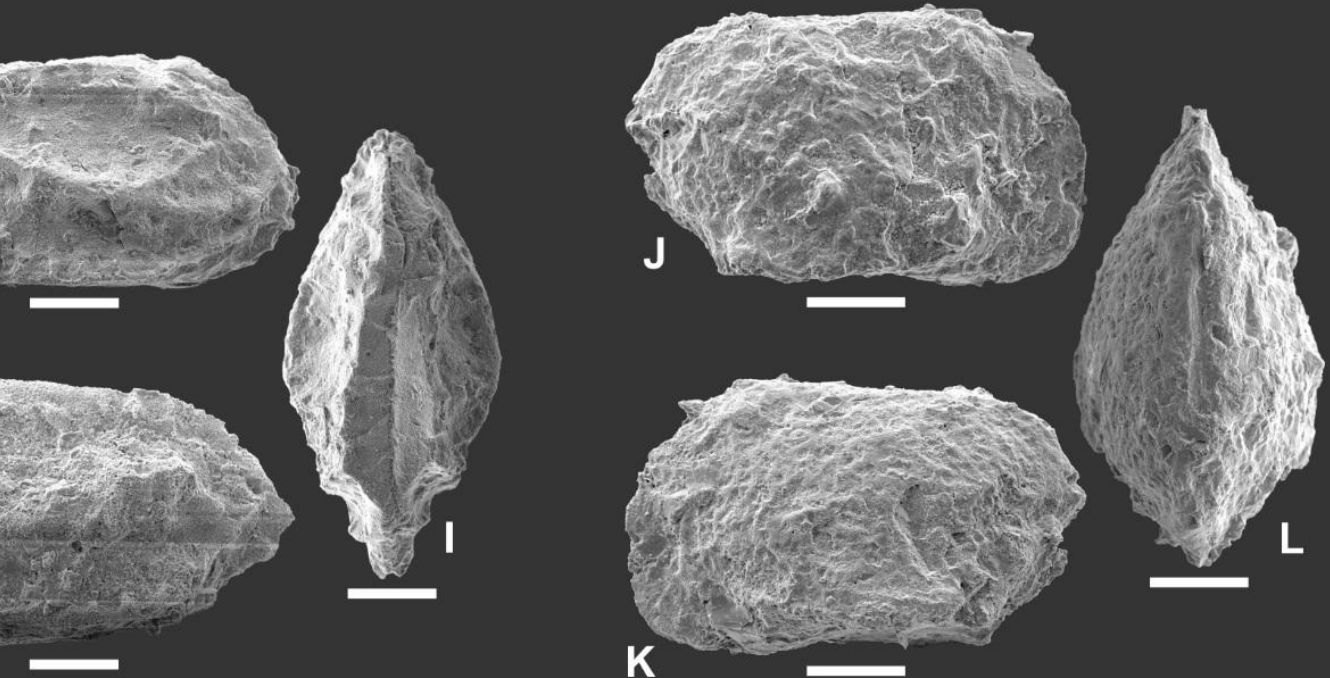

K
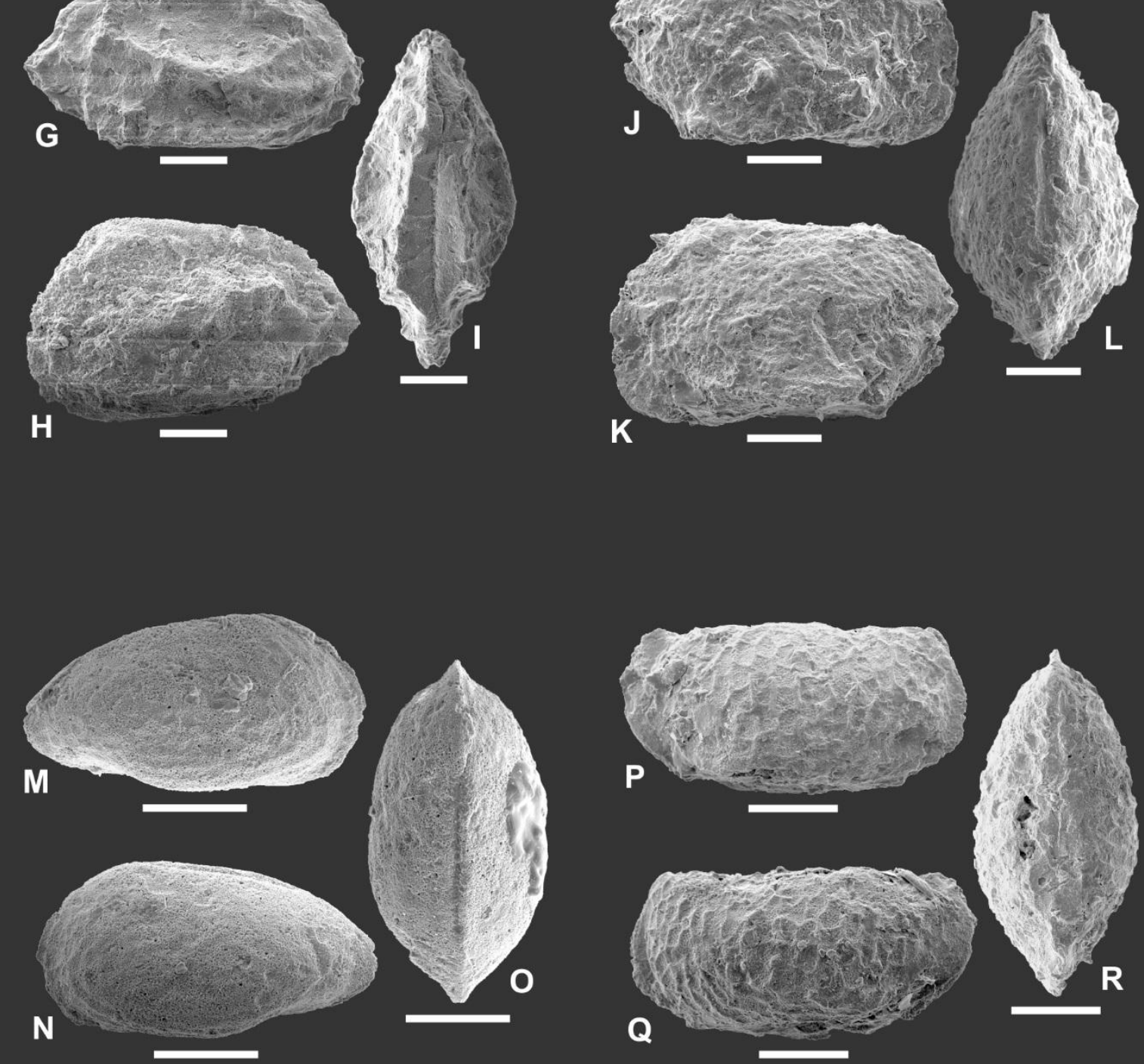
et al. (2000) como Neocythere sp. GA B 21, a partir de Grosdidier (1979). Todavia, esses exemplares não são da mesma espécie, considerando que a espécie no último é, na verdade, Neocythere pseudovanveeni.

Distribuição geográfica e estratigráfica. Inglaterra, Albiano médio (Kaye, 1965; Neale, 1978). Formação Açu, bacia Potiguar, Albiano superior-Cenomaniano inferior; membros Maruim (Viviers et al., 2000) e Taquari (presente trabalho), Formação Riachuelo, SergipeAlagoas bacia, Albiano médio, Zona Aracajuia benderi (MSA-0), Subzona Praebythoceratina amsittenensis (MSA-0.3); Brasil.

SUPERFAMÍLIA Cytheroidea Baird, 1850 FAMÍLIA Cytheridae Baird, 1850

SUBFAMÍLIA Schizocytherinae Mandel'shtam, 1960

TRIBO Schizocytherini Mandel'shtam, 1960

GÊNERO Aracajuia Krömmelbein, 1967

Aracajuia antiqua (Rosenfeld \& Raab, 1983)

Figs 10G-I

1983 Amphicytherura antiqua Rosenfeld \& Raab: p. 96, est. 2, figs 1, 2.

Homótipos. CP-709 (valva esquerda, fêmea) e CP-710 (carapaça, macho).

Ocorrência. Abundante, nas amostras MP-1515, MP-1516, MP-1517, MP-1518, MP-1519, MP-1520, MP-1521, MP-1522, MP-1530, MP-1534, MP-1538, MP-1540, MP-1541, MP1542, MP-1543, MP-1546 e MP-1547 (afloramento Massapê), Município de Riachuelo; também nas profundidades de 480, 510, 555 e 1140m na perfuração 1-US-1, Município de Laranjeiras, Estado de Sergipe, Brasil.

Medidas. $\mathrm{CP}-709$, comprimento $=0.51 \mathrm{~mm}$, altura $=0.32 \mathrm{~mm} ; \mathrm{CP}-710$, comprimento $=0.50$ $\mathrm{mm}$, altura $=0.26 \mathrm{~mm}$, largura $=0.24 \mathrm{~mm}$.

Figura 10. Ostracodes da Formação Riachuelo, bacia de Sergipe-Alagoas, Nordeste do Brasil, Albiano. A, B, Neocythere pseudovanveeni Gründel, 1966; A, CP-705, vista lateral direita, B, CP-706, vista lateral esquerda. C, D, Neocythere tenuis (Kaye, 1965); C, CP-707, vista lateral direita, D, CP-708, vista lateral esquerda. E, F, Quasihermanites? sp. 1; E, CP-766, vista lateral direita, F, CP-715, vista lateral esquerda. G-I, Aracajuia antiqua (Rosenfeld \& Raab, 1983); G, I, CP-709, G, vista lateral direita, I, vista dorsal, H, CP-710, vista lateral esquerda. J-L, Eocytheropteron sp. 1; CP-765, J, vista lateral direita, K, vista lateral esquerda, L, vista dorsal. M-O, Metacytheropteron sp. 1; CP-712, M, vista lateral direita, N, vista lateral esquerda, O, vista dorsal. P-R, Microceratina azazoulensis Andreu \& Colin, 2005 in Colin et al., 2005; CP-713, P, vista lateral direita, Q, vista lateral esquerda, R, vista dorsal. Escala $=100 \mu \mathrm{m}$. 
Discussão. A identificação segue Antonietto et al. (2013a) para o gênero e Rosenfeld \& Raab (1983) para a espécie.

Distribuição geográfica e estratigráfica. Formações Telamim e Talme Yafe, bacia Levantina, Israel, Aptiano-Albiano (Rosenfeld \& Raab, 1983). No presente trabalho, Membro Maruim, Formação Riachuelo, bacia de Sergipe-Alagoas, Brasil, Albiano superior, Zona Aracajuia antiqua (MSA-1).

Aracajuia benderi Krömmelbein, 1967

Fig. 8V

1966 Ostracoda sp. B. Krömmelbein: p. 121, figs 2a-c.

1967 Aracajuia benderi Krömmelbein: p. 529, figs 1, 2a, b, 3, 4a-c.

2000 Amphicytherura benderi (Krömmelbein). Viviers et al.: p. 413, figs 16.1-16.3.

2000 Amphicytherura sp. P3. Viviers et al.: p. 411, figs 16.11-16.14.

?2000 Amphicytherura aff. Amphicytherura benderi. Viviers et al.: p. 427, figs 16.4-16.6.

?2000 Amphicytherura sp. P4. Viviers et al.: p. 411, figs 16.15-16.17.

2008 Aracajuia benderi Krömmelbein. Musacchio \& Simeoni: p. 252, fig. 8.

2013a Aracajuia benderi Krömmelbein. Antonietto et al.: p. 7, figs 6a-r.

Homótipo. CP-711 (carapaça, fêmea).

Ocorrência. Abundante, nas amostras MP-1419, MP-1420 (afloramento Santa Bárbara) e MP-1423 (afloramento ESTRE), Município de Rosário do Catete; MP-1449, MP-1450, MP1451, MP-1452, MP-1453, MP-1455, MP-1456, MP-1457 (afloramento Penha), MP-1460, MP-1461, MP-1462, MP-1463, MP-1464, MP-1465, MP-1466, MP-1468, MP-1469, MP1470, MP-1471, MP-1472, MP-1474, MP-1475, MP-1476, MP-1477, MP-1481, MP-1482 (afloramento Porto dos Barcos 3), MP-1496, MP-1497, MP-1500, MP-1504, MP-1506, MP1507, MP-1508, MP-1509, MP-1510, MP-1511, MP-1512, MP-1513 (afloramento P384), MP-1550, MP-1551, MP-1552, MP-1553, MP-1554, MP-1555, MP-1556, MP-1557, MP1558, MP-1559, MP-1560, MP-1561, MP-1563, MP-1564, MP-1565, MP-1566, MP-1567, MP-1568, MP-1569, MP-1570, MP-1571, MP-1572, MP-1573, MP-1574, MP-1575, MP1576, MP-1577, MP-1578, MP-1680, MP-1694, MP-1695, MP-1696, MP-1697 e MP-1698 (afloramento São José 1), Município de Riachuelo; também nas profundidades de 493m na perfuração 7-CP-252, Santo Amaro das Brotas, e 690, 711, 720, 726, 741, 831 e 1161m na perfuração 1-US-1, Município de Laranjeiras; Estado de Sergipe, Brasil.

Medidas. Comprimento $=0.43 \mathrm{~mm}$, altura $=0.24 \mathrm{~mm}$, largura $=0.20 \mathrm{~mm}$.

Discussão. A identificação segue Antonietto et al. (2013a).

Distribuição geográfica e estratigráfica. Formação Madiéla, bacia do Gabão, Aptiano 
superior-Albiano inferior, Gabão (Krömmelbein, 1966; Bertels, 1977). Bacia Potiguar, Formação Açu, Albiano médio (Viviers et al., 2000); Membro Angico, Formação Riachuelo, bacia de Sergipe-Alagoas, Aptiano superior-Albiano, Zona Aracajuia benderi (MSA-0) (Krömmelbein, 1967; Bertels, 1977; Viviers et al., 2000; Musacchio \& Simeoni, 2008, Antonietto et al., 2013a); no presente trabalho, adicionalmente ao Angico, também é observado no Membro Taquari da Formação Riachuelo; Brasil.

\section{Aracajuia fragilis (Piovesan \& Nicolaidis, 2013)}

Fig. 9S

2013 Amphicytherura fragilis Piovesan \& Nicolaidis in Piovesan et al.: p. 247, figs 4.7a-d.

Homótipo. CP-764 (valva esquerda, fêmea).

Ocorrência. Abundante, nas amostras MP-1424, MP-1425, MP-1426, MP-1427, MP-1428, MP-1429, MP-1430, MP-1431 (afloramento ESTRE).

Medidas. Comprimento $=0.45 \mathrm{~mm}$, altura $=0.24 \mathrm{~mm}$.

Discussão. A identificação segue Piovesan et al. (2013). Após extensa revisão dos gêneros Amphicytherura Butler \& Jones, 1957 e Aracajuia Krömmelbein, 1967 por Antonietto et al. (2013a), o presente trabalho opta por transferir Aracajuia fragilis (Piovesan \& Nicolaidis, 2013) para o último gênero, uma vez que a maioria das espécies do Cretáceo inferior identificadas como Amphicytherura, tendo-se em conta características morfológicas da carapaça, pertencem de fato a Aracajuia, incluindo a presente espécie.

Distribuição geográfica e estratigráfica. Formação São Mateus, bacia do Espírito Santo, Albiano (Piovesan et al., 2013); no presente trabalho, Membro Taquari, Formação Riachuelo, bacia de Sergipe-Alagoas, Albiano médio, Zona Aracajuia benderi (MSA-0), Subzona Reticulocosta edrianae (MSA-0.4); Brasil.

FAMÍLIA Cytheruridae Müller, 1894

SUBFAMÍLIA Cytherurinae Müller, 1894

TRIBO Eocytheropterini Mandel'shtam, 1960

GÊNERO Eocytheropteron Alexander, 1933

Eocytheropteron sp. 1

Figs 10J-L

Hipótipos. CP-765 (carapaça) e CP-767 (valva esquerda).

Ocorrência. Comum, nas amostras MP-1515, MP-1516, MP-1518, MP-1519, MP-1521, MP1540, MP-1542, MP-1545 e MP-1547 (afloramento Massapê), Município de Riachuelo; 
também nas profundidades de 996 e 1080m na perfuração 1-US-1, Município de Laranjeiras; Estado de Sergipe, Brasil.

Medidas. CP-765, Comprimento $=0.47 \mathrm{~mm}$, altura $=0.27 \mathrm{~mm}$, largura $=0.21 \mathrm{~mm} ;$ CP-767, comprimento $=0.43 \mathrm{~mm}$, altura $=0.23 \mathrm{~mm}$.

Discussão. A identificação de gênero segue Alexander (1933), e a supragenérica, Gründel (1976). Devido à ausência de espécimes melhor preservados, não foi possível descrever adequadamente Eocytheropteron sp. 1.

Distribuição geográfica e estratigráfica. Membro Maruim, Formação Riachuelo, bacia de Sergipe-Alagoas, Brasil, Aptiano superior-Albiano, zonas Aracajuia benderi (MSA-0) Subzona Sergipella viviersae (MSA-0.2) - e Aracajuia antiqua (MSA-1).

GÊNERO Metacytheropteron Oertli, 1957

Metacytheropteron minuta? (Swain, 1976)

Figs 10M-O

?1976 Majungaella? minuta Swain: p. 747, est. 1, figs 19-21, 23.

?1976 Eocytheropteron? sp. Swain: p. 745, est. 2, fig. 14.

1979 Metacytheropteron GA B 14. Grosdidier: p. 8, figs 40a-c.

2000 Metacytheropteron aff. M. sp. GA C 26. Viviers et al.: p. 414, fig. 15.9.

Homótipos. CP-712 (carapaça).

Ocorrência. Rara, na amostra MP-1557 (afloramento São José 1), Município de Riachuelo, Estado de Sergipe, Brasil.

Medidas. Comprimento $=0.33 \mathrm{~mm}$, altura $=0.17 \mathrm{~mm}$, largura $=0.16 \mathrm{~mm}$.

Discussão. A identificação de gênero segue Oertli (1957), e a supragenérica, Gründel (1976). A reclassificação de Metacytheropteron minuta (Swain, 1976) tem sido sugerida por diversos autores, incluindo Babinot \& Colin (1988) e Piovesan et al. (2012), de modo que no presente trabalho a mesma se encontra transferida de gênero. $\mathrm{O}$ espécime figurado possivelmente pertence a Metacytheropteron minuta, embora seja significativamente diferente quanto à sobreposição ao longo da margem dorsal (evidente nesta última). Ainda assim, o primeiro é coespecífico com aqueles identificados como Metacytheropteron GA B 14 em Grosdidier (1979) e Metacytheropteron aff. M. sp. GA C 26 em Viviers et al. (2000).

Distribuição geográfica e estratigráfica. Possivelmente Guiana, Aptiano superiorCenomaniano inferior (Swain, 1976). Formação Madiéla, bacia do Gabão, Gabão, Albiano (Grosdidier, 1979). Membro Maruim, Formação Riachuelo, bacia de Sergipe-Alagoas, Brasil, Albiano superior, Zona Aracajuia benderi (MSA-0), Subzona Metacytheropteron aff. M. sp. 
GA C 24 (MSA-0.5) (Viviers et al., 2000); no presente trabalho, expandida para o Membro Taquari, Aptiano superior-Albiano inferior, Subzona Sergipella viviersae (MSA-0.2).

SUBFAMÍLIA Eucytherurinae Puri, 1974 emend. Maddocks \& Steineck, 1987

GÊNERO Microceratina Swanson, 1980

Microceratina azazoulensis Andreu \& Colin, 2005

Figs 10P-R

?1985 Chapmanicythereis? sp. 1. Hart \& Critenden: p. 228, fig. 9d.

1991 Pseudomonoceratina sp. 1. Andreu-Boussut: p. 502, est. 42, fig. 3.

1991 Pseudomonoceratina sp. 3. Andreu-Boussut: p. 503, est. 42, figs 4, 6.

2005 Microceratina azazoulensis Andreu \& Colin in Colin et al.: p. 21, est. 2, figs 2-8.

2009 Microceratina sp. Babinot et al.: p. 7, est. 1, figs 23, 23 a.

Homótipo. CP-713 (carapaça).

Ocorrência. Rara, nas amostras MP-1460, MP-1470 (afloramento Porto dos Barcos 3) e MP1520 (afloramento Massapê), Município de Riachuelo, Estado de Sergipe, Brasil.

Medidas. Comprimento $=0.39 \mathrm{~mm}$, altura $=0.18 \mathrm{~mm}$, largura $=0.19 \mathrm{~mm}$.

Discussão. A identificação segue Colin et al. (2005). Microceratina sp. em Babinot et al. (2009), é aqui incluída na lista sinonímica da espécie. Chapmanicythereis? sp. 1 em Hart \& Critenden (1985), também é incluído nesta lista, embora dubiamente, já que o espécime figurado apresenta a mesma forma geral, mas não a ornamentação, algo que pode ser causado por processos tafonômicos.

Distribuição geográfica e estratigráfica. Formação Andranomaimbo, Madagascar, Cenomaniano inferior (Babinot et al., 2009). Formação Aït Lamine, bacia de Azazoul, Marrocos, Cenomaniano médio-superior (Andreu-Boussut, 1991, Colin et al., 2005). No presente trabalho, Membro Maruim, Formação Riachuelo, bacia de Sergipe-Alagoas, Brasil, Albiano médio-superior, zonas Aracajuia benderi (MSA-0) - Subzona Praebythoceratina amsittenensis (MSA-0.3) - e Aracajuia antiqua (MSA-1).

\section{Microceratina? sp. 1}

Fig. 9T

Hipótipo. CP-714 (valva esquerda).

Ocorrência. Rara, na amostra MP-1470 (afloramento Porto dos Barcos 3), Município de Riachuelo, Estado de Sergipe, Brasil.

Medidas. Comprimento $=0.41 \mathrm{~mm}$, altura $=0.24 \mathrm{~mm}$. 
Discussão. Microceratina? sp. 1 se assemelha vagamente a outras espécies de Microceratina Swanson, 1980 em Colin et al. (2005) no formato geral (o qual está incompleto no presente espécime). Sua ornamentação, entretanto, não tem qualquer semelhança com qualquer uma destas, motivo pelo qual Microceratina? sp. 1 é colocada apenas provisoriamente neste gênero.

Distribuição geográfica e estratigráfica. Membro Taquari, Formação Riachuelo, bacia de Sergipe-Alagoas, Brasil, Albiano médio, Zona Aracajuia benderi (MSA-0), Subzona Praebythoceratina amsittenensis (MSA-0.3).

\author{
SUPERFAMÍLIA Trachyleberidoidea Sylvester-Bradley, 1948 \\ FAMÍLIA Cytherettidae Triebel, 1952 \\ SUBFAMÍLIA Cytherettinae Triebel, 1952 \\ TRIBO Protocytherini Ljubimova, 1955 \\ GÊNERO Veenia Butler \& Jones, 1957 \\ Veenia guianensis Swain, 1976
}

Figs 11B-D

1976 Veenia guianensis Swain: p. 748, p1. 1, fig. 22; p1. 3, figs 1a, b, 2-5, 10.

1991 Veenia (Protoveenia) cf. florentinensis Damotte, 1961. Andreu-Boussut: p. 677, est. 49, figs 4-8.

2000 Veenia guianensis Swain. Viviers et al.: p. 437, figs 23.1, 23.2.

2000 Veenia aff. V. sp. GA D 16. Viviers et al.: p. 414, fig. 22.11.

Hipótipo. CP-732 (carapaça).

Ocorrência. Rara, nas amostras MP-1545 e MP-1546 (afloramento Massapê), Município de Riachuelo, Estado de Sergipe, Brasil.

Medidas. Comprimento $=0.57 \mathrm{~mm}$, altura $=0.30 \mathrm{~mm}$, largura $=0.27 \mathrm{~mm}$.

Discussão. A identificação segue Swain (1976). Veenia (Protoveenia) cf. florentinensis Damotte, 1961 em Andreu-Boussut (1991) é na verdade Veenia guianensis Swain, 1976, assim como os espécimes identificados como Veenia aff. $V$. sp. GA D 16 em Viviers et al. (2000).

Distribuição geográfica e estratigráfica. Guiana, Aptiano-Cenomaniano inferior (Swain, 1976). formações Jbel El Hajer e El Jir, bacia Azazoul, Marrocos, Albiano (Andreu-Boussut, 1991). Formação Ponta do Mel, bacia Potiguar, Albiano médio-superior (Viviers et al., 2000); no presente trabalho, Membro Maruim, Formação Riachuelo, bacia de Sergipe-Alagoas, Albiano superior, Zona Aracajuia antiqua (MSA-1); Brasil. 


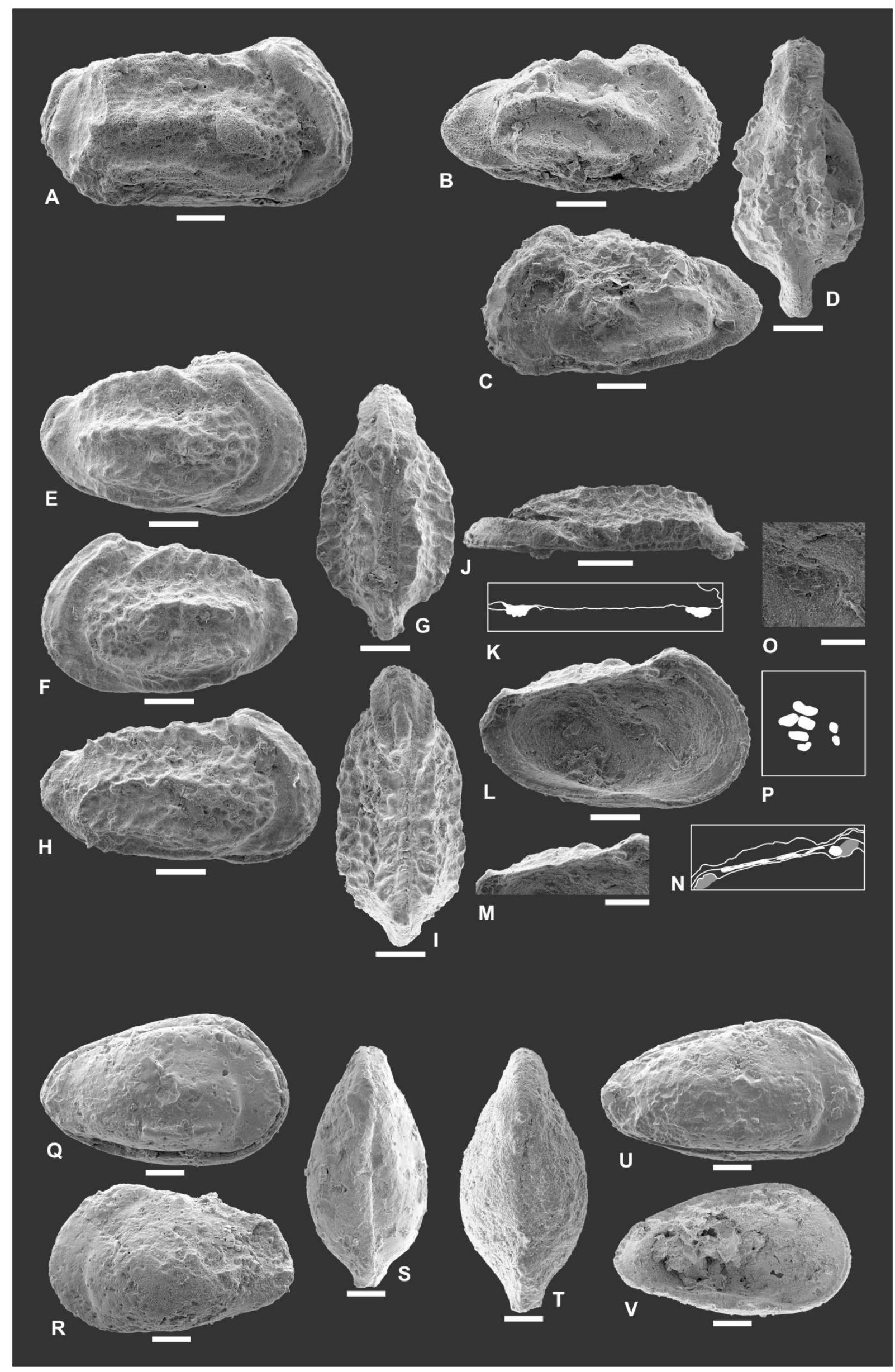




\section{SUBFAMÍLIA Palaeocytherideinae Ljubimova, 1955 \\ TRIBO Cytherettini Triebel, 1952 \\ GÊNERO Reticulocosta Gründel, 1974a \\ Reticulocosta edrianae sp. nov.}

Figs 11E-P

2000 Veenia guianensis Swain, 1976. Viviers et al.: p. 413, fig. 22.10.

2000 Veenia sp. P1. Viviers et al.: p. 410, figs 23.3, 23.4.

Holótipo. CP-716 (carapaça, fêmea).

Alótipo. CP-717 (carapaça, macho).

Parátipos. CP-718 (carapaça, fêmea), CP-719 (carapaça, fêmea), CP-720 (valva esquerda, fêmea) e CP-768 (valva direita, macho).

Localidade tipo e horizonte tipo. Amostra MP-1461, Afloramento Porto dos Barcos 3 (699059N/8814030L, quadrante UTM 24L, sistema SAD69), Município de Riachuelo, Estado de Sergipe, Brasil, Albiano Médio, Zona Aracajuia benderi (MSA-0), Subzona Praebythoceratina amsittenensis (MSA-0.3).

Ocorrência. Abundante, nas amostras MP-1419, MP-1420 (afloramento Santa Bárbara), MP1423, MP-1424 (afloramento ESTRE), Município de Rosário do Catete; e MP-1460, MP1461, MP-1462, MP-1463, MP-1464, MP-1465, MP-1466, MP-1468, MP-1469, MP-1470, MP-1471, MP-1472, MP-1474, MP-1475, MP-1476, MP-1477, MP-1481, MP-1482 (afloramento Porto dos Barcos 3), MP-1496, MP-1497, MP-1499, MP-1506, MP-1509, MP1510, MP-1511, MP-1512 e MP-1513 (afloramento P384), Riachuelo; Estado de Sergipe, Alagoas.

Etimologia. Forma latinizada de "Edriana", primeiro nome de Edriana Araújo de Lima. O nome desta espécie é uma homenagem à mesma.

Diagnose. Ornamentação consistindo de três costelas fortemente acuminadas, bastante

Figura 11. Ostracodes da Formação Riachuelo, bacia de Sergipe-Alagoas, Nordeste do Brasil, Albiano. A, Sergipella viviersae Do Carmo et al., 2012; CP-728, vista lateral direita. B-D, Veenia guianensis Swain, 1976; CP-732, B, vista lateral direita, C, vista lateral esquerda, D, vista dorsal. E-P, Reticulocosta edrianae sp. nov.; E, CP-716, vista lateral direita, F, CP-718, vista lateral esquerda, G, CP-719, vista dorsal, H, I, CP-717, H, vista lateral direita, I, vista dorsal, J, K, CP-768, J, vista dorsal, I, interpretação das estruturas da charneira na valva direita, L-P, CP-720, L, vista interna esquerda, M, detalhe da charneira na valva esquerda, N, interpretação das estruturas da charneira na valva esquerda, $\mathrm{O}$, detalhe das cicatrizes musculares central e anterior, $\mathrm{P}$, interpretação das cicatrizes musculares central e anterior. Q-V, Brachycythere smithsoniana sp. nov.; Q, CP-721, vista lateral direita, R, CP-723, vista lateral esquerda, S, CP-724, vista dorsal, T, CP-726, vista dorsal, U, CP-722, vista lateral direita, V, CP-725, vista interna esquerda. Escala $=100 \mu \mathrm{m}$. 
variadas em espessura, nas áreas dorsal, central e ventral da superfície lateral: a costela dorsal,curva e geralmente lisa, vai da região posterior à anterodorsal, projetando-se além da margem dorsal; a central, ondulada e ligeiramente nodulada na sua porção posterior, vai da região posterocentral até a central, onde se conecta ao tubérculo centroanterior, que é reticulado; e a ventral, curva e ligeiramente nodulada na sua porção posterior, vai da região posteroventral à anteroventral.

Descrição. Carapaça subtriangular a sub-retangular, com maior altura na região anterocentral e maior comprimento na central. Valva esquerda maior que a direita, com recobrimento ao longo de toda a margem livre, porém mais pronunciado nas margens anterodorsal, posterodorsal e anteroventral. Extremidade anterior arredondada, tornando-se ligeiramente retilínea próximo à margem dorsal, onde um ângulo cardinal obtuso é formado. Extremidade posterior arredondada, supracurvada, tornando-se ligeiramente retilínea próximo a margem dorsal, onde ambas formam um ângulo cardinal obtuso; um pequeno processo caudal está presente. Margem dorsal retilínea a ligeiramente côncava. Margem ventral arredondada, com uma concavidade leve na região oral. Ornamentação primária consistindo de três costelas fortemente acuminadas, bastante variadas em espessura, nas áreas dorsal, central e ventral da superfície lateral: a costela dorsal, curva e geralmente lisa, vai da região posterior à anterodorsal, projetando-se além da margem dorsal; a central, ondulada e ligeiramente nodulada na sua porção posterior, vai da região posterocentral até a central, onde se conecta ao tubérculo centroanterior, que é reticulado; e a ventral, curva e ligeiramente nodulada na sua porção posterior, vai da região posteroventral à anteroventral. Duas pequenas costelas também estão presentes: uma proveniente do tubérculo ocular corre ao longo da extremidade anterior, logo atrás da mesma, e outra de formato irregular, atravessando a região centroventral e cobrindo parcialmente a margem ventral. Adicionalmente, vários dentículos se irradiam a partir das extremidades anterior e posterior. Ornamentação secundária inclui reticulação arredondada a foveolada em vários graus de extensão sobre a superfície lateral, mas sempre presente na região centroanterior. Tubérculo ocular arredondado, bem desenvolvido. Em vista dorsal, elíptica, com maior largura centroposterior; uma superfície plana é formada entre os ângulos cardinais posterior e anterior e as costelas dorsais. Em vista interna, charneira paranfidonte, formada na valva direita por um dente elíptico quadrilobado, seguido de uma fosseta arredondada anterior, uma barra lisa e um dente posterior também quadrilobado; elementos na valva esquerda são complementares. Lamela interna bem desenvolvida, não visível na região oral, onde a margem da valva se invagina para dentro de forma expressiva. Selvage não visível nas regiões posteroventral e posterocentral. Cicatrizes musculares 
centraies consistindo de um conjunto ligeiramente côncavo de quatro cicatrizes adutoras, a segundo do dorso para o ventre subdividida em duas, e duas cicatrizes frontais elípticas. Dimorfismo sexual pronunciado: as fêmeas são mais curtas e mais largas em vista dorsal do que os machos; as costelas são mais espessas em fêmeas do que machos; e as fêmeas apresentam menos ornamentação reticulada que os machos. Variação intraespecífica observada da seguinte maneira: grau de reticulação da superfície lateral da carapaça variando entre generalizado e concentrado ao longo da região central, e razão altura/comprimento dos espécimes resultando em formas mais alongadas ou mais compactas.

Medidas. CP-716, comprimento $=0.54 \mathrm{~mm}$, altura $=0.33 \mathrm{~mm}$, largura $=0.27 ; \mathrm{CP}-717$, comprimento $=0.57 \mathrm{~mm}$, altura $=0.31 \mathrm{~mm}$, largura $=0.26 \mathrm{~mm} ; \mathrm{CP}-718$, comprimento $=0.52$ $\mathrm{mm}$, altura $=0.32 \mathrm{~mm}$, largura $=0.29 \mathrm{~mm} ; \mathrm{CP}-719$, comprimento $=0.52 \mathrm{~mm}$, altura $=0.31$ $\mathrm{mm}$, largura $=0.28 \mathrm{~mm} ;$ CP-720, comprimento $=0.55 \mathrm{~mm}$, altura $=0.33 \mathrm{~mm} ;$ CP-768, comprimento $=0.56 \mathrm{~mm}$, altura $=0.28 \mathrm{~mm}$.

Discussão. As identificações de gênero, tribo e subfamília seguem Gründel (1974a). Reticulocosta edrianae sp. nov. é semelhante a Reticulocosta tarfayensis (Reyment, 1978), inclusive apresentando determinado grau de variação intraespecífica na ornamentação reticulada como esta última (Reyment, 1978; Andreu-Boussut, 1991; Majoran, 1991). Estas espécies diferem entre si e de Reticulocosta vitiliginosa (Apostolescu, 1961) pela reticulação menos intensa e costelas mais acuminadas em Reticulocosta edrianae. Além disso, esta tem sua ocorrência restrita ao Cretáceo Inferior (Albiano), enquanto as outras espécies são do Cretáceo Superior (Cenomaniano superior-Santoniano) (Apostolescu, 1961).

Distribuição geográfica e estratigráfica. Formação Açu, bacia Potiguar, Albiano médio; membros Maruim (Viviers et al., 2000) e Taquari (presente trabalho), Formação Riachuelo, bacia de Sergipe-Alagoas, Albiano médio, Zona Aracajuia benderi (MSA-0), subzonas Praebythoceratina amsittenensis (MSA-0.3) e Reticulocosta edrianae (MSA-0.4); Brasil.

FAMÍLIA Trachyleberididae Sylvester-Bradley, 1948

SUBFAMÍLIA Brachycytherinae Puri, 1954

GÊNERO Brachycythere Alexander 1933 emend. Puckett, 2002

Brachycythere smithsoniana sp. nov.

Figs 11Q-V

1979 "Veenia" GAD 34. Grosdidier: p. 8, figs 28a-c.

Holótipo. CP-721 (carapaça, fêmea).

Alótipo. CP-722 (carapaça, macho). 
Parátipos. CP-723 (carapaça, fêmea), CP-724 (carapaça, fêmea), CP-725 (valva esquerda, possivelmente fêmea) e CP-726 (carapaça, macho).

Localidade tipo e horizonte tipo. Amostra MP-1515, afloramento Massapê (700764N/881233L, quadrante UTM 24L, sistema SAD69), Município de Riachuelo, Estado de Sergipe, Brasil, Albiano superior, Zona Aracajuia antiqua (MSA-1).

Ocorrência. Abundante, nas amostras MP-1514, MP-1516, MP-1517, MP-1518, MP-1519, MP-1520, MP-1522, MP-1542, MP-1543, MP-1545, MP-1546 e MP-1547 (afloramento Massapê), Município de Riachuelo, Estado de Sergipe, Brasil.

Etimologia. Do inglês Smithson, sobrenome de James Smithson, fundador do Instituto Smithsonian, organização à qual pertence o Museum Nacional de História Natural de Washington, D.C., onde parte importante do presente trabalho foi realizada entre os anos de 2013 e 2014; acrescido do sufixo latino -ana.

Diagnose. Ornamentação geralmente lisa, diferindo da valva esquerda, lisa, para a direita, onde três costelas lisas fracamente distinguíveis nas posições dorsal, central e centroventral estão presentes: a dorsal, curva, vai da região centroposterior à anterodorsal, ligeiramente encobrindo a margem dorsal na região anterodorsal; a central vai da região posterocentral à central; e a ventral, levemente curva, vai da região posteroventral à anteroventral.

Descrição. Carapaça subtriangular, com maior altura na região anterocentral e maior comprimento na central. Valva esquerda maior que a direita, sobrepondo esta pronunciadamente ao longo da margem livre, exceto na margem posteroventral, onde o recobrimento é discreto. Extremidade anterior arredondada, tornando-se retilínea próximo à margem dorsal, onde um ângulo cardinal ligeiramente obtuso é formado. Extremidade posterior levemente acuminada, formando um pequeno processo caudal que é retilíneo abaixo e acima do ponto mais extremo, que é arredondado; com a margem dorsal, esta extremidade forma um ângulo cardinal obtuso. Margem dorsal ligeiramente côncava a retilínea. Margem ventral arredondada, com uma concavidade muito discreta na região oral na valva esquerda. Ornamentação geralmente lisa, diferindo da valva esquerda, lisa, para a direita, onde três costelas lisas fracamente distinguíveis nas posições dorsal, central e centroventral estão presentes: a dorsal, curva, vai da região centroposterior à anterodorsal, ligeiramente encobrindo a margem dorsal na região anterodorsal; a central vai da região posterocentral à central; e a ventral, levemente curva, vai da região posteroventral à anteroventral. Tubérculo ocular elíptico, fracamente desenvolvido. Em vista dorsal, elíptica, com maior largura centroposterior; extremidades posterior e anterior achatadas, conferindo aspecto pontiagudo à carapaça. Em vista interna, charneira holanfidonte, composta na valva esquerda por uma 
fosseta frontal arredondada, seguida de um dente arredondado bilobado, uma barra lisa e uma fosseta elíptica e alongada. Lamela interna bem desenvolvida, não visível na região oral, onde a margem da valva se invagina para dentro de forma expressiva. Selvage não visível nas regiões posteroventral e posterocentral. Dimorfismo sexual discreto: as fêmeas possuem processo caudal mais curto em vista dorsal e são mais arredondadas em vista lateral que os machos, e apresentam maior recobrimento ao longo da margem livre e que os machos.

Medidas. CP-721, comprimento $=0.65 \mathrm{~mm}$, altura $=0.39 \mathrm{~mm}$, largura $=0.28 \mathrm{~mm} ; \mathrm{CP}-722$, comprimento $=0.66 \mathrm{~m}$, altura $=0.35 \mathrm{~mm}$, largura $=0.31 \mathrm{~mm} ;$ CP-723, comprimento $=0.64$ $\mathrm{mm}$, altura $=0.39 \mathrm{~mm}$, largura $=0.31 \mathrm{~mm} ;$ CP-724, comprimento $=0.63 \mathrm{~mm}$, altura $=0.37$ $\mathrm{mm}$, largura $=0.30 \mathrm{~mm} ; \mathrm{CP}-725$, comprimento $=0.62 \mathrm{~mm}$, altura $=0.35 \mathrm{~mm} ; \mathrm{CP}-726$, comprimento $=0.69 \mathrm{~mm}$, altura $=0.38 \mathrm{~mm}$, largura $=0.33 \mathrm{~mm}$.

Discussão. A identificação supragenérica segue Puckett (2002). Brachycythere smithsoniana sp. nov. apresenta uma característica bastante distintiva entre espécies de Brachycythere Alexander, 1933, ou seja, ornamentação diferenciada entre as valvas esquerda e direita: a direita possui três costelas fracamente distinguíveis nas regiões dorsal, central e ventral, enquanto a esquerda é lisa. A presença dessas costelas também é observável em algumas espécies de outro género da mesma subfamília, Acuminobrachycythere Puckett, 2002, embora nunca variando da valva esquerda para a direita do mesmo indivíduo (Puckett, 2002). “Veenia” GAD 34 Grosdidier (1979) é co-específica a Brachycythere smithsoniana.

Distribuição geográfica e estratigráfica. Formação Madiéla, bacia do Gabão, Gabão, Aptiano superior-Albiano médio (Grosdidier, 1979). No presente trabalho, Membro Maruim, Formação Riachuelo, bacia de Sergipe-Alagoas, Brasil, Albiano superior, Zona Aracajuia antiqua (MSA-1).

SUBFAMÍLIA Trachyleberidinae Sylvester-Bradley, 1948

GÊNERO Algeriana Majoran, 1989

Algeriana? sp. 1

Fig. 9U

Hipótipo. CP-727 (valva esquerda).

Ocorrência. Rara, na amostra MP-1419 (afloramento Santa Bárbara), Município de Rosário do Catete, Estado de Sergipe, Brasil.

Medidas. Comprimento $=0.57 \mathrm{~mm}$, altura $=0.28 \mathrm{~mm}$.

Discussão. A identificação de gênero segue parcialmente Majoran (1989). A principal diferença entre o presente espécime e os de espécies previamente descritas de Algeriana 
Majoran, 1989 é a presença no primeiro de uma costela submarginal anterior originando-se no tubérculo ocular. Devido ao número limitado de exemplares, não foi possível tecer comentários adicionais sobre a classificação taxonômica de Algeriana? sp. 1.

Distribuição geográfica e estratigráfica. Membro Taquari, Formação Riachuelo, bacia de Sergipe-Alagoas, Brasil, Albiano médio, Zona Aracajuia benderi (MSA-0), Subzona Praebythoceratina amsittenensis (MSA-0.3).

\section{GÊNERO Quasihermanites Gründel, 1964 \\ Quasihermanites? sp. 1}

Figs 10E, F

Hipótipos. CP-715 (valva esquerda) e CP-766 (valva direita).

Ocorrência. Rara, nas amostras MP-1423 e MP-1424 (afloramento ESTRE), Município de Rosário do Catete, Estado de Sergipe, Brasil.

Medidas. $\mathrm{CP}-715$, comprimento $=0.43 \mathrm{~mm}$, altura $=0.25 \mathrm{~mm}$; $\mathrm{CP}-766$, comprimento $=0.38$ $\mathrm{mm}$, altura $=0.23 \mathrm{~mm}$.

Discussão: A identificação de gênero segue Gründel (1964), e a supragenérica, Gründel (1966). O espécime aqui figurado possui ornamentação menos aparente do que outras espécies descritas de Quasihermanites Gründel, 1964, especialmente no que diz respeito ao conjunto de costelas laterais característico deste gênero (Kuznetsova, 1961; Gründel, 1964; Donze, 1965; Pokorný, 1973; Colin, 1974; Babinot et al., 1985a; Babinot \& Colin, 2011). O provável motivo seria a diagênese sobre os espécimes, similar à observada nos espécimes tipo de Quasihermanites spiralus Schudack \& Schudack, 2000 (Schudack \& Schudack 2000). Por isso, os presentes autores classificam os presentes exemplares como Quasihermanites, porém com dubiedade.

Distribuição geográfica e estratigráfica. Membro Taquari, Formação Riachuelo, bacia de Sergipe-Alagoas, Brasil, Albiano médio, Zona Aracajuia benderi (MSA-0), Subzona Reticulocosta edrianae (MSA-0.4).

GÊNERO Sergipella Krömmelbein, 1967 emend. Do Carmo et al., 2012 Sergipella viviersae Do Carmo et al., 2012

Fig. 11A

2000 Sergipella transatlantica Krömmelbein, 1967. Viviers et al.: p. 437, figs 23.12, 23.13.

2012 Sergipella viviersae Do Carmo et al.: p. 10, est. 2, figs 1-7.

2013 Sergipella aff. viviersae Do Carmo et al. Piovesan et al.: p. 249, figs 5.9a, b. 
Homótipo. CP-728 (carapaça, macho).

Ocorrência. Abundante, nas amostras MP-1449, MP-1450, MP-1451, MP-1452, MP-1453, MP-1456, MP-1457, MP-1459 (afloramento Penha), MP-1550, MP-1551, MP-1552, MP1553, MP-1554, MP-1555, MP-1556, MP-1557, MP-1558, MP-1559, MP-1560, MP-1561, MP-1562, MP-1563, MP-1564, MP-1565, MP-1566, MP-1567, MP-1568, MP-1569, MP1570, MP-1571, MP-1572, MP-1573, MP-1574, MP-1575, MP-1576, MP-1578, MP-1680, MP-1694, MP-1695, MP-1696, MP-1697 e MP-1698 (afloramento São José 1), Município de Riachuelo; também nas profundidades de 348, 348.5 e 364.5m na perfuração 1-CPB-1, Carmópolis; e 951, 1146 e 1200m na perfuração 1-US-1, Município de Laranjeiras; Estado de Sergipe, Brasil.

Medidas. Comprimento $=0.65 \mathrm{~mm}$, altura $=0.35 \mathrm{~mm}$, largura $=0.31 \mathrm{~mm}$.

Discussão. A identificação segue Do Carmo et al. (2012).

Distribuição geográfica e estratigráfica. Formação São Mateus, bacia do Espírito Santo, Albiano (Piovesan et al., 2013); Formação Riachuelo, bacia de Sergipe-Alagoas, Albiano inferior-médio (Do Carmo et al., 2012); no presente trabalho, restrita ao Membro Taquari da formação mencionada e reposicionada no Aptiano superior-Albiano inferior, Zona Aracajuia benderi (MSA-0), subzonas Harbinia sinuata? (MSA-0.1) e Sergipella viviersae (MSA-0.2); Brasil.

\subsection{BIOESTRATIGRAFIA DO APTIANO SUPERIOR-ALBIANO DA FORMAÇÃO RIACHUELO}

O primeiro zoneamento do Andar Albiano na bacia de Sergipe-Alagoas foi proposto por Beurlen (1968), com base em cefalópodes. Este foi seguido por Schaller (1969) e Koutsoukos \& Bengtson (1993), os quais integraram à bioestratigrafia de cefalópodes os zoneamentos baseados em foraminíferos planctônicos e bentônicos. O primeiro arcabouço bioestratigráfico do Albiano baseado em ostracodes foi proposto somente por Viviers et al. (2000), porém já integrado àqueles mencionados acima. Cabe mencionar ainda Troelsen \& Quadros (1971), cujo zoneamento baseado em nanofósseis calcários jamais foi comparado aos demais com fins de unificação na literatura. Nenhum destes zoneamentos, todavia, menciona as análises litoestratigráficas de supersequências de Mendes (1994).

Segundo Viviers et al. (2000), o Aptiano superior-Albiano da bacia de Sergipe-Alagoas compreende uma biozona de amplitude, a Zona Amphicytherura benderi (OSE-1), mais tarde renomeada Aracajuia benderi (Antonietto et al., 2013a). Esta zona foi subdividida em seis subzonas do tipo diferencial superior, da base para o topo: Pattersoncypris ex. gr. angulata 
(Krömmelbein \& Weber 1971) (OSE-1.1), Sergipella transatlantica (OSE-1.2), rebatizada como Sergipella viviersae Do Carmo et al., 2012 (Do Carmo et al., 2012), 'Patellacythere' sp. GA E 27 (OSE-1.3), Veenia guianensis Swain, 1976 (OSE-1.4), Metacytheropteron aff. M. sp. GA C 24 (OSE-1.5) e Amphicytherura benderi (OSE-1.6), também Aracajuia benderi após Antonietto et al. (2013a). Entre as subzonas OSE-1.3 e OSE-1.4, há um intervalo em que não foi possível estabelecer zoneamento com base em ostracodes, mesmo observando-se transição de faunas de foraminíferos planctônicos (término da Zona Ticinella bejaouensis, Subzona Ticinella bejaouensis), foraminíferos bentônicos (fim da Zona Epistomina carpenteri, Subzona Osangularia schloenbachi-Pseudogaudryinella/Spiroplectinata ex gr. dividens) e cefalópodes (término da Zona Douvilleiceras) (Figura 4).

Na presente revisão da bioestratigrafia do Albiano da bacia de Sergipe-Alagoas (anexo III), os diversos afloramentos foram correlacionados ao das perfurações utilizadas na proposição original de Viviers et al. (2000) (fig. 12A), tomando-se por base a distribuição das espécies guia ao longo das seções analisadas e eventos de extinção ou desaparecimento local. Além da integração bioestratigráfica, os afloramentos e perfurações foram perfilados e correlacionados espacialmente com base no novo zoneamento proposto (fig. 12B). Com base nessa seção esquemática, mudanças na distribuição das espécies guia por unidade litológica da Formação Riachuelo são propostas. Embora as zonas e subzonas identificadas apresentem relativa continuidade ao longo dos pontos analisados, discordâncias baseadas na presença/ausência de determinadas subzonas eventualmente ocorrem entre as mesmas, particularmente nas perfurações 7-CP-252 (Subzona MSA-1 para Subzona MSA-3; ausência de MSA-0.2) e 1-US-1 (Subzona MSA-0.2 para Subzona MSA-0.5; ausência de MSA-0.3 e MSA-0.4). O motivo mais provável para a existência desses hiatos bioestratigráficos é o tectonismo, causador da erosão desses níveis do perfil.

\subsubsection{Revisão bioestratigráfica da Zona Aracajuia benderi (OSE-1)}

Várias alterações foram realizadas na zona de ostracodes que marca o Albiano da bacia de Sergipe-Alagoas, OSE-1 e suas subzonas, e uma nova zona foi criada, MSA-1, no Albiano mais superior desta zona (fig. 13). A espécie guia da Zona OSE-1, Amphicytherura benderi, foi renomeada Aracajuia benderi, seguindo revisão proposta por Antonietto et al. (2013a), e código da zona foi alterado para MSA-0. A Subzona OSE-1.1, nomeada e estabelecida com base na espécie Pattersoncypris ex. gr. angulata, foi alterada para Harbinia sinuata? (Krömmelbein \& Weber, 1971), e o código para MSA-0.1. Esta mudança foi motivada pela abundância de espécimes desta espécie nas amostras revisadas das perfurações 1-CPB-1 e 7- 


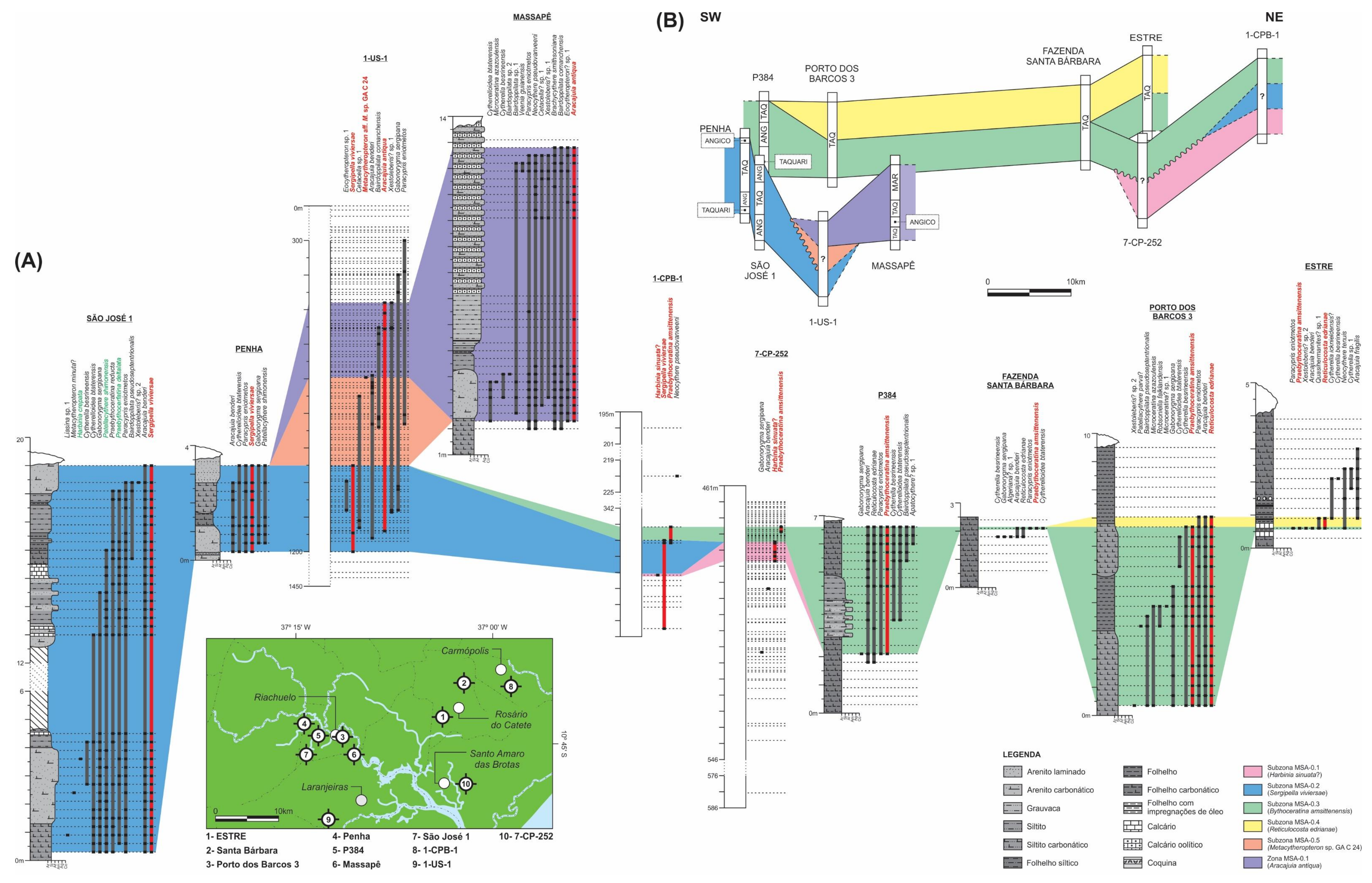

Figura 12. Correlação (A) e seção esquemática bioestratigráfica (B) da Formação Riachuelo nos afloramentos e perfuraçães estudados no presente trabalho, bacia de Sergipe-Alagoas, Nordeste do Brasil. 

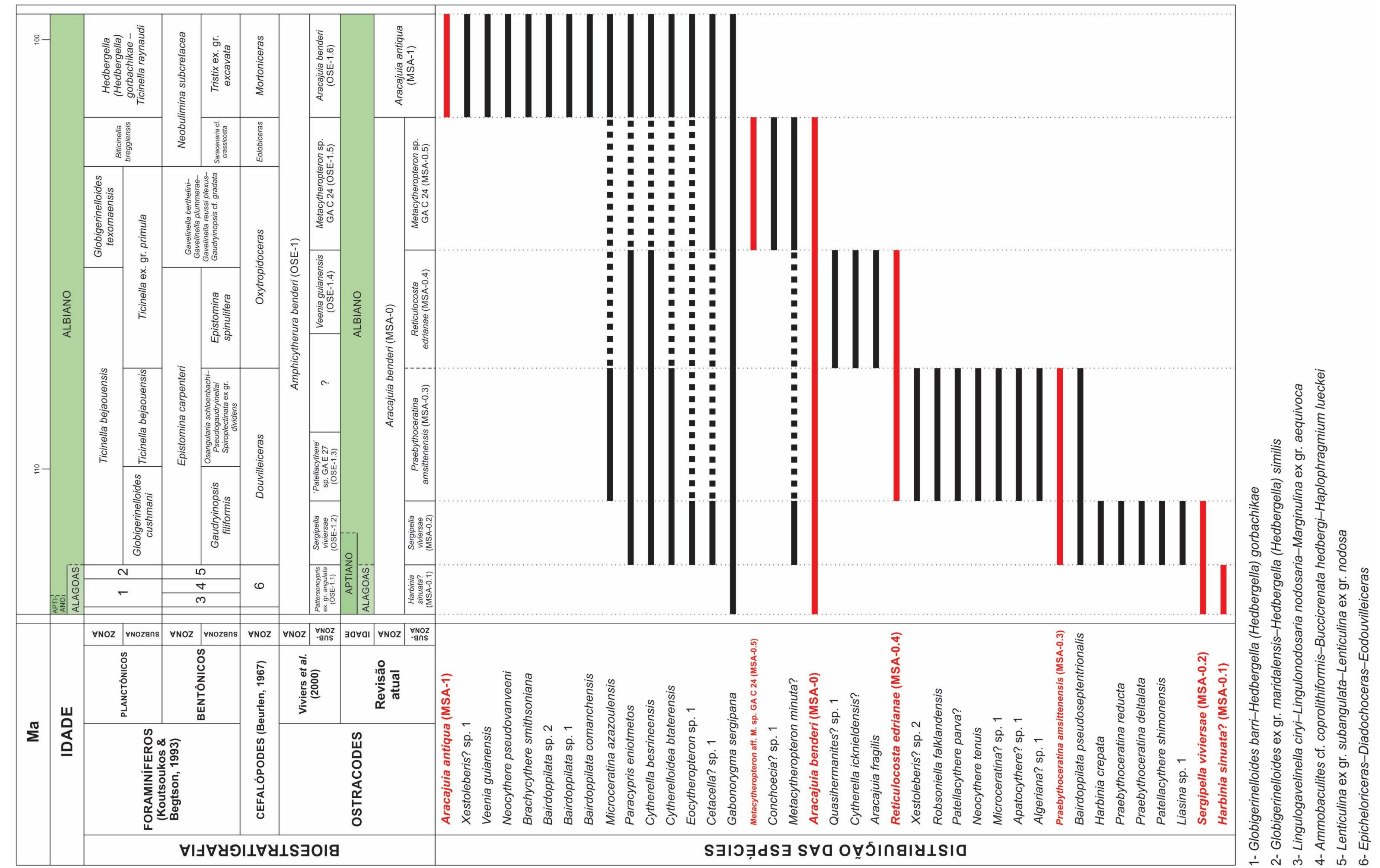

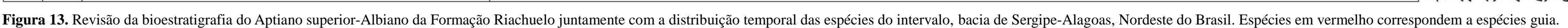


CP-252, em comparação à anteriormente designada (o qual não foi observado durante a presente revisão). O código da Subzona OSE-1.2 mudou para MSA-0.2, um estratótipo foi estabelecido para a mesma e seu limite inferior foi reposicionado do Albiano inferior para o Aptiano superior.

A espécie a partir da qual a Subzona OSE-1.3, agora MSA-0.3, é nomeada em Viviers et al. (2000), 'Patellacythere' sp. GA E 27 - a partir de Grosdidier (1979) -, foi amplamente reestudada, e parte dos espécimes reclassificados como Praebythoceratina amsittenensis, aqui considerada como guia para MSA-0.3. Entre as subzonas MSA-0.3 e MSA-0.4, Viviers et al. (2000) observaram um intervalo aberto, não zoneável, devido à ausência de espécies marcadoras. O presente trabalho estabelece o contato entre estas duas subzonas junto aos limites de zona definidos através do estudo de foraminíferos e cefalópodes, ou seja, as transições entre Ticinella bejaouensis e Ticinella ex. gr. primula (foraminíferos planctônicos), Osangularia schloenbachi-Pseudogaudryinella/Spiroplectinata ex gr. dividens e Epistomina spinulifera (foraminíferos bentônicos) e Oxytropidoceras e Douvilleiceras (cefalópodes).

Os exemplares identificados como Veenia guianensis, espécie guia para a Subzona OSE-1.4, recodificada MSA-0.4, pertencem a Reticulocosta edrianae, o que acarreta na mudança de nome desta subzona de Veenia guianensis para Reticulocosta edrianae. A Subzona OSE-1.5 foi apenas recodificada para MSA-0.5, porém não redescrita, uma vez que seus limites inferior e superior não foram observados simultaneamente em nenhuma das localidades estudadas. Indivíduos anteriormente considerados Aracajuia benderi na Subzona OSE-1.6, no topo da Zona OSE-1, foram reclassificados como Aracajuia antiqua. Assim, uma nova zona diferencial superior é criada no Albiano superior daFormação Riachuelo. Esta zona é nomeada Aracajuia antiqua, seguindo a espécie que marca a mesma, e codificada como MSA-1.

\section{ZONA DE AMPLITUDE ARACAJUIA BENDERI (MSA-0)}

Definição. Limites inferior e superior da subzona definidos respectivamente pela primeira e última ocorrências de Aracajuia benderi.

Caracterização. Da base para o topo, as seguintes subzonas são reconhecidas: Harbinia sinuata? (MSA-0.1), Sergipella viviersae (MSA-0.2), Praebythoceratina amsittenensis (MSA-0.3), Reticulocosta edrianae (MSA-0.4) e Metacytheropteron aff. M. sp. GA C 24 (MSA-0.5).

Andar. Aptiano superior-Albiano superior.

Estratótipo. Perfuração 1-US-1, Município de Laranjeiras, Estado de Sergipe, Brasil. 
Observações. Uma discussão detalhada da Zona MSA-0 pode ser encontrada em Viviers et al. (2000). O presente trabalho formaliza as mudanças taxonômicas feitas em MSA-0 por Antonietto et al. (2013a). O estratótipo da zona também é aqui proposto.

\section{SUBZONA DE AMPLITUDE HARBINIA SINUATA? (MSA-0.1)}

Definição. Limites inferior e superior da subzona definidos respectivamente pela primeira e última ocorrências de Harbinia sinuata?.

Caracterização. Intervalo contendo uma associação característica de Harbinia sinuata, Aracajuia benderi, Sergipella viviersae e Gabonorygma sergipana.

Estratótipo. Perfuração 7-CP-252, entre as profundidades de 478.45 e 484.4m, Município de Santo Amaro das Brotas, Estado de Sergipe, Brasil.

Andar. Aptiano superior.

Observações. Uma discussão detalhada da Subzona MSA-0.1, ainda com a nomenclatura antiga, pode ser encontrada em Viviers et al. (2000). Esta subzona foi nomeada e estabelecida usando Pattersoncypris ex gr. angulata como fóssil guia. Entretanto, Harbinia sinuata? é mais abundante nas amostras estudadas (incluindo as de perfurações revisadas), o que justifica a preferência pela mesma como marcador para o interval. Um estratótipo também é proposto para a subzona pela primeira vez. Várias espécies da zona em Viviers et al. (2000), tais como Ovocytheridea? aff. Ovocytheridea? Sp. GA D 6, Pattersoncypris ex gr. angulata e Conchoecia? sp. Se1, não foram observadas na presente revisão.

\section{SUBZONA DIFERENCIAL SUPERIOR SERGIPELLA VIVIERSAE (MSA-0.2)}

Definição. Limites inferior e superior da subzona definidos respectivamente pelas últimas ocorrências de Harbinia sinuata? e Sergipella viviersae.

Caracterização. Outras espécies observadas nesta zona incluem Cytherella besrineensis, Cytherelloidea btaterensis, Bairdoppilata pseudoseptentrionalis, Cetacella sp. 1, Paracypris eniotmetos, Harbinia crepata, Liasina sp. 1, Praebythoceratina amsittenensis, Praebythoceratina deltalata, Praebythoceratina reducta, Patellacythere shimonensis, Xestoleberis? sp. 1, Xestoleberis? sp. 2, Gabonorygma sergipana, Aracajuia antiqua, Aracajuia benderi, Eocytheropteron sp. 1, Metacytheropteron aff. M. sp. GA C 24 e Metacytheropteron minuta?.

Estratótipo. Perfuração 1-CPB-1, entre as profundidades de 348 e 354.5m, Município de Carmópolis, Estado de Sergipe, Brasil.

Andar. Aptiano superior-Albiano inferior. 
Observações. Uma discussão detalhada da Subzona MSA-0.2 pode ser encontrada em Viviers et al. (2000). O presente trabalho formaliza a mudanças taxonômicas em Do Carmo et al. (2012) da espécie tida como espécie guia de MSA-0.2, ao mesmo tempo em que designa um estratótipo para esta subzona. Originalmente, esta subzona era restrita ao Membro Taquari; todavia, no presente trabalho, a mesma também ocorre em sedimentos do Membro Angico. A presença de Harbinia crepata, espécie característica do Aptiano do Brasil (Do Carmo et al., 2013), na porção inferior dessa subzona, associada a outras espécies com aparecimento no Aptiano (Cytherella besrineensis, Cytherelloidea btaterensis, Patellacythere shimonensis e Aracajuia benderi) (Bischoff, 1964; Swain, 1976; Rosenfeld \& Raab, 1983; Viviers et al., 2000), motivou no presente trabalho o reposicionamento do limite inferior dessa subzona, do Albiano inferior para o Aptiano superior. Conchoecia? sp. Se1, não foi observada na Subzona MSA-0.2 na presente revisão.

\section{SUBZONA DIFERENCIAL SUPERIOR PRAEBYTHOCERATINA AMSITTENENSIS (MSA-}

Definição. Limites inferior e superior da subzona definidos respectivamente pelas últimas ocorrências de Sergipella viviersae e Praebythoceratina amsittenensis.

Caracterização. A assemblagem de ostracodes da subzona compreende também Cytherella besrineensis, Cytherelloidea btaterensis, Bairdoppilata pseudoseptentrionalis, Robsoniella falklandensis, Paracypris eniotmetos, Praebythoceratina amsittenensis, Patellacythere parva?, Xestoleberis? sp. 2, Apatocythere? sp. 1, Gabonorygma sergipana, Neocythere tenuis, Aracajuia benderi, Microceratina azazoulensis, Microceratina? sp. 1, Reticulocosta edrianae, Algeriana? sp. 1 e Quasihermanites? sp. 1.

Estratótipo. Perfuração 1-CPB-1, entre as profundidades de 345.5 e $348.5 \mathrm{~m}$, Município de Carmópolis, Estado de Sergipe, Brasil.

Andar. Albiano inferior-médio.

Observações. A espécie que originalmente nomeou esta subzona, 'Patellacythere' sp. GA E 27, de fato representa um grupo de espécies da Família Bythocytheridae. O espécime figurado em Viviers et al. (2000) foi reclassificado como Patellacythere shimonensis, uma espécie restrita a MSA-0.2. A maioria do material atribuído a 'Patellacythere' sp. GA E 27, de fato, pertence a outro táxon, Praebythoceratina amsittenensis, particularmente aqueles observados nas amostras acima de MSA-0.2. Portanto, Praebythoceratina amsittenensis é considerada o verdadeiro marcador de MSA-0.3. Uma discussão detalhada da Subzona MSA-0.3, ainda com a nomenclatura antiga, pode ser encontrada em Viviers et al. (2000). Originalmente, esta 
subzona era restrita ao Membro Angico; todavia, no presente trabalho, a mesma também ocorre em estratos do Membro Taquari. Entre as espécies do trabalho mencionado acima não observadas em MSA-0.3 durante a presente revisão, encontram-se Cytherella sp. Se4, Liasina sp. 1, Veenia guianensis, Sergipella aff. transatlantica, Cetacella aff. C. sp. GA D 24 e Metacytheropteron aff. M. sp. GA C 24.

\section{SUBZONA DIFERENCIAL SUPERIOR RETICULOCOSTA EDRIANAE (MSA-0.4)}

Definição. Limites inferior e superior da subzona definidos respectivamente pelas últimas ocorrências de Praebythoceratina amsittenensis e Reticulocosta edrianae.

Caracterização. A assemblagem desta subzona também inclui Cytherella icknieldensis?, Paracypris eniotmetos, Neocythere tenuis, Aracajuia benderi e Aracajuia fragilis.

Estratótipo. Afloramento Porto dos Barcos $3(699059$ N, 8814030 E, quadrante de referência UTM 24L, sistema padrão SAD69), entre 6.7 e 7m acima da base, Município de Riachuelo, Estado de Sergipe, Brasil.

Andar. Albiano médio.

Observações. Os espécimes identificados como Veenia guianensis, espécie guia de MSA-0.4, pertencem a Reticulocosta edrianae, o que acarreta mudança de nome desta subzona. Entretanto, espécimes de Veenia guianensis, agora Veenia guianensis, também foram encontrados no presente material, embora não associadas com Reticulocosta edrianae. Entre as subzonas MSA-0.3 e MSA-0.4, Viviers et al. (2000) observaram uma ausência de qualquer espécie marcadora de biozona, e o intervalo entre aquelas foi deixado em dúvida. O presente trabalho estabelece o contato entre as duas zonas, embora não seja possível determinar o tempo relativo em que o mesmo ocorreu. Portanto, opta-se por estabelecê-lo com dúvidas junto ao topo das zonas Ticinella bejaouaensis (A12), de foraminíferos planctônicos, e Douvilleiceras, de cefalópodes. Uma discussão detalhada da Subzona MSA-0.4 pode ser encontrada em Viviers et al. (2000). Originalmente, não foi informado em quais membros da Formação Riachuelo a subzona ocorreu; no presente trabalho, a mesma foi observada em sedimentos dos membros Angico e Taquari. Ovocytheridea? sp. Se1 de Viviers et al. (2000) não foi observada na presente revisão.

\section{ZONA DIFERENCIAL SUPERIOR ARACAJUIA ANTIQUA (MSA-1)}

Definição. Limite inferior da subzona definido pelas últimas ocorrências de Aracajuia benderi e Metacytheropteron aff. $M$. sp. GA C 24, e superior pela última ocorrência de Aracajuia antiqua. 
Caracterização. A Zona MSA-1 se estende através das áreas próximas ao afloramento Massapê e à perfuração 1-US-1, entre as cidades de Riachuelo e Laranjeiras, Estado de Sergipe, Brasil. É observável no afloramento Massapê em todos os três membros da Formação Riachuelo. Sua espessura varia entre 11 (afloramento Massapê) e quase 300m de espessura (perfuração 1-US-1). Outros táxons presentes nesta zona incluem Cytherella besrineensis, Cytherelloidea btaterensis, Bairdoppilata comanchensis, Bairdoppilata sp. 1, Bairdoppilata sp. 2, Cetacella sp. 1, Paracypris eniotmetos, Xestoleberis? sp. 1, Gabonorygma sergipana, Neocythere pseudovanveeni, Aracajuia benderi, Eocytheropteron? sp. 1, Microceratina azazoulensis, Veenia guianensis e Brachycythere smithsoniana.

Estratótipo. Perfuração 1-US-1, entre as profundidades de 480 e 681m, Município de Laranjeiras, Estado de Sergipe, Brasil.

Idade. Albiano mais superior.

Observações. Os espécimes anteriormente considerados Aracajuia benderi na Subzona OSE1.6, porção superior de MSA-0, foram reclassificados no presente trabalho como Aracajuia antiqua, criando uma zona completamente nova no Albiano mais superior da Formação Riachuelo, a Zona Diferencial Superior Aracajuia antiqua, após sua espécie guia, e codificada como MSA-1. Apesar do limite inferior da zona ser estabelecido com base em duas espécies, Aracajuia benderi e Metacytheropteron aff. $M$. sp. GA C 24, estas desaparecem do registro fóssil em 1-US-1 no decorrer de um curto intervalo cronoestratigráfico. Em Viviers et al. (2000), não foi informado em quais membros da Formação Riachuelo esta unidade ocorreu; no presente trabalho, a mesma foi observada em sedimentos do membros Angico, Taquari e Maruim.

\subsection{PALEOZOOGEOGRAFIA DO ALBIANO-EOCENOMANIANO DO PROTO- OCEANO ATLÂNTICO}

Tentativas anteriores de estabelecer relações faunísticas entre a ostracodofauna do Albiano da bacia de Sergipe-Alagoas e litologias coevas da África ocidental indicaram grande similaridade entre as formações Riachuelo e Madiéla, da bacia do Gabão, Gabão (Krömmelbein, 1966a, b, 1975; Krömmelbein \& Wenger, 1966; Bertels, 1977; Grosdidier, 1979; Koutsoukos \& Silva-Telles, Jr., 1993). Tambareau (1982) chegou a sugerir a existência de uma bioprovíncia "Brasil-África Central ocidental". Essa correlação foi posteriormente expandida por Koutsoukos \& Dias-Britto (1987) e Piovesan et al. (2013), ao observar a coocorrência de espécies e gêneros de ostracodes da Formação Riachuelo em outras bacias da costa brasileira, como as de Campos, Santos e Potiguar. 
A primeira evidência de similaridade faunística entre a Formação Riachuelo e estratos fora do centro do proto-oceano Atlântico Sul foi fornecida por Colin \& Andreu (1990), ao estudar ostracodes halocypridídeos. Estes observaram que as formações no Brasil e na África ocidental estão fortemente correlacionadas às do oceano Atlântico Norte, por exemplo na bacia de Agadir, Marrocos (Andreu-Boussut, 1991), a região do Jura, Suíça (Charollais et al., 1977), o sul da Inglaterra (Kaye, 1965), o golfo Pérsico e Israel (Rosenfeld \& Raab, 1983). Estas observações foram corroboradas em parte por Piovesan et al. (2013), seguindo revisão de Andreu (2002), o qual identificou alguns gêneros distribuídos ao longo da costa brasileira (incluindo a bacia de Sergipe-Alagoas) e no Marrocos.

Dias-Brito (2000), com base na ocorrência de pitonelídeos (calcisferas), estabeleceu a conceito de "Megatétis", ou "domínio Tetiano mesocretáceo". De acordo com aquele conceito, a distribuição global de pitonelídeos define uma província ecológica ocupando ambos os hemisférios, aproximadamente entre as latitudes $40^{\circ} \mathrm{N}$ e $40^{\circ} \mathrm{S}$, durante o AlbianoTuroniano. Este oceano de Megatétis atingiu sua máxima extensão no final do Albiano, quando águas tropicais alcançaram regiões temperadas de alta latitude, onde organismos tropicais inicialmente se estabeleceram durante breves incursões. O limite sul deste domínio no proto-oceano Atlântico Sul coincidiu com a cordilheira Walvis, uma barreira topográfica de baixa altitude, porém eficaz nesse momento.

Reyment (1980) e Dingle (1999) analisaram o papel da cordilheira de Walvis como barreira geográfica entre os ostracodofaunas das regiões central e meridional do proto-oceano Atlântico Sul durante o Berriasiano-Santoniano. Após revisão taxonômica de vários andares do Cretáceo da bacia de Sergipe-Alagoas, Viviers et al. (2000) sumarizaram as relações da Formação Riachuelo com estratos em vários domínios neocretáceos ao longo do proto-oceano Atlântico. Estas correlações foram feitas com base nas distribuições cronológica e geográfica dos gêneros Conchoecia, Amphicytherura e Veenia. Aproximadamente no Mesocenomaniano, foi registrada significativa renovação faunística, com a primeira aparição na bacia de gêneros como Brachycythere e Paracypris Sars, 1866.

Os resultados do presente trabalho corroboram análises prévias sobre a paleozoogeografia dos ostracodes da Formação Riachuelo, tanto em nível de espécie quanto de gênero (fig. 14, anexos III e VI). Embora a maioria das espécies identificadas fosse endêmica da Província Brasil-África Ocidental Central, algum intercâmbio foi observado com faunas tethyanas mais ao norte durante todo o Albiano (fig. 14A-C), como detalhado nas subseções "distribuição geográfica e estratigráfica" ao longo da seção "Taxonomia" do presente trabalho. Espécies como Veenia guianensis e Bairdoppilata comanchensis coocorreram em 
regiões norte e centro-americanas (Veenia guianensis também é encontrada na África), enquanto Conchoecia? sp. 1, Cytherella besrineensis, Cytherelloidea btaterensis, Praebythoceratina amsittenensis, Patellacythere shimonensis e Aracajuia antiqua (Rosenfeld\& Raab, 1983) apareceram tanto no Brasil-África Central Ocidental quanto na região do Levante no Oriente Médio (Israel e Líbano). Bairdoppilata pseudoseptentrionalis, Praebythoceratina reducta, Neocythere pseudovanveeni e Neocythere tenuis coocorreram na Formação Riachuelo e bacias europeias na Inglaterra, França e Alemanha.

A mudança faunística observada após a transição da Zona MSA-0 para a Zona MSA-1, no Albiano mais superior da Formação Riachuelo, não afetou o intercâmbio dentro de Megatétis. Novas espécies compartilhadas durante este intervalo com regiões mais ao norte incluíram Neocythere pseudovanveeni, Bairdoppilata comanchensis, Aracajuia antiqua e Veenia guianensis (fig. 14C). Apenas no Eocenomaniano observou-se coocorrências entre asporções central e austral do proto-oceano Atlântico. As duas espécies em comum com domínios ao sul da cordilheira Walvis, Microceratina azazoulensis e Robsoniella falklandensis, provavelmente se originaram durante o Mesoalbiano no Brasil- África Central Ocidental (fig. 14B-C), posteriormente se expandindo para outras áreas ao longo do Cenomaniano (fig. 14D).

O intercâmbio de gêneros entre as províncias durante o Albiano parece seguir o mesmo padrão observado em nível de espécie. Gêneros como Cytherella, Cytherelloidea, Bairdoppilata, Paracypris, Bythoceratina Hornibrook, 1952 e Patellacythere foram geografica e cronologicamente cosmopolitas. Entretanto, outros apresentam uma distribuição mais limitada, pelo menos durante o Eocretáceo, e parecem indicar, considerando a origem dos mesmos, maior proximidade paleozoogeográfica do proto-oceano Atlântico Central com domínios tetianos. Estes gêneros incluíram Gabonorygma (Christensen, 1965), Neocythere, Veenia Butler \& Jones, 1957, Reticulocosta, Robsoniella (Gramm \& Kuznetsova, 1970) e Microceratina (Colin et al., 2005). Sergipella foi o único gênero endêmico da região, de acordo com as ocorrências resumidas em Do Carmo et al. (2012).

O Gênero Brachycythere parece ter se originado durante o Albiano, em algum lugar do domínio tetiano as costas da África do Norte e da América do Norte (Colin \& Babinot, 1996; Puckett, 2002), embora ocorrências da mesma idade também tenham sido relatadas na Índia (Andreu et al., 2008). A presença de Brachycythere smithsoniana na Província Brasil-África Ocidental Central no Neoaptiano (Grosdidier, 1979), foi significantemente anterior a Brachycythere sapucariensis, o mais antigo registro desse grupo na província até então (Cenomaniano) (Viviers et al., 2000). Por esse motivo, a origem da Subfamília 

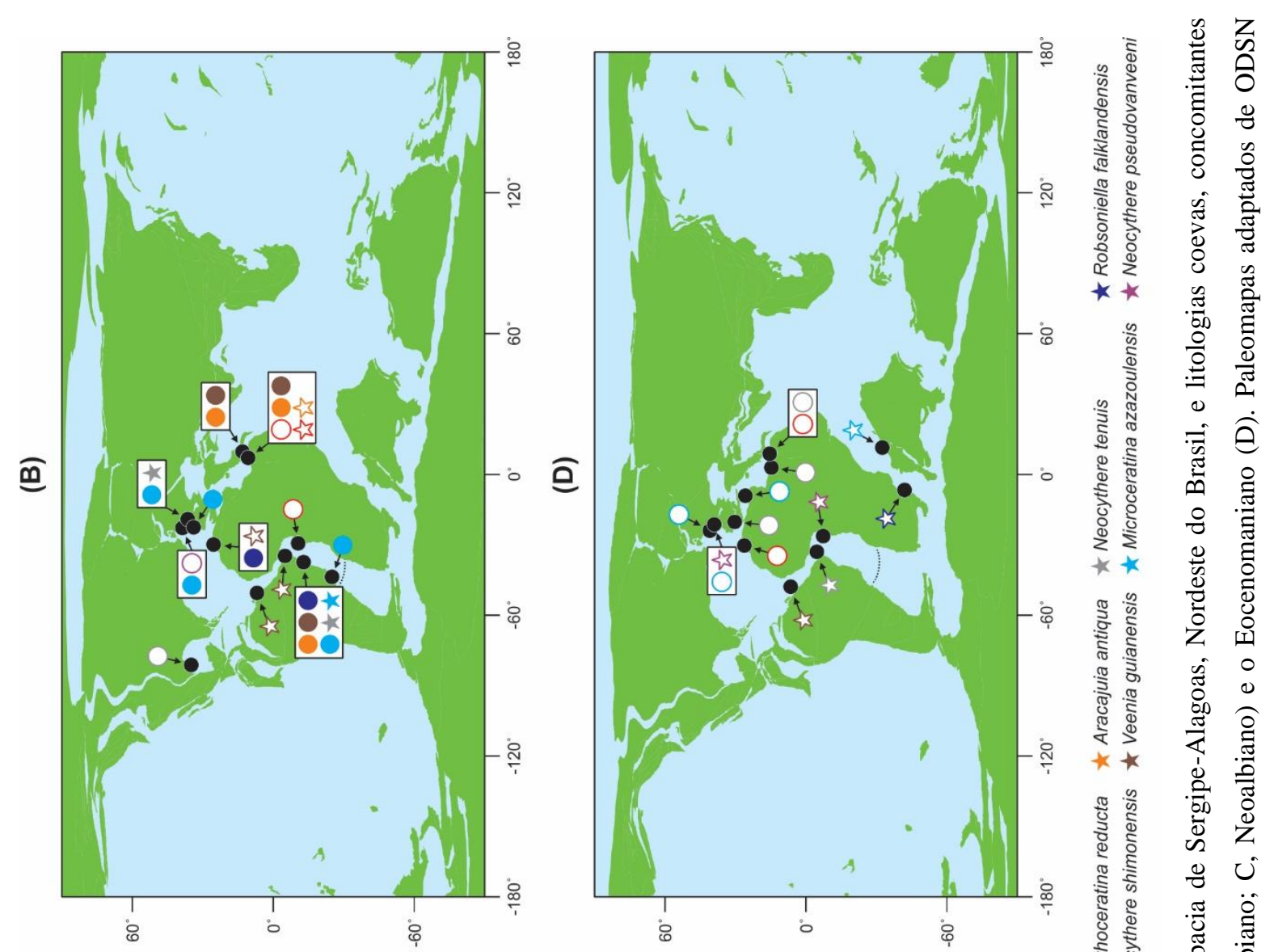

$* *$

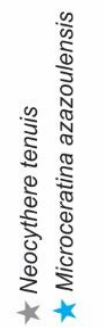

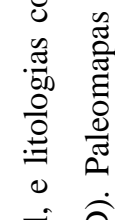

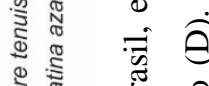

จุ कूँ

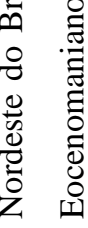

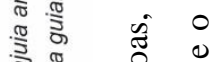

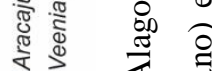

$* \star$

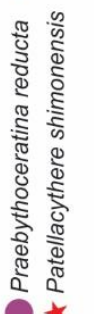

范

すั

蛋 च
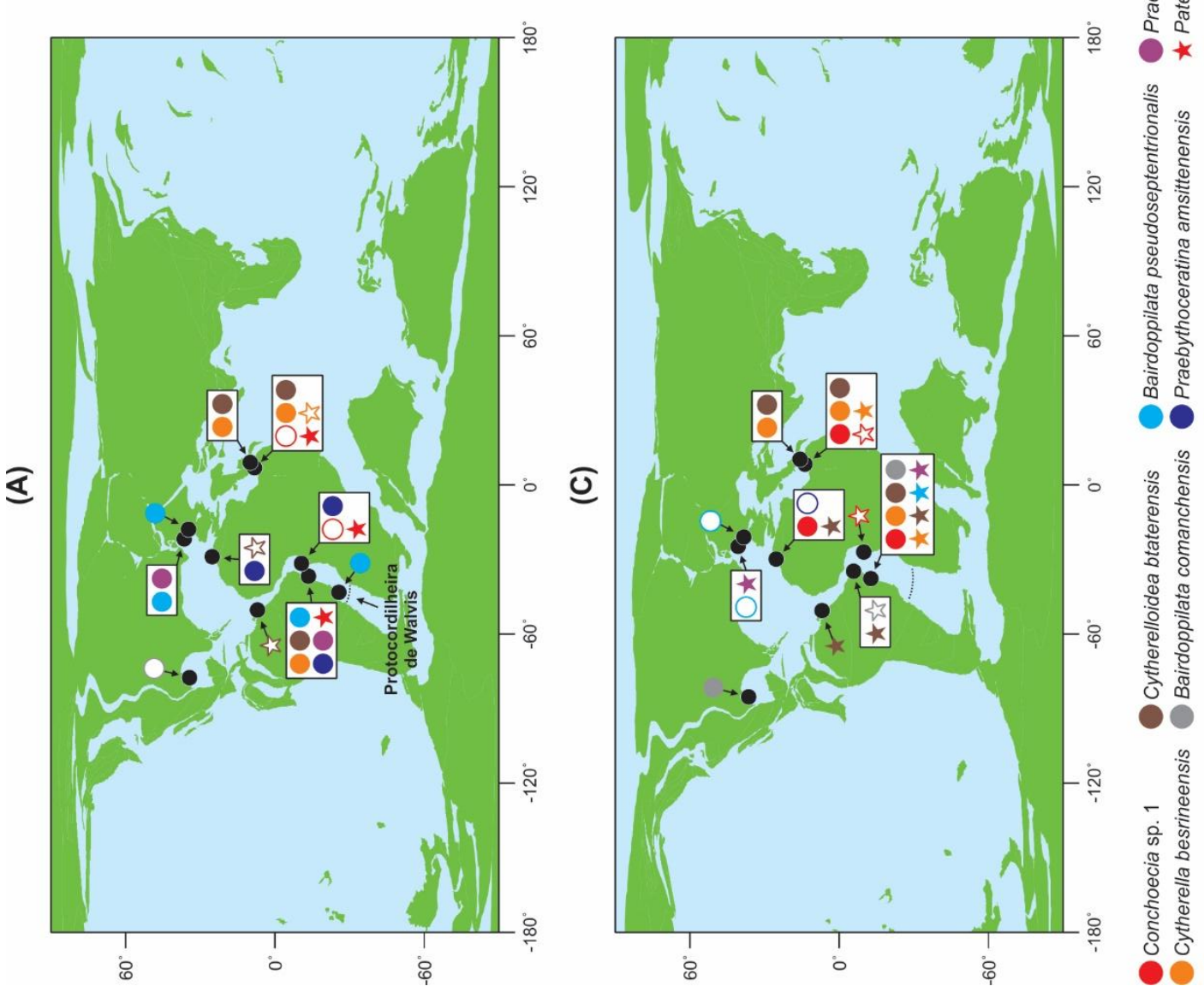

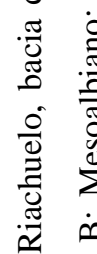

幽

范

苛

$\Xi$

苞

离

ป

包

范

융

恶

\&

¿

के

ذ̇

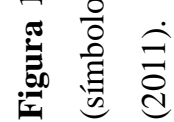




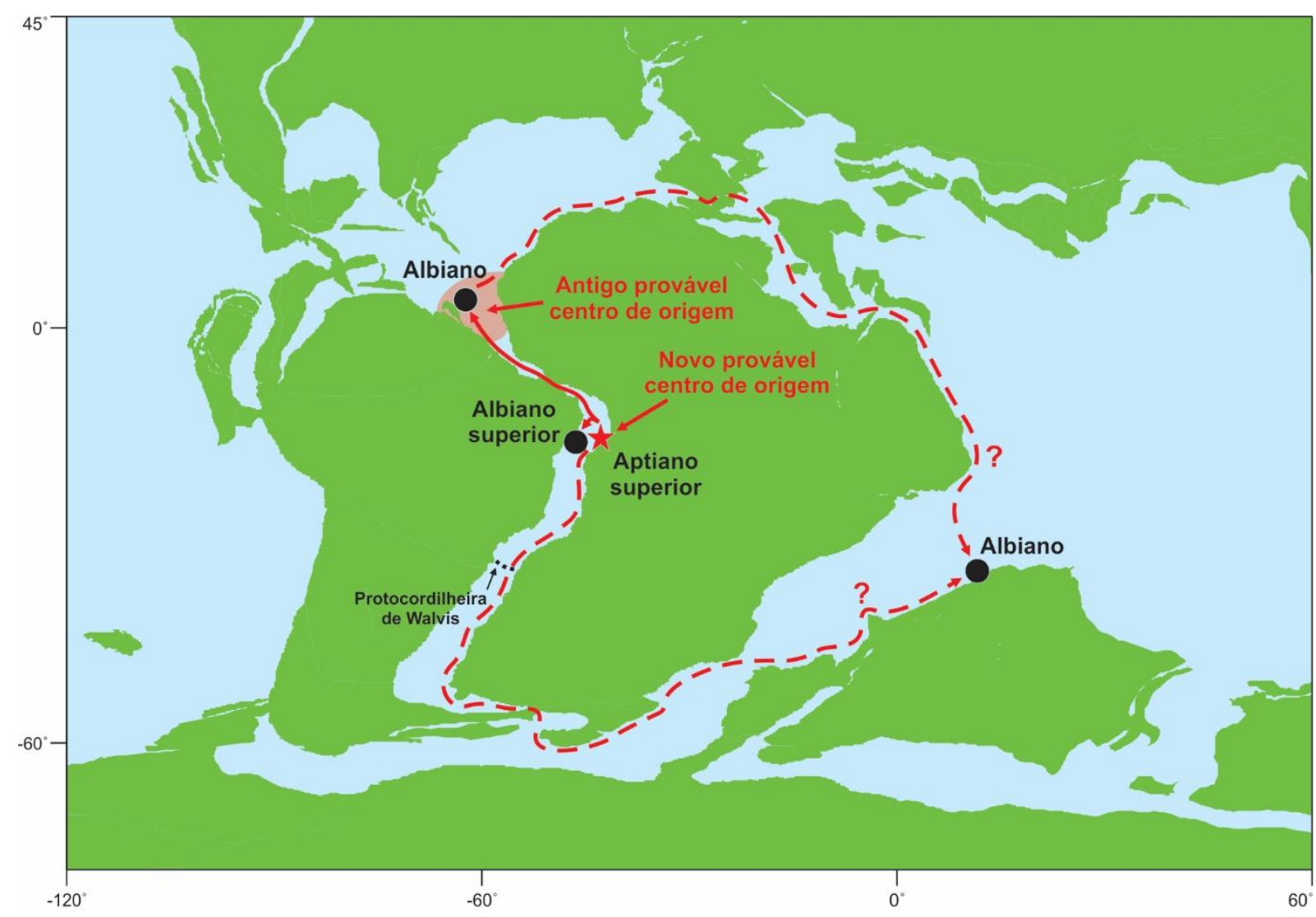

Figura 15. Distribuição estratigráfica e paleozoogeografia da Subfamília Brachycytherinae Puri, 1954, desde sua possível origem no Neoaptiano até o fim do Albiano. Linhas cheias indicam rotas prováveis de dispersão, enquanto as tracejadas representam rotas possíveis. Paleomapa adaptado de ODSN (2011).

Brachycytherinae Puri, 1954 é alterada geográfica e cronologicamente em direção a sul, ou seja, na Província Brasil-África Ocidental Central durante o Neoaptiano (fig. 15). Estes novos dados ajudam a explicar as ocorrências do grupo tanto no domínio Austral quanto no Tetiano durante o Albiano.

Segundo Dingle (1999), influxos limitados de ostracodes marinhos em direção a norte através da cordilheira de Walvis ocorreram durante o Mesoaptiano, enquanto grandes migrações para sul a partir do proto-oceano Atlântico Central foram registradas no Eocenomaniano-Turoniano. Esta observação é confirmada pelas ocorrências de Aracajuia no Neoalagoas-Neoalbiano da bacia de Sergipe-Alagoas (Antonietto et al., 2013a, b). Os registros mais antigos de Aracajuia são da África do Sul, possivelmente do Tithoniano da região de Knysna (Dingle, 1984). Até o final do Valanginiano (Berriasiano?), o gênero se espalhou para a bacia de Neuquén, Argentina, estando ainda presente nas bacias de Algoa e Outeniqua da África do Sul. Aracajuia ocorreu na bacia de Neuquén até o final do Hauteriviano (Eobarremiano?) (Dingle, 1969; Brenner \& Oertli, 1976; McLachlan et al., 1976; Musacchio, 1978; Valicenti \& Stephens, 1984; Musacchio \& Simeoni, 2008) (fig. 
$16 \mathrm{~A})$.

A partir do Eoaptiano, Aracajuia espalhou-se para o Marrocos (bacias Essaouira e Middle High Atlas) (Andreu-Boussut, 1991; Andreu, 1992), possivelmente a partir da Argentina. O gênero, então, passou por um evento de especiação, o que resultou no Albiano em diversas novas espécies ocorrendo ao longo das costas sul-americana, africana, levantina e

(A)

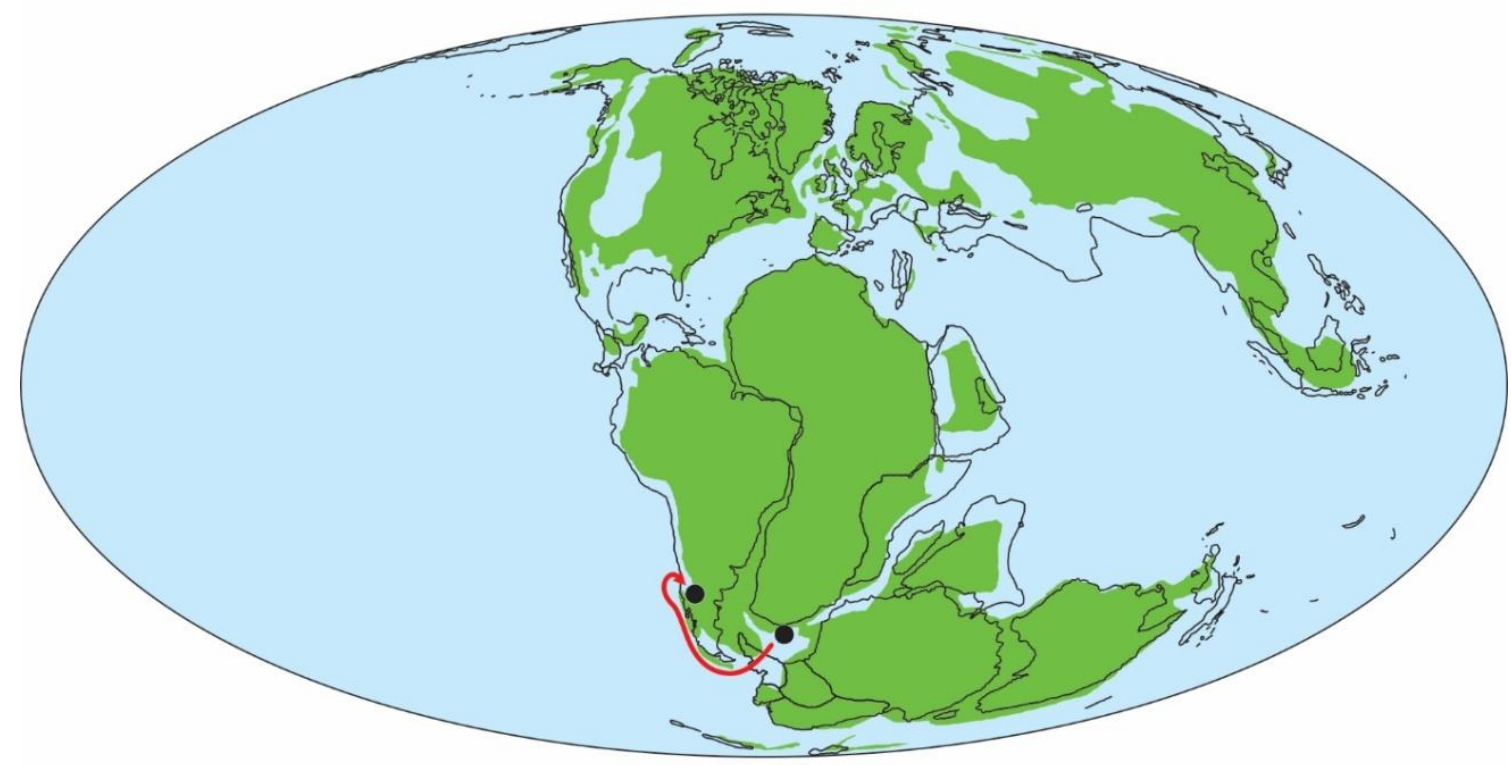

(B)

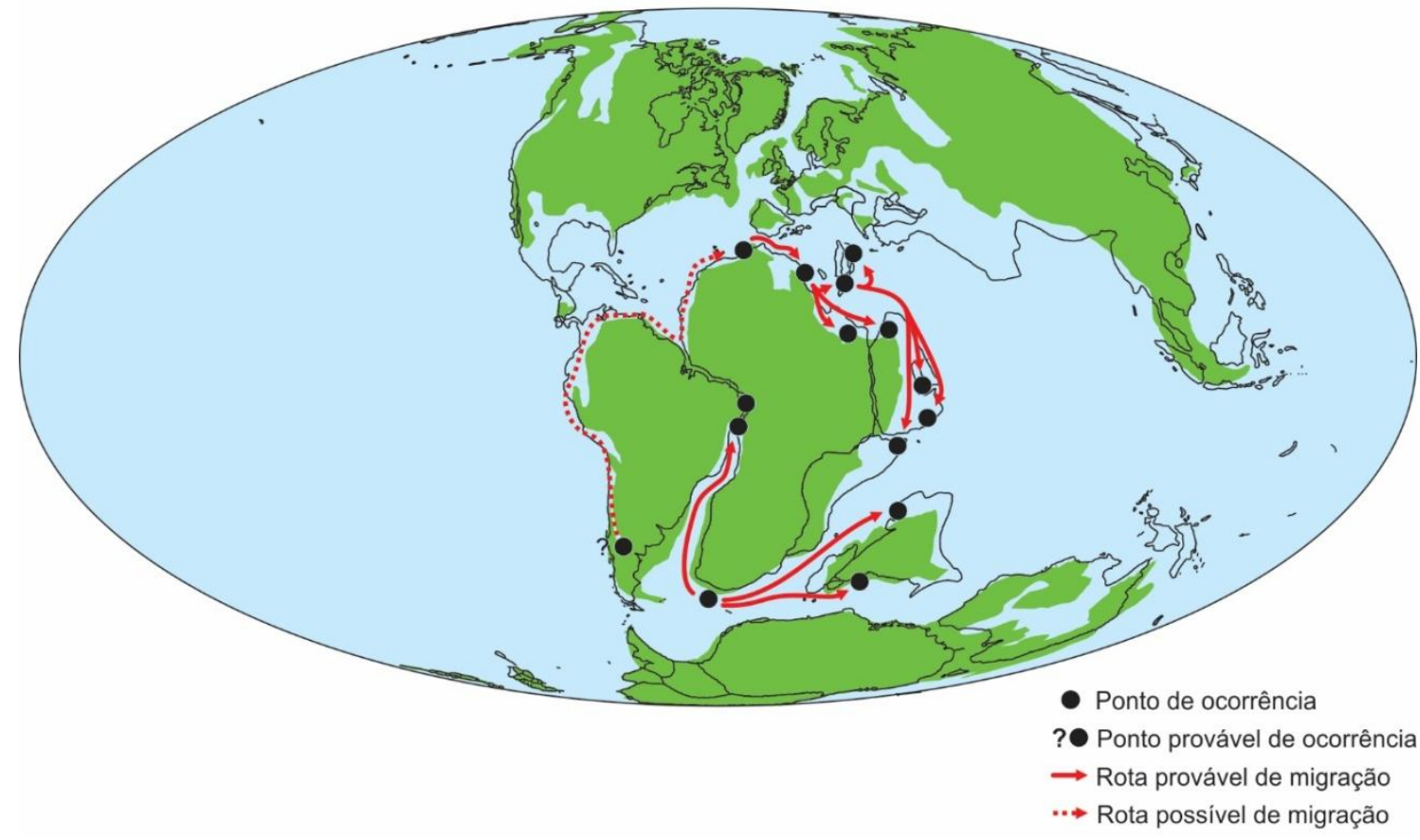

Figura 16. Paleozoogeografia e rotas de migração de Aracajuia Krömmelbein de 1967 durante o TithonianoBarremiano (A) e o Barremiano-Turoniano (B) (modificado de Smith et al., 1994). 
indiana (bacias Outeniqua e Natal-Zululand, África do Sul; bacias de Sergipe-Alagoas e Potiguar, Brasil; bacia do Gabão, Gabão; Líbano; Abu Dhabi, Emirados Árabes Unidos; bacia Khazduni, Iran; bacia Bab, Omã; bacia do Golfo de Áden, Somália; bacia de Jaffa, Israel; e bacia Cauvery, Índia) (Krömmelbein, 1966a, 1967, 1975; Jain, 1976; Bertels, 1977; Grosdidier, 1979; Dingle, 1982, 1984; Rosenfeld \& Raab, 1984; Dingle, 1996; Luger, 2003; Andreu et al., 2008). A maioria destas espécies desapareceu no final do Albiano, e apenas aquelas em Marrocos e na África do Sul alcançaram o Neocretáceo (Dingle, 1984; Gebhardt, 1999) (fig. 16B).

Os últimos registros de Aracajuia foram do Cenomaniano-Santoniano (fig. 17). Durante estes estágios, novas espécies apareceram no norte da África e Oriente Médio (bacia Western Desert, Egito, bacias de Essaouira e West High Atlas, Marrocos; Douleb e Djebel Chemla, Tunísia; bacia Wadi Sirhan, Jordânia; e bacias Jaffa e Mount Carmel, Israel) (Bold, 1964; Gerry \& Rosenfeld, 1973; Rosenfeld \& Raab, 1974; Andreu-Boussut, 1991; Andreu et al., 2008; Ruault-Djerrab \& Kechid-Benkherouf, 2011). Espécimes identificados como Aracajuia sp. 5 e Amphicytherura aff. A. yakhiniensis também foram observados no CenomanianoConiaciano da Índia (bacia de Jaisalmer) (Jain, 1976; Andreu et al., 2008), provavelmente a partir da África do Sul. Ao fim do Turoniano, a distribuição geográfica de Aracajuia tornouse muito reduzida; ainda assim, o gênero atingiu a Laurásia (Formação Räcknitzer e bacia Sub-hercyniana, Alemanha), vindo da costa do Levante. Aracajuia se extinguiu no final do Santoniano (Gründel, 1970, 1974b).

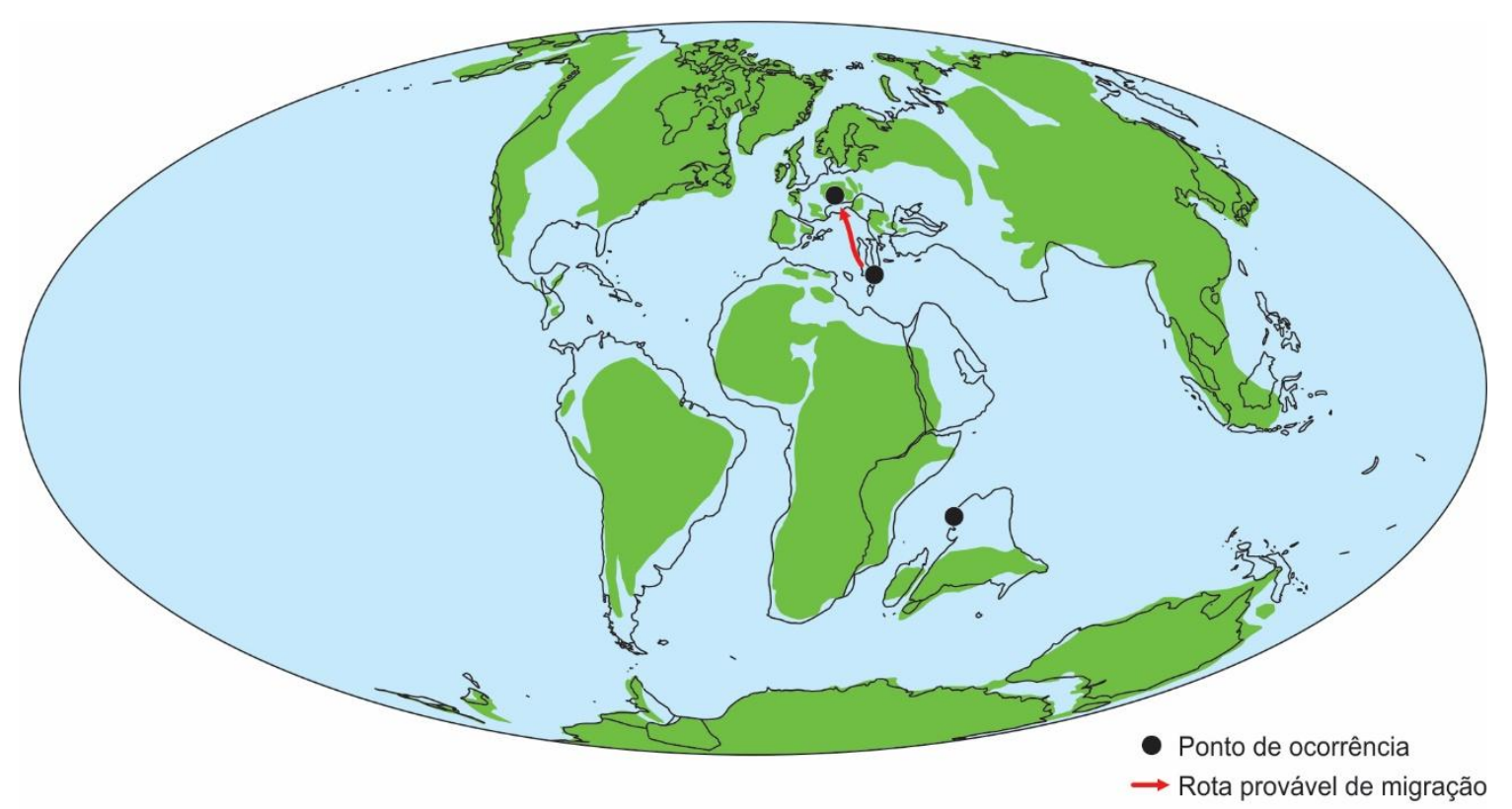

Figura 17. Paleozoogeografia e rotas de migração de Aracajuia Krömmelbein de 1967 durante o TuronianoSantoniano (modificado de Smith et al., 1994). 


\section{CONCLUSÃO}

O presente estudo taxonômico trata dos ostracodes do Aptiano superior-Albiano da Formação Riachuelo, bacia de Sergipe-Alagoas, Nordeste do Brasil. Trinta e nove espécies foram identificadas, sendo quatro destas novas: Cytherella besrineensis, Cytherella icknieldensis?, Cytherella sp. 1, Cytherelloidea btaterensis, Bairdoppilata comanchensis, Bairdoppilata pseudoseptentrionalis, Bairdoppilata sp. 1, Bairdoppilata sp. 2, Robsoniella falklandensis, Cetacella sp. 1, Paracypris eniotmetos, Harbinia sinuata?, Harbinia crepata, Liasina sp. 1, Praebythoceratina deltalata sp. nov., Praebythoceratina amsittenensis, Praebythoceratina reducta, Patellacythere shimonensis, Patellacythere parva?, Xestoleberis? sp. 1, Xestoleberis? sp. 2, Apatocythere? sp. 1, Gabonorygma sergipana gen. et sp. nov., Neocythere pseudovanveeni, Neocythere tenuis, Aracajuia antiqua, Aracajuia benderi, Aracajuia fragilis, Eocytheropteron sp. 1, Metacytheropteron minuta?, Microceratina azazoulensis, Microceratina? sp. 1, Veenia guianensis, Reticulocosta edrianae sp. nov., Brachycythere smithsoniana sp. nov., Algeriana? sp. 1, Quasihermanites? sp. 1, Sergipella viviersae e Conchoecia? sp. 1. Um novo gênero, Gabonorygma, também é aqui proposto.

A revisão bioestratigráfica dos ostracodes identificados neste trabalho resultou em mudanças no zoneamento previamente estabelecido para este intervalo. Uma zona e suas seis subzonas, no intervalo entre o Aptiano superior e o Albiano superior, sofreram alterações: OSE-1, cuja espécie guia foi reclassificada como Aracajuia benderi e renomeada MSA-0; OSE-1.1, agora definida por Harbinia sinuata e renomeada MSA-0.1; OSE-1.3, doravante marcada por Praebythoceratina amsittenensis e renomeada MSA-0.3; e OSE-1.4, renomeada MSA-0.4, cuja espécie guia corresponde a uma nova espécie, Reticulocosta edrianae. O limite inferior desta subzona também foi reposicionado, junto ao fim de MSA-0.3. A Subzona OSE-1.2 teve seu estratótipo definido, limite inferior modificada (Albiano inferior para Aptiano superior) e código alterado para MSA-0.2. A subzona OSE-1.5 teve seu código alterados para MSA-0.5. Uma nova zona foi criada em detrimento da Subzona OSE-1.6, nomeada MSA-1 e baseada na espécie Aracajuia antiqua.

Tanto em nível de gênero quanto de espécie, a paleozoogeografia dos ostracodes do Aptiano superior-Albiano da formação corrobora interpretações prévias a cerca da extensão do domínio de Megatétis na região da bacia de Sergipe-Alagoas durante o final do Eocretáceo. Embora a maioria das espécies da bacia seja endêmica da Província Brasil-África Ocidental Central, observa-se o intercâmbio durante o Albiano entre faunas locais e nortetethyanas, com a ocorrência de várias espécies da costa norte-centro-americana até a região do 
Levante, no Oriente Médio. Estas incluem Cytherella besrineensis, Cytherelloidea btaterensis, Bairdoppilata comanchensis, Bairdoppilata pseudoseptentrionalis, Praebythoceratina amsittenensis, Praebythoceratina reducta, Patellacythere shimonensis, Aracajuia antiqua, Veenia guianensis, Neocythere tenuis e Neocythere pseudovanveeni.

Poucas espécies observadas tem ocorrência compartilhada entre os domínios ao sul (proto-oceano Atlântico Austral) e ao norte (proto-oceano Atlântico central) da cordilheira de Walvis. Ambas as observadas, Robsoniella falklandensis, Microceratina azazoulensis, provavelmente se originaram na Província Brasil-África Ocidental Central durante o Albiano, alcançando regiões mais austrais durante o Cenomaniano. Tal fato é atribuído à eficiência da cordilheira como barreira geográfica, separando as águas temperadas frias das regiões ao sul daquelas tropicais ao norte da mesma, e consequentemente suas faunas.

A presença de ostracodes da Subfamília Brachycytherinae na Província Brasil-África Ocidental Central já a partir do Eoaptiano realoca a origem geográfica desta subfamília. Originalmente, esta subfamília teria surgido no centro-norte de Megatétis, onde está presente desde o Albiano; porém com as novas ocorrências, é mais provável que tenha aparecido primeiramente na Província Brasil-África Ocidental Central. Essa ocorrência pode ajudar a explicar a presença de espécies de Brachycytherinae tanto em domínios austrais quanto nortetetianos desde o início do Albiano.

A dispersão de gêneros para a Província Brasil-África Ocidental Central a partir de Megatétis no Albiano parece seguir padrão similar ao observado em nível específico. Uma exceção a esse cenário é o Gênero Aracajuia, de ampla distribuição na bacia, o qual se originou em ambientes marinhos subtropicais de Gondwana, possivelmente no início do Eocretáceo. Este atingiu sua máxima diversidade ao final dessa época, em ambientes tropicais do Albiano ao longo das atuais África, América do Sul e Ásia (Oriente Médio). Apenas o gênero Sergipella é endêmico do Albiano do Proto-Atlântico Central, ocorrendo nas regiões litorâneas da Província Brasil-África Ocidental Central. 


\section{REFERÊNCIAS BIBLIOGRÁFICAS}

Alexander, C.I. 1929. Ostracoda of the Cretaceous of North Texas. Texas University Bulletin, 2907:1-137.

Alexander, C.I. 1932. Sexual dimorphism in fossil Ostracoda. American Midland Naturalist, 13(5):302-310.

Alexander, C.I. 1933. Shell structure of the ostracode genus Cytheropteron, and fossil species from the Cretaceous of Texas. Journal of Paleontology, 7(2):181-214.

Alexander, C.I. 1934a. Ostracoda of the Midway Eocene of Texas. Journal of Paleontology, 8(2):206-237.

Alexander, C.I. 1934b. Ostracoda of the genera Monoceratina and Orthonotacythere from the Cretaceous of Texas. Journal of Paleontology, 8(1):57-67.

Andreu, B. \& Bilotte, M. 2006. Ostracodes du Cénomanien supérieur et du Turonien de la zone sous-pyrénéenne orientale (Corbières méridionales, SE France). Systématique, biostratigraphie, paléoécologie et paléobiogéographie. Revue de Micropaléontologie, 49:55-73.

Andreu, B. 1992. Associations d'ostracodes et paléoécologie du Crétacé (Barrémien à Turonien) le long d'une transversale Agadir-Nador (Maroc). Palaeogeography, Palaeoclimatology, Palaeoecology, 99:291-319.

Andreu, B. 2002. Cretaceous ostracode biochronology of Morocco. Eclogae Geologicae Helvetiae, 95:133-152.

Andreu, B., Colin, J.P. \& Singh, J. 2008. Cretaceous (Albian to Coniacian) ostracodes from the subsurface of the Jaisalmer basin, Rajasthan, India. Micropaleontology, 53(5):345-370.

Andreu-Boussut, B. 1991. Les ostracodes du Crétacé moyen (Barrémien à Turonien), le long dúne transversale Agadir-Nador (Maroc). Strata, 2(14):1-765.

Antonietto, L., Abrahão, A., Do Carmo, D.A. \& Meireles R. 2013b. Taxonomic, biostratigraphic and palaeozoogeographic aspects of Amphicytherura Butler \& Jones, 1957 and Aracajuia Krömmelbein, 1967 (Cytheridae, Schizocytherinae). Il Naturalista Siciliano, Serie Quarta, 37(1):39-40.

Antonietto, L.S., Abrahão, A., Do Carmo, D.A. \& Meireles, R.P. 2013a. Taxonomy, biostratigraphy and paleozoogeography of Amphicytherura Butler and Jones, Aracajuia Krömmelbein and Dinglecythere Antonietto et al., n. gen. (Crustacea, Ostracoda). Marine Micropaleontology, 105:1-17.

Antonietto, L.S., Do Carmo, D.A., Viviers, M.C. \& Adôrno, R.R. (aceito). Biostratigraphic and paleozoogeographic review of the uppermost Alagoas-Albian ostracods of Riachuelo 
Formation, Sergipe-Alagoas basin, Northeastern Brazil. Revista Brasileira de Paleontologia.

Antonietto, L.S., Gobbo, S.R., Do Carmo, D.A., Assine, M.L., Fernandes, M.A.M.C.C. \& Silva, J.E.L. 2012. Taxonomy, ontogeny and paleoecology of two species of Harbinia Tsao, 1959 (Crustacea, Ostracoda) from the Santana Formation, lower Cretaceous, Northeastern Brazil. Journal of Paleontology, 86(4):659-668.

Apostolescu, V. 1961. Contribution a l'étude paléontologique (ostracodes) et stratigraphique des bassins crétacés et tertiaires de l'Afrique Occidentale. Revue de l'Institut Français du Pétrole, 16(7-8):779-867.

Arienti, L.M. 1996. Análise estratigráfica, estudos de fluxos gravitacionais e geometria dosdepósitos "rift" da Formação Maceió e Formação Poção, bacia de Alagoas. Universidade Federal do Rio Grande do Sul, Tese de Doutorado, 398 p.

Assine, M.L. 1992. Análise estratigráfica da bacia do Araripe, Nordeste do Brasil. Revista Brasileira de Geociências, 22(3):289-300.

Assine, M.L. 1994. Paleocorrentes e paleogeografia na bacia do Araripe, Nordeste do Brasil. Revista Brasileira de Geociências, 24(4):223-232.

Assine, M.L. 2007. Bacia do Araripe. Boletim de Geociências da PETROBRAS, 15(2):371389.

Babinot, J.F. \& Colin, J.P. 1988. Paleobiogeography of Tethyan Cretaceous Marine Ostracods. In: Hanai, T., Ikeya, N. \& Ishizaki, K. (Eds) Evolutionary Biology of Ostracoda: Its Fundamentals and Applications. Developments in Palaeontology and Stratigraphy, 11:823839.

Babinot, J.F. \& Colin, J.P. 2011. Barremian ostracods from the Serre de Bleyton (Drôme, SE France). Annalen des Naturhistorischen Museums in Wien, Serie A, 113:1-41.

Babinot, J.F., Colin, J.P. \& Damotte, R. 1985b. Crétacé supérieur. In: Oertli, H.J. (Ed.) Atlas des ostracodes de France. Bulletin des Centres de Recherche Exploration-Production ElfAquitaine, Mémoire, 9:211-255.

Babinot, J.F., Colin, J.P. \& Randrianasolo, A. 2009. Les ostracodes de l'Albien-Turonien moyen de la région d'Antsiranana (Nord Madagascar): systématique, paléoécologie et paléobiogéographie. Carnets de Géologie, 2009(01):1-25.

Babinot, J.F., Damotte, R., Donze, P., Grosdidier, E., Oertli, H.J. \& Scarenzi-Carboni, G. 1985a. Crétacé inférieur. In: Oertli, H.J. (Ed.) Atlas des ostracodes de France. Bulletin des Centres de Recherche Exploration-Production Elf-Aquitaine, Mémoire, 9:163-209.

Bandeira Júnior, A..N. 1978. Sedimentologia e Microfacies Calcárias das Formações Riachuelo e Cotinguiba da Bacia Sergipe/Alagoas. Boletim Técnico da PETROBRÁS, 
21(1):17-69.

Bassoulet, J.P. \& Damotte, R. 1969. Quelques ostracodes nouveaux du Cénomano-Turonien de l'Atlas Saharien occidental (Algérie). Revue de Micropaléontologie, 12(3):130-144.

Bate, R.H. 1972. Phosphatized ostracods with appendages from the lower Cretaceous of Brazil. Palaeontology, 15(3):379-393.

Becker, G., Lord, A.R. \& Malz, H. 1989. In the footsteps of Griffith and M'Coy or, Lower Carboniferous Ostracoda from Ireland and the definition of the genus Bairdia M'Coy 1844 (Part 1). Courier Forschungsinstitut Senckenberg, 113:29-36.

Becker, G. 1990. Eine ostracoden-fauna von thüringer gepräge aus dem unterkarbonischen deckdiabas von Günterod (typicus-zone; Dill-mulde, Rechtsrheinisches schiefergebirge, blatt 5216 Oberscheld). Geologisches Jahrbuch Hessen, 118:29-52.

Bengtson, P. \& Nordlund, U. 1987. The Ammonite Fauna and Genesis of a Mid-Cretaceous Siliceous Oolite from the Alagoas basin, Brasil. Cretaceous Research, 8(1987):305-333.

Benson, R.H. \& Tatro, J.O. 1964. Faunal description of Ostracoda of the Marlbrook Marl (Campanian), Arkansas. The University of Kansas Paleontological Contributions Arthropoda, 7:1-32.

Benson, R.H. 1984. Estimating greater paleodepths with ostracodes, especially in past thermospheric oceans. Palaeogeography, Palaeoclimatology, Palaeoecology, 48(1984):107-141.

Bertani, R.T. \& Carozzi, A.V. 1985. Lagoa Feia Formation (Lower Cretaceous), Campos basin, offshore Brasil: rift valley stage lacustrine carbonate reservoirs - I. Journal of Petroleum Geology, 8(1):37-58.

Bertels, A. 1977. Cretaceous Ostracoda - South Atlantic. In: Swain, F.M. (Ed.) Stratigraphic micropaleontology of Atlantic Basin and borderlands. Developments in Palaeontology and Stratigraphy, 6:271-304.

Beurlen, G. 1968. A fauna do complexo Riachuelo/Maruim. I - Ammonoidea. Boletim Técnico da PETROBRÁS, 11(4):437-482.

Bischoff, G. 1964. Ostracoden-Studien im Libanon, 3): Die Gattung Cytherelloidea im Oberen Jura und in der Unterkreide. Senckenbergiana Lethaea, 45(1-4):1-27.

Blake, D.B. 1950. Gosport Eocene Ostracoda from Little Stave creek, Alabama. Journal of Paleontology, 24(2):174-184.

Bold, W.A. 1946. Contribution to the study of Ostracoda, with special reference to the Tertiary and Cretaceous fauna of the Caribbean region. De Bussy, Amsterdam, 167p.

Bold, W.A. 1958. Ostracoda of the Brasso Formation of Trinidad. Micropaleontology, 4(4):391-418. 
Bold, W.A. 1960. Eocene and Oligocene Ostracoda of Trinidad. Micropaleontology, 6(2):145196.

Bold, W.A. 1964. Ostracoden aus der Oberkreide von Abu Rawash, Ägypten. Palaeontographica, 123(A):111-136.

Bold, W.A. 1967. Ostracoda of the Gatún Formation, Panama. Micropaleontology, 13(3):306318.

Bonnema, J.H. 1941. Ostracoden aus der Kreide des Untergrundes der nordöstlichen Niederlande. Natuurhistorich Maanblad, 29(9-12):91-95, 104-108, 115-118, 129-132; 30(1-6):8-12, 21-29, 40-43, 56-60, 70, 71.

Borba, C., Aguiar, L.A.M., Maciel, W.B., Almeida, M.S., Dias Filho, D.C. \& Souza, R.S. 2003. Aspectos controladores do potencial selante de falhas: exemplo do Campo de Pilar, bacia de Sergipe-Alagoas, Brasil. Boletim de Geociências da PETROBRAS, 12(1):103-123.

Bosquet, J. 1854. Les Crustacés Fossiles du Terrain Crétacé du Limbourg. J.P. Berghaus, 127 p.

Brenner, P., Oertli, H.J., 1976. Lower Cretaceous ostracodes (Valanginian to Hauterivian) from the Sundays River Formation, Algoa Basin, South Africa. Bulletin des Centres de Recherche de Pau-SNPA, 10(2):471-533.

Brown, P.M. 1957. Upper Cretaceous ostracoda from Northern Carolina. North Carolina Department of Conservation and Development Bulletin, 70:1-27.

Bueno, G.V. 2004. Diacronismo de eventos no rifte Sul-Atlântico. Boletim de Geociências da PETROBRAS, 12(2):203-229.

Butler, E.A., Jones, D.E., 1957. Cretaceous ostracoda of Prothro and Rayburns Salt Domes, Bienville Parish, Louisiana. Bulletin of the Louisiana Geological Survey, 32:1-65.

Cainelli, C. \& Mohriak, W.U. 1999. Some remarks on the evolution of sedimentary basins along the eastern Brasilian continental margin. Episodes, 22(3):206-216.

Cainelli, C. 1992. Sequence stratigraphy, canyons, and gravity mass flow deposits in the Piaçabuçu Formation, Sergipe-Alagoas basin, Brasil. University of Texas, Tese de Doutorado, $233 \mathrm{p}$.

Campos Neto, O.P.A., Souza-Lima, W. \& Cruz, F.E.G. 2007. Bacia de Sergipe-Alagoas. Boletim de Geociências da PETROBRAS, 15(2):405-415.

Carbonnel, G. 1991. Dispersion et peuplement de Soudanella laciniosa Apostolescu, 1961 (Ostracoda), au Danien/Paléocène supérieur durant l'ouverture de l'Atlantique équatorial. Palaeogeography, Palaeoclimatology, Palaeoecology, 88(1991):109-120.

Carvalho, M.A. 2004. Palynological assemblage from Aptiano/Albiano of the Sergipe basin: paleoenvironmental reconstruction. Revista Brasileira de Paleontologia, 7(2):159-168. 
Carvalho, M.A., Oliveira, D.C., Machado, L.G. \& Mendonça Filho, J.G. 2005. Sedimentação albo-aptiana de partículas vegetais (fitoclastos) em rochas do Membro Taquari, Formação Riachuelo, bacia de Sergipe, Brasil. Arquivos do Museu Nacional, 63(3):411-424.

CENE/SBG. 1986. Código brasileiro de nomenclatura estratigráfica - guia de nomenclatura estratigráfica. Revista Brasileira de Geociências, 16(4):370-415.

Cesero, P. \& Ponte, F.C. 1997. Análise comparativa da paleogeologia dos litorais atlânticos brasileiro e africano. Boletim de Geociências da PETROBRAS, 11(1/2):1-18.

Charollais, J., Moullade, M., Oertli, H.J. \& Rapin, F. 1977. Découverte de microfaunes de l'albien moyen et supérieur dans la vallée de Joux (Jura Vaudois, Suisse). Géobios, 1(5):683-695.

Chiossi, D.S.N. 2005. Seqüências deposicionais de $3^{\text {a }}$ ordem em riftes continentais: um modelo de tratos de sistemas para grábens assimétricos aplicado ao Cretáceo Inferior da bacia de Sergipe-Alagoas. Boletim de Geociências da PETROBRAS, 13(2):181-203.

Christensen, O.B. 1965. The Ostracod Genus Dicrorygma POAG 1962 from Upper Jurassic and Lower Cretaceous. Danmarks Geologiske Undersøgelse II. Rakke, 90:3-23.

Coimbra, J.C., Arai, M. \& Carreño, A.L. 2002. Biostratigraphy of Lower Cretaceous microfossils from the Araripe basin, northeastern Brazil. Geobios, 35(6):687-698.

Colin, J.P. \& Andreu, B. 1990. Cretaceous Halocypridid Ostracoda. In: Whatley, R. \& Maybury, C. (Eds) Ostracoda and Global Events. Chapman and Hall, Cambridge, 515526.

Colin, J.P. \& Babinot, J.F. 1996. Preliminary account of ostracodes from the Aptian-Albian of Venezuela: palaeobiogeographic implications. In: Keen, M.C. (Ed.) Proceedings of the 2 nd European ostracodologists meeting : University of Glasgow, Scotland 23rd-27th July 1993. British Micropalaeontological Society, Londres, 29-34.

Colin, J.P. \& Dépêche, F. 1997. Faunes d'ostracodes lacustres des bassins intra-cratoniques d'âge albo-aptien en Afrique de l'Ouest (Cameroun, Tchad) et au Brésil: considérations d'ordre paléoécologique et paléobiogéographique. Africa Geoscience Review, 4(3/4):431450 .

Colin, J.P. 1974 Contribution a l'étude des ostracodes du Crétacé supérieur de Dordogne. Géobios, 7(1):19-42.

Colin, J.P., Andreu, B., Dejax, J. \& Gèze, R. 2005. Sur l'origine du genre Microceratina Swanson, 1980 (Ostracoda, Eucytherurinae) et sa présence téthysienne dès le Jurassique supérieur. Revue de Micropaléontologie, 48:15-24.

Córdoba, V.C., Sá, E.F.J., Sousa, D.C. \& Antunes, A.F. 2007. Bacia de Pernambuco-Paraíba. Boletim de Geociências da PETROBRAS, 15(2):391-403. 
Coryell, H.N. \& Fields, S. 1937. A Gatun ostracod fauna from Panama. American Museum Novitates, 956:1-18.

Coryell, H.N., Sample, C.H. \& Jennings, P.H. 1935. Bairdoppilata, a new genus of Ostracoda, with two new species. American Museum Novitates, 777:1-5.

Crane, M.J. 1965. Upper Cretaceous ostracodes of the Gulf Coast area. Micropaleontology, 11(2):191-254.

Damotte, R. \& Fleury, J.J. 1987. Ostracodes maastrichtiens et paléocènes du Djebel Dyr. Géologie Méditerranéenne, 14(2):87-107.

Damotte, R. \& Saint-Marc, P. 1972. Contribution à la connaissance des ostracodes crétacés du Liban. Revista Española de Micropaleontología, 4(3):273-296.

Damotte, R. 1961. Un nouveau sous-genre d'ostracode de l'albien moyen de l'Yonne; Veenia (Protoveenia) florentinensis n.subgen., n.sp. Revue de Micropaléontologie, 2:99-104.

Damotte, R. 1992. Data report: Cretaceous ostracodes from holes 761B and 764A (Wombat plateau) and holes 762C, 763B, and 763C (Exmouth plateau). In: Rad, U., Haq, B.U., Kidd, R.B. \& O'Connell, S. (Eds) Exmouth Plateau. Proceedings of the Ocean Drilling Program, Scientific Results, 122:819-834.

Dana, J.D. 1849. Conspectus crustaceorum quae in orbis terrarum circumnavigatione, Carolo Wilkes et classe Reipublicae Foederatae Duce, lexit et descripsit Jacobus D. Dana. Pars 2. Proceedings of the American Academy of Arts and Sciences, 2:9-61.

Dépêche, F., Bérthou, P.Y. \& Campos, D.A. 1990. Quelques observations sur les faunes d'ostracodes du Crétacé du Bassin d'Araripe (NE du Brésil). Atas do $1^{\circ}$ Simpósio sobre a Bacia do Araripe e Bacias Interiores do Nordeste. R. Esteves, Fortaleza, 293-308.

Deroo, G. 1956. Études critiques au sujet des ostracodes marins du Crétacé inférieur et moyen de la Champagne humide et du Bas Boulonnais. Revue de l' Institut Français du Pétrole, 11(12):1499-1535.

Dias, J.L. 2004. Tectônica, estratigrafia e sedimentação no Andar Aptiano da margem leste brasileira. Boletim de Geociências da PETROBRAS, 13(1):7-25.

Dias-Brito, D. 2000. Global stratigraphy, palaeobiogeography and palaeoecology of AlbianMaastrichtian pithonellid calcispheres: impact on Tethys configuration. Cretaceous Research, 21:315-349.

Dingle, R.V. 1969. Marine Neocomian Ostracoda from South Africa. Transactions of the Royal Society of South Africa, 38(2):139-163.

Dingle, R.V. 1980. Marine Santonian and Campanian ostracods from a borehole at Richards bay, Zululand. Annals of the South African Museum, 82(1):1-70.

Dingle, R.V. 1982. Some aspects of Cretaceous Ostracod biostratigraphy of South Africa and 
relationships with other Gondwanide localities. Cretaceous Research, 3:367-389.

Dingle, R.V. 1984. Mid-Cretaceous Ostracoda from Southern Africa and the Falkland Plateau. Annals of the South African Museum, 93(3):97-211.

Dingle, R.V. 1996. Cretaceous Ostracoda of the SE Atlantic and SW Indian Ocean: a stratigraphical review and atlas. In: Jardiné, S., Klazs, I. \& Debenay, J.P. (Eds) Géologie de 1'Afrique et de l'Atlantique Sud. Mémoire Elf Aquitaine, 16:1-17.

Dingle, R.V. 1999. Walvis Ridge barrier: its influence on palaeoenvironments and source rock generation deduced from ostracod distributions in the early South Atlantic ocean. In: N.R. Cameron, R.H. Bate \& V.S. Clure (eds.) Special Publication, 153 - The Oil and Gas Habitats of the South Atlantic, London, Geological Society of London, p. 293-302.

Do Carmo, D.A., Coimbra, J.C., Whatley, R.C., Antonietto, L.S. \& Citon, R.T.P. 2013. Taxonomy of limnic Ostracoda (Crustacea) from the Alagamar Formation, middle-upper Aptian, Potiguar Basin, Northeastern Brazil. Journal of Paleontology, 87(1):91-104.

Do Carmo, D.A., Colin, J.P., Hidalgo, P.H.P., Meireles, R.P., Berbert-Born, M.L.C. \& Almeida, C.M. 2012. Reassessment of the genus Sergipella Krömmelbein, 1967 (Ostracoda, Trachyleberididae), uppermost Aptian-Albian of Brazil and West Africa: Taxonomy and paleogeographic distribution. Revue de Micropaléontologie, 55:3-15.

Do Carmo, D.A., Rafael, R.M.L., Vilhena, R.M. \& Tomassi, H.Z. 2004. Redescrição de Theriosynoecum silvai e Darwinula martinsi, Membro Crato (Formação Santana), Cretáceo inferior, bacia do Araripe, NE, Brasil. Revista Brasileira de Paleontologia, 7(2):151-158.

Do Carmo, D.A., Whatley, R., Queiroz Neto, J.V. \& Coimbra, J.C. 2008. On the validity of two Lower Cretaceous non-marine ostracode genera: biostratigraphic and paleogeographic implications. Journal of Paleontology, 82:790-799.

doi:10.1006/cres.2000.0196, available online at http://www.idealibrary.com on

Donze, P. 1964. Ostracodes berriasiens des massifs subalpins septentrionaux (Bauges et Chartreuse). Travaux du Laboratoire de Géologie de la Faculté des Sciences de Lyon, 11:103-158.

Donze, P. 1965. Espèces nouvelles d'ostracodes des couches de base du Valanginien de Berrias (Ardèche). Travaux du Laboratoire de Géologie de la Faculté des Sciences de Lyon, 12:87-107.

El-Nady, H. Abu-Zied, R. \& Ayyad, S. 2008. Cenomanian - Maastrichtian ostracods from Gabal Arif El-Naga anticline, Eastern Sinai, Egypt. Revue de Paléobiologie, 27(2):533573.

Falconi, C.M.O. 2006. Sedimentação mista carbonato-siliciclástico durante o Albo-aptiano na 
porção emersa da bacia Sergipe-Alagoas. Universidade Vale do Rio dos Sinos, Tese de Doutorado, $169 \mathrm{p}$.

Fauth, G. 2002. Paleobiogeography of the Upper Cretaceous and Lower Tertiary marine ostracods from the Atlantic ocean. Revista Brasileira de Paleontologia, 4:65-71.

Fauth, G., Colin, J.P., Koutsoukos, E.A.M. \& Bengtson, P. 2005. Cretaceous-Tertiary boundary ostracodes from the Poty quarry, Pernambuco, northeastern Brasil. Journal of South American Earth Sciences, 19:285-305.

Feijó, F.J. 1980. Estudo dos carbonatos Muribeca e Riachuelo no alto de Aracaju-- bacia Sergipe/Alagoas - Nordeste do Brasil. In: Silva, Z.C.C. (Ed.) Anais do XXXI Congresso, Volume 1, Balneário de Camboriú, SC - Outubro/1980. SBG, São Paulo, 320-332.

Feijó, F.J. 1994. Bacias de Sergipe e Alagoas. Boletim de Geociencias da PETROBRÁS, 8(1):149-161.

Ferreira, E.P., Carvalho, M.A. \& Viviers, M.C. 2005. Palinologia (fungos) da Formação Calumbi, Paleoceno da bacia de Sergipe, Brasil. Arquivos do Museu Nacional, 63(3):395410.

Florêncio, C.P. 1996. Geologia dos evaporitos Paripueira na porção alagoana da bacia de Sergipe-Alagoas. Universidade de São Paulo, Dissertação de Mestrado, 94 p.

Garcia, A.J.V., Morad, S., De Ros, L.F \& Al-Aasm, I.S. 1998. Palaeogeographical, palaeoclimatic and burial history controls on the diagenetic evolution of reservoir sandstones: evidence from the Lower Cretaceous Serraria sandstones in the SergipeAlagoas basin, NE Brasil. In: Morad, S. (Ed.) Carbonate Cementation in Sandstones. Special Publication of the International Association of Sedimentologists, 26:107-140.

Gebhardt, H. 1999. Cenomanian to Coniacian ostracodes from the Nkalagu area (SE Nigeria): biostratigraphy and palaeoecology. Paläontologische Zeitschrift, 73(1/2):77-98.

Gerry, E. \& Rosenfeld, A. 1973. Amphicytherura distincta and Neocyprideis vandenboldi (Ostracoda), new species from the Cenomanian-Turonian of Israel. Revista Española de Micropaleontología, 5:99-105.

Gomes, P.O. 2000. Distensão crustal, implantação de crosta oceânica e aspectos evolutivos das zonas de fratura e da sedimentação no segmento nordeste da margem continental brasileira. Universidade do Estado do Rio de Janeiro, Tese de Doutorado, 130 p.

Gonçalves, F.T.T. 2001. Controles limnológicos sobre a formação de rochas geradoras de petróleo lacustres: o exemplo da bacia de Camamu, Nordeste do Brasil. Geociências, 20(1):5-23.

Graddi, J.C.S.V., Campos Neto, O.P.A. \& Caixeta, J.M. 2007. Bacia de Jacuípe. Boletim de Geociências da PETROBRAS, 15(2):417-421. 
Gramann, F. 1963. Liasina n. gen. (Ostracoda) aus dem deutschen Lias. Geologisches Jahrbuch, 82:65-74.

Gramm, M.N. \& Kuznetsova, Z.V. 1970. Sistematicheskoye polozheniye roda Robsoniella (Ostracoda). Paleontologicheskii Zhurnal, 3:89-94.

Grekoff, N. \& Deroo, G. 1956. Algunos Ostrácodos del Cretácico medio del Norte de España. Boletín del Instituto Geológico y Minero de España, 12(31/32):215-235.

Grekoff, N. 1963. Contribution à l'étude des ostracodes du Mesozoïque moyen (BathonienValanginien) du Bassin de Majunga, Madagascar. Revue de l'Institut Français du Pétrole, 18:1709-1762.

Grosdidier, E. 1979. Principaux ostracodes marins de l'intervale Aptien-Turonien du Gabon (Afrique Occidentale). Bulletin des Centres de Recherche Exploration-Production du Pétrole, 3:1-33.

Gründel, J. \& Kozur, H. 1971. Zur Taxonomie der Bythocytheridae und Tricorninidae (Podocopida, Ostracoda). Monatsberichte der Deutschen Akademie der Wissenschaften zu Berlin, 13:907-937.

Gründel, J. 1964. Neue Ostracoden as der deutschen Unterkreide II. Monatsberichte der Deutschen Akademie der Wissenschaften zu Berlin, 8(3):849-858.

Gründel, J. 1966. Taxonomische, biostratigraphische und variationstatistiche Untersuchungen an den Ostracoden der Unterkreide in Deutschland. Freiberger Forschungshefte C, Paläontologie, 200:1-105.

Gründel, J. 1967. Neue Ostracoden aus dem Hauterive und Alb Deutschlands. Jahrbuch fur Geologie, 1:629-650.

Gründel, J. 1970. Die Ostracoden aus dem unteren Mittelturon (Racknitzer Schichten, OberKreide) Sachsens. Abhandlungen des Staatlichen Museums für Mineralogie und Geologie zu Dresden, 16:41-54.

Gründel, J. 1974a. Zur Taxonomie und Phylogenie der Cytherettidae Triebel 1952 (Ostracoda, Crustacea). Freiberger Forschungshefte Reihe C, 298:81-99.

Gründel, J. 1974b. Die Ostracoden aus dem Salzbergmergel des Salzberges bei Quedlinburg (unter Ausschluss der Trachyleberididae). Abhandlungen des Staatlichen Museums für Mineralogie und Geologie zu Dresden, 21:101-118.

Gründel, J. 1976. Zur Taxonomie und Phylogenie der Cytherurinae G. W. Müller, 1894 (Cytherocopina, Ostracoda) im Zeitraum höhere Trias bis Unterkreide. Zeitschrift für Geologische Wissenschaften, 4(11):1531-1541.

Gründel, J. 1977. Zur Phylogenie der Trachyleberidacea (Cytherocopina, Ostracoda). Freiberger Forschungshefte, Reihe C, 326:33-43. 
Gründel, J. 1978a. Zur Taxonomie und Phylogenie der Cytherideidae Sars, 1925 (Cytherocopina, Ostracoda) mit Beiträgen zu den Krithidae Mandel'shtam, 1959. Schriftenreihe für Geologische Wissenschaften, 10:73-86.

Gründel, J. 1978b. Bemerkungen zur Phylogenie der Cytherideidacea Sars, 1925 (Cytherocopina, Ostracoda). Zeistchrift für Geologische Wissenschaften, 6(10):1251-1261. Hamsi Júnior, G.P., Karner, G.D. \& Barros, F.A.R. 2006. A crosta transicional da bacia Sergipe-Alagoas. In: Anais do $43^{\circ}$ Congresso Brasileiro de Geologia, SBG, Aracaju, 17.

Hanai, T. 1970. Studies on the ostracod Subfamily Schizocytherinae Mandel'shtam. Journal of Paleontology, 44(4):693-729.

Hart, M.B. \& Crittenden, S. 1985. Early Cretaceous Ostracoda from the Goban Spur; D.S.D.P. Leg 80, Site 549. Cretaceous Research, 6:219-233.

Hart, M.B. 1973. A correlation of the macrofaunal and microfaunal zonations of the Gault Clay in southeast England. In: Casey, R. \& Rawson, P.F. (Eds) The Boreal Lower Cretaceous. Seel House, Liverpool, 267-288.

Herrig, E. 1966. Ostracoden aus der Weißen Schreibkreide (Unter-Maastricht) der Insel Rügen. Paläontologische Abhandlungen, Abteilung A, 2(4):693-1024.

Hessel, M.H. 2005. Anditrigonia britoi n.sp. (Bivalvia) do Eo-Albiano de Sergipe, Brasil. Arquivos do Museu Nacional, 63(3):437-450.

Holden, J.C. 1964. Upper Cretaceous Ostracods from California. Palaeontology, 7(3):393429.

Honigstein, A., Raab, M. \& Rosenfeld, A. 1985. Manual of Cretaceous ostracodes from Israel. Israel Geological Survey Special Publication, 5:1-25.

Hornibrook, N.B. 1952. Tertiary and Recent marine Ostracoda of New Zealand: their origin, affinities, and distribution. New Zealand Geological Survey Palcontological Bulletin, 18:5-82.

Hou, Y. 1984. Guānyú Harbinia; Sinocypris; Quadracypris jí Nanxiongium sì shŭ de fênlèi wèntí (qíkān lùnwén). Acta Micropaleontologica Sinica, 9(1):17-34.

Hou, Y.T., Gōu, Y.X. \& Chén, D.Q. 2002. Zhōngguó jiè xíng lèi huàshí - dì ȳ̄ juàn 1 Cypridacea hé Darwinulidacea. Science Press, Beijing, 1090 p.

Howe, H.V. \& Laurencich, L. 1958. Introduction to the study of Cretaceous Ostracoda. Louisiana State University Press, Baton Rouge, 536 p.

Howe, H.V. \& Law, J.B.S. 1936. Louisiana Vicksburg Oligocene Ostracoda. Bulletin of the Louisiana Geological Survey, 7:1-96.

Howe, H.V. 1935. Ostracoda of the Arca zone of the Choctawhatchee Miocene of Florida. State of Florida Department of Conservation - Geological Bulletin, 13:1-47. 
Howe, H.V. 1951. New Tertiary ostracod fauna from Levy county, Florida. Florida Geological Survey Bulletin, 34:1-32.

Ismail, A.A. \& Soliman, S.I. 1997. Cenomanian-Santonian foraminifera and ostracodes from Horus Well-I, North Western Desert, Egypt. Micropaleontology, 43(2):165-183.

Jain, S.P. 1976. Ostracoda from the Dalmiapuram Formation (Lower Cretaceous), Tiruchirapalli District, Tamil Nadu. Bulletin of the Indian Geologits'Association, 9(1):3342.

Jarvis, I., Carson, G.A., Cooper, M.K.E., Hart, M.B., Leary, P.N., Tocher, B.A., Horne, D. \& Rosenfeld, A. 1988. Microfossil assemblages and the Cenomanian-Turonian (late Cretaceous) oceanic anoxic event. Cretaceous Research, 9:3-103.

Jones, T.R. \& Hinde, G.J. 1890. A supplementary monograph of the Cretaceous Entomostraca of England and Ireland. C. \& J. Adlard, Londres, 70 p.

Jones, T.R. 1849. A monograph of the Entomostraca of the Cretaceous Formation of England. C. \& J. Adlard, Londres, 40 p.

Kaye, P. 1963. The ostracod genus Neocythere in the Speeton clay. Palaeontology, 6(2):274281.

Kaye, P. 1964. Revision of British marine Cretaceous Ostracoda with notes on additional forms. Bulletin of the British Museum (Natural History) - Geology, 10:239-279.

Kaye, P. 1965. Some new british Albian Ostracoda. Bulletin of the British Museum (Natural History) - Geology, 11:215-253.

Keen, M.C. \& Siddiqui, Q.A. 1971. Cenomanian Ostracoda from the Carr's Glen shell bed of Belfast, Northern Ireland. Revue de Micropaléontologie, 14(1):62-68.

Kempf, E.K. 1986. Index and Bibliography of Marine Ostracoda. Sonderveröffentlichungen des Geologischen Instituts der Universität Köln, 50:1-762.

Kesling, R.V. 1951. Terminology of ostracod carapaces. Contributions from the Museum of Paleontology, University of Michigan, 1(4):93-171.

Kilenyi, T.I. 1965. Oertliana, a new ostracod genus from the Upper Jurassic of north-west Europe. Palaeontology, 8(3):572-576.

Koutsoukos, E.A.M. \& Bengtson, P. 1993.Towards an integrated biostratigraphy of the upper Aptian-Maastrichtian of the Sergipe basin, Brazil. Documents des Laboratoires de Géologie de Lyon, 125:241-262.

Koutsoukos, E.A.M. \& Dias-Brito, D. 1987. Paleobatimetria da margem continental do Brasil durante o Albiano. Revista Brasileira de Geociências, 17(2):86-91.

Koutsoukos, E.A.M. \& Hart, M.B. 1990. Cretaceous foraminiferal morphogroup distribution patterns, palaeocommunities and trophic structures: a case study from the Sergipe basin, 
Brazil. Transactions of the Royal Society of Edinburgh: Earth Sciences, 81:221-246.

Koutsoukos, E.A.M. \& Silva Telles Júnior, A.C. 1993. Stratigraphic and palaeoenvironmental distributions of mid-Cretaceous Ostracoda from the Sergipe Basin, NE Brazil, and biogeographic affinities with NW Africa. In: Jones, P.J. \& McKenzie, K.G. (Eds.) Ostracoda in Earth and Life Sciences. Balkema, Rotterdam, 664.

Koutsoukos, E.A.M. 1989. Mid to late cretaceous microbiostratigraphy, paleo-ecology and paleogeography of the Sergipe basin, northeastern Brasil. Plymouth University, Tese de Doutorado, 645 p.

Koutsoukos, E.A.M. 1992. Neoaptiano a Maastrichtian foraminiferal biogeography and palaeoceanography of the Sergipe basin, Brazil. Palaeogeography, Palaeoclimatology, Palaeoecology, 92:295-324.

Kozur, H. 1972. Einige Bemerkungen zur Systematik der Ostracoden und Beschreibung neuer Platycopida aus der Trias ungarns und der Slowakei. Geologisch-Paläontologische Mitteilungen Innsbruck, 2:1-27.

Krömmelbein, K. \& Weber, R. 1971. Ostracoden des Nordost-Brasilianischen Wealden. Beihefte zum Geologischen Jahrbuch, 115:1-93.

Krömmelbein, K. \& Wenger, R. 1966. Sur quelques analogies remarquables dans les Microfaunes Crétacées du Babon et du Brésil Oriental (Bahia et Sergipe). In: Hinte, E.J. (Ed.) Proceedings of the Second West African Micropaleontological Colloquium - Ibadan, June 18th-July 1st. E.J. Brill, Leiden, 193-196.

Krömmelbein, K. 1961. Über dimorphismus bei arten der ostracoden-gattung Paracypridea Swain (Cyprideinae) aus dem NE-brasilianischen „Wealden“. Senckenbergiana Lethaea, 42(5/6):353-375.

Krömmelbein, K. 1962. Zur Taxonomie und Biochronologie stratigraphisch wichtiger Ostracoden-Arten aus der oberjurassich?-unterkretazischen Bahia-Serie (Wealden-Fazies) NE-Brasiliens. Senckenbergiana Lethaea, 43(6):437-527.

Krömmelbein, K. 1964a. Ostracoden aus der marinen "Küsten-Kreide" Brasiliens. 1: Brachycythere (Brachycythere) sapucariensis n. sp. Aus dem Turonium. Senckenbergiana Lethaea, 45(6):489-495.

Krömmelbein, K. 1964b. Über einige neue Arten der Ostracoden-Gattung Reconcavona Krömmelbein 1962 aus der NE-brasilianischen Bahia-Serie (nicht-mariner Oberjura? Unterkreide). Senckenbergiana Lethaea, 45(1-4):29-41.

Krömmelbein, K. 1965. Neue, für vergleiche mit West-Afrika wichtige ostracoden arten der brasilianischen Bahia-serie (Ober-Jura?/Unter-Kreide in Wealden-fazies). Senckenbergiana Lethaea, 46(a):177-213. 
Krömmelbein, K. 1966a. Preliminary remarks on some marine ostracodes from northeastern Brazil and West Africa. In: Hinte, J.E. (Ed.) Proceedings of the Second West African Micropaleontological Colloquium-Ibadan, June 18th-July 1st. E.J. Brill, Leiden, 119-123.

Krömmelbein, K. 1966b. On "Gondwana Wealden" Ostracoda from NE Brasil and West Africa". In: Hinte, E.J. (Ed.) Proceedings of the second West African Micropaleontological Colloquium - Ibadan, June 18th-July 1st. E.J. Brill, Leiden, 113-119.

Krömmelbein, K. 1967. Ostracoden aus der marinen "Küsten-Kreide" Brasiliens. 2: Sergipella transatlantica n. g., n. sp., und Aracajuia benderi n. g., n. sp., aus dem Ober Aptium/Albium. Senckenbergiana Lethaea, 48(6):525-533.

Krömmelbein, K. 1970. Non-marine Cretaceous Ostracods and their importance for the hypotesis of "Gondwanaland". In: 2nd Gondwana Symposium: Proceedings and Papers, (Cape Town \& Johannesburg) South Africa, July - August 1970. Council for Scientific and Industrial Research, Pretória, 617-619.

Krömmelbein, K. 1975. Remarks on marine Cretaceous ostracodes of gondwanic distribution. In: Proceedings of the 5th African Colloquium on Micropalaeontology, Adis Abbaba, 1972. Enadimsa, Madrid, 539-551.

Krömmelbein, K. 1976. African Cretaceous ostracods and their relations a surrounding continents. In: Gray, J. \& Boucot, A.J. (Eds) Historical Biogeography, Plate Tectonics and the Changing Environment, OSU Press, Corvallis, 305-310.

Kuznetsova, Z.V. 1956. Rod Robsoniella Kuznetzova gen. nov. In: Kiparisov, L.D., Markovskogo, B.P. \& Radchenko, G.P. (Eds) Materialy po paleontologii - Novyye semeystva i rody. Gosgeoltekhizdat, Moscou, 119, 120.

Kuznetsova, Z.V. 1961. Ostrakody melovykh otlozheniy Severo-Vostochno Azerbaydzhana stratigraficheskoye znacheniye. Azerbaydzhana Gosudarstvennyy Izdatel'stvo, Baku, 149 p.

Lana, C.C. \& Beurlen, G. 2007. Microbioestratigrafia do Mesozóico-Cenozóico Brasileiro: Um Passeio pelo Tempo. Anuário do Instituto de Geociências, 30(1):207-209.

Lana, C.C. \& Carvalho, I.S. 2002. Cretaceous conchostracans from Potiguar basin (northeast Brazil): relationships with West African conchostracan faunas and palaeoecological inferences. Cretaceous Research, 23:351-362.

Lana, M.C. 1985. Rifteamento na bacia Sergipe-Alagoas, Brasil. Universidade Federal de Ouro Preto, Dissertação de Mestrado, 124 p.

Liebau, A. 2005. A revised classification of the higher taxa of the Ostracoda (Crustacea). Hydrobiologia, 538:115-137.

Luger, P. 2003. Paleobiogeography of late Early Cretaceous to Early Paleocene marine 
Ostracoda in Arabia and North to Equatorial Africa. Palaeogeography, Palaeoclimatology, Palaeoecology, 196:319-342.

Lüttig, G. 1962. Zoologische und paläontologische ostracoden-systematik. Paläontologische Zeitschrift, 36(1):154-184.

M'Coy, F. 1844. A Synopsis of the Characters of the Carboniferous Limestone Fossils of Ireland. University Press, Dublin, 207 p.

Maddocks, R.F. 1969. Revision of Recent Bairdiidae (Ostracoda). United States National Museum Bulletin, 295:1-126.

Magnavita, L., Destro, N., Carvalho, M.S.S., Milhomem, P.S. \& Souza-Lima, W. 2003. Bacia de Tucano. Phoenix, 52:1-7.

Majoran, S. 1989. Mid-Cretaceous Ostracoda of northeastern Algeria. Fossil and Strata, 27:167.

Majoran, S. 1991 Morphometric relationships among upper Cretaceous samples of Oertliella tarfayensis Reyment (Crustacea, Ostracoda). Revista Española de Paleontología, 6(2):117125.

Malz, H. \& Lord, A. 2004. Ankumia van Veen, 1932 retained and not replaced by the Junior taxon Platella Coryell \& Fields, 1937 (Ostracoda, Platycopina, Cytherelloidea). Journal of Micropalaeontology, 23:163.

Mandel'shtam, M.I. 1947. Ostracoda iz otlozheniy sredney yury poluostrova Mangyshlaka. Vserossiyskiy Neftyanoy Nauchno-Issledovatel'skiy Geologorazvedochnyy Institut: Mikrofauna Neftyanykh Mestorozhdeniy Kavkaza, Emby i Sredney Azii, 239-256.

Marques, R.C. 1965 Campo petrolífero de Carmópolis: histórico da descoberta - geologia do campo - perspectivas econômicas. Boletim Técnico da PETROBRÁS, 8(3):307-328.

Martin, G.P.R. 1958. Cetacella, eine neue Ostracoden-Gattung aus dem Kimmeridge Nordwestdeutschlands. Paläontologische Zeitschrift, 32(3/4):190-196.

Martins Neto, R.G. 2005. Estágio atual da paleoartropodologia brasileira: hexápodes, miriápodes, crustáceos (Isopoda, Decapoda, Eucrustacea e Copepoda) e quelicerados. Arquivos do Museu Nacional, 63(3):471-494.

Mendes, J.M.C. 1994. Análise estratigráfica da seção neo-Aptiana/Eocenomaniana (Fm. Riachuelo) na área do Alto de Aracajú e adjacências - bacia de Sergipe/Alagoas. Universidade Federal do Rio Grande do Sul, Tese de Doutorado, 166 p.

Mendonça, P.M.M, Spadini, A.R. \& Milani, E.J. 2003. Exploração na Petrobras: 50 anos de sucesso. Boletim de Geociências da PETROBRAS, 12(1):9-58.

Mertens, E. 1956. Zur Grenzziehung Alb/Cenoman in Nordwestdeutschland mit Hilfe von Ostracoden. Geologisches Jahrbuch, Reihe B, 72:174-230. 
Milani, E.J., Rangel, H.D., Bueno, G.V., Stica, J.M., Winter, W.R., Caixeta, J.M. \& Pessoa Neto, O.C. 2007. Bacias Sedimentares Brasileiras - Cartas Estratigráficas: Introdução. Boletim de Geociências da PETROBRAS, 15(2):183-205.

Mohriak, W., Nemčok, M. \& Enciso, G. 2008. South Atlantic divergent margin evolution: rift-bordem uplift and salt tectonics in the basins of SE Brasil. In: Pankhurst, R.J., Trouw, R.A.J. Brito-Neves, B.B. \& Wit, M.J. (Eds) West Gondwana: Pre-Cenozoic Correlations Across the South Atlantic Region. The Geological Society Special Publications, 294:365398.

Mohriak, W.U., Bassetto, M. \& Vieira, I.S. 1997. Observações sobre a carta estratigráfica e a evolução tectono-sedimentar das bacias de Sergipe e Alagoas. Boletim de Geociências da PETROBRAS, 11(1/2):84-115.

Mohriak, W.U., Rabelo, J.H.L., Matos, R.D. \& Barros, M.C. 1995. Deep seismic reflection profiling of sedimentary basins offshore Brasil: geological objectives and preliminary results in the Sergipe basin. Journal of Geodynamics, 20(4):515-539.

Morsi, A.M.M., Faris, M., Zalat, A.E. \& Salem, R.F.M. 2008. Maastrichtian-Early Eocene ostracodes from west-central Sinai, Egypt - taxonomy, biostratigraphy, paleoecology and paleobiogeography. Revue de Paléobiologie, 27(1):159-189.

Moura, J.A. \& Praça, U.M. 1985. Ostracodes das seqüências não marinhas e transicionais mesozóicas (andares Jiquiá e Alagoas), bacia de Campos. Coletânea de Trabalhos Paleontológicos - Série Geologia, 27(2):401-408.

Moura, J.A. 1972. Algumas espécies e subespécies novas de ostracodes da bacia Recôncavo/Tucano. Boletim Técnico da PETROBRÁS, 15(3):245-263.

Moura, J.A. 1988. Ostracods from non-marine Early Cretaceous sediments of the Campos Basin, Brazil, In: Hanai, T., Ikeya, N. \& Ishizaki, K. (Eds) Evolutionary Biology of Ostracoda: Its Fundamentals and Applications. Developments in Palaeontology and Stratigraphy, 11:1207-1216.

Moysey, D.G. \& Maddocks, R.F. 1982. Ostracoda and associated fauna of the lower Walnut Formation (lower Cretaceous) of Travis and Williamson counties, Texas. In: Maddocks, R.F. (Ed.) Texas Ostracoda: guidebook of excursions and related papers for the Eighth International Symposium on Ostracoda, July 24-25 and July 30-August 3, 1982. Department of Geosciences - University of Houston, Houston, 143-165.

Münster, G. 1830. Ueber einige fossile Arten Cypris (Müller, Lamk.) und Cythere (Müller, Latreille, Desmarest). Jahrbuch für Mineralogie, Geognosie, Geologie und Petrefaktenkunde, 1:60-67.

Musacchio, E.A. \& Simeoni, M. 2008. Valanginian and Hauterivian marine ostracods from 
Patagonia (Argentina): correlations and palaeogeography. Revue de Micropaléontologie, 51:239-257.

Musacchio, E.A. 1978. Ostracodos del Cretacico Inferior em el Grupo Mendoza, Provincia del Neuquen, Argentina. In: Actas del VII Congreso Geológico Argentino: Tomo 2. Asociación Geológica Argentina, Buenos Aires, 459-473.

Neale, J.W. 1978. The Cretaceous. In: Bate, R. \& Robinson, E. (Eds) A stratigraphical index of British Ostracoda. Geological Journal Special Issue, 8:325-384.

Neale, J.W. 1982. Aspects of the Subfamily Schulerideinae. In: Bate, R.H., Robinson, E. \& Sheppard, L.M. (Eds) Fossil and Recent Ostracods. Ellis Horwood, Chichester, 178-192.

Neufville, E.M.H. 1973. Upper Cretaceous-Palaeogene ostracods from the South Atlantic. Publications from the Palaeontological Institution of the University of Uppsala, Special volume, 1:1-205.

Neufville, E.M.H. 1979. Upper Cretaceous-Paleogene marine ostracods from the SergipeAlagoas basin, northeastern Brazil. Bulletin of the Geological Institutions of the University of Uppsala, 8:135-172.

Nogueira, M.S., Lemos, V.B. \& Terra, G.J.S. 2003. As "coquinas" do Membro Morro do Chaves, Cretáceo Inferior da bacia de Alagoas, e seu potencial para reservatório de petróleo. In: $2^{\circ}$ Congresso Brasileiro de P\&D em Petróleo \& Gás. UFRJ, Rio de Janeiro.

ODSN, 2011. ODSN Plate Tectonic Reconstruction Service. http://www.odsn.de/odsn/ services/paleomap/paleomap.html (acessado em 24 de março de 2014).

Oertli, H.J. 1957. Ostracodes du Jurassique Supérieur du Bassin de Paris (sondage Vernon 1). Revue de l'Institut Français du Pétrole, 12(6):647-695.

Oertli, H.J. 1963. Faunes d'Ostracodes du Mésozöique de France. E.J. Brill, Leiden, 57 p.

Oertli, H.J. 1974. Lower Cretaceous and Jurassic ostracods from DSDP Leg 27-a preliminary account. Deep Sea Drilling Project Initial Reports, 27:947-965.

Oertli, H.J., Brotzen, F. \& Bartenstein, H. 1961. Mikropaläontologisch-feinstratigraphische untersuchung der Jura-Kreide-Grenzschichten in Südschweden. Sveriges Geologiska Undersökning Avhandlingar och Uppsatser Serie C, 55(3):1-24.

Ojeda, H.A.O. \& Fujita, A.M. 1976. Bacia Sergipe/Alagoas: Geologia regional e perspectivas petrolíferas. In: Sanguinetti (Ed.) Anais do XVIII Congresso, Volume 1, Porto Alegre, RSOutubro/1974. SBG, São Paulo, 137-158.

Oliveira, L.C.V., Rodrigues, R. \& Lemos, V.B. 2004. Análise multivariada em nanofósseis calcários e isótopos estáveis $\left(\delta^{18} \mathrm{O}\right.$ e $\left.\delta^{13} \mathrm{C}\right)$ do Campaniano superior - Maastrichtiano inferior na bacia de Campos. Boletim de Geociências da PETROBRAS, 13(1):81-104.

Petri, S. 1987. Cretaceous paleogeographic maps of Brasil. Palaeogeography, 
Palaeoclimatology, Palaeoecology, 59:117 168.

Piovesan, E.K., Ballent, S. \& Fauth, G. 2012. Cretaceous palaeogeography of southern Gondwana from the distribution of the marine ostracod Majungaella Grekoff: New data and review. Cretaceous Research, 37:127-147.

Piovesan, E.K., Bergue, C.T. \& Fauth, G. 2009. Cretaceous ostracodes from Pará-Maranhão Basin, Brazil: taxonomy and preliminary paleoecological and paleobiogeographical inferences. Revue de Paléobiologie, 28(2):437-456.

Piovesan, E.K., Nicolaidis, D.D., Fauth, G. \& Viviers, M.C. 2013. Ostracodes from the Aptian-Santonian of the Santos, Campos and Espírito Santo basins, Brazil. Journal of South American Earth Sciences, 48:240-254.

Poag, Jr., C.W. 1962. Dicrorygma, a new ostracod genus from the Lower Cretaceous of Texas. Journal of Paleontology, 36(4):827-837.

Pokorný, V. 1964. Conchoecia? cretacea n. sp., first fossil species of the family Halocyprididae (Ostracoda, Crustacea). Acta Universitatis Carolinae - Geologica, 2:175180.

Pokorný, V. 1973. The Ostracoda of the Klentnice Formation (Tithonian?) Czechoslovakia. Ústřední Ústav Geologický, 1:1-108.

Ponte, F.C. \& Asmus, H.E. 1976. The Brazilian marginal basins: current state of knowledge. Anais da Academia Brasileira de Ciências - Suplemento, 48:215-289.

Poropat, S.F. \& Colin, J.P. 2012a. Early Cretaceous ostracod biostratigraphy of eastern Brazil and western Africa: an overview. Gondwana Research, 22:772-798.

Poropat, S.F. \& Colin, J.P. 2012b. Reassessment of the Early Cretaceous non-marine ostracod genera Hourcqia Krömmelbein, 1965 and Pattersoncypris Bate, 1972 with the description of a new genus, Kroemmelbeincypris. Journal of Paleontology, 86(4):700-720.

Puckett, T.M. 2002. Systematics and paleobiogeography of brachycytherine Ostracoda. Micropaleontology, 48(2):1-87.

Puckett, T.M., Colin, J.P. \& Mitchell, S. 2012. New species and genera of Ostracoda from the Maastrichtian (Late Cretaceous) of Jamaica. Micropaleontology, 58(5):397-455.

Ramos, M.I.F., Rossetti, D.F. \& Paz, J.D.S. 2006. Caracterização e significado paleoembiental da fauna de ostracodes da Formação Codó (Neoaptiano), leste da bacia de Grajaú, MA, Brasil. Revista Brasileira de Paleontologia, 9(3):339-348.

Rand, H.M. \& Mabesoone, J.M. 1982. Northeastern Brazil and the final separation of South America and Africa. Palaeogeography, Palaeoclimatology, Palaeoecology, 38(1982):163183.

Reuss, A.E. 1845. Die Versteinerungen der Böhmischen Kreideformation. Schweitzebart, 
Stuttgart, $148 \mathrm{p}$.

Reyment, R.A. 1978. Quantitative biostratigraphical analysis exemplified by Moroccan Cretaceous ostracods. Micropaleontology, 24(1):24-43.

Reyment, R.A. 1980. Paleo-oceanology and paleobiogeography of the Cretaceous South Atlantic. Oceanologica Acta, 3(1):127-133.

Reyment, R.A. 1981. West Africa. In: Reyment, R.A. \& Bengtson, P. (Eds) Aspects of midCretaceous regional geology. Academic Press, Londres, 133-160.

Rodrigues, G.B., Bom, M.H. \& Fauth, G. 2012. Recovery of ostracods in Cretaceous dolomitic carbonate: The efficiency of acetolysis. Marine Micropaleontology, 92-93:8186.

Roemer, F.A. 1841. Die Versteinerungen des Norddeutschen Kreidegebirges. Hahnsche Buchhandlung, Hannover, 145 p.

Rosenfeld, A. \& Raab, M. 1974. Cenomanian-Turonian ostracodes from the Judea group in Israel. Geological Survey of Israel Bulletin, 62:1-64.

Rosenfeld, A. \& Raab, M. 1983. Lower Cretaceous ostracodes from Israel and Sinai. Israel Journal of Earth Sciences, 33(3):85-134.

Roth, R. 1928. Monoceratina: a new genus of Ostracoda from the Pennsylvanian of Oklahoma. Journal of Paleontology, 2(1):15-19.

Ruault-Djerrab, M. \& Kechid-Benkherouf, F. 2011. Micropaleontological study (foraminifera, ostracods) and characterization of the paleoenvironment of middle Cretaceous deposits (Djebel Chemla area, north-eastern Algeria). Arabian Journal of Geosciences, 4:1289-1299.

Sars, G.O. 1866. Oversigt af Norges marine ostracoder. Forhandlinger i Videnskabs-Selskabet i Christiania, 1-130.

Schaller, H. 1969. Revisão estratigráfica da bacia de Sergipe-Alagoas. Boletim Técnico da PETROBRÁS, 12(1):21-86.

Schmidt, R.A. 1948. Ostracoda from the Upper Cretaceous and Lower Eocene of Maryland, Delaware, and Virginia. Journal of Paleontology, 22(4):389-431.

Schornikov, E.I. \& Mikhailova, E.D. 1990. Ostrakody Bythocytheridae: rannego etapa, razvitiya, Sravnitel'naya morfologiya, paleoekologiya, puti evolyutsii. Nauka, Moscou. 278 p.

Schornikov, E.I. 1990. Evolution and classification of Bythocytheridae. Courier Forschungsinstitut Senckenberg, 123:291-302.

Schudack, U. \& Schudack, M.E. 2000. Ostracods from the Upper Jurassic (OxfordianTithonian) of southern Germany. Journal of Micropalaeontology, 19:97-112. 
Seeling, J. \& Bengtson, P. 1999. Cenomanian oysters from the Sergipe basin, Brazil. Cretaceous Research, 20:747-765.

Seeling, J. \& Bengtson, P. 2003. The bivalve Pinna cretacea (Schlotheim, 1813) from the Cretaceous of Brasil. Acta Palaeontologica Polonica, 48(3):475-480.

Shahin, A. 1991. Cenomanian-Turonian ostracods from Gebel Nezzazat, southwestern Sinai, Egypt, with observations on $\delta^{13} \mathrm{C}$ values and the Cenomanian/Turonian boundary. Journal of Micropaleontology, 12(2):133-150.

Silva Filho, F.M.A., Santana, A.C. \& Bonfim, L.F.C. 1978. Evolução tectono-sedimentar do Grupo Estância: suas correlações. In: Anais do XXX Congresso Brasileiro de Geologia. SBG, Recife, 685-699.

Silva, M.A.M., Lowestein, T. \& Timofeeff, M. 1997. Composição química da água do mar inferida através da análise das inclusões fluidas nas halitas dos evaporitos aptianos da bacia de Sergipe. Boletim de Geociências da PETROBRAS, 11(1/2):166-167.

Silva, O.B., Caixeta, J.M., Milhomem, P.S. \& Kosin, M.D. 2007. Bacia do Recôncavo. Boletim de Geociências da PETROBRAS, 15(2):423-431.

Silva-Telles Júnior, A.C. \& Viana, M.S.S. 1990. Paleoecologia dos ostrácodes da Formação Santana (bacia do Araripe): um estudo ontogenético de populações. In: Campos, D.A., Viana, M.S.S., Brito, P.M. \& Beurlen, G. (Eds) Atas do $1^{o}$ Simpósio sobre a Bacia do Araripe e Bacias Interiores do Nordeste, Volume 1. DNPM/SBP/SBG - Núcleo Nordeste, Fortaleza, 309-328.

Smith, A.G., Smith, D.G. \& Funnell, B.M. 1994. Atlas of Mesozoic and Cenozoic Coastlines. Cambridge, Cambridge University Press, 99p.

Smith, R.J. 2000. Morphology and ontogeny of Cretaceous ostracods with preserved appendages from Brasil. Palaeontology, 43(1):63-98.

Souza-Lima, W. \& Hamsi Junior, G.P. 2003a. Bacias da margem continental. Phoenix, 50:16.

Souza-Lima, W. \& Hamsi Junior, G.P. 2003b. Origem, evolução e classificação das bacias sedimentares. Phoenix, 49:1-8.

Souza-Lima, W., Andrade, E.J., Bengston, P. \& Galm, P.C. 2002. A bacia de Sergipe-Alagoas: evolução geológica, estratigrafia e conteúdo fóssil. Phoenix, Edição Especial, 1:1-34.

Swain, F.M. \& Brown, P.M. 1964. Cretaceous Ostracoda From Wells in the Southeastern United States. Bulletin, North Carolina Division of Mineral Resources, 78:1-55.

Swain, F.M. \& Brown, P.M. 1972. Lower Cretaceous, Jurassic(?) and Triassic Ostracoda from the Atlantic coastal region. United States Geological Survey Professional Paper, 795:1-55.

Swain, F.M. 1946. Middle Mesozoic nonmarine Ostracoda from Brazil and New Mexico. 
Journal of Paleontology, 20(6):543-555.

Swain, F.M. 1976. Lower and Middle? Cretaceous Ostracoda from the Atlantic Ocean off Guiana and off West Africa. Journal of Paleontology, 50(4):734-753.

Swanson, K.M. 1980. Five new species of Ostracoda from Port Pegasus, Stewart Island. New Zealand Journal of Marine \& Freshwater Research, 14(2):205-211.

Sylvester-Bradley, P.C. \& Benson, R.H. 1971. Terminology for surface features in ornate ostracodes. Lethaia, 4(3):249-286.

Tambareau, Y. 1982. Les Ostracodes et l'histoire géologique de l'Atlantique Sud au Crétacé. Bulletin des Centres de Recherche et Exploration-Production Elf-Aquitaine, 6:1-37.

Tesakova, E.M. 2010. Novyye dannyye o Pozdnesantonskikh i Rannemaastrikhtskikh ostrakodakh Saratovskoy oblasti. Paleontologicheskiy Zhurnal, 2010(2):47-56.

Triebel, E. 1940. Die Ostracoden der deutschen Kreide. 3.*) Cytherideinae und Cytherinae aus der Unteren Kreide. Senckenbergiana, 22(3/4):160-227.

Troelsen, J.C. \& Quadros, L.P. Distribuição Bioestratigráfica elos Nanofósseis em Sedimentos Marinhos (Aptiano - Mioceno) do Brasil. Anais da Academia Brasileira de Ciências, 43(Suplemento):577-609.

Tsao, L.P. 1959. Rod Harbinia Tsao, 1959. In: Nechayeva, M.A., Liu, T.Y., Su, T.I., Sou, T.S., Tem, K.D. \& Tsao, L.P (Eds) Ostrakody nižnemelovyh otloženij ravniny Sunlâo. Monographs of the Institute of Geology, Ministry of Geology, People's Republic of China, Series B (Stratigraphy and Palaeontology), 1(2):48-49.

Valença, L.M.M., Neumann, V.H. \& Mabesoone, J.M. 2003. An overview on CallovianCenomanian intracratonic basins of Northeast Brasil: Onshore stratrigraphic record of the opening of the southern Atlantic. Geologica Acta, 1(3):261-275

Valicenti, V.H. \& Stephens, J.M. 1984. Ostracods from the Upper Valanginian and Upper Hauterivian of the Sundays River Formation, Algoa Basin, South Africa. Revista Española de Micropaleontología, 16:171-239.

Veen, J.E. 1936. Die Cytheridae der Maastrichter Tuffkreide und des Kunrader Korallenkalkes von Süd-Limburg - III. Die Gattungen Loxoconcha, Monoceratina, Paracytheridea, Xestoleberis, Cytheropteron und Cytherura. Natuurhistorisch Maandblad, 25: 21-23, $32-$ 36, 42-45, 61-64, 69-71, 82-86, 98-101, 108-113.

Viana, C.F. 1966. Stratigraphic distribution of Ostracoda in the Bahia Supergroup (Brazil). In: Hinte, E.J. (Ed.) Proceedings of the second West African Micropaleontological Colloquium - Ibadan, June 18th-July 1st. E.J. Brill, Leiden, 240-257.

Viviers, M.C., Koutsoukos, E.A.M., Silva-Telles Júnior, A.C. \& Bengtson, P. 2000. Stratigraphy and biogeographic affinities of the late Aptian-Campanian ostracods of the 
Potiguar and Sergipe basins in northeastern Brazil. Cretaceous Research, 21:407-455.

Weaver, P.P.E. 1982. Ostracoda from the British lower Chalk and Plenus Marls. Monograph of the Palaeontographical Society, 562:1-127.

Wicher, C.A. 1959. Ein Beitrag zur Altersdeutung des Reconcavo, Bahia (Brasilien). Geologisches Jahrbuch, 77:35-58.

Wilkinson, I.P. 1988. Ostracoda Across the Albian/Cenomanian Boundary in Cambridgeshire and Western Suffolk, Eastern England. In: Hanai, T., Ikeya, N. \& Ishizaki, K. (Eds) Evolutionary Biology of Ostracoda: Its Fundamentals and Applications. Developments in Palaeontology and Stratigraphy, 11:1229-1244.

Williamson, W.C. 1847. On some microscopical objects found in the mud of the Levant, and other deposits; with remarks on the mode of formation of calcareous and influsional siliceous rocks. Transactions of the Literary and Philosophical Society of Manchester, 8:1128.

Witte, L., Lissenberg, T. \& Schuurman, H. 1992. Ostracods from the Albian/Cenomanian boundary in the Achterhoek area (eastern part of the Netherlands). Scripta Geologica, 102:33-84. 
Anexo I. Tabelas de distribuição estratigráfica por amostra das espécies de ostracodes identificadas nos afloramentos e perfurações do presente trabalho. 
Tabela 3. Distribuição estratigráfica por amostra das espécies de ostracodes identificadas no afloramento Penha, Município de Riachuelo, Estado de Sergipe, Brasil; Formação Riachuelo, bacia de Sergipe-Alagoas. Espécies guia para as zonas e subzonas identificadas se encontram sombreadas.

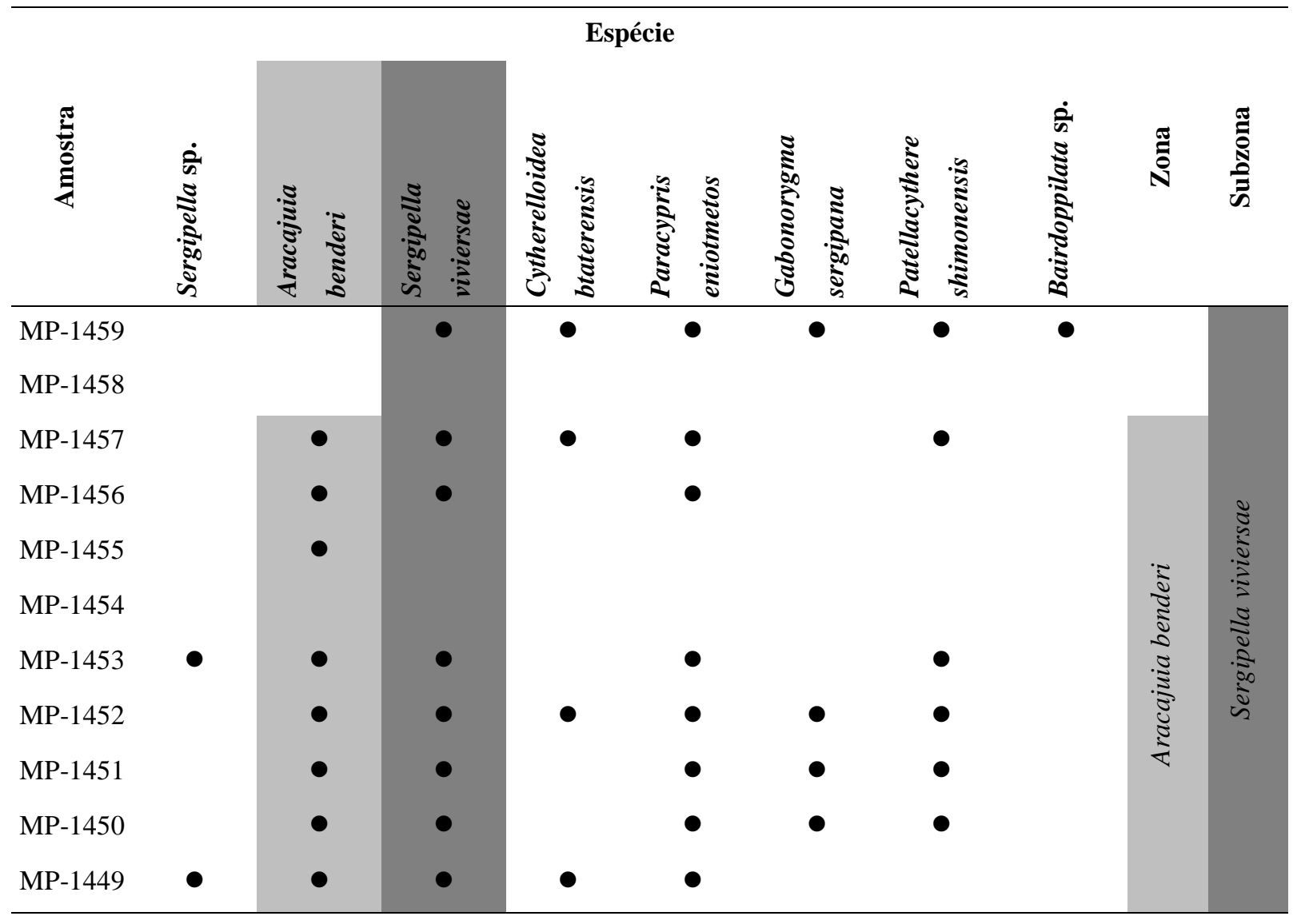

Tabela 4. Distribuição estratigráfica por amostra das espécies de ostracodes identificadas no afloramento Fazenda Santa Bárbara, Município de Rosário do Catete, Estado de Sergipe, Brasil; Formação Riachuelo, bacia de Sergipe-Alagoas. Espécies guia para as zonas e subzonas identificadas se encontram sombreadas.

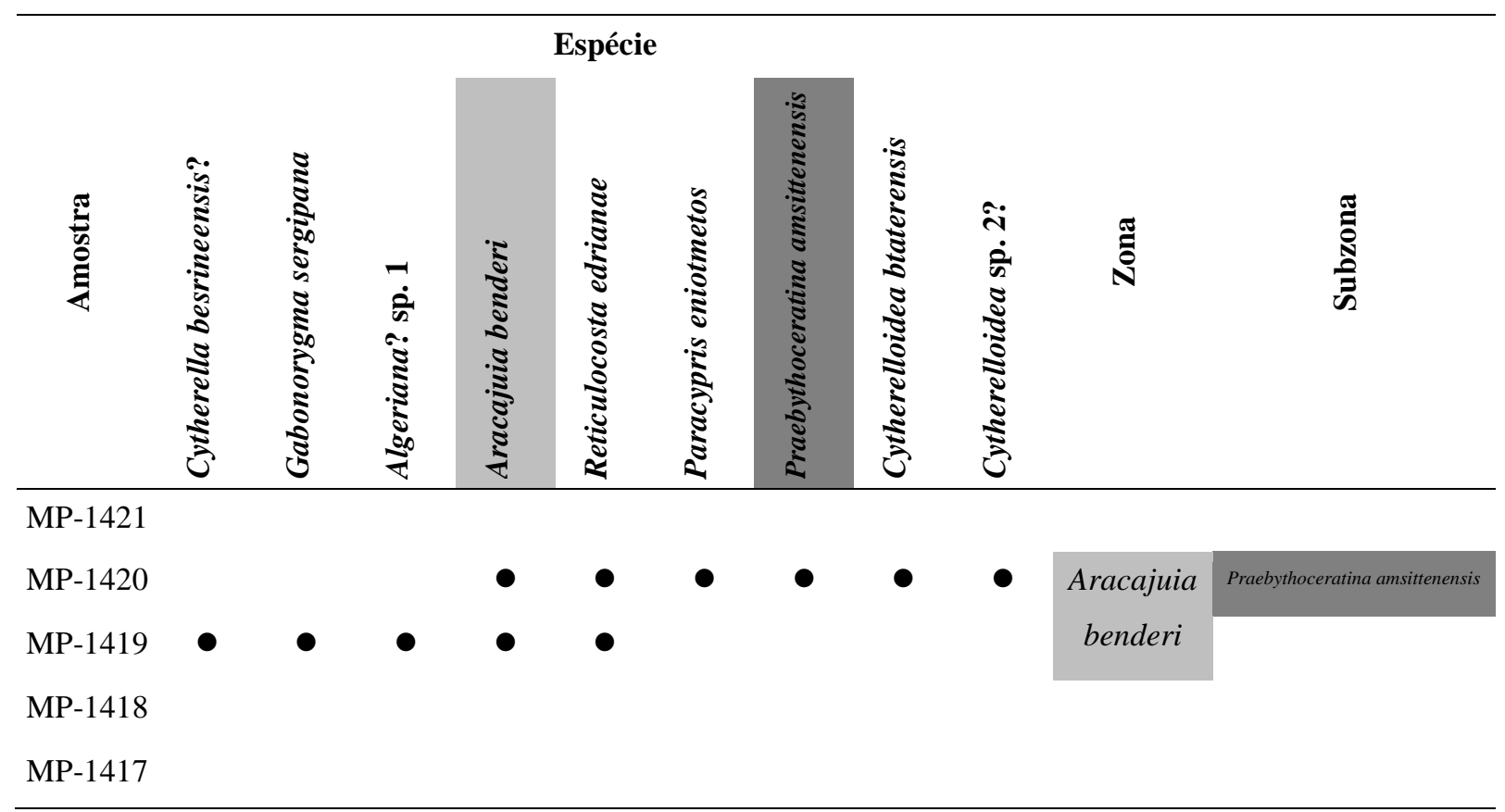


Tabela 4 (continuação). Distribuição estratigráfica por amostra das espécies de ostracodes identificadas no afloramento Fazenda Santa Bárbara, Município de Rosário do Catete, Estado de Sergipe, Brasil; Formação Riachuelo, bacia de Sergipe-Alagoas. Espécies guia para as zonas e subzonas identificadas se encontram sombreadas.

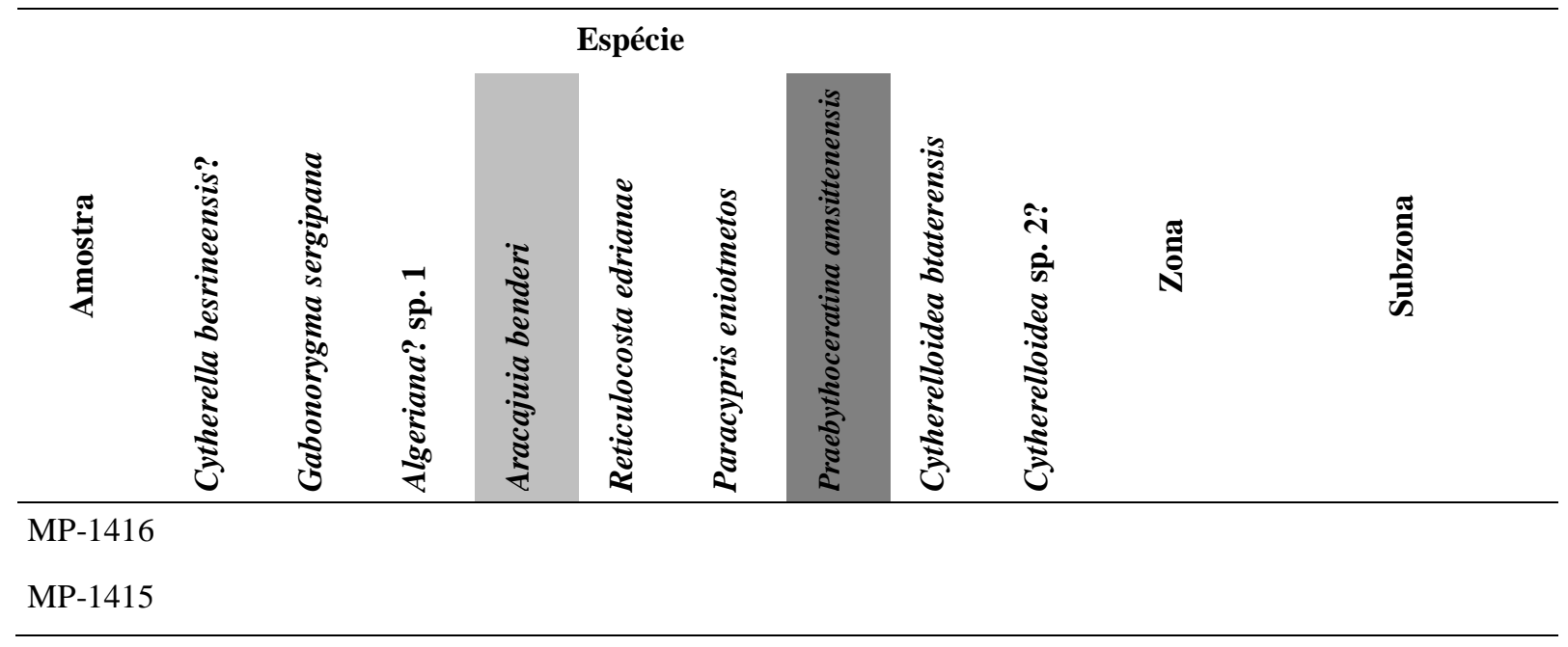

Tabela 5. Distribuição estratigráfica por amostra das espécies de ostracodes identificadas no afloramento ESTRE, Município de Rosário do Catete, Estado de Sergipe, Brasil; Formação Riachuelo, bacia de SergipeAlagoas. Espécies guia para as zonas e subzonas identificadas se encontram sombreadas.

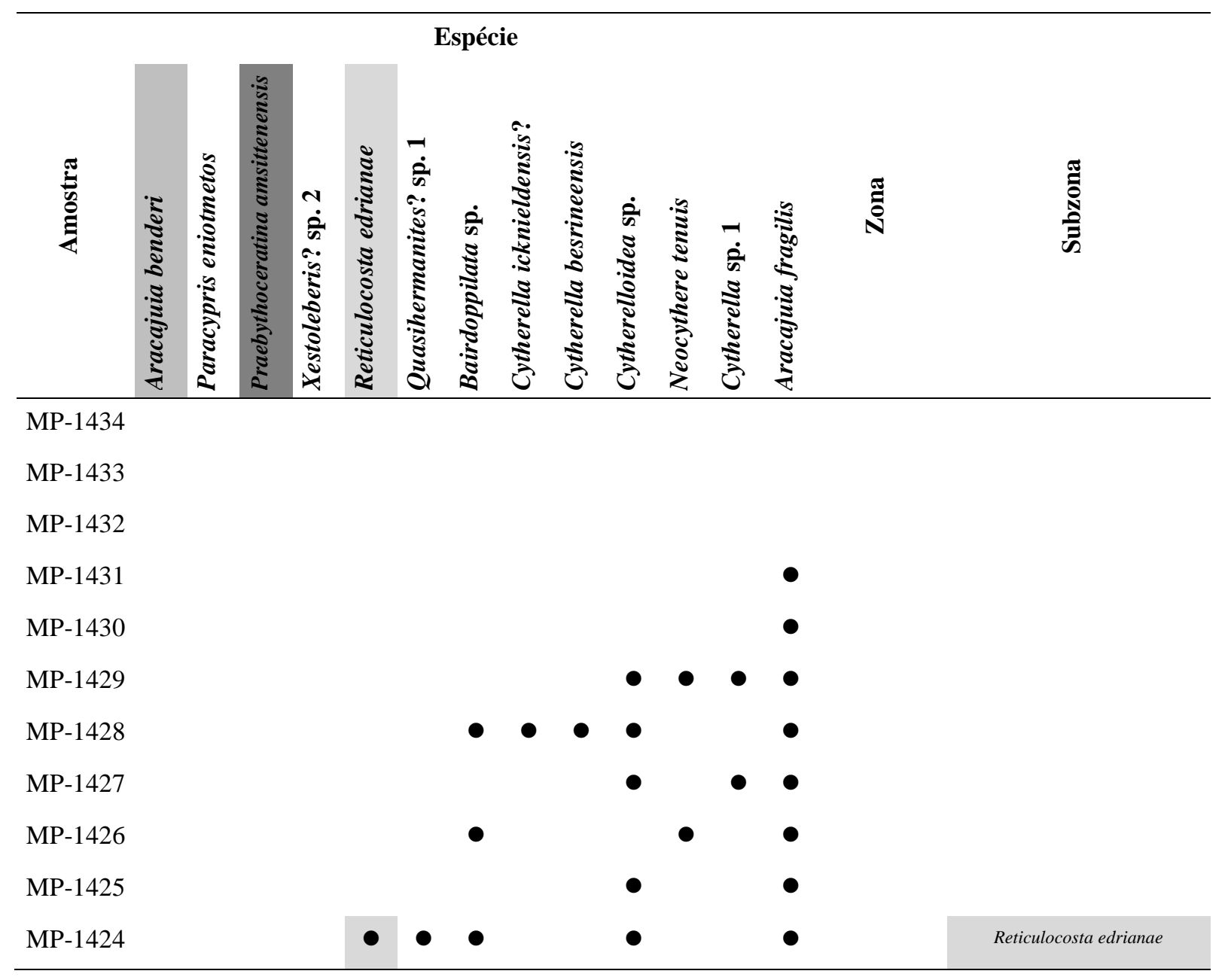


Tabela 5 (continuação). Distribuição estratigráfica por amostra das espécies de ostracodes identificadas no afloramento ESTRE, Município de Rosário do Catete, Estado de Sergipe, Brasil; Formação Riachuelo, bacia de Sergipe-Alagoas. Espécies guia para as zonas e subzonas identificadas se encontram sombreadas.

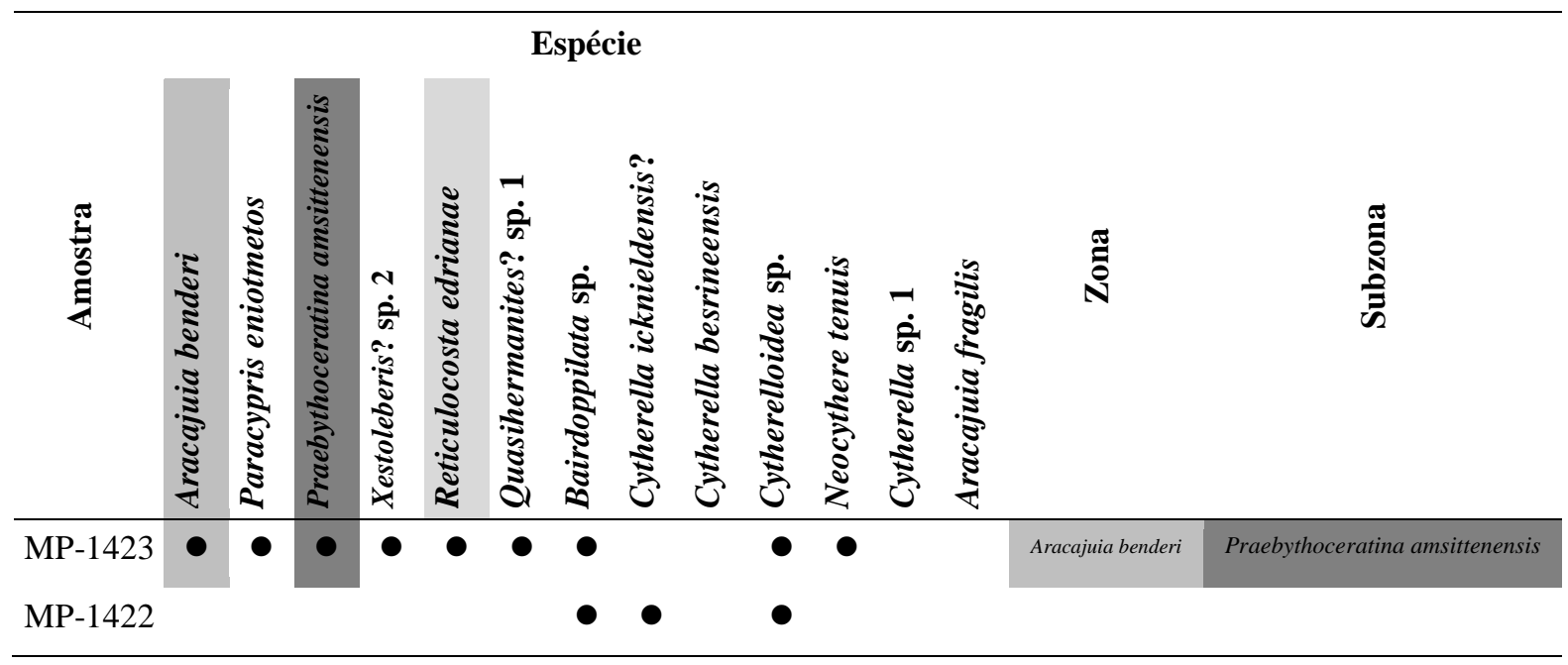

Tabela 6. Distribuição estratigráfica por amostra das espécies de ostracodes identificadas no afloramento P384, Município de Riachuelo, Estado de Sergipe, Brasil; Formação Riachuelo, bacia de Sergipe-Alagoas. Espécies guia para as zonas e subzonas identificadas se encontram sombreadas.

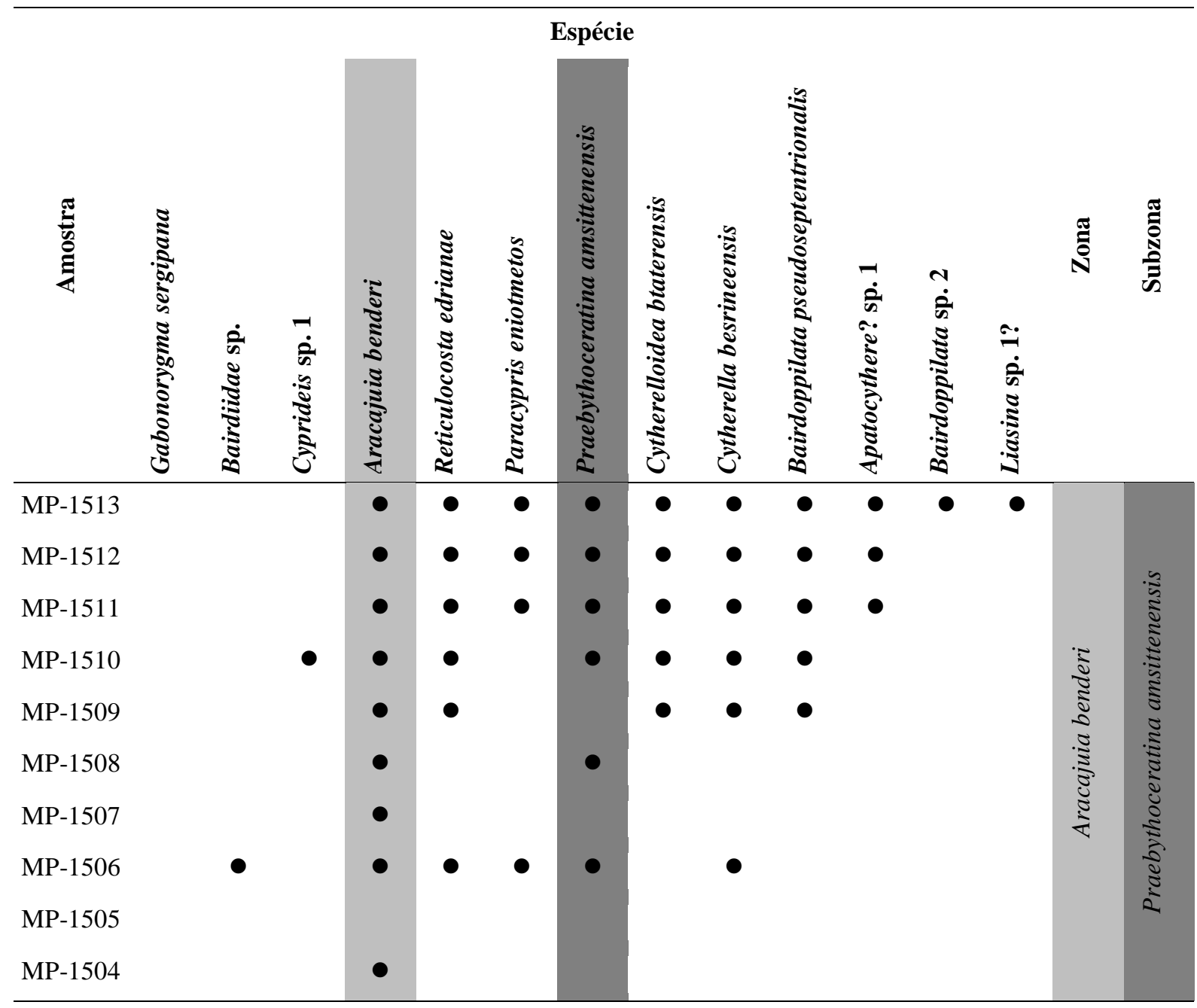


Tabela 6 (continuação). Distribuição estratigráfica por amostra das espécies de ostracodes identificadas no afloramento P384, Município de Riachuelo, Estado de Sergipe, Brasil; Formação Riachuelo, bacia de SergipeAlagoas. Espécies guia para as zonas e subzonas identificadas se encontram sombreadas.

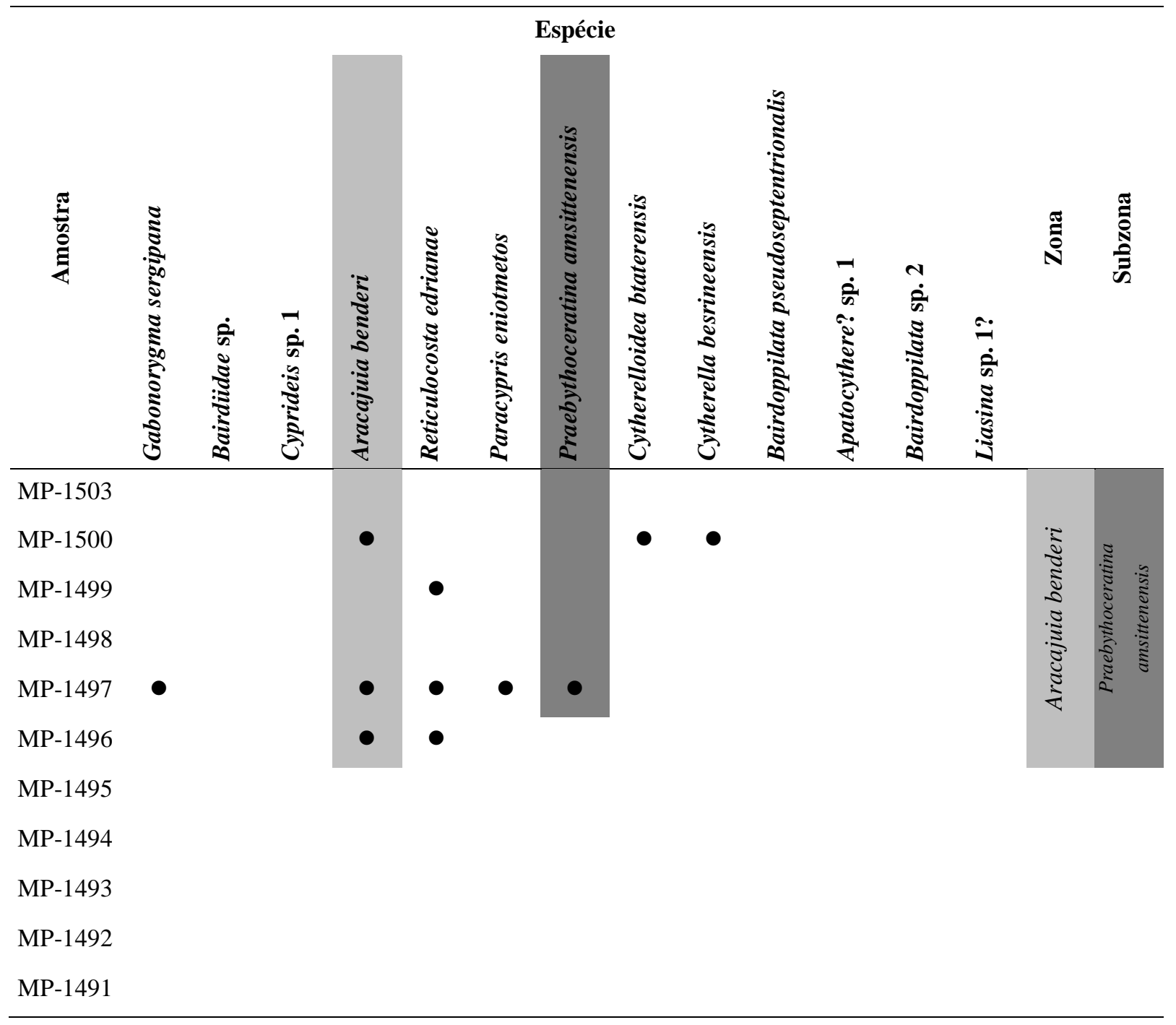

Tabela 7. Distribuição estratigráfica por amostra das espécies de ostracodes identificadas no afloramento Porto dos Barcos 3, Município de Riachuelo, Estado de Sergipe, Brasil; Formação Riachuelo, bacia de SergipeAlagoas. Espécies guia para as zonas e subzonas identificadas se encontram sombreadas.

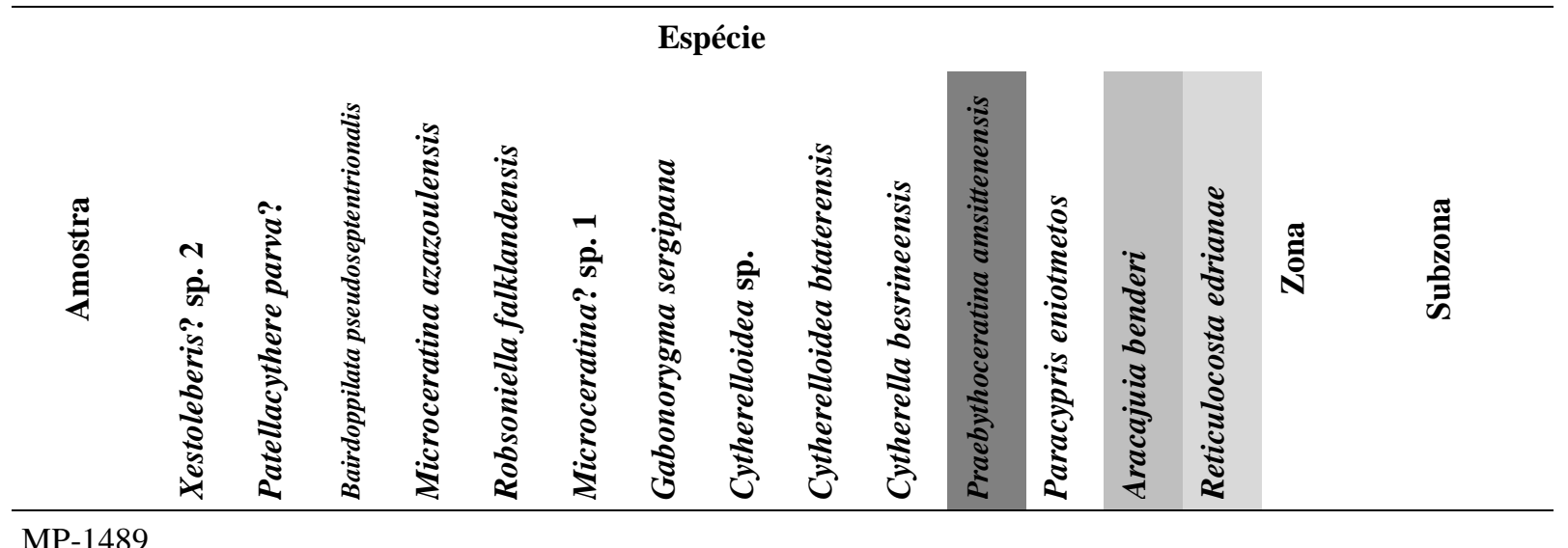


Tabela 7 (continuação). Distribuição estratigráfica por amostra das espécies de ostracodes identificadas no afloramento Porto dos Barcos 3, Município de Riachuelo, Estado de Sergipe, Brasil; Formação Riachuelo, bacia de Sergipe-Alagoas. Espécies guia para as zonas e subzonas identificadas se encontram sombreadas.

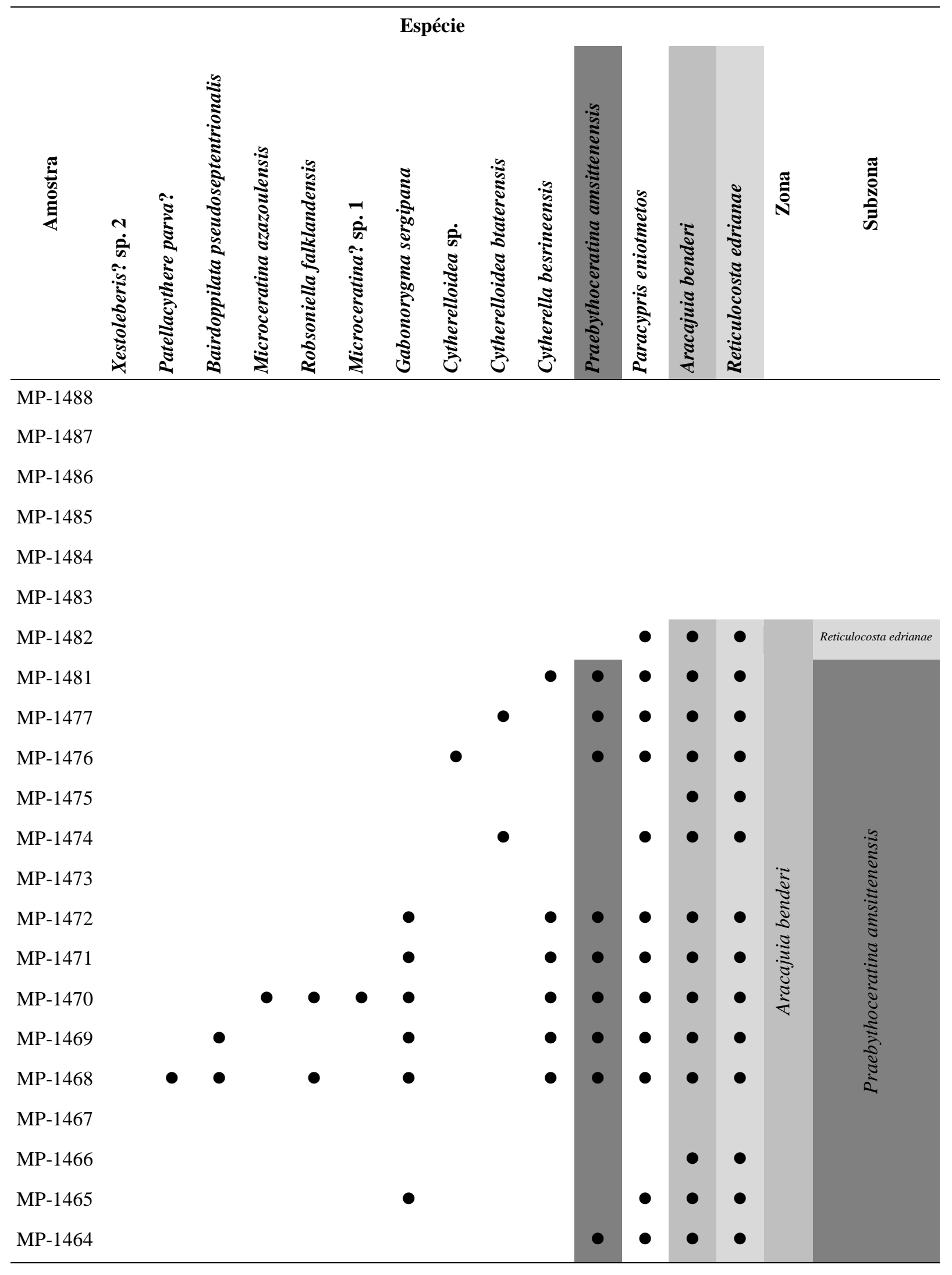


Tabela 7 (continuação). Distribuição estratigráfica por amostra das espécies de ostracodes identificadas no afloramento Porto dos Barcos 3, Município de Riachuelo, Estado de Sergipe, Brasil; Formação Riachuelo, bacia de Sergipe-Alagoas. Espécies guia para as zonas e subzonas identificadas se encontram sombreadas.

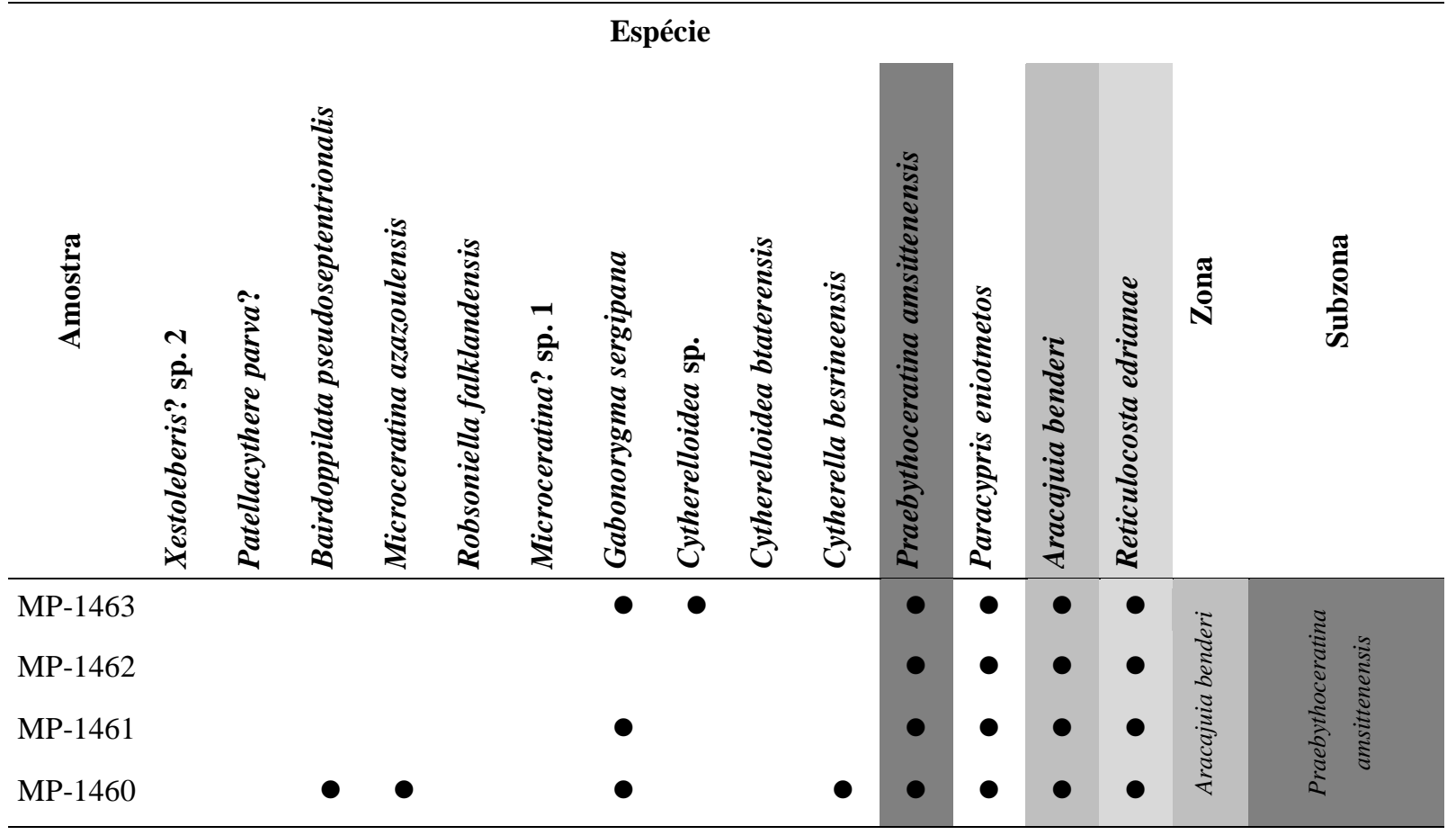

Tabela 8. Distribuição estratigráfica por amostra das espécies de ostracodes identificadas no afloramento Massapê, Município de Riachuelo, Estado de Sergipe, Brasil; Formação Riachuelo, bacia de Sergipe-Alagoas. Espécies guia para as zonas e subzonas identificadas se encontram sombreadas.

\section{Espécie}

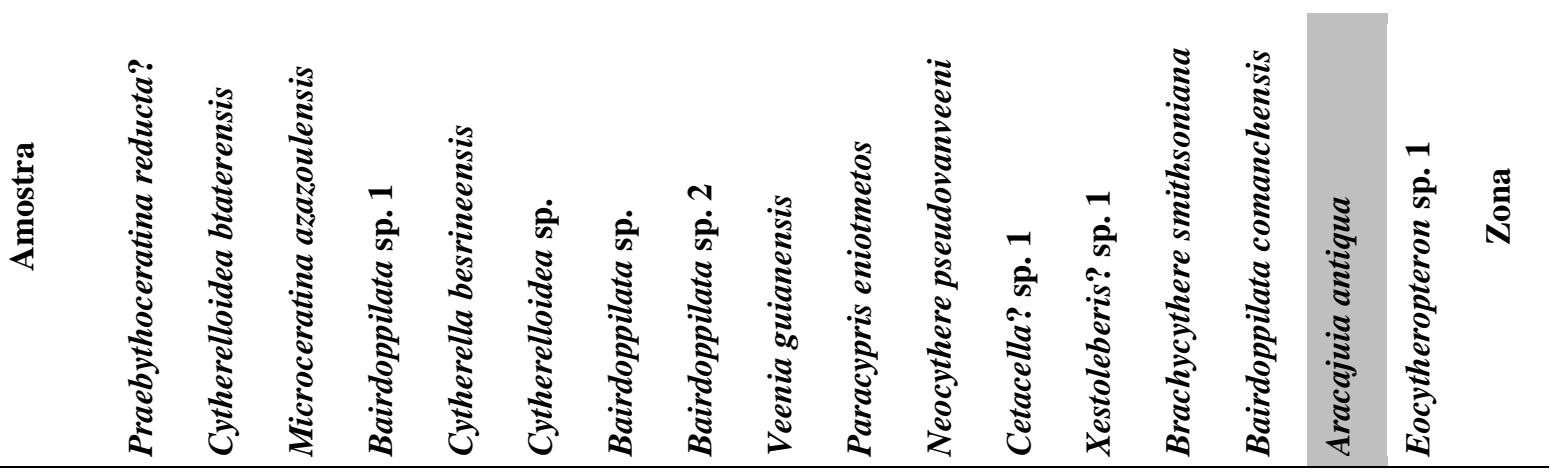

MP-1548

MP-1542

MP-1547

MP-1546

MP-1545

MP-1544

MP-1543

MP-1541 
Tabela 8 (continuação). Distribuição estratigráfica por amostra das espécies de ostracodes identificadas no afloramento Massapê, Município de Riachuelo, Estado de Sergipe, Brasil; Formação Riachuelo, bacia de Sergipe-Alagoas. Espécies guia para as zonas e subzonas identificadas se encontram sombreadas.

\section{Espécies}

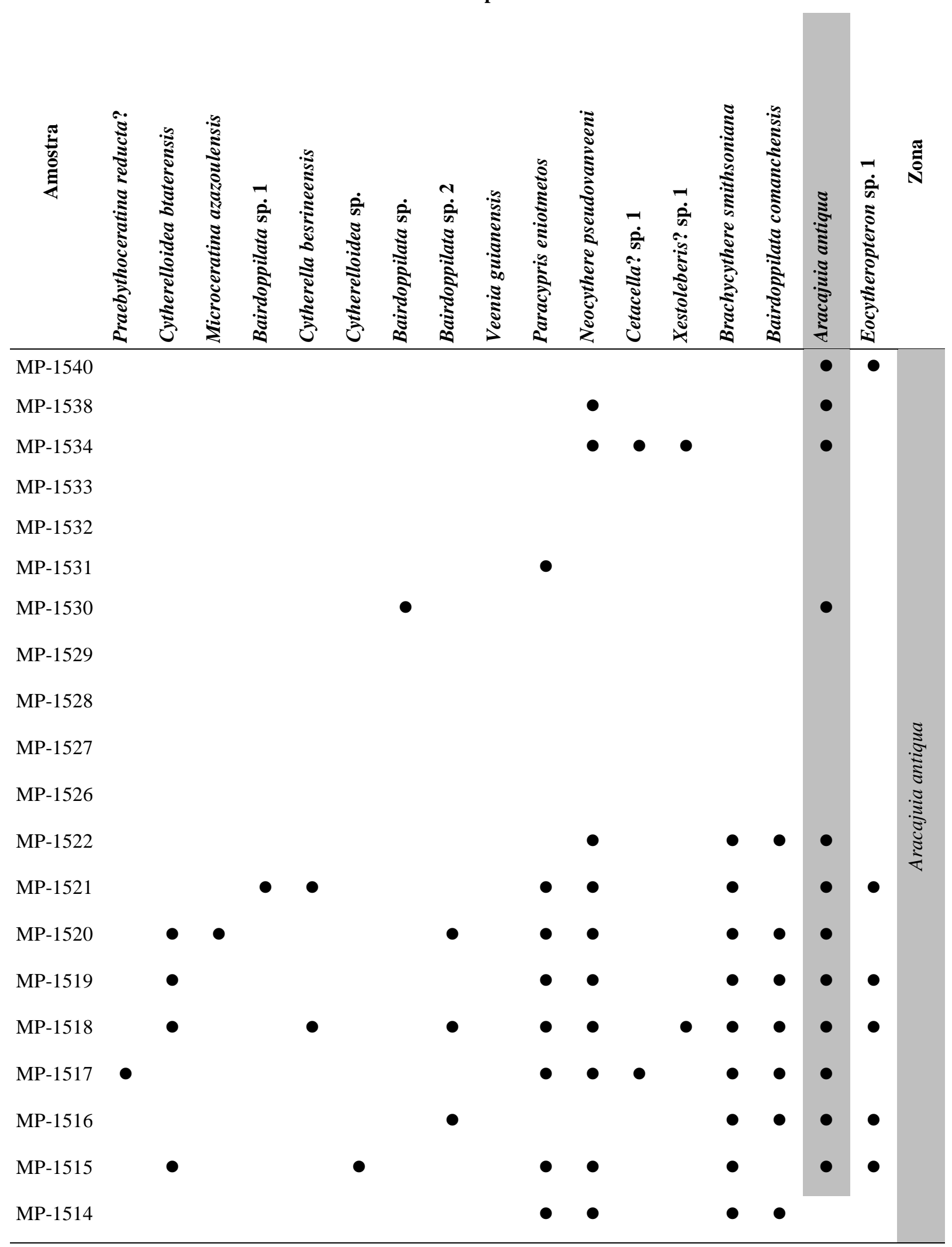


Tabela 9. Distribuição estratigráfica por amostra das espécies de ostracodes identificadas no afloramento São José 1, Município de Riachuelo, Estado de Sergipe, Brasil; Formação Riachuelo, bacia de Sergipe-Alagoas. Espécies guia para as zonas e subzonas identificadas se encontram sombreadas.

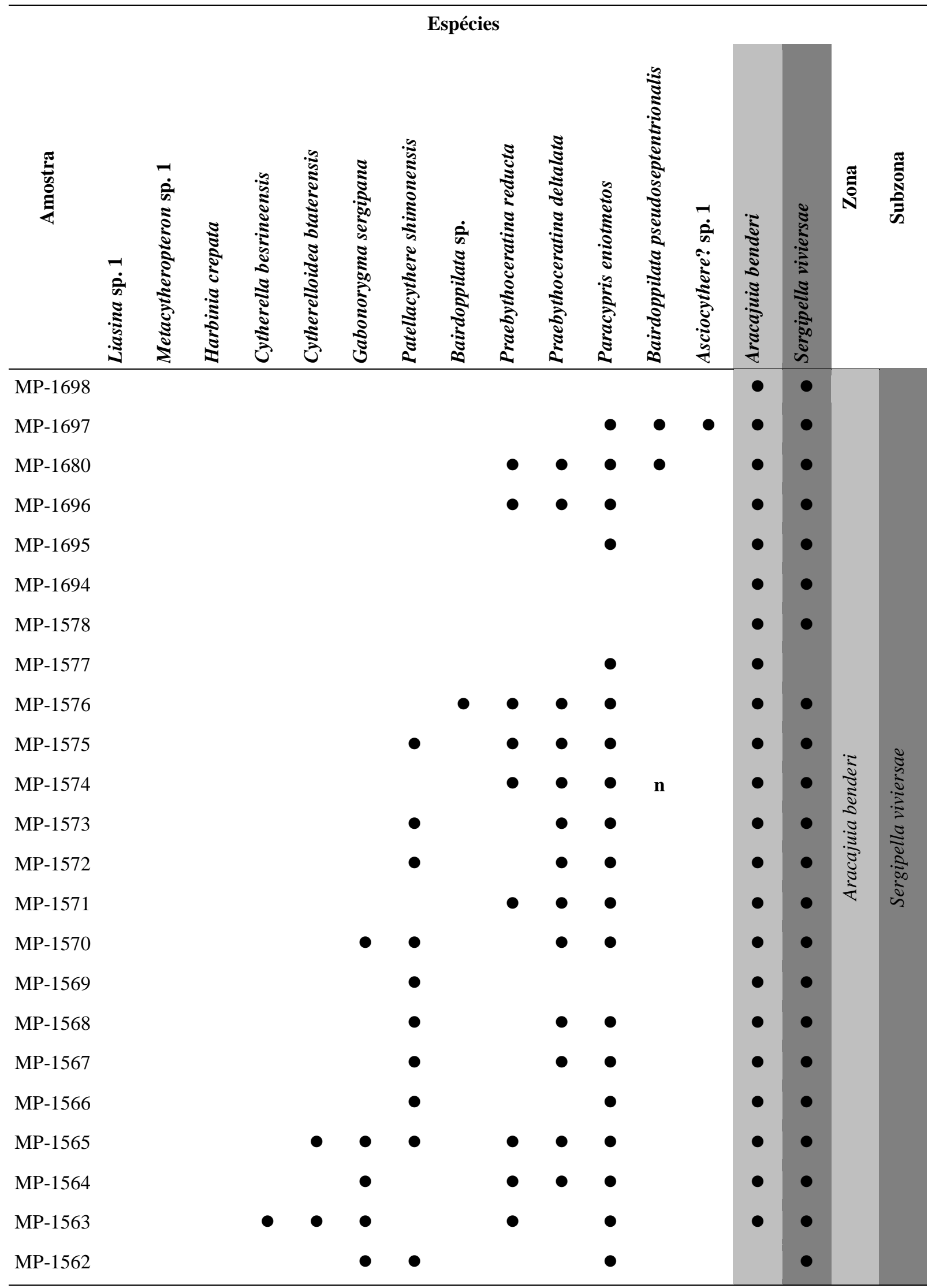


Tabela 9 (continuação). Distribuição estratigráfica por amostra das espécies de ostracodes identificadas no afloramento São José 1, Município de Riachuelo, Estado de Sergipe, Brasil; Formação Riachuelo, bacia de Sergipe-Alagoas. Espécies guia para as zonas e subzonas identificadas se encontram sombreadas.

\section{Espécies}

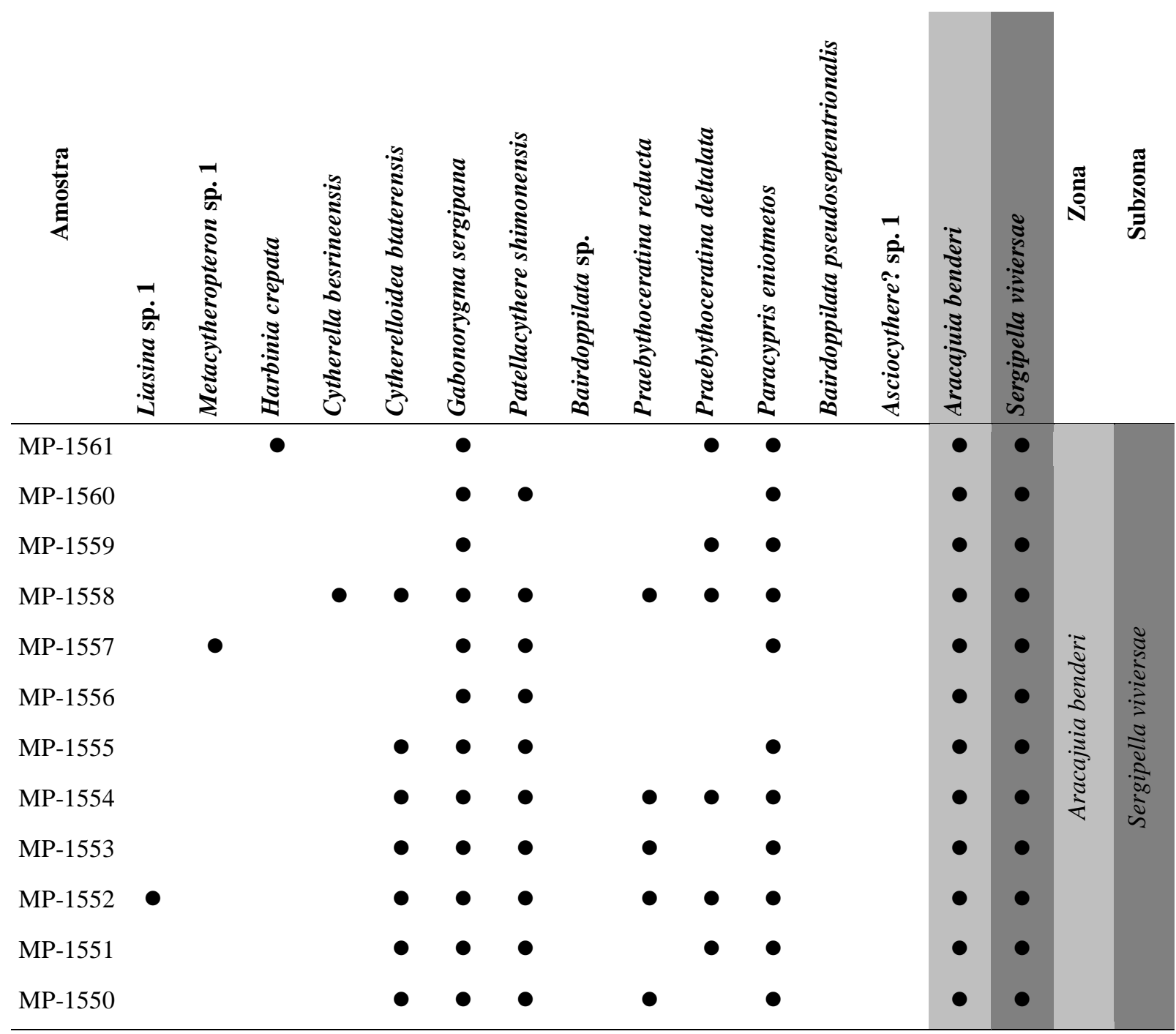

Tabela 10. Distribuição estratigráfica por amostra das espécies de ostracodes identificadas na perfuração 1-CPB1, Município de Carmópolis, Estado de Sergipe, Brasil. Espécies guia para as zonas e subzonas identificadas se encontram sombreadas.

Espécie

๕્⿹

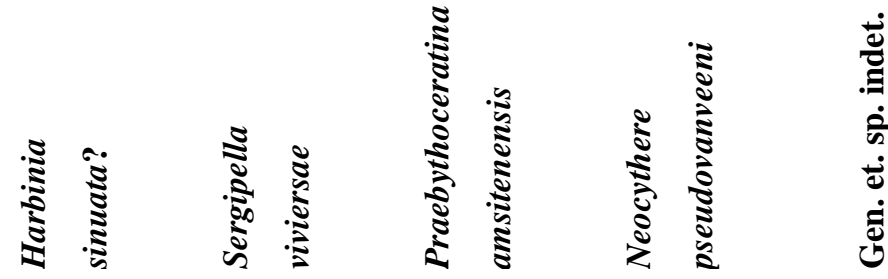

Subzona

$\frac{\dot{m}}{\dot{m}}$

$\dot{0}$

ฮั

198,00

222,00 
Tabela 10 (continuação). Distribuição estratigráfica por amostra das espécies de ostracodes identificadas na perfuração 1-CPB-1, Município de Carmópolis, Estado de Sergipe, Brasil. Espécies guia para as zonas e subzonas identificadas se encontram sombreadas.

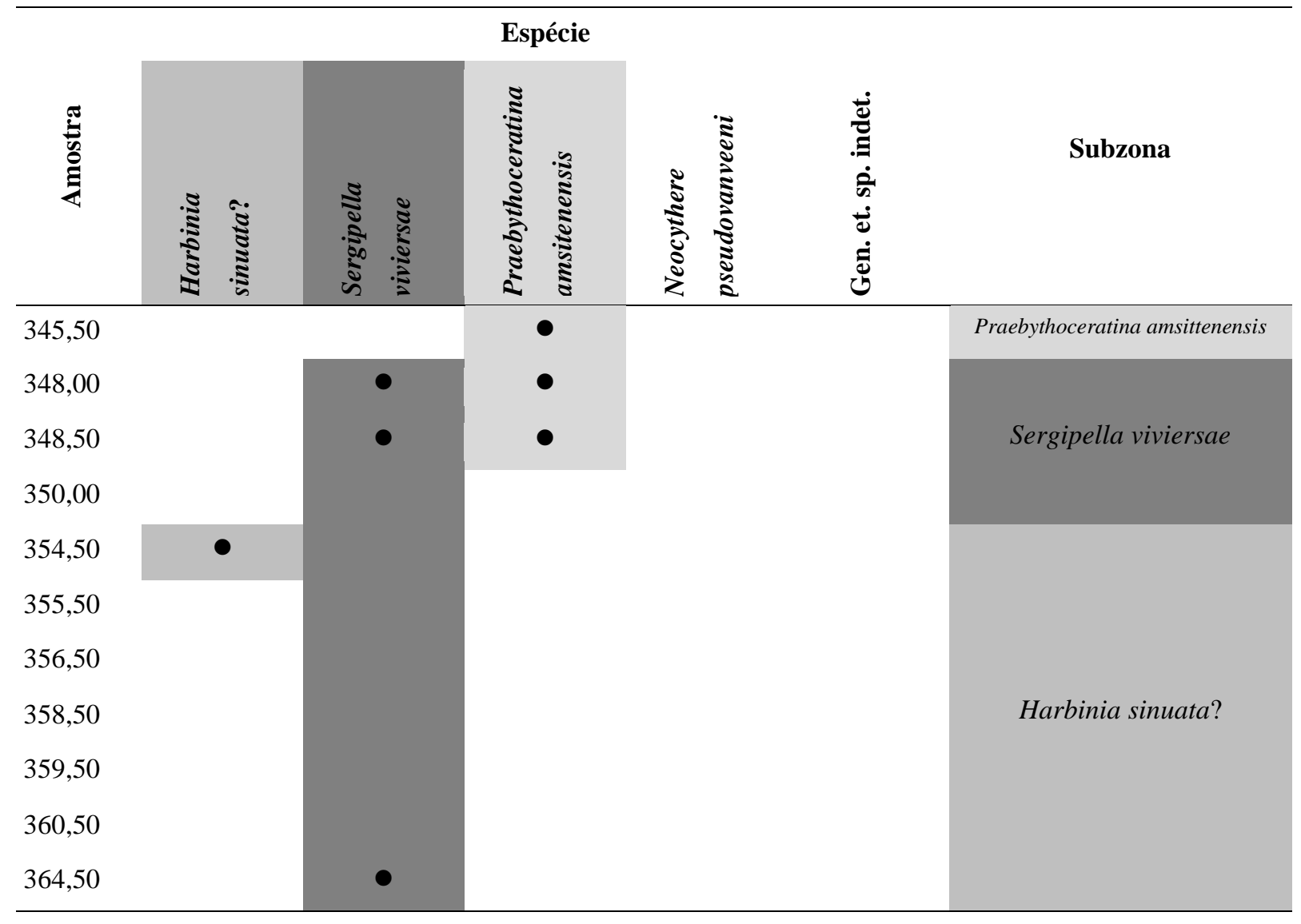

Tabela 11. Distribuição estratigráfica por amostra das espécies de ostracodes identificadas na perfuração 1-US1, Município de Laranjeiras, Estado de Sergipe, Brasil. Espécies guia para as zonas e subzonas identificadas se encontram sombreadas.

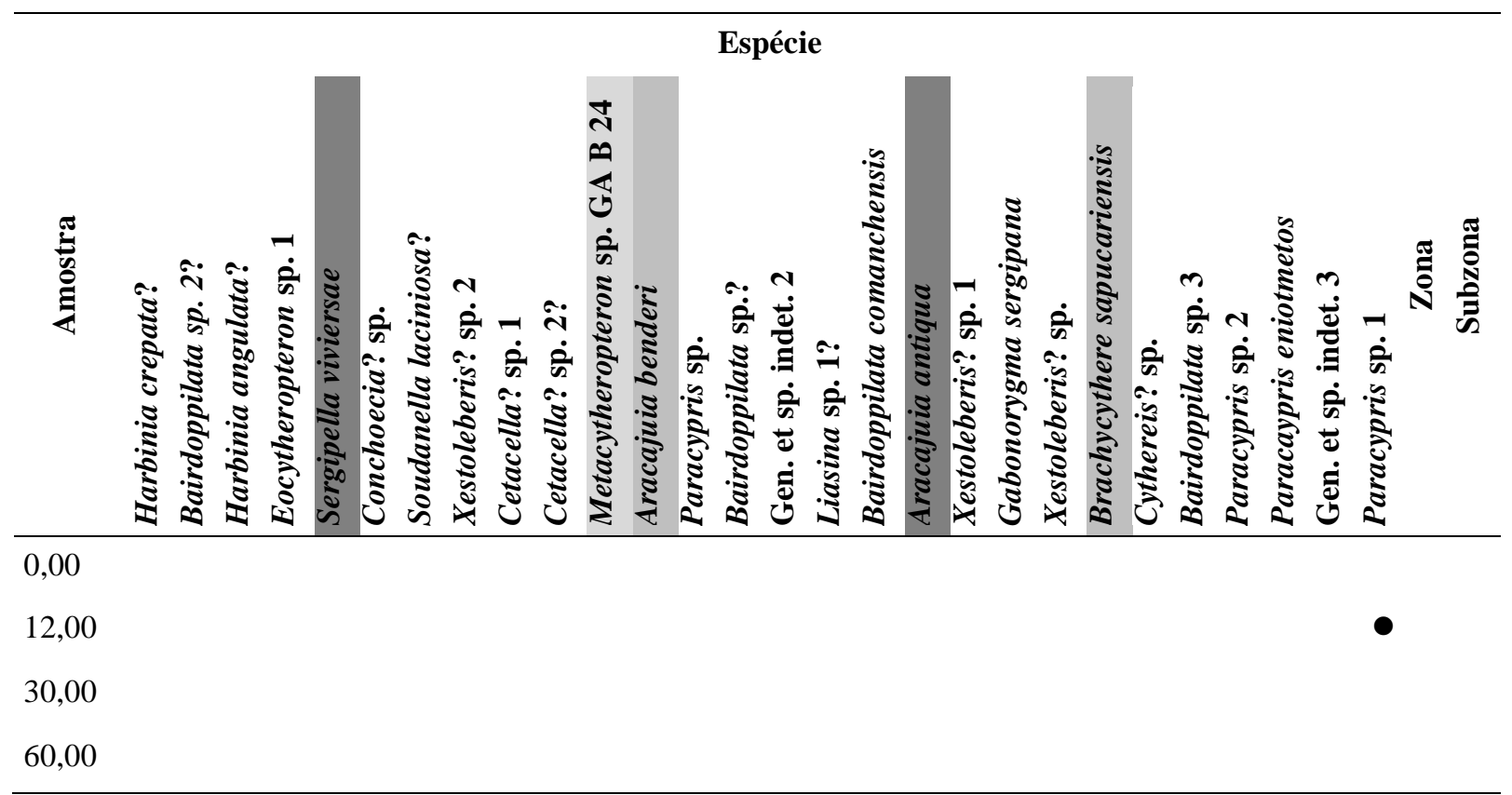


Tabela 11 (continuação). Distribuição estratigráfica por amostra das espécies de ostracodes identificadas na perfuração 1-US-1, Município de Laranjeiras, Estado de Sergipe, Brasil. Espécies guia para as zonas e subzonas identificadas se encontram sombreadas.

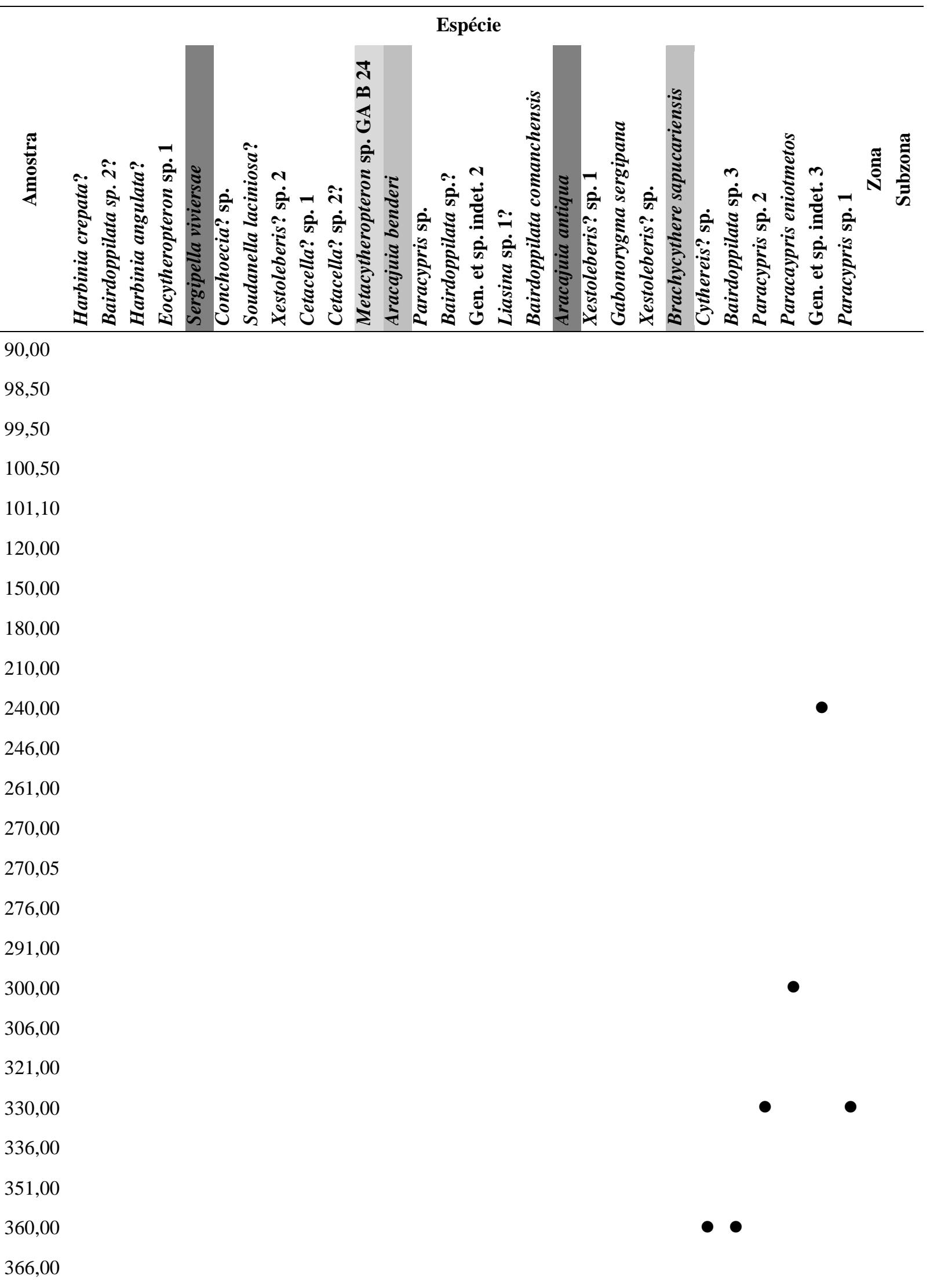


Tabela 11 (continuação). Distribuição estratigráfica por amostra das espécies de ostracodes identificadas na perfuração 1-US-1, Município de Laranjeiras, Estado de Sergipe, Brasil. Espécies guia para as zonas e subzonas identificadas se encontram sombreadas.

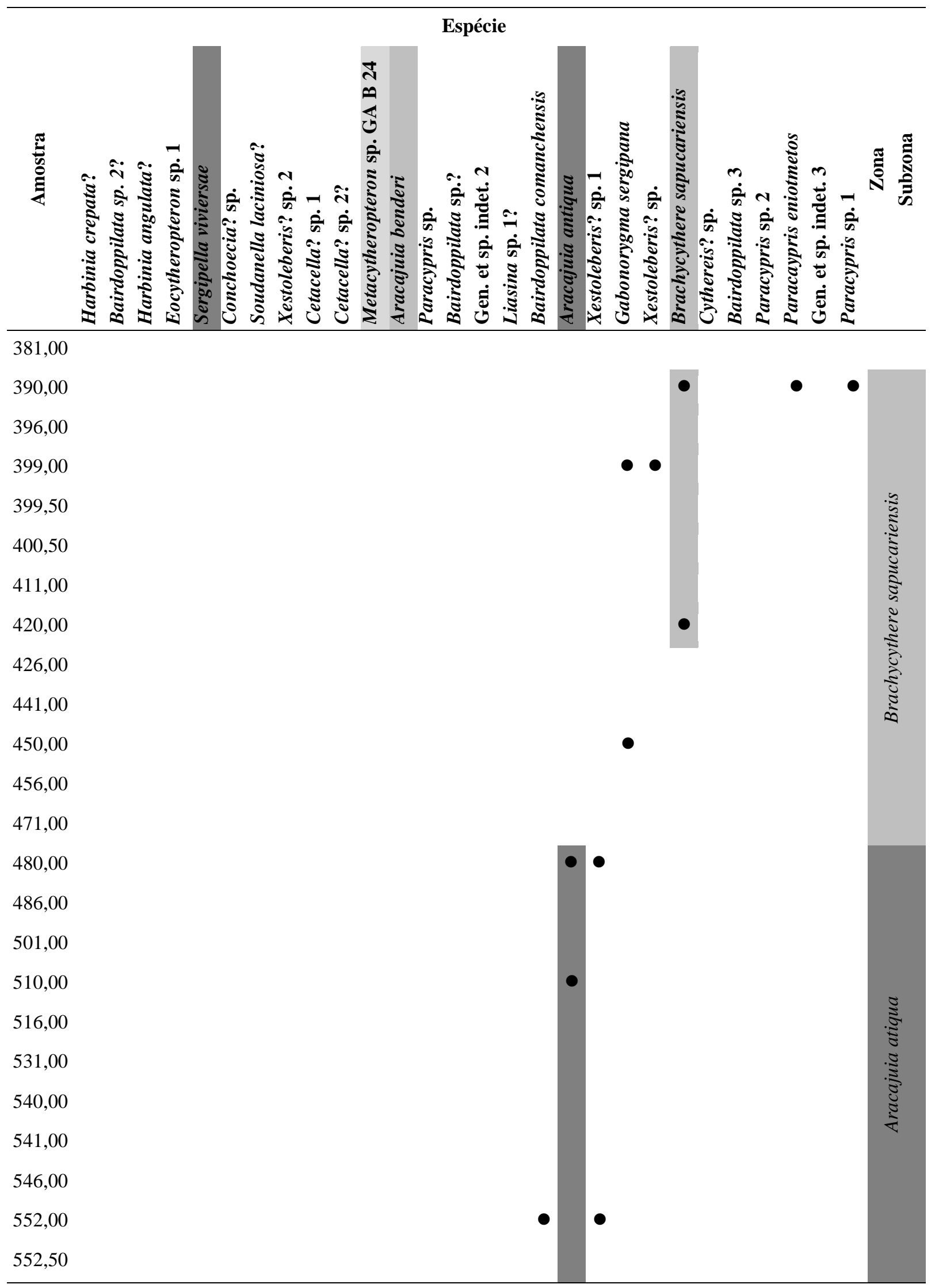


Tabela 11 (continuação). Distribuição estratigráfica por amostra das espécies de ostracodes identificadas na perfuração 1-US-1, Município de Laranjeiras, Estado de Sergipe, Brasil. Espécies guia para as zonas e subzonas identificadas se encontram sombreadas.

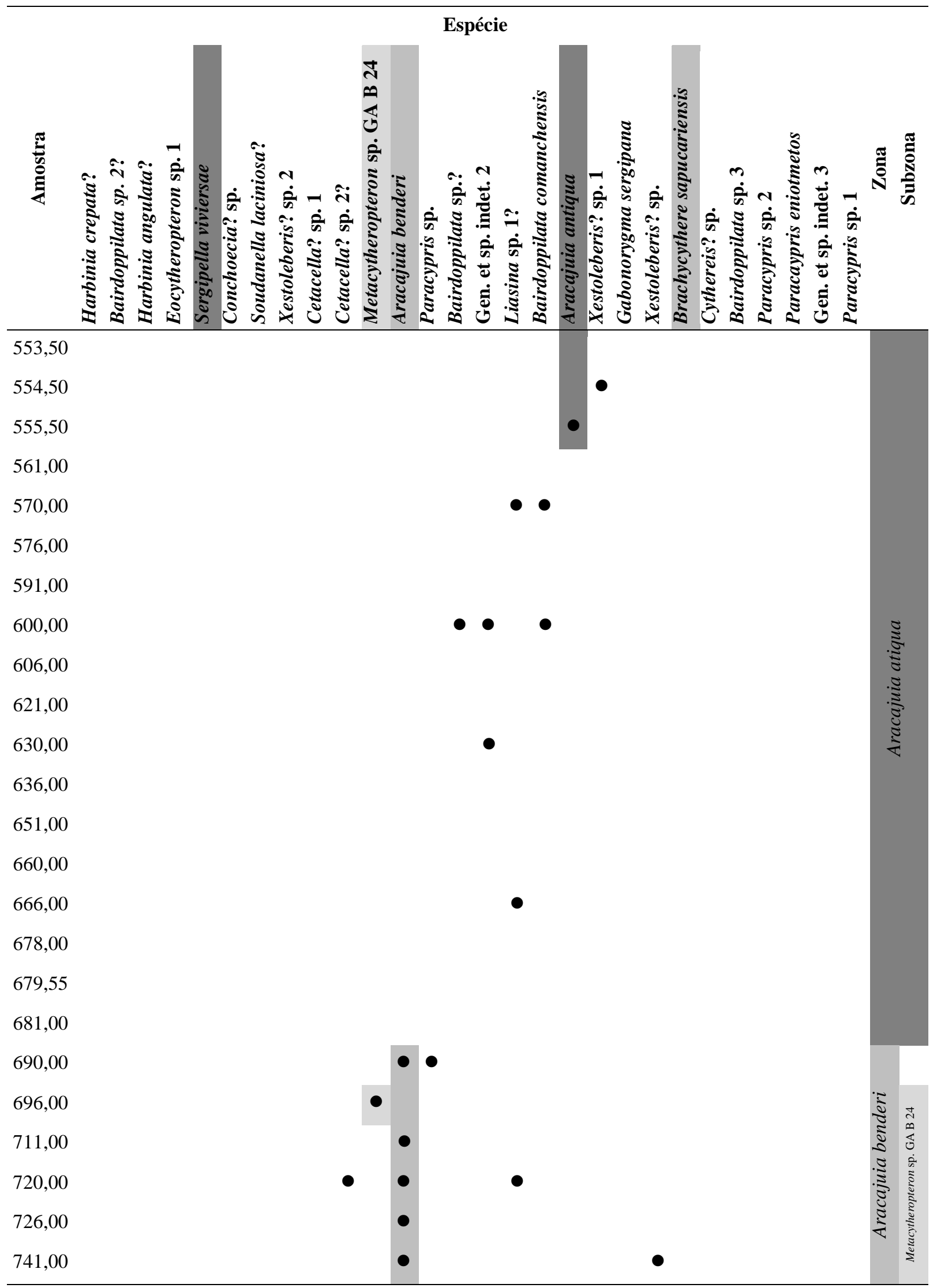


Tabela 11 (continuação). Distribuição estratigráfica por amostra das espécies de ostracodes identificadas na perfuração 1-US-1, Município de Laranjeiras, Estado de Sergipe, Brasil. Espécies guia para as zonas e subzonas identificadas se encontram sombreadas.

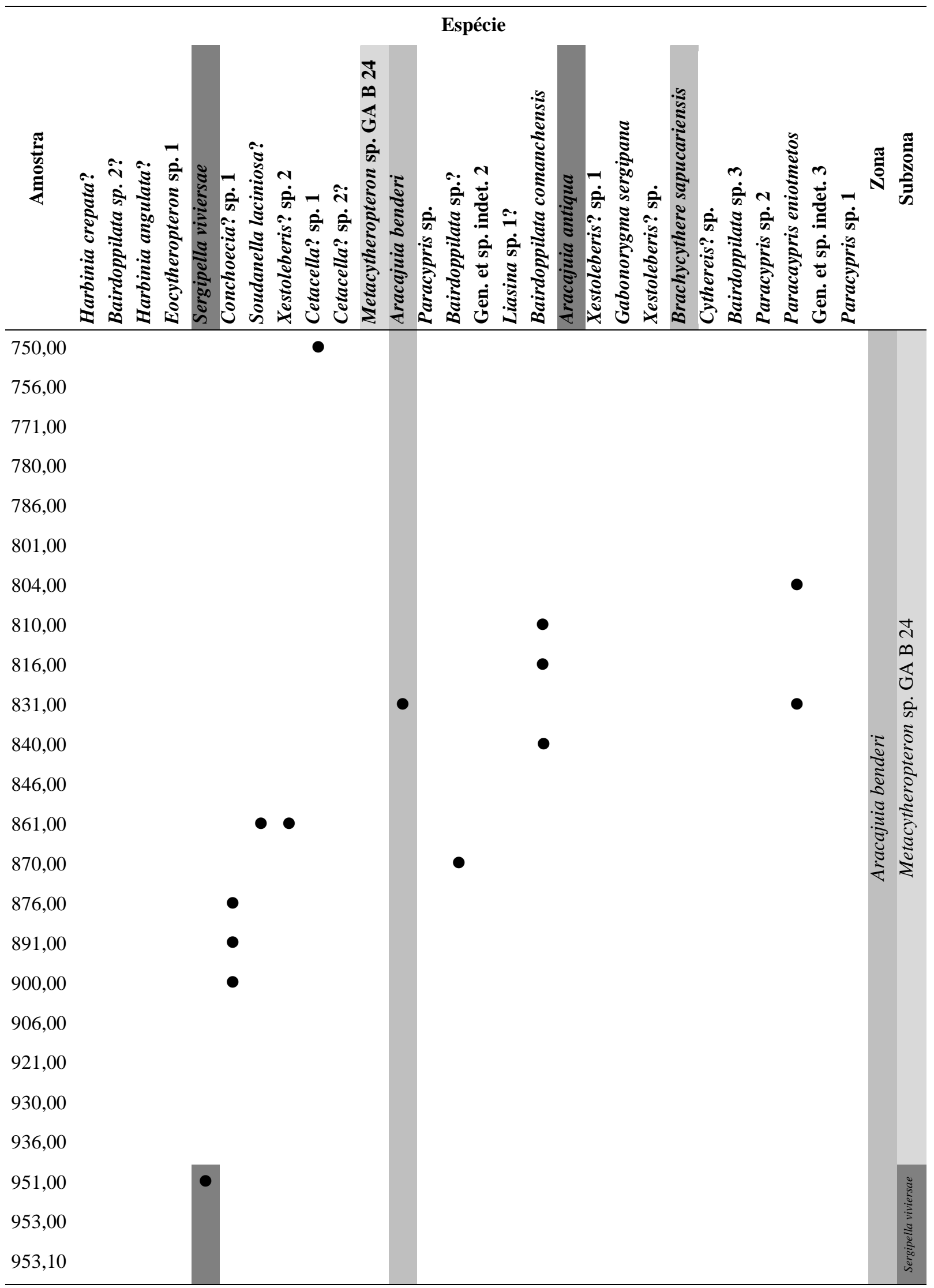


Tabela 11 (continuação). Distribuição estratigráfica por amostra das espécies de ostracodes identificadas na perfuração 1-US-1, Município de Laranjeiras, Estado de Sergipe, Brasil. Espécies guia para as zonas e subzonas identificadas se encontram sombreadas.

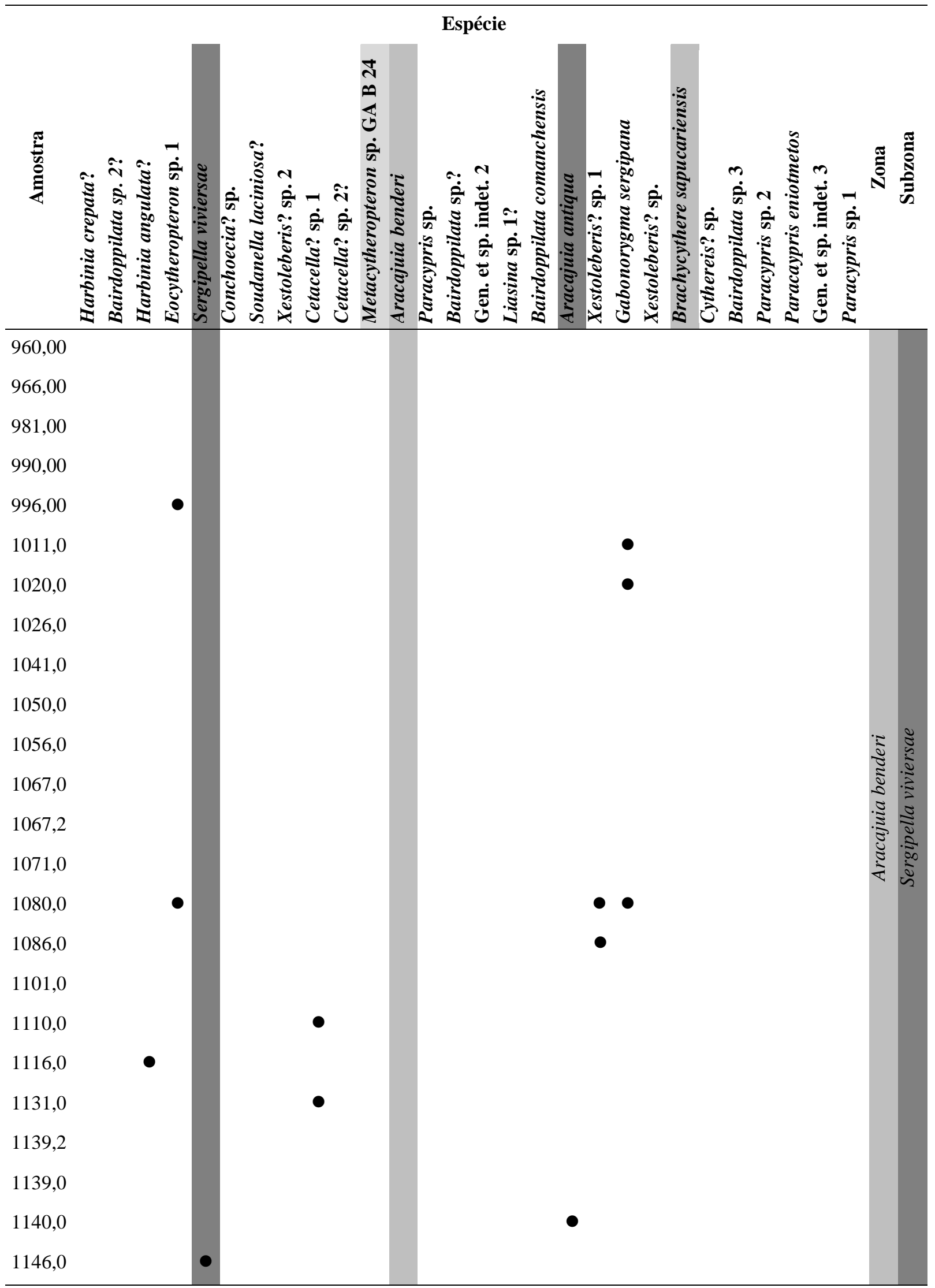


Tabela 11 (continuação). Distribuição estratigráfica por amostra das espécies de ostracodes identificadas na perfuração 1-US-1, Município de Laranjeiras, Estado de Sergipe, Brasil. Espécies guia para as zonas e subzonas identificadas se encontram sombreadas.

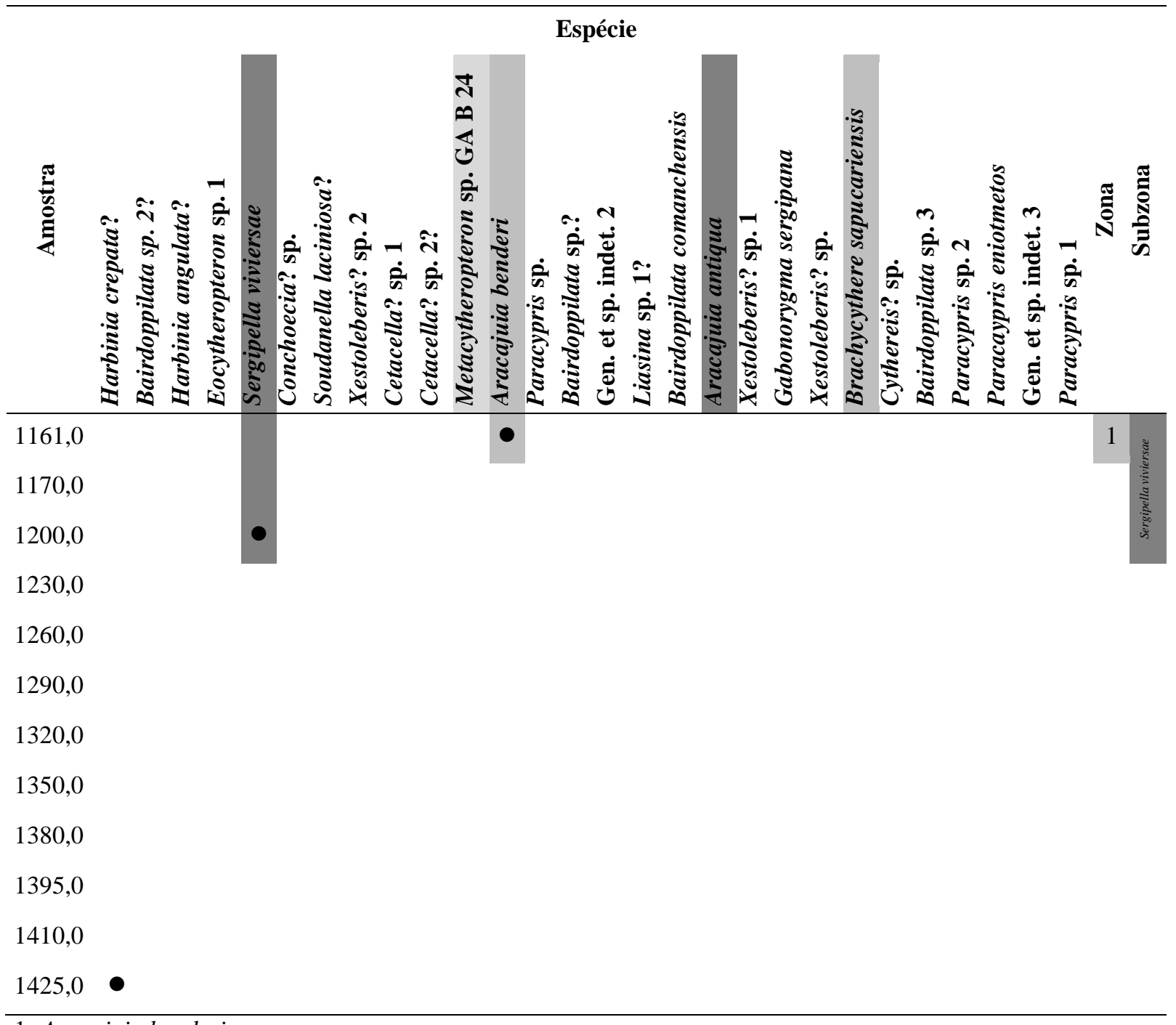

1- Aracajuia benderi.

Tabela 12. Distribuição estratigráfica por amostra das espécies de ostracodes identificadas na perfuração 7-CP252, Município de Santo Amaro das Brotas, Estado de Sergipe, Brasil. Espécies guia para as zonas e subzonas identificadas se encontram sombreadas.

\begin{tabular}{|c|c|c|c|c|c|c|c|c|c|c|}
\hline \multirow[b]{2}{*}{ 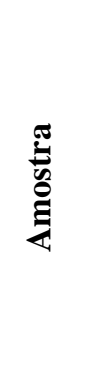 } & \multirow[b]{2}{*}{ 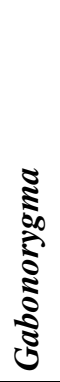 } & \multirow[b]{2}{*}{ 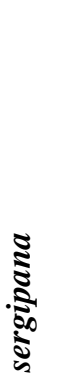 } & \multirow[b]{2}{*}{ 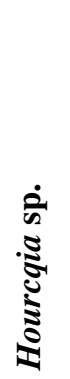 } & \multirow[b]{2}{*}{ 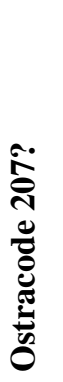 } & Espécie & \multirow[b]{2}{*}{ 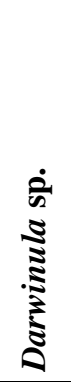 } & \multirow[b]{2}{*}{ 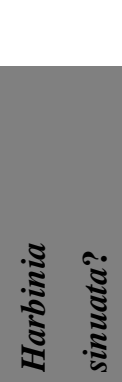 } & \multirow[b]{2}{*}{ 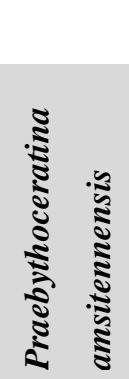 } & \multirow[b]{2}{*}{ ڤ్ّ } & \multirow[b]{2}{*}{ 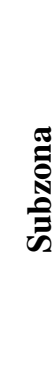 } \\
\hline & & & & & 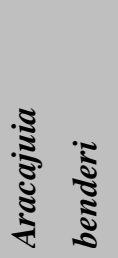 & & & & & \\
\hline \multicolumn{11}{|l|}{466,00} \\
\hline 466,20 & & & & & & & & & & \\
\hline
\end{tabular}


Tabela 12 (continuação). Distribuição estratigráfica por amostra das espécies de ostracodes identificadas na perfuração 7-CP-252, Município de Santo Amaro das Brotas, Estado de Sergipe, Brasil. Espécies guia para as zonas e subzonas identificadas se encontram sombreadas.

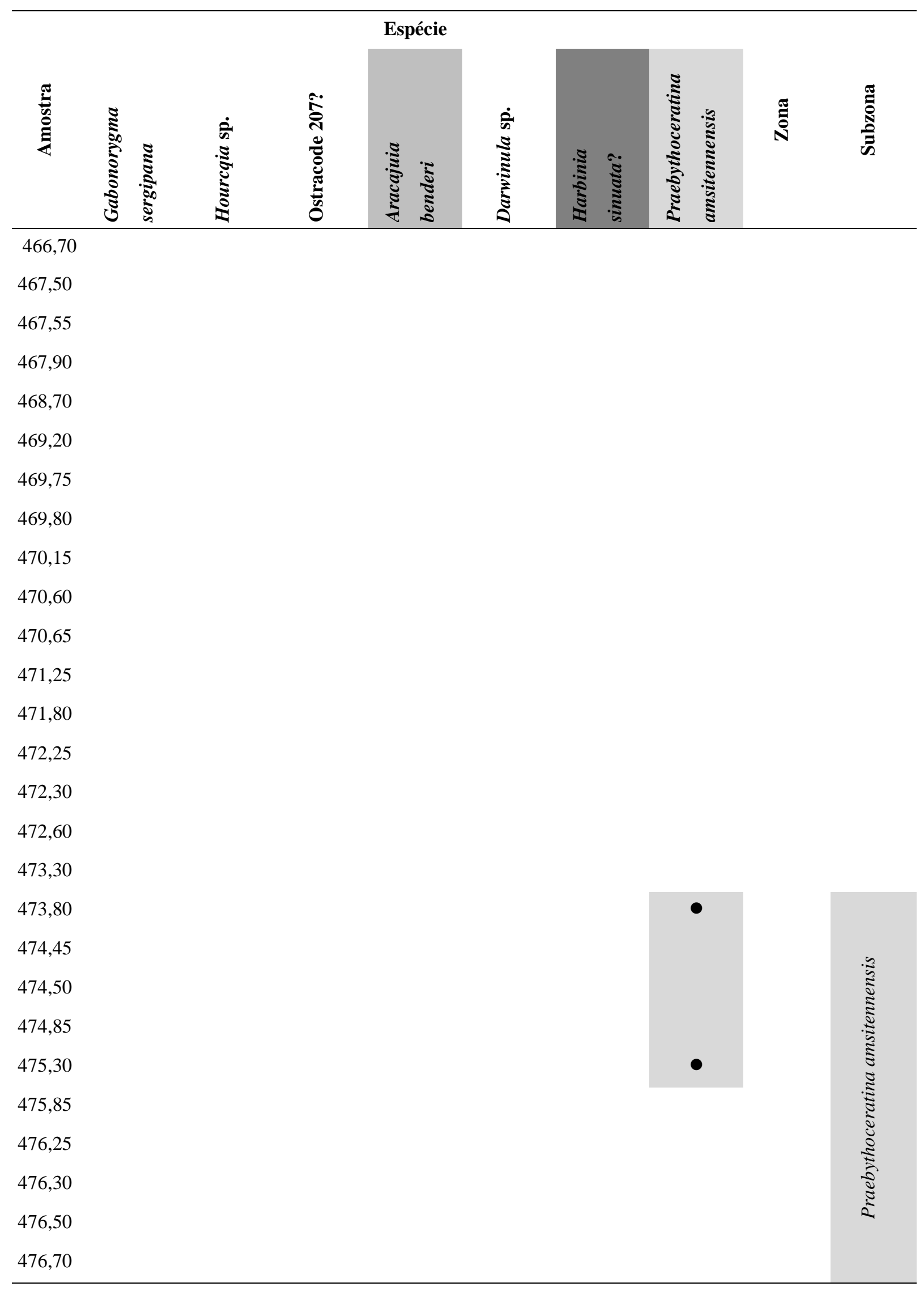


Tabela 12 (continuação). Distribuição estratigráfica por amostra das espécies de ostracodes identificadas na perfuração 7-CP-252, Município de Santo Amaro das Brotas, Estado de Sergipe, Brasil. Espécies guia para as zonas e subzonas identificadas se encontram sombreadas.

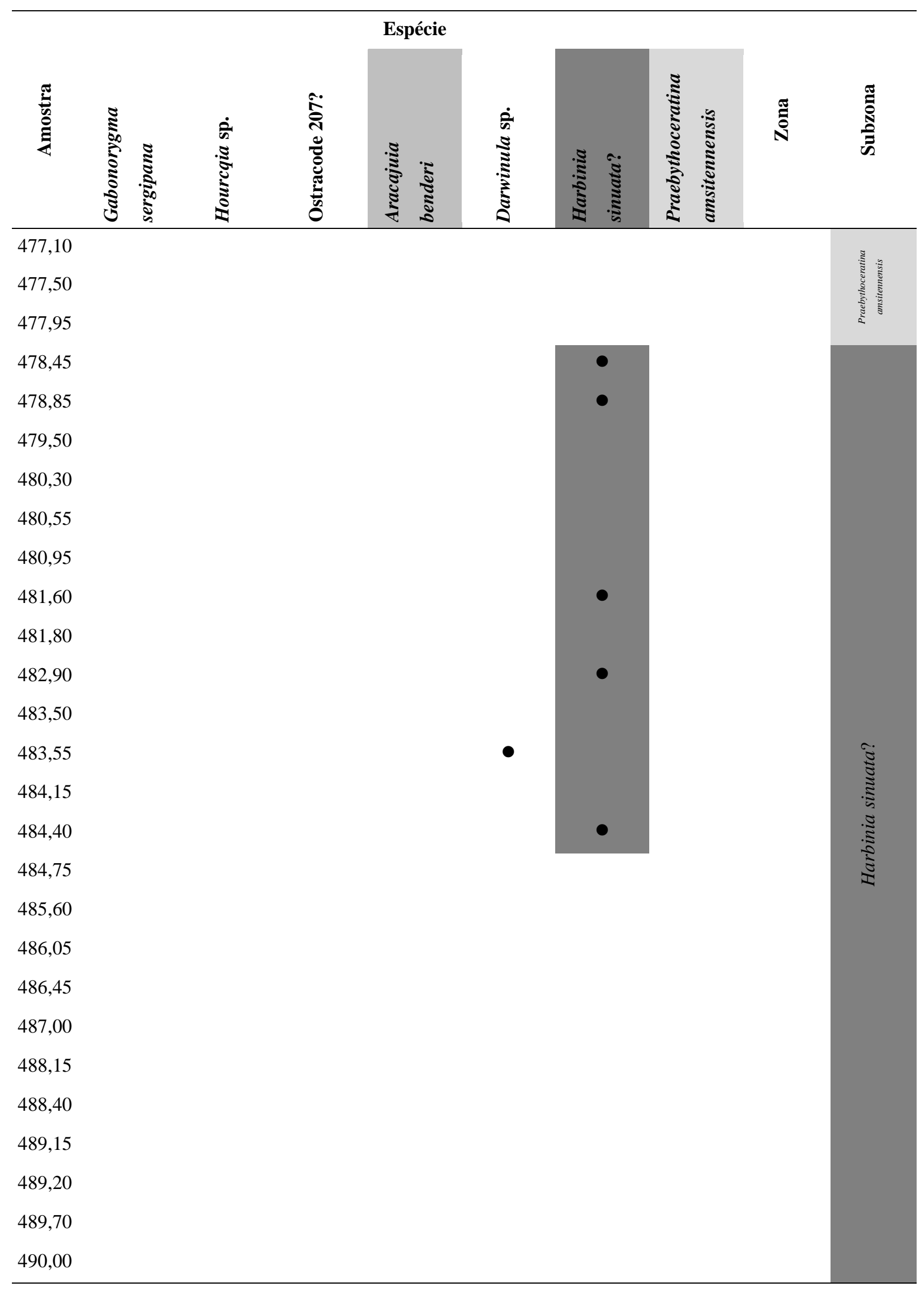


Tabela 12 (continuação). Distribuição estratigráfica por amostra das espécies de ostracodes identificadas na perfuração 7-CP-252, Município de Santo Amaro das Brotas, Estado de Sergipe, Brasil. Espécies guia para as zonas e subzonas identificadas se encontram sombreadas.

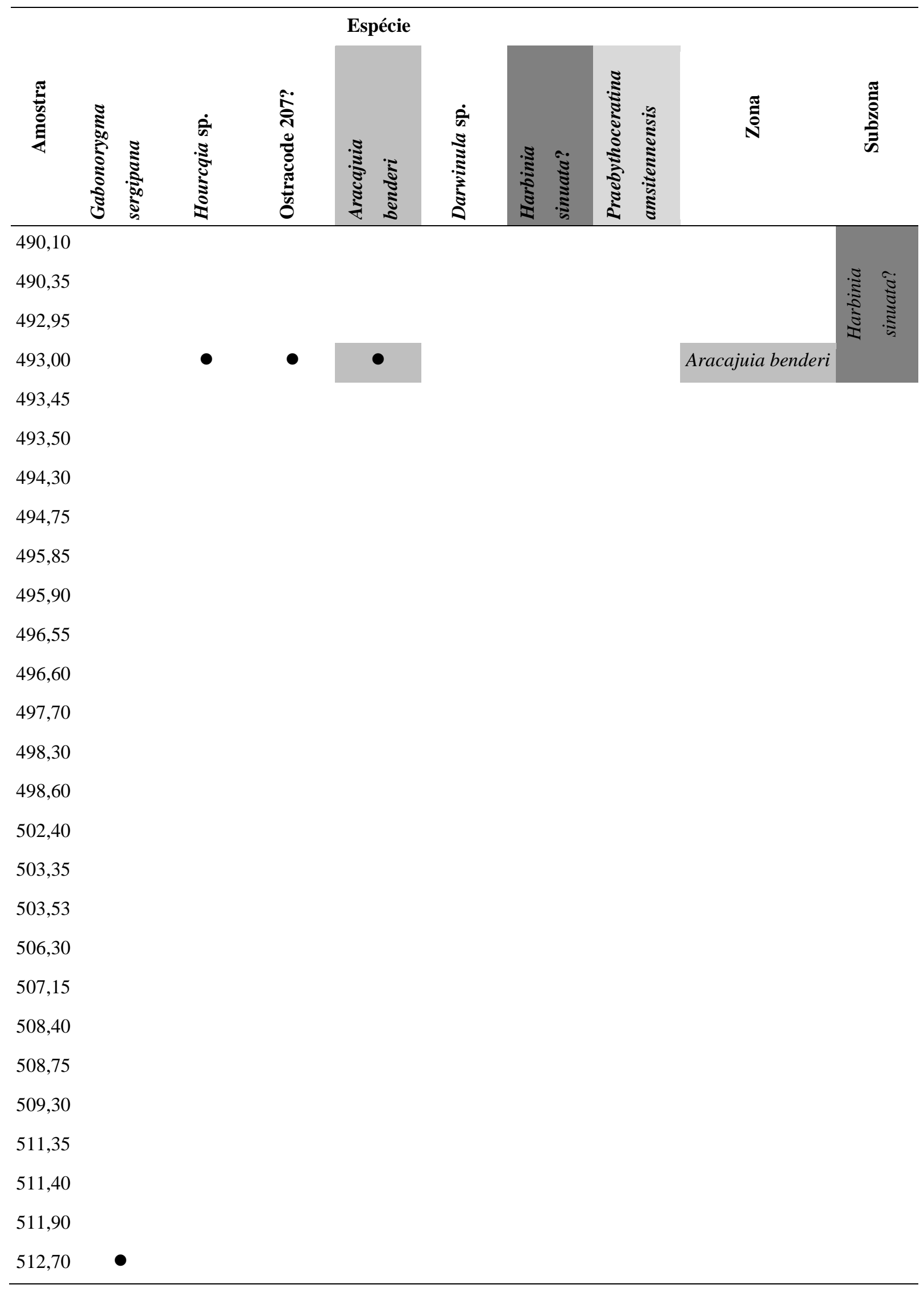


Tabela 12 (continuação). Distribuição estratigráfica por amostra das espécies de ostracodes identificadas na perfuração 7-CP-252, Município de Santo Amaro das Brotas, Estado de Sergipe, Brasil. Espécies guia para as zonas e subzonas identificadas se encontram sombreadas.

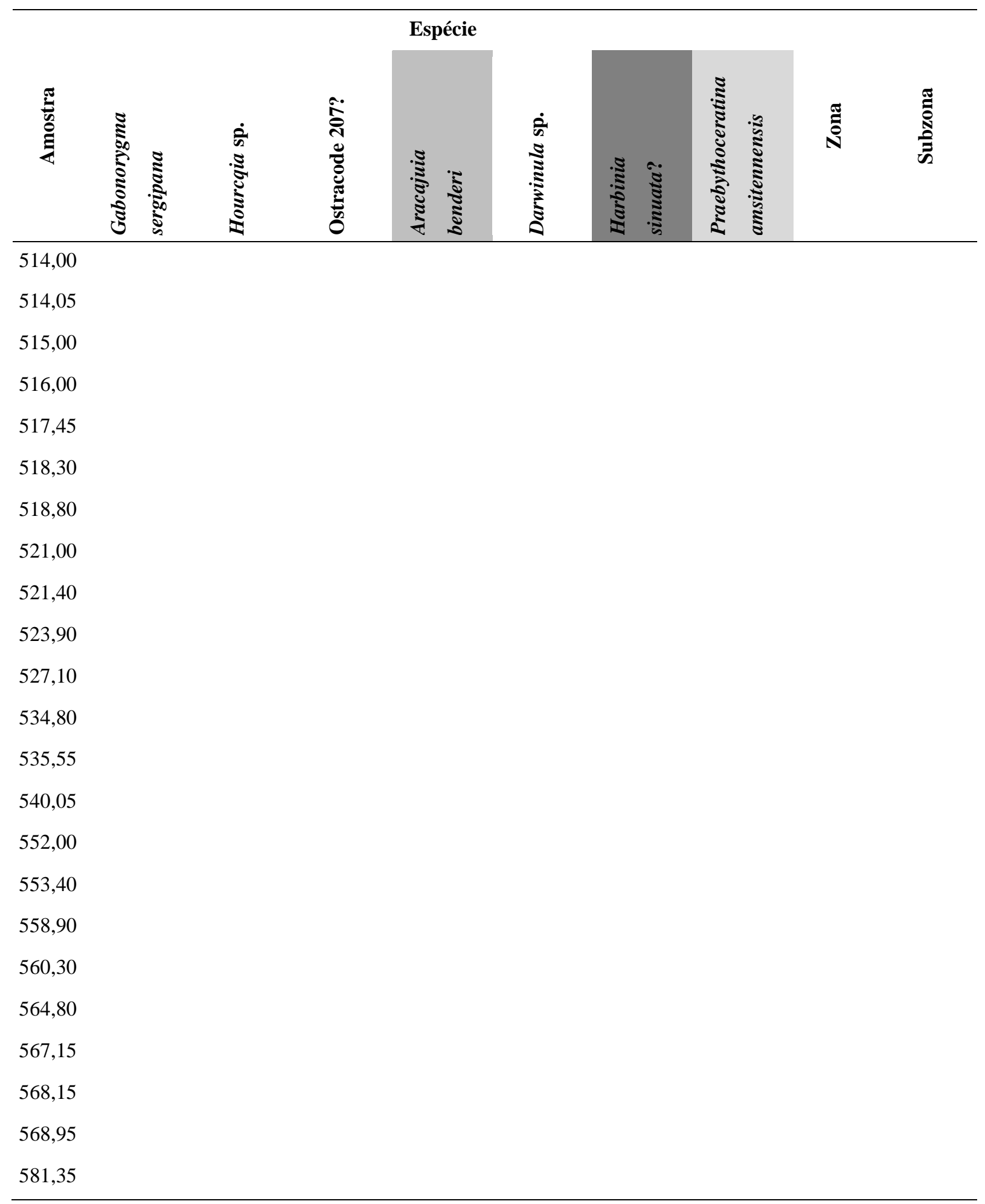


Anexo II. Artigo intitulado Taxonomy, biostratigraphy and paleozoogeography of Amphicytherura Butler and Jones, Aracajuia Krömmelbein and Dinglecythere Antonietto et al., n. gen. (Crustacea, Ostracoda), publicado no periódico Marine Micropaleontology. 


\title{
Taxonomy, biostratigraphy and paleozoogeography of Amphicytherura Butler and Jones, Aracajuia Krömmelbein and Dinglecythere Antonietto et al., n. gen. (Crustacea, Ostracoda)
}

\author{
Lucas Silveira Antonietto $^{\mathrm{a}, *}$, Anna Abrahão ${ }^{\mathrm{b}}$, Dermeval Aparecido do Carmo ${ }^{\mathrm{a}}$, Ricardo Piazza Meireles ${ }^{\mathrm{c}}$ \\ a Laboratory of Micropaleontology, Institute of Geosciences, University of Brasilia, Darcy Ribeiro Campus, ZIP 70919-970 Brasilia, Distrito Federal, Brazil \\ b P.O. Box 6109, Department of Botany, Institute of Biology, University of Campinas, 'Zeferino Vaz' University City, Monteiro Lobato Street, 255, ZIP 13083-862, Campinas, São Paulo, Brazil

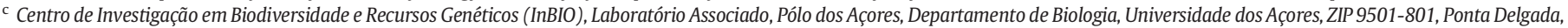 \\ Azores, Portugal
}

\section{A R T I C L E I N F O}

\section{Article history:}

Received 15 February 2013

Received in revised form 4 September 2013

Accepted 12 September 2013

Available online 18 September 2013

\section{Keywords:}

Sergipe-Alagoas Basin

Cretaceous-Paleogene

Marine ostracods

Taxonomy

\begin{abstract}
A B S T R A C T
There is a certain ambiguity in the taxonomy of Amphicytherura Butler \& Jones, Aracajuia Krömmelbein and Sondagella Dingle. Recent publications have addressed the separation of these three genera, but a deeper taxonomic analysis is still needed. Aracajuia benderi Krömmelbein, type-species of Aracajuia and an index fossil for the upper Aptian-Albian of the Sergipe-Alagoas Basin, northeastern Brazil, was previously attributed to Amphicytherura, but this replacement is nowadays considered debatable. To approach this problem, the typespecies Aracajuia benderi is re-described herein. Sexual dimorphism and some of its instars are illustrated for the first time using scanning electron microscopy. At the generic level, emended diagnoses of Amphicytherura and Aracajuia are proposed in an effort to consolidate the validity of both. Sondagella, which was originally proposed as a subgenus of Amphicytherura and later elevated to the generic level, is here considered to be a synonym of Aracajuia. A new genus, Dinglecythere, is created to group certain species previously identified as Amphicytherura. Because Aracajuia benderi is an index fossil for the Zone Amphicytherura benderi and a homonymous subzone, the nomenclature of both is changed to Aracajuia benderi, based on the results of this taxonomic revision. Additional palaeozoogeographic studies make it possible to trace the evolutionary history of Amphicytherura, Aracajuia and Dinglecythere. Aracajuia and Dinglecythere were found from tropical to warm-temperate marine environments, mostly restricted to Gondwana, but the first occurred mostly during the Early Cretaceous, while the second was a Late Cretaceous genus. Amphicytherura occurred throughout Laurasia in warm-temperate and "paratropical" waters, reaching great diversity in the Late Cretaceous.
\end{abstract}

(c) 2013 Elsevier B.V. All rights reserved.

\section{Introduction}

The problematic status of the genera Amphicytherura Butler and Jones, Sondagella Dingle and Aracajuia Krömmelbein has been mentioned by several authors (Valicenti and Stephens, 1984; Musacchio and Simeoni, 2008; Ballent, 2009; Concheyro et al., 2009; RuaultDjerrab and Kechid-Benkherouf, 2011). Therefore, a detailed and precise systematic analysis of these genera is needed to improve their taxonomic treatment and application in biostratigraphic studies. These ostracod genera appear in several basins from Gondwana and Laurasia paleocontinents, and their distribution encompasses several marine environments established during the Cretaceous-Paleogene, including the proto-South Atlantic Ocean.

\footnotetext{
* Corresponding author. Tel.: + 556131077028.

E-mail addresses: antoniettols@gmail.com (L.S. Antonietto), anna.abrahao@gmail.com (A. Abrahão), derme@unb.br (D.A. do Carmo), ricomeireles@gmail.com (R.P. Meireles).
}

Three tectonic phases are generally recognised during the opening of the South Atlantic Ocean, ranging from the early Aptian to nowadays: rift, gulf and drift (Santos and Bonhomme, 1993; Cesero et al., 1997; Almeida and Carneiro, 1998; Pletsch et al., 2001; Souza-Lima and Hamsi Junior, 2003; Valença et al., 2003; Bueno, 2004; Dias, 2004). The relative dating of strata deposited during the gulf and early drift is mainly based on cephalopods, ostracods, foraminifers and palynomorphs (Schaller, 1969; Feijó, 1994; Do Carmo et al., 2008, 2012, 2013). Aracajuia benderi Krömmelbein is considered to be an index fossil for the homonymous range zone that marks the upper Aptian-Albian period in the Sergipe-Alagoas Basin (Viviers et al., 2000). During that period, the paleoenvironments of the region were already marine (although restricted), indicating the beginning of the drift that led to the opening of the South Atlantic Ocean (Campos Neto et al., 2007a).

The present study is based on a population of Aracajuia benderi isolated from a sample named MP-291. It was collected at the "Porto dos Barcos 3" outcrop, a very fossil-rich lithologic succession which serves as the type locality to the genus Aracajuia and its type- 
species. This outcrop belongs to the Taquari Member of the Riachuelo Formation, from the late Aptian-Albian of the SergipeAlagoas Basin, northeastern Brazil.

The purpose of this study is to review the taxonomic status of the genera Amphicytherura, Sondagella and Aracajuia, also focusing on its type-species, Aracajuia benderi. This paper presents a re-description of the external and internal carapace features and ontogeny of this species accompanied by scanning electron microscope (SEM) photographs. To re-describe Aracajuia benderi and create a new diagnosis for this species, the genera Amphicytherura, Aracajuia and Sondagella are also reviewed. Certain species of Amphicytherura share morphological characters that are unusual in this genus and are therefore re-assigned to a new genus, Dinglecythere Antonietto et al., n. gen. The paleozoogeography and stratigraphic distribution of the three genera are also shown in order to infer the species' migration pathways.

\subsection{Historical background of Amphicytherura, Sondagella and Aracajuia}

The genus Amphicytherura was proposed by Butler and Jones (1957), based on species of Cytherura Sars (Cytherura? dubia Israelsky, the typespecies) and Eucytherura Müller [Eucytherura chelodon (Marsson), previously assigned to Cythere Müller]. Further reviews by Howe and Laurencich (1958) and Kaye (1965) added taxa transferred from several genera, including Cythereis Jones (Cythereis icenica Jones and Hinde and Cythereis curta Jennings), Eucytherura (Eucytherura aculeata Bonnema) and Orthonotacythere Alexander (Orthonotacythere roemeri Bartenstein). Traits shared by these species include a general lateral outline and the presence of an amphidont hinge.

Dingle (1969a) described Sondagella as a subgenus of Amphicytherura. Amphicytherura (Sondagella) theloides theloides (Dingle) and Amphicytherura (Sondagella) theloides acuta Dingle were assigned to this subgenus by Dingle (1971). Bate (1972) raised Sondagella to the generic level, although many authors continued to describe new species within or to re-assign existing species to Amphicytherura (Sondagella), including Amphicytherura (Sondagella) distincta Gerry and Rosenfeld (Andreu-Boussut, 1991), Amphicytherura (Sondagella) lestai Musacchio, Amphicytherura (Sondagella) gigantodistincta Andreu-Boussut and Amphicytherura (Sondagella) zemzenensis Andreu-Boussut (Musacchio, 1978; Andreu-Boussut, 1991). Valicenti and Stephens (1984), following Bate (1972), described two additional species, Sondagella valanginiana Valicenti and Stephens and Sondagella colchesterensis Valicenti and Stephens. The elevation of Sondagella to the generic level was adopted by later authors, including Ballent (1990, 2009), Dingle (1984, 1996) and Concheyro et al. (2009). Musacchio and Simeoni (2008) considered Sondagella a junior synonym of the genus Aracajuia, but provided no further details on this subject.

Aracajuia was described by Krömmelbein (1967) from the upper Aptian-Albian of the Sergipe-Alagoas Basin, Brazil. Musacchio and Simeoni (2008), studying the Valanginian and Hauterivian strata of the Neuquén Basin, Argentina, assigned two Amphicytherura species, Amphicytherura (Sondagella) lestai Musacchio and Amphicytherura theloides Dingle, and two Sondagella species, Sondagella colchesterensis and Sondagella valanginiana, to Aracajuia. The generic status of Aracajuia? lestai was left in doubt because this species lacked certain morphological traits shared by other Aracajuia species, including the general outline and the presence of a caudal process. Until then, the genus was monospecific, comprising only the type-species, Aracajuia benderi.

Several species currently placed in Aracajuia have stratigraphic importance as the index fossils for seven zones or subzones in two basins, one in Brazil and one in Argentina. Aracajuia benderi marks two units in the upper Aptian-Albian of the Sergipe-Alagoas Basin in Brazil, Zone Amphicytherura benderi (OSE-1) and Subzone Amphicytherura benderi (OSE-1.6) (Viviers et al., 2000). Species of this genus define five zones in the Neuquén Basin, Argentina, possibly ranging from the Berriasian to the Hauterivian: Aracajuia cf. valanginiana fauna, Aracajuia colchesterensis fauna, Cytherelloidea agrioensis -Aracajuia? sp. EM assemblage zone, Aracajuia theloides fauna and Aracajuia? lestai fauna (Musacchio and Simeoni, 2008).

\section{Regional setting}

The Sergipe-Alagoas Basin, located in northeastern Brazil, is the reference basin for chronostratigraphic studies in Brazil due to its abundantly fossiliferous outcrops and to drillings in its oil- and gasproducing strata (Carvalho et al., 2005). This basin is one of many bordering the South Atlantic Ocean, which formed as a result of the late-Mesozoic rifting of South America and Africa (Bengtson, 1983). The sedimentary succession of the basin begins with a Paleozoic sequence followed by an extensive Juro-Cretaceous-Pleistocene interval, recording all of the tectonic phases of the breakup of Gondwana. The Riachuelo Formation presents the first sediments deposited under fully (although still restricted) marine conditions (Souza-Lima et al., 2002; Campos Neto et al., 2007a).

The Riachuelo Formation crops out around the Japoatã-Penedo high, which partially separates the Sergipe-Alagoas Basin into two areas, one in Sergipe State and one in Alagoas State (Campos Neto et al., 2007a). Together with the Muribeca and Cotinguiba formations, the Riachuelo Formation is part of a complex of clastic-calcareous rocks linked to the gulf and drift phases of the basin. It is divided into three members: Angico, Taquari and Maruim (Feijó, 1994; Campos Neto et al., 2007b) (Fig. 1). The Taquari Member, which inter-digitates with the Angico and Maruim members, is characterized by alternate layers of marlstones and shales deposited under shelf conditions (Souza-Lima et al., 2002). The outcrop studied here, "Porto dos Barcos 3" (8814200 N, 698900 E, quadrant 23 L UTM, SAD69) (Fig. 2), belongs to the Taquari Member (Manso and Souza-Lima, 2003) and consists of grey shales intercalated with ochre silt-claystone, containing some centimetric sandstone lenses. It represents a very rich fossil content (ostracods, foraminifers, ammonites, gastropods, bivalves, serpulid polychaetes and skeletal fragments of sponges, echinoderms and fishes).

\section{Material and methods}

To analyse the ostracods from sample MP-291, it was treated mechanically and chemically for sediment disaggregation according to the standard methods for carbonate microfossils used by the Laboratory of Micropaleontology of the Institute of Geosciences, University of Brasilia, Brazil. This sample, collected from the "Porto dos Barcos 3" outcrop, Sergipe-Alagoas Basin, contains a remarkable association of ostracods with hundreds of Aracajuia benderi specimens representing several instars. Additionally 13 specimens of Sergipella transatlantica Krömmelbein, 1967, another ostracod species, are present, along with 42 non-identified ostracod carapaces and valves.

After mechanical fragmentation, $60 \mathrm{~g}$ of sample MP-291 was chemically processed by treatment with $30 \%$ hydrogen peroxide $\left(\mathrm{H}_{2} \mathrm{O}_{2}\right)$ for $24 \mathrm{~h}$. To stop the reaction, $92 \%$ ethanol was added to neutralise the peroxide. The resulting material was washed in running water through a sieve set $(630 \mu \mathrm{m}, 250 \mu \mathrm{m}, 120 \mu \mathrm{m}$ and $80 \mu \mathrm{m}$ mesh sizes). The material was then oven-dried at $60{ }^{\circ} \mathrm{C}$ and stored for later microfossil examination under a Leika Zoom 2000 stereoscopic microscope.

Carapaces and valves identified as Aracajuia benderi were analyzed to define an ontogenetic series for the species. Height and length measurements were made for these specimens using a Heerbrugg Wild M3Z microscope with special Leica measuring lenses. The values obtained were plotted into an $\mathrm{x} / \mathrm{y}$ graphic; those which did not present repetitions were excluded, to avoid deviations in the curve caused by diagenetic deformation of some of the carapaces and valves. SEM photographs were taken with a JEOL JCM-5000 Neoscope, using carbon coating to enhance the contrast and definition. Specimens examined by SEM are housed in the Scientific Collection of the Laboratory of Micropaleontology, University of Brasilia, under the prefix " $\mathrm{CP}$ (Coleção de Pesquisa) and numeration from 619 to 631. For comparison, 

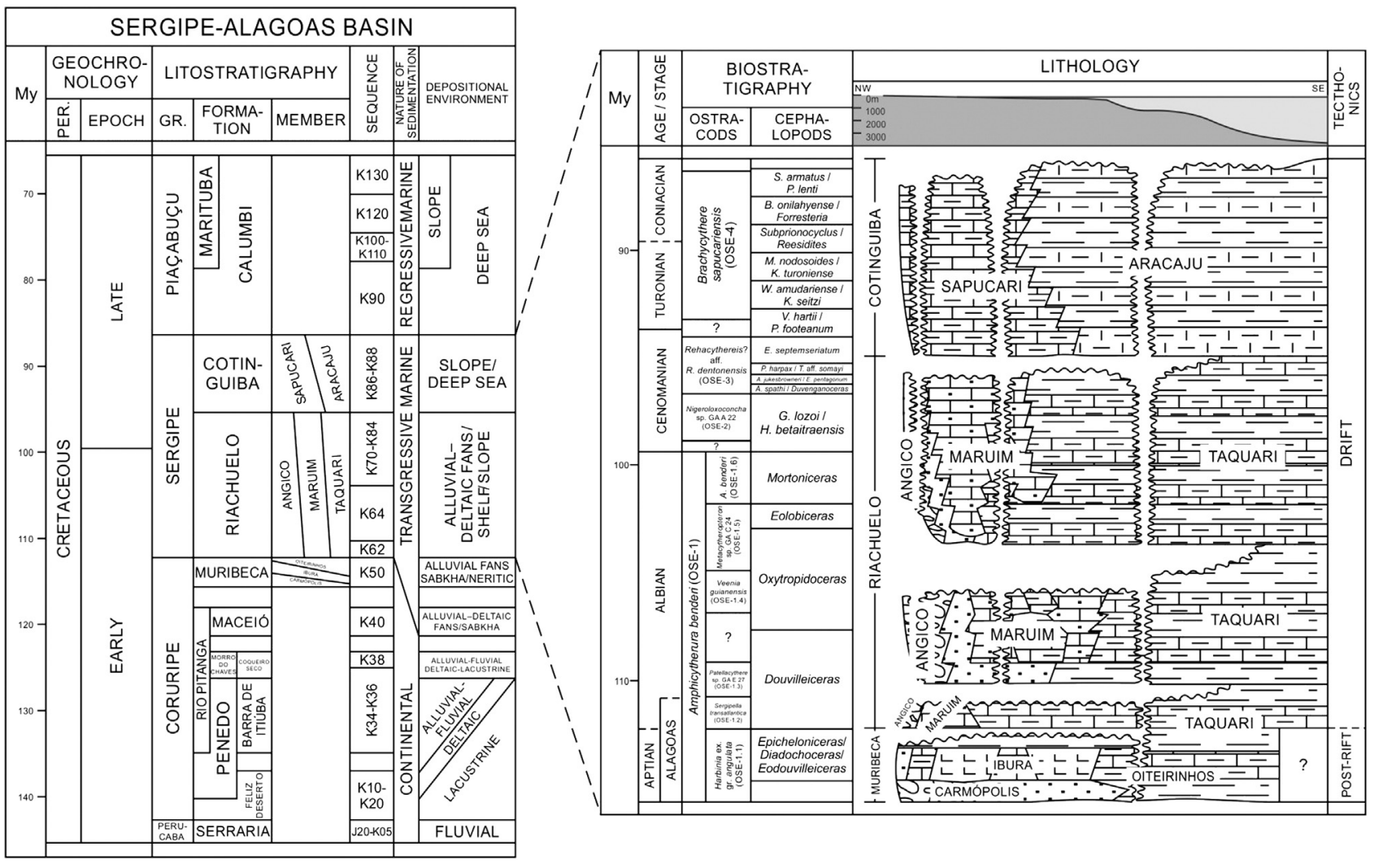

Fig. 1. Stratigraphic chart of the Cretaceous section of the Sergipe-Alagoas basin, emphasising the Muribeca, Riachuelo and Cotinguiba formations. Modified from Campos Neto et al. (2007a).

additional specimens of the genus Amphicytherura belonging to the Smithsonian National Museum of Natural History (Washington, D.C., United States) and the Natural History Museum (London, United Kingdom) were photographed by SEM.

\section{Taxonomy}

The supra-generic classification used here follows that of Hanai (1970) and Liebau (2005). The morphological terminology follows Kesling (1951) and Sylvester-Bradley and Benson (1973). Based on a bibliographic review and the analysis of specimens, new diagnoses are proposed for the genera Amphicytherura and Aracajuia. A re-description and new diagnosis are given for the type-species of Aracajuia, Aracajuia benderi, and a description and diagnosis are presented for the new genus Dinglecythere.

Subclass Ostracoda Latreille, 1802

Superorder Podocopomorpha Kozur, 1972

Order Podocopida Sars, 1866

Suborder Cytherocopina Gründel, 1967

Infraorder Nomocytherinina Liebau, 1991

Superfamily Cytheroidea Baird, 1850

Family Cytheridae Baird, 1850

Subfamily Schizocytherinae Mandelstam, 1959

Tribe Schizocytherini Mandelstam, 1960

Gsenus Amphicytherura Butler and Jones, 1957 emend.

(Fig. 3A-Q)

Type-species. Cytherura? dubia Israelsky, 1929; Saratoga Chalk Formation, lower Maastrichtian; western Clark County, southwestern Arkansas (Israelsky, 1929).
Diagnosis. Carapace sub-rectangular to sub-quadrate. Lateral surface with three longitudinal ridges (central, dorsal and ventral); additional, weakly developed transverse ribs or riblets present. Dorsal ridge obscuring the hinge margin, then crossing the eye tubercle and ending at the antero-central region. Central ridge thick and nodose, usually running from the postero-central region to the antero-central region. Ventral ridge thick, carinate. Additional ornamentation of the lateral surface may include irregularities, reticulation, or both. In internal view, hinge amphidont; central and frontal muscle-scar pattern consisting of a row of four elongated central scars and two rounded, partially fused frontal muscle scars.

Occurrence. France, Cenomanian-early Campanian (Damotte, 1965; Donze and Thomel, 1972; Babinot et al., 1985); England, TuronianMaastrichtian (Jones and Hinde, 1890; Kaye, 1964; Slipper, 2009); United States, late Coniacian-Maastrichtian (Alexander, 1936; Benson and Tatro, 1964; Crane, 1965; Brouwers and Hazel, 1978; Smith, 1978; Gohn, 1992; Puckett, 1992; Gohn, 1997; Self-Trail and Gohn, 1997; Swain, 2002; Puckett, 2005); Germany, Santonian-Maastrichtian (Marsson, 1880; Clarke, 1983; Slipper, 2009); Ukraine, CampanianMaastrichtian (Ljubimova et al., 1960; Andreev et al., 1999); Russia, Campanian-Paleocene (Ljubimova et al., 1960; Kuznetsova, 1961; Andreev et al., 1999); Poland, Campanian-Eocene (Szczechura, 1965); Belgium and Netherlands, late Campanian-Maastrichtian (Kaye, 1964; Szczechura, 1965; Deroo, 1966; Slipper, 2009); Jamaica, Maastrichtian (Puckett et al., 2012) (Table 1; Fig. 4).

Remarks. The original diagnosis of Amphicytherura was rewritten for simplicity so that the diagnostic features would be more identifiable. Some of the original features were removed from the diagnosis (number and shape of marginal pore canals), while others were incorporated (central muscle scar pattern). The separation of Amphicytherura from Eucytherura is discussed by Butler and Jones (1957) and Howe and Laurencich (1958), and based both in general size (Amphicytherura 


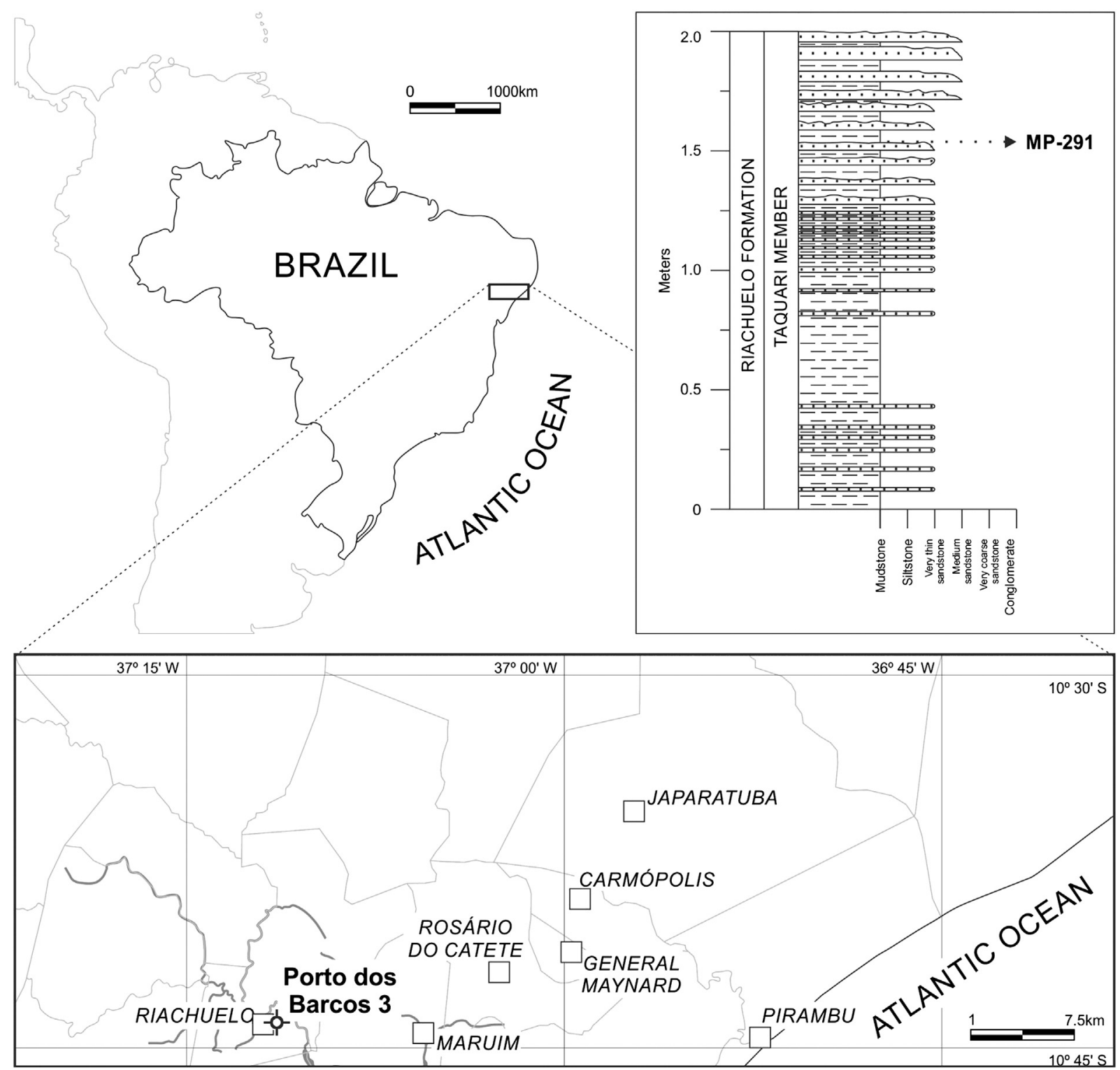

Fig. 2. Location of the study area and sampled levels in the "Porto dos Barcos 3" outcrop. Modified from Souza-Lima et al. (2002).

is greater than Eucytherura) and hinge type (amphidont against merodont). Schizocythere Triebel and Amphicytherura present similar morphologies, but overall can be distinguished as discussed by Hanai (1970). The genus differs from Cythere by the absence of dorsal and central ridges and eye tubercle, more sparse arrangement of the central muscle scars and merodont/entomodont hinge of the latter, according to the review by Tsukagoshi and Ikeya (1987). Compared to Amphicytherura, Cythereis is distinguishable by its ornamentation (irregular, reticular or spiny, with a distinct central tubercle and without central ridge) and shape and arrangement of the central and frontal muscle scars, as described by Sylvester-Bradley (1948). Following the emended diagnoses by Benson and Kaesler (1963) and Ornellas and Fallavena (1978), Cytherura presents different ornamentation patterns (multi-ribbed surface) and frontal muscle scar shapes from Amphicytherura. Aracajuia and Amphicytherura were treated as separate genera by previous works (Musacchio and Simeoni, 1995, 1996, 2008). Other publications, such as those of Viviers et al. (2000) and Andreu et al. (2008), have considered Aracajuia to be a junior synonym of Amphicytherura. However, the two genera can be separated mainly by the shape of their central and ventral ridges, which are much larger in Amphicytherura than in Aracajuia. In Amphicytherura, the central ridge extends from the postero-central region to the antero-central region; in Aracajuia, the central ridge runs from the posterior to the anterior end, where it bifurcates: the upper branch usually reaches the lower one of the dorsal ridge, while the lower branch extends to the anterior end. The ventral ridge forms a carina-like process that is much more visible in Amphicytherura than in Aracajuia. Additional differences include the shape of the frontal muscle scar (reniform in Amphicytherura, rounded in Aracajuia) and hingement (amphidont against schizodont, although some species of Amphicytherura are also schizodont, according to Herrig (1966)]. Based on these considerations, the species remaining in Amphicytherura are shown in Table 1. The generic assignments of some Amphicytherura species are still uncertain. Amphicytherura? bartensteini (Kaye and Barker) and Amphicytherura? arcuata Luppold do not share the diagnostic ornamentation pattern (especially the shape of the three main ridges) and general layout (sub-quadratic overall shape or presence of a caudal process) with other Amphicytherura species. Amphicytherura? lecta Stepanaytys and 


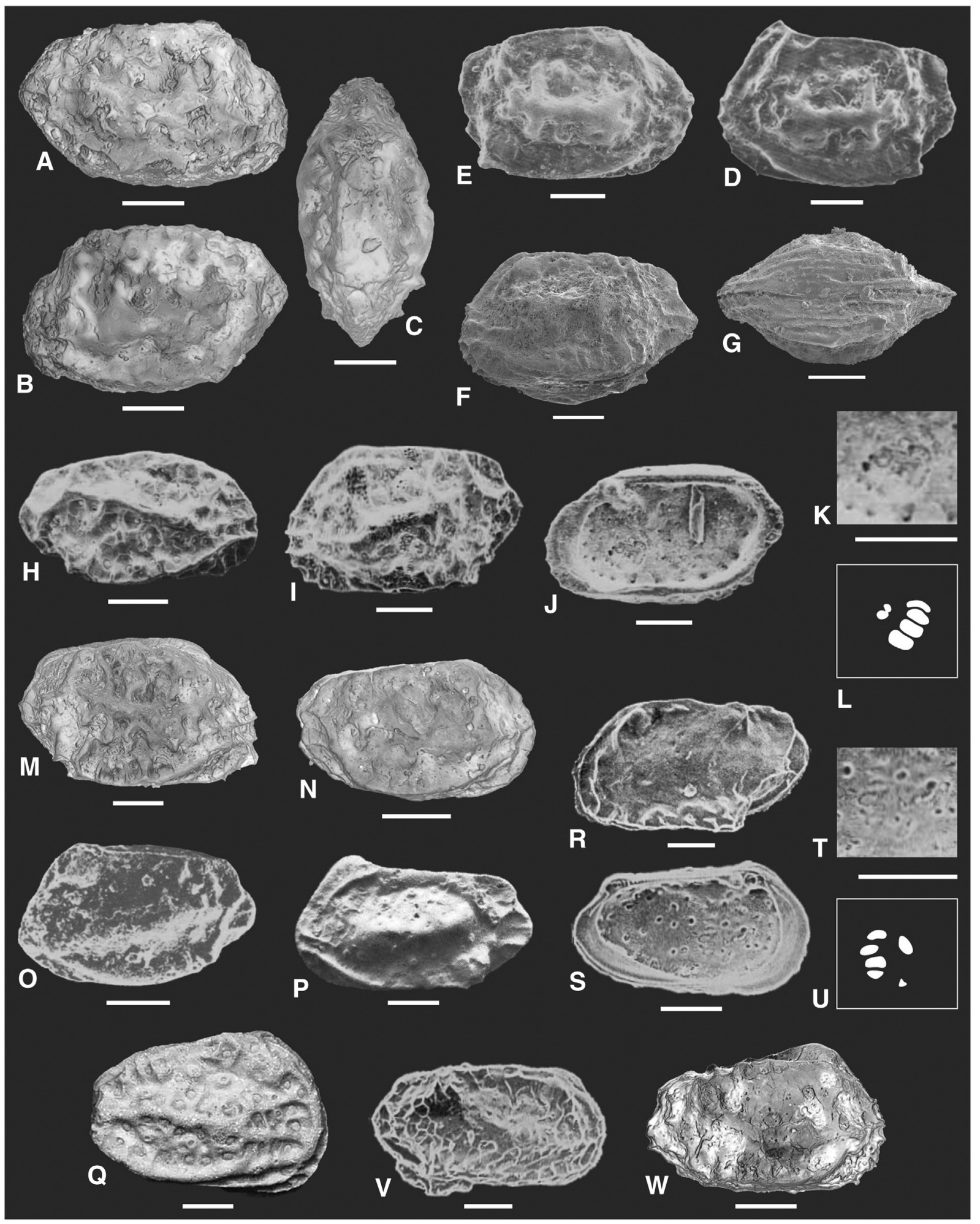

Fig. 3. Species of Amphicytherura Butler and Jones, 1957 and Dinglecythere Antonietto et al., n. gen. A-C, Amphicytherura dubia (Israelsky, 1929), holotype (no. 80234), A, Right lateral view, B, left lateral view, C, dorsal view; D-E, Amphicytherura chelodon (Marsson, 1880), D, homotype (IO1561), right lateral view, E, homotype (IO1560), left lateral view (Slipper, 2009): F-G, Amphicytherura icenica (Jones and Hinde, 1890), lectotype (IN19279-82), F, left lateral view, G, ventral view; H-L, Amphicytherura curta (Jennings, 1936), H, homotype (USNM 255711), right lateral view, I, homotype (USNM 255713), left lateral view, J-L, homotype (USNM 255712), J, right internal view, K, detail of the central and anterior muscle scars, L, interpretation of the central and anterior muscle scars (Smith, 1978); M, Amphicytherura copicosta Crane, 1965, holotype (no. 649060), right lateral view; N, Amphicytherura pandicosta Crane, 1965, holotype (no. 649061), right lateral view; O, Amphicytherura bergiguierensis Colin, 1974 (holotype), left lateral view (Colin, 1974); P, Amphicytherura subchelodon (Clarke, 1983), holotype (SGPIH 2613), left lateral view (Clarke, 1983); Q Amphicytherura grandicribra Puckett and Colin, 2012, holotype (USNM 543820), right lateral view (Puckett et al., 2012); R-U, Dinglecythere zululandensis (Dingle, 1980), R, paratype (SAM-K5599), left lateral view, S-U, paratype (SAM-K5601), S, left internal view, T, detail of the central and anterior muscle scars, U, interpretation of the central and anterior muscle scars; V, Dinglecythere tumidus (Dingle, 1969b), homotype (SAM-K5594), right lateral view (Dingle, 1980); W, Dinglecythere iniquus (Holden, 1964), paratype (USNM 131802), right lateral view. Scale bars $=100 \mu \mathrm{m}$ 
Table 1

Species currently attributed to Amphicytherura Butler and Jones, 1957, Aracajuia Krömmelbein, 1967, Dinglecythere Antonietto et al., n. gen. and other genera.

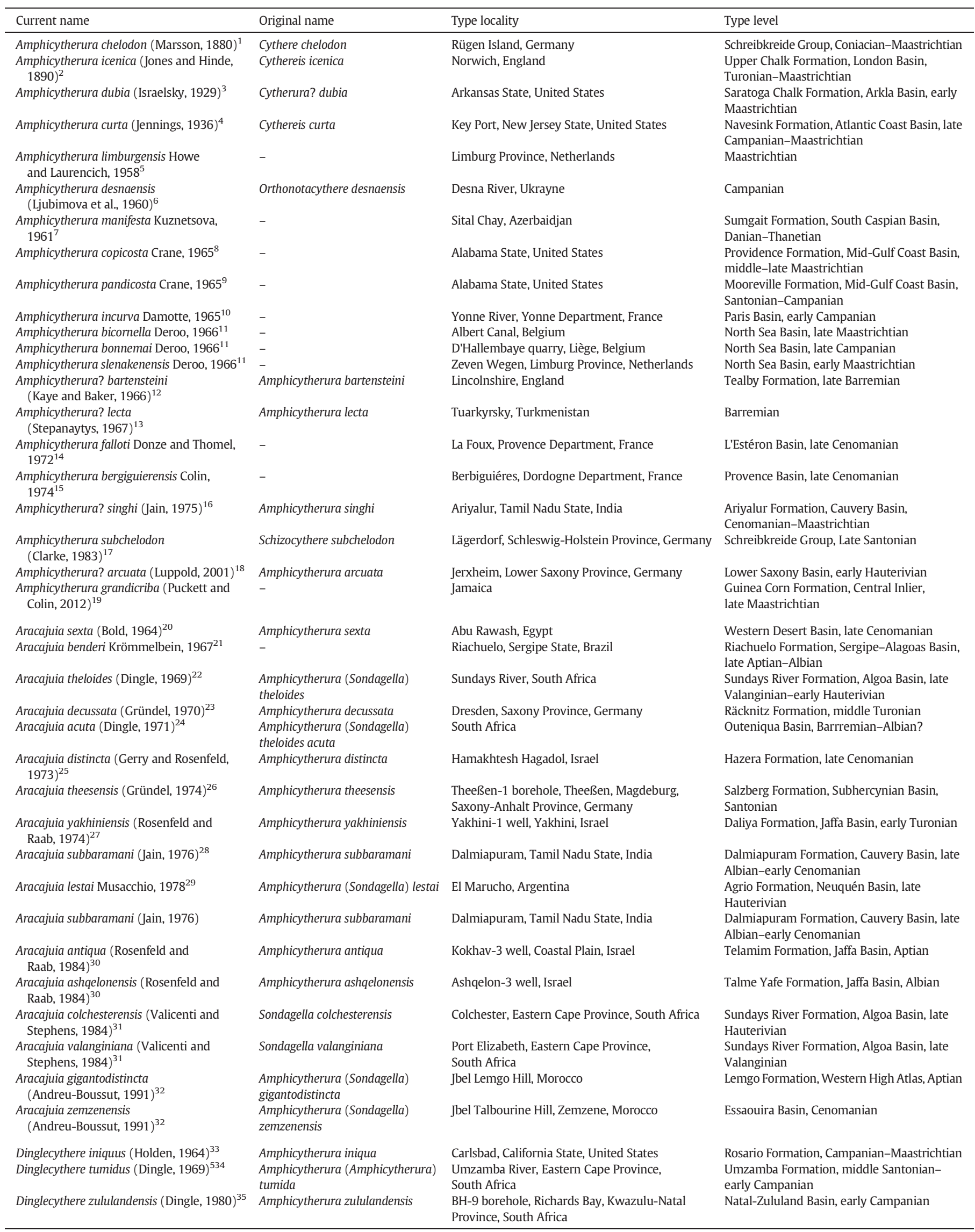


Table 1 (continued)

\begin{tabular}{|c|c|c|c|}
\hline Current name & Original name & Type locality & Type level \\
\hline Dinglecythere armatus (Dingle, 1981) ${ }^{36}$ & Amphicytherura armatus & $\begin{array}{l}\text { Mfolozi River and Lake Mfutululu, } \\
\text { Kwazulu-Natal Province, South Africa }\end{array}$ & $\begin{array}{l}\text { St. Lucia Formation, Natal-Zululand Basin, } \\
\text { Maastrichtian }\end{array}$ \\
\hline $\begin{array}{l}\text { Dinglecythere dinglei } \\
\quad(\text { McKenzie et al., 1993) }\end{array}$ & Amphicytherura dinglei & Castle Cove, New South Wales State, Australia & $\begin{array}{l}\text { Browns Creek Formation, Otway Basin, } \\
\text { Priabonian }\end{array}$ \\
\hline $\begin{array}{l}\text { Dinglecythere occultus } \\
\quad(\text { Puckett and Colin, 2012) }\end{array}$ & Amphicytherura occulta & Jamaica & $\begin{array}{l}\text { Guinea Corn Formation, Central Inlier, late } \\
\text { Maastrichtian }\end{array}$ \\
\hline $\begin{array}{l}\text { Apateloschizocythere aculeata } \\
\quad(\text { Bonnema, 1941) }\end{array}$ & Eucytherura aculeata & Drenthe Province, Netherlands & Cenomanian-Maastrichtian \\
\hline Arculicythere kallakkudiensis Jain, $1978^{39}$ & Amphicytherura kallakkudiensis & $\begin{array}{l}\text { Kallakkudi quarry, Kallakkudi, } \\
\text { Tamil Nadu State, India }\end{array}$ & $\begin{array}{l}\text { Kallakkudi Member, Dalmiapuram } \\
\text { Formation, Cauvery Basin, Early Cenomanian }\end{array}$ \\
\hline $\begin{array}{l}\text { Orthonotacythere roemeri Bartenstein, } \\
1956^{40}\end{array}$ & Orthonotacythere roemeri & Nettelton Beck, Caistor, England & Tealby Formation, Hauterivian \\
\hline \multicolumn{4}{|c|}{ 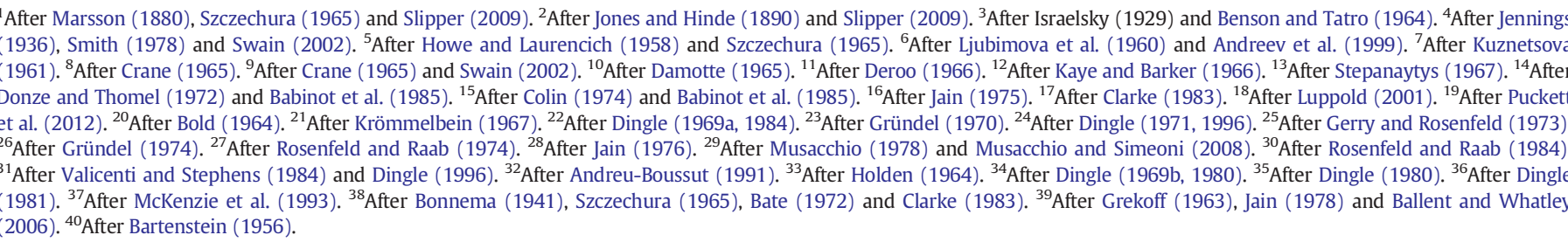 } \\
\hline
\end{tabular}

Amphicytherura? singhi Jain are poorly described and figured in their original publications. Amphicytherura roemeri (Bartenstein) is returned to the genus Orthonotacythere, as it also does not resemble Amphicytherura. Amphicytherura kallakkudiensis Jain is re-classified as Arculicythere kallakkudiensis, following Grekoff (1963) and Ballent and Whatley (2006). Amphicytherura aculeata (Bonnema), originally placed in Eucytherura, is renamed as Apateloschizocythere aculeata, based on Bate (1972) and Clarke (1983).

\section{Genus Aracajuia Krömmelbein, 1967 emend.}

(Fig. 5E-S)

Type-species. Aracajuia benderi Krömmelbein, 1967; “Porto dos Barcos 3" outcrop, Riachuelo Formation, Sergipe-Alagoas Basin, upper Aptian-Albian; road east of Usina Fortuna, northern Divina Pastora Municipality Sergipe State, northeastern Brazil (Krömmelbein, 1967).

Diagnosis. Carapace sub-rectangular to sub-quadrate. Lateral surface with three longitudinal ridges (central, dorsal and ventral); additional transverse ribs or riblets present, varying in degree of development. Dorsal ridge obscuring the hinge margin, then bifurcating at the antero-dorsal region; the upper branch reaching the anterior end, until right after the cardinal angle; the lower one crossing the welldeveloped eye tubercle and usually connecting with the central ridge. Central ridge thin, more or less zigzag-like, bifurcating in the anterocentral region. In internal view, hinge schizodont, consisting of striated terminal teeth and a bifid pit on the anterior end, a slightly crenulated groove and a posterior striated tooth at the right valve. Sexual dimorphism strong: in dorsal view, males elliptical and females biconvex, with a more evident caudal process; in lateral view, male carapace elongated, female carapace compact.

Occurrence. South Africa, ?Tithonian-Albian (Dingle, 1969a; Brenner and Oertli, 1976; McLachlan et al., 1976; Dingle, 1982, 1984; Valicenti and Stephens, 1984; Musacchio and Simeoni, 2008); Argentina, ?BerriasianHauterivian (Musacchio, 1978; Ballent et al., 2006; Musacchio and Simeoni, 2008; Ballent, 2009); Morocco, Aptian-Cenomanian (AndreuBoussut, 1991; Gebhardt, 1999); Israel, Aptian-early Turonian (Gerry and Rosenfeld, 1973; Rosenfeld and Raab, 1974, 1984; Rosenfeld et al., 1988); Brazil and Gabon, late Aptian-Albian (Krömmelbein, 1966, 1967; Bertels, 1977); Iran, Lebanon, Oman, Somalia and United Arab Emirates, Albian (Luger, 2003); India, Albian-Coniacian (Jain, 1976; Andreu et al., 2008); Egypt and Jordan, Cenomanian (Bold, 1964; Gebhardt, 1999);
Germany, late Cenomanian-Santonian (Gründel, 1970, 1974; Damotte et al., 1981) (Table 1; Fig. 4).

Remarks. Aracajuia was placed in the Family Cytheruridae Müller by Musacchio and Simeoni (2008), with no further systematic details. However, it is here classified in the Family Cytheridae, Subfamily Schizocytherinae, based on the presence of a distinctive schizodont hinge in the type-species, Aracajuia benderi, which characterizes this group. The original diagnosis was emended for simplicity so that the diagnostic features would be more identifiable. Some of the original features were removed from the diagnosis (shape of lateral and marginal pore canals; structures of the marginal zone, such as the inner margin and concrescence line; and taxonomic ranking), while others were incorporated (the central muscle scar pattern). Aracajuia is considered a valid genus, distinguished mainly by the position of the three ridges along the lateral surface of the carapace and by its sexual dimorphism. Musacchio and Simeoni (2008) described Aracajuia as entomodont, but examination of the individuals from sample MP-291 shows that it clearly is not; these authors also stated that Acrocythere Neale resembles Aracajuia but has a different hinge. According to the original diagnosis, the hinge of Acrocythere is entomodont as for Orthonotacythere (Alexander, 1933; Neale, 1960). Aracajuia could be derived from Acrocythere, which would explain their similarities, but also the greater complexity of the former's hinge. Fissocarinocythere Brouwers and Hazel is comparable to Aracajuia, but the two genera can be separated by their outline in dorsal view and by the ornamentation of the anterior end (smooth in Fissocarinocythere and ridged in Aracajuia). The similarity between Aracajuia and Sondagella was first noted by Dingle (1999), and the synonymy was employed by Musacchio and Simeoni (2008) and Ruault-Djerrab and Kechid-Benkherouf (2011). Some authors (Ballent, 2009; Ballent and Whatley, 2009; Concheyro et al., 2009) continued to recognize Sondagella as a valid genus, based on Bate (1972), despite previous discussion. Species originally attributed to Sondagella present the diagnostic characteristics described above for Aracajuia overall carapace shape, lateral surface ornamentation, especially the morphology of the three main ridges, hinge type and sexual dimorphism; therefore, Sondagella is here considered to be a junior synonym of Aracajuia. The present authors assign several species previously identified as Amphicytherura or Sondagella to Aracajuia, as detailed in Table 1.

Aracajuia benderi Krömmelbein, 1967 emend.

(Fig. 6A-R) 


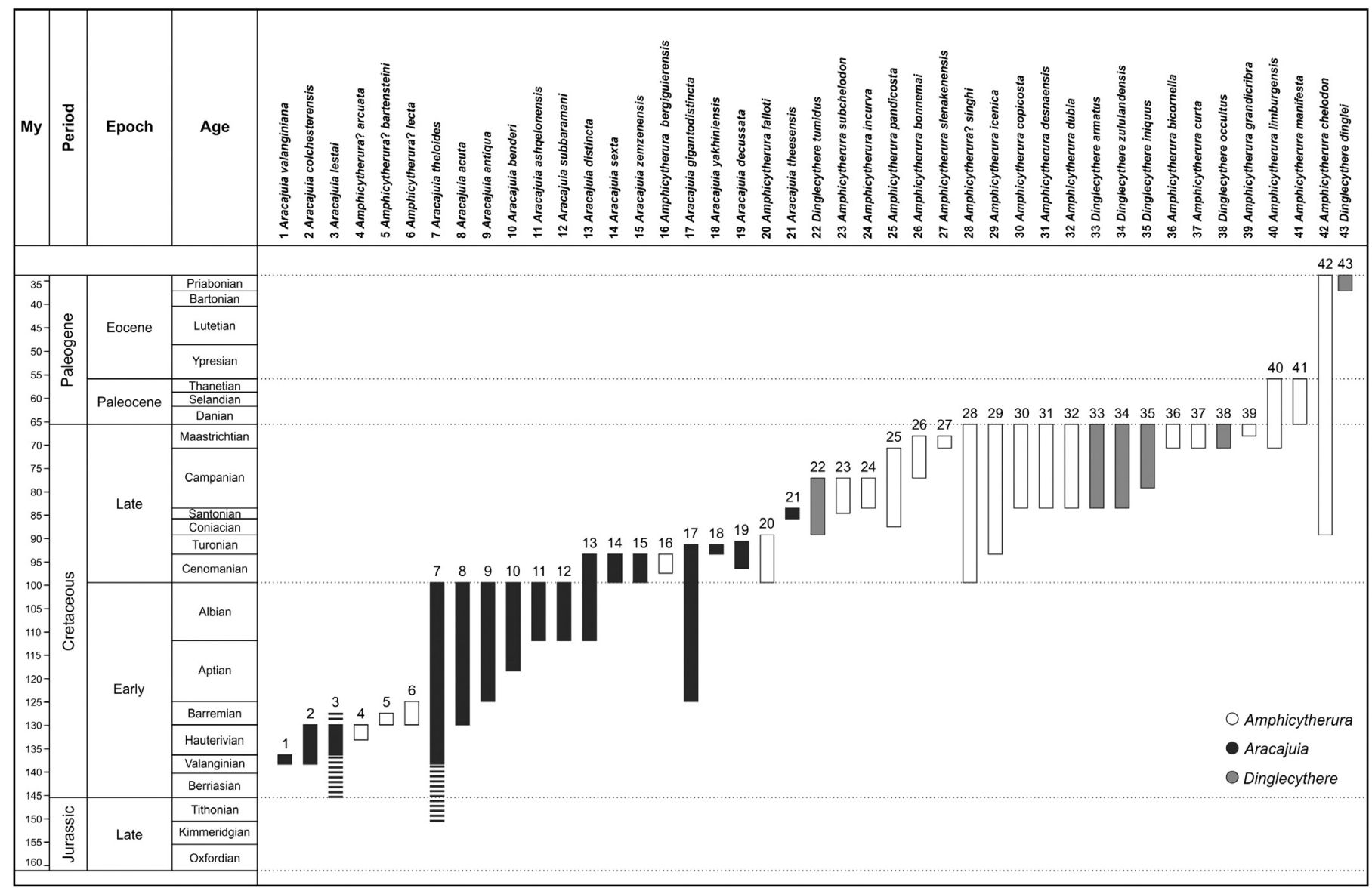

Fig. 4. Stratigraphic distributions of Amphicytherura Butler and Jones, 1957, Aracajuia Krömmelbein, 1967 and Dinglecythere Antonietto et al., n. gen.

Ostracoda sp. B; Krömmelbein, 1966: 121, figs. 2a-c.

Aracajuia benderi Krömmelbein, 1967: 529, figs. 1, 2a, 2b, 3, 4a-c. Amphicytherura benderi (Krömmelbein); Viviers et al. (2000): 413, figs. 16.1-3.

?Amphicytherura aff. Amphicytherura benderi (Krömmelbein); Viviers et al. (2000): 427, figs. 16.4-6.

Amphicytherura sp. P3; Viviers et al. (2000): 411, figs. 16.11-14.

?Amphicytherura sp. P4; Viviers et al. (2000): 411, figs. 16.15-17.

Aracajuia benderi Krömmelbein; Musacchio and Simeoni (2008): 252, fig. 8.

Type material. Holotype: SMF Xe 5492; paratypes: SMF Xe 5463-5496 and SMF Xe 5505. Deposited in the collection of the Naturmuseum und Forschungsinstitut Senckenberg, Frankfurt, Germany (Krömmelbein, 1967).

Diagnosis. Carapace sub-rectangular (male) to sub-quadratic (female). Posterior end with an evident caudal process. Dorsal, central and ventral ridges not linked by smaller sub-vertical ridges, which are primarily concentrated along the central ridge. Central ridge slightly zigzag-like, bifurcating in the antero-central region, with the upper branch ending at mid-length of the lower one of the dorsal ridge, and the lower branch reaching the anterior end. Ventral ridge forming a small carina-like process that overshadows part of the ventral margin, especially on females. Normal pore-canals along the lateral surface sparse, celate, forming pustules.

Material. 141 carapaces (including CP-619 and CP-620), 194 valves (including CP-621 to CP-630) and 17 lost specimens, totalling 352; sample MP-291.
Occurrence. Sergipe-Alagoas Basin, Riachuelo Formation, Taquari Member, upper Aptian-lower Albian, northeastern Brazil (Krömmelbein, 1967; Bertels, 1977; Viviers et al., 2000; Musacchio and Simeoni, 2008); Potiguar Basin, Açu Formation, middle Albian, northeastern Brazil (Viviers et al., 2000); Gabon Basin, Madiela Formation, upper Aptian-lower Albian, Gabon, western Africa (Krömmelbein, 1966; Bertels, 1977).

Description. Carapace sub-rectangular to sub-quadratic in lateral view. Left valve larger than right valve and slightly overlapping it on the dorsal margin. Greatest height antero-central; greatest length central. Anterior end rounded. Posterior end angulate, with an evident caudal process. Dorsal margin sub-rectilinear; posterior cardinal angle at approximately $90^{\circ}$. Ventral margin slightly concave in the oral region. Lateral surface ornamented with three horizontal ridges (dorsal, central and ventral) not linked by smaller sub-vertical ridges; very weak inter-ridge reticulation present; the ridges converge at the anterior end and the postero-central region. Dorsal ridge thin, overshadowing the hinge line, bifurcated; the upper branch runs along the dorsal margin until right after the cardinal angle, and the lower one extends to the antero-central region. Central ridge thin, slightly zigzag-like, bifurcating at the antero-central region; the upper branch ends at the mid-length of the lower one of the dorsal ridge, and the lower branch reaches the anterior end. Ventral ridge thin, forming a carina-like process that overshadows the carapace outline. Pore-canals along the lateral surface sparse and celate, forming pustules. Eye-tubercle well developed. In dorsal view, biconvex, with greatest width at the postero-median region. In ventral view, three thin, concentric longitudinal ribs running between the ventral ridges and ending just behind the anterior and 


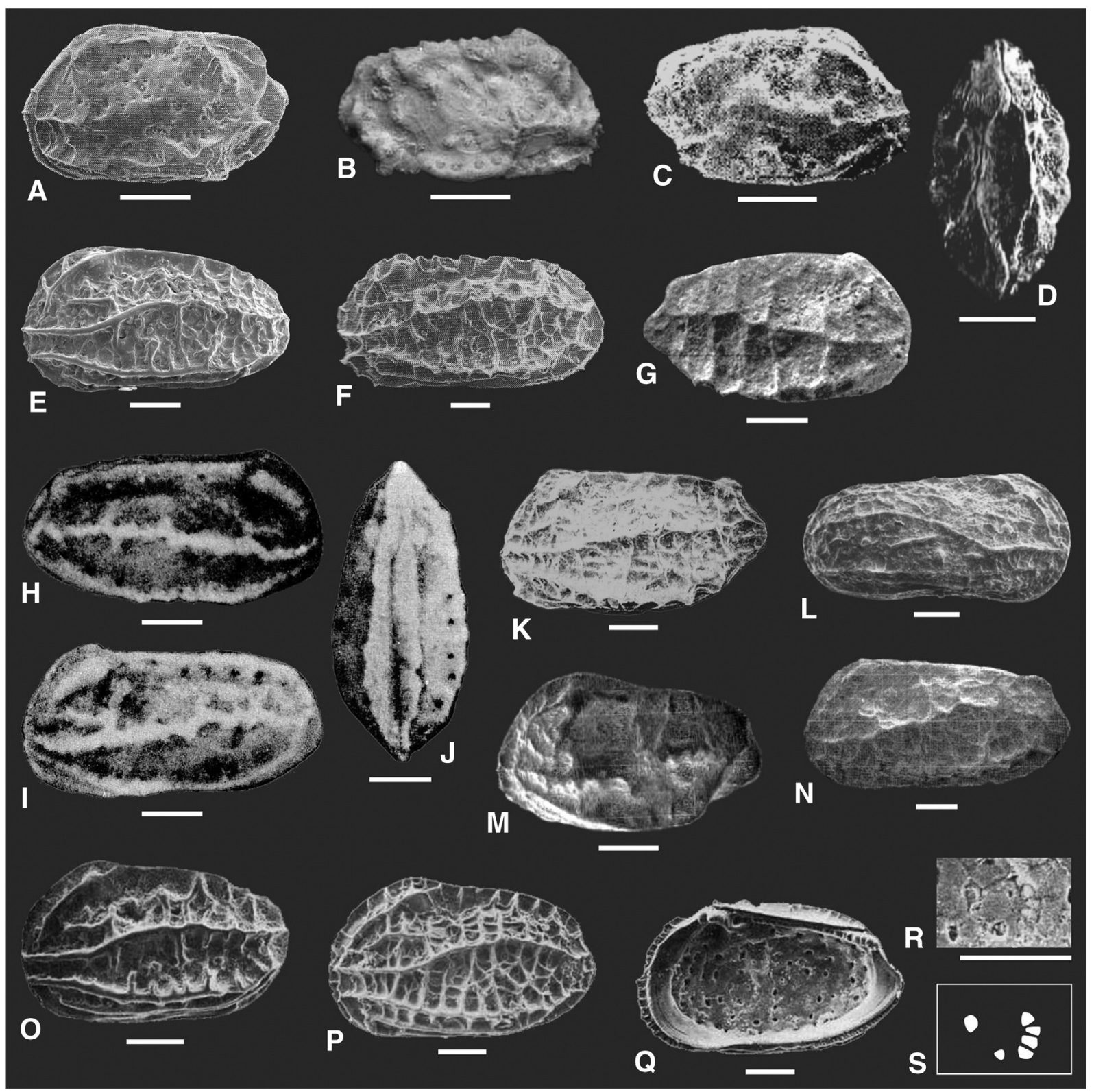

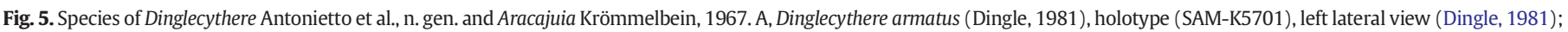

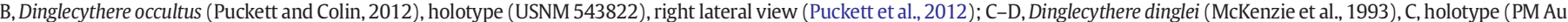

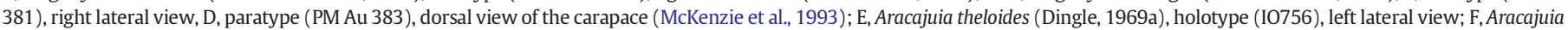

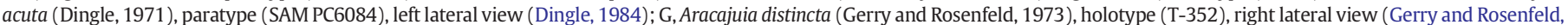

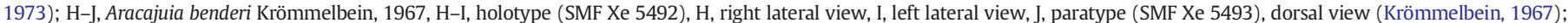

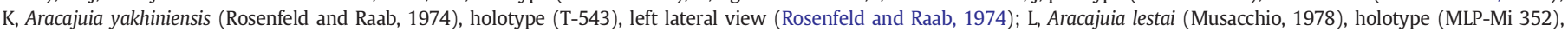

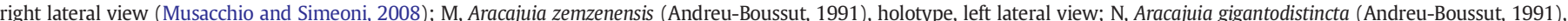

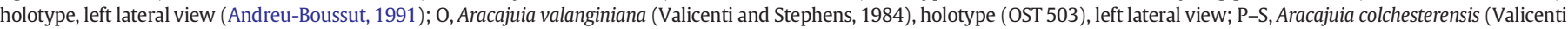

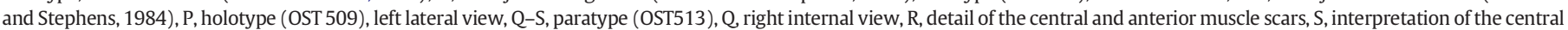
and anterior muscle scars (Valicenti and Stephens, 1984). Scale bars $=100 \mu \mathrm{m}$.

posterior ends. In internal view, hinge schizodont, consisting in the right valve of a tripartite anterior tooth followed by a socket, a bar and a crenulate terminal tooth; elements of the left hinge complementary. Inner margin well developed (except in the oral region), coincident with the concrescence line. Selvage visible only around the oral region. Sexual dimorphism strong: in lateral view, male sub-rectangular, female subquadrate; left valve slightly overlapping the right valve in the anterior and posterior regions of the ventral margin in males but not in females; greatest height more anterior in females than in males; in dorsal view, female biconvex, male elliptical; females with larger caudal processes and more visible centro-anterior constrictions than males; in ventral view, females with a larger ventral surface than males. Juveniles subtriangular, with ornamentation similar to adults; ridges thinner overall than in adults, the central ridge sub-straight. Internal features as in adults.

Remarks. The adult morphological features of Aracajuia benderi are herein re-described, with the objective of making it simpler to identify. Some of the original features were removed from the diagnosis (shape of lateral and marginal pore canals), while others were incorporated (detailing of the central muscle scar pattern, selvage and eye tubercle and description of A-1, A-2, A-3 and possibly A-5 juvenile instars). The ontogenic development of the species is also presented (Fig. 7). 


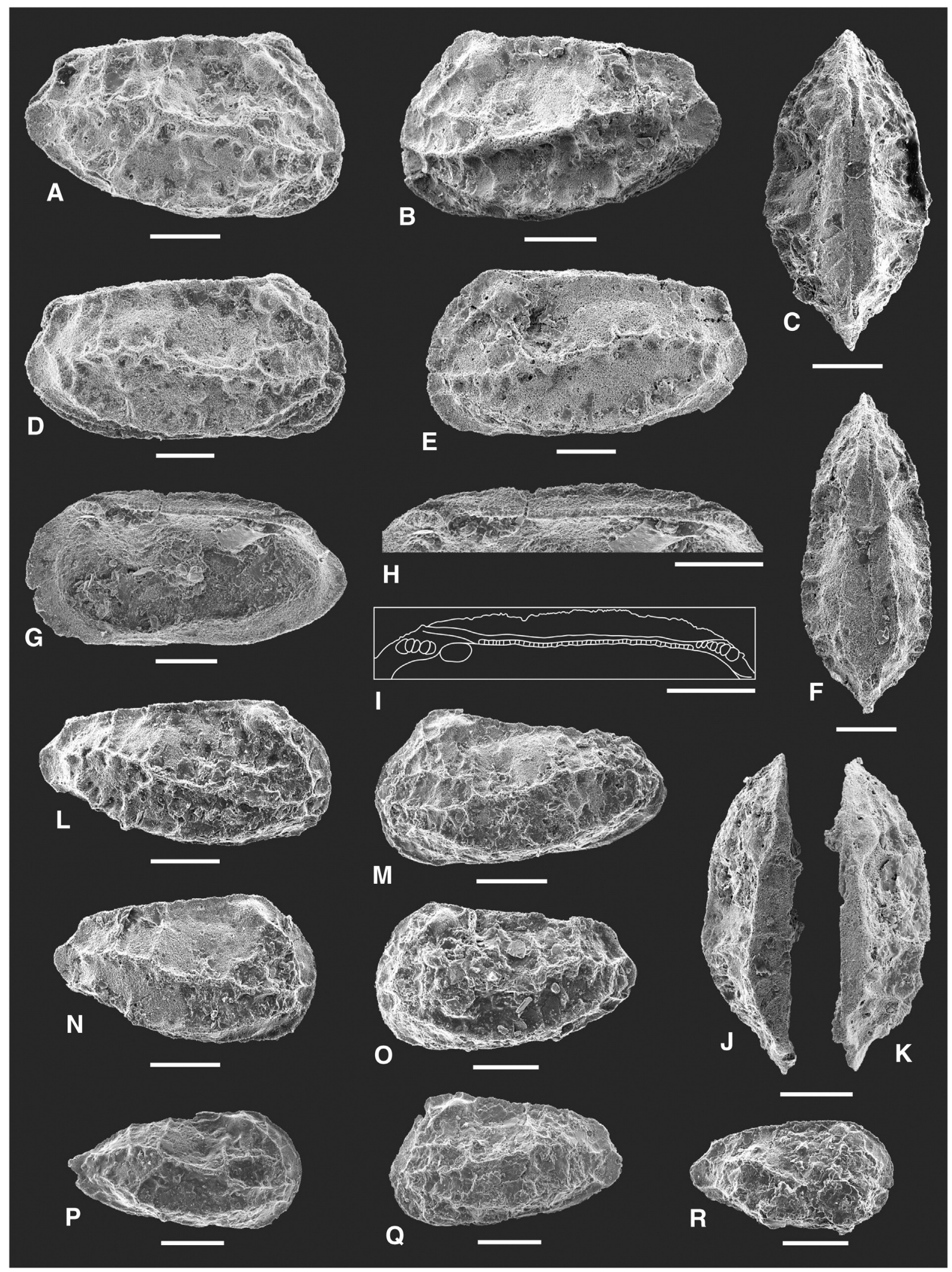

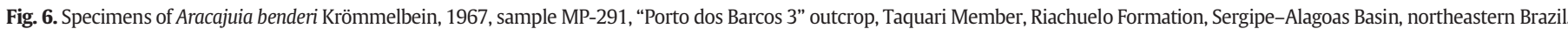

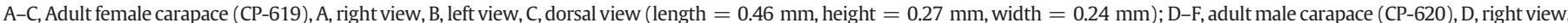

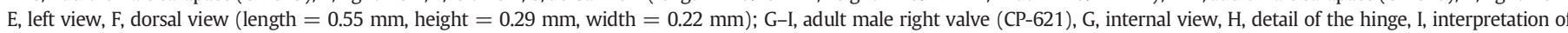

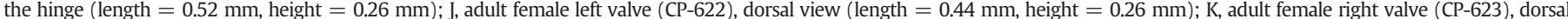

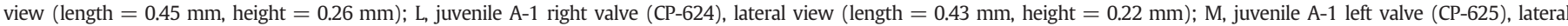

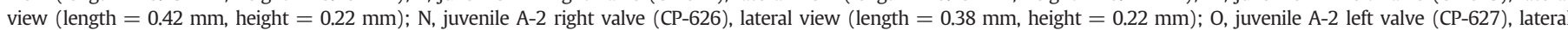

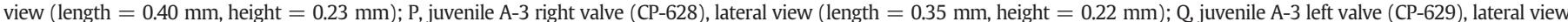
(length $=0.36 \mathrm{~mm}$, height $=0.20 \mathrm{~mm})$; $\mathrm{R}$, juvenile A-5? right valve $(\mathrm{CP}-630)$, lateral view $($ length $=0.31 \mathrm{~mm}$, height $=0.18 \mathrm{~mm})$. Scale bars $=100 \mu \mathrm{m}$. 
Aracajuia distincta Gerry and Rosenfeld and Aracajuia benderi differ in the size of the carapace, the shape of the central ridge and the overall thickness of the longitudinal ridges. However, the two species are highly similar, and Aracajuia distincta could represent an A-1 individual of Aracajuia benderi; thus, these two species may be synonyms. Aracajuia yakhininensis Rosenfeld and Raab is also a possible synonym; it differs from Aracajuia benderi only in having more developed ornamentation and the carina-like process on the ventral margin, which is actually a much-enlarged ventral ridge. Aracajuia benderi and Aracajuia gigantodistincta Andreu-Boussut can be separated by the orientation of the longitudinal central ridge (more zigzag-like in Aracajuia gigantodistincta than in Aracajuia benderi) and by the orientation of the dorsal margin (which is more strongly sloped toward the posterior end in Aracajuia gigantodistincta than in Aracajuia benderi). Aracajuia zemzenensis Andreu-Boussut differs from Aracajuia benderi in the development of the ventro-lateral carina-like process (which is stronger in Aracajuia zemzenensis). Aracajuia benderi is distinguished from Aracajuia theloides by the shape of the upper branch of the central ridge (which is highly developed in Aracajuia theloides) and the caudal process (less apparent in Aracajuia theloides). Compared to Aracajuia colchesterensis, Aracajuia valanginiana and Aracajuia acuta, Aracajuia benderi can be separated by its more rectangular overall shape and by its well-developed caudal process. Aracajuia benderi also has an ornamentation pattern more similar to that of Aracajuia valanginiana than to that of Aracajuia colchesterensis. Aracajuia benderi differs from Aracajuia lestai by the highly characteristic general outline of the latter species. Aracajuia ashqelonensis Rosenfeld and Raab is clearly distinguished by its strongly zigzag-like central ridge, where the ramifying branch appears to be the lower one instead of the upper. Females of Aracajuia benderi and Aracajuia antiqua Rosenfeld and Raab are nearly identical, but the males of Aracajuia antiqua have a more developed ventro-central carina-like process. In relation to Aracajuia sexta Bold, both can be differentiated by the shape in dorsal view (more slender than in Aracajuia benderi, with a larger anterior region). Aracajuia benderi can be separated from Aracajuia subbaramani Jain by the inclination of the slender central rib, which is steeply pointed in the anteroventral and postero-dorsal regions in Aracajuia subbaramani but much less oblique in Aracajuia benderi, running more parallel to the ventral and dorsal margins. Aracajuia decussata Gründel has a much thicker central ridge than Aracajuia benderi, resembling the central ridge of Amphicytherura species, although anteriorly bifurcate. Specimens of Aracajuia theesensis Gründel possess a similar but highly nodulated central ridge and a carina-like ventral ridge. These species are the earliest representatives of Aracajuia, and with their similarities to
Amphicytherura, they could indicate a possible evolutionary trend between these genera.

Genus Dinglecythere Antonietto et al., n. gen.

(Figs. 3R-W, 5A-D)

Type-species. Amphicytherura (Amphicytherura) tumida Dingle, 1969; Umzamba Formation, Santonian; Umzamba River mouth, Pondoland State, South Africa (Dingle, 1969b, 1980).

Diagnosis. Carapace sub-rectangular to sub-quadratic. Lateral surface with irregular ornamentation and a well-developed tubercle in the postero-dorsal region. Dorsal and ventral ridges present, the dorsal ridge running from the postero-dorsal margin to the anterior end, where it fuses with the ventral ridge, which is usually carinate and extends to the postero-ventral margin. In internal view, hinge schizodont, consisting of a bifid tooth and a bifid pit on the anterior end, a crenulated groove and a posterior striated tooth at the right valve; central and frontal muscle-scar pattern composed by four elongated central scars and a rounded frontal scar. Sexual dimorphism present but weak: in lateral view, male carapace elongated, female carapace compact.

Derivation of name. The genus is named in honor of Professor R.V. Dingle, who greatly contributed to the study of South African ostracods, some of which are currently reassigned to genera Aracajuia and Dinglecythere.

Occurrence. South Africa, Santonian-Maastrichtian (Dingle, 1969b, 1980, 1981); United States, middle Campanian-Maastrichtian (Holden, 1964); Jamaica, Maastrichtian (Puckett et al., 2012); Australia, Priabonian (McKenzie et al., 1993) (Table 1, Fig. 4).

Remarks. Species of Dinglecythere share features that separate them from Aracajuia, Amphicytherura and other similar genera, especially the ornamentation pattern in lateral view, with two ridges along the dorsal and ventral margins, overall irregular lateral surface and a highly conspicuous postero-dorsal tubercle. Three of the species assigned to the new genus, Dinglecythere iniquus (Holden), Dinglecythere tumidus (Dingle) (the type-species) and Dinglecythere occultus (Puckett and Colin) had their specific epithet changed to agree with the masculine gender of Dinglecythere, in opposition to the feminine name Amphicytherura. The new genus also includes other species listed in Table 1.

\section{Biostratigraphy}

The occurrence of Aracajuia benderi is considered to be a biostratigraphic marker of late Aptian-Albian sequences in the Sergipe-Alagoas Basin (Viviers et al., 2000). One formal zone and one formal subzone

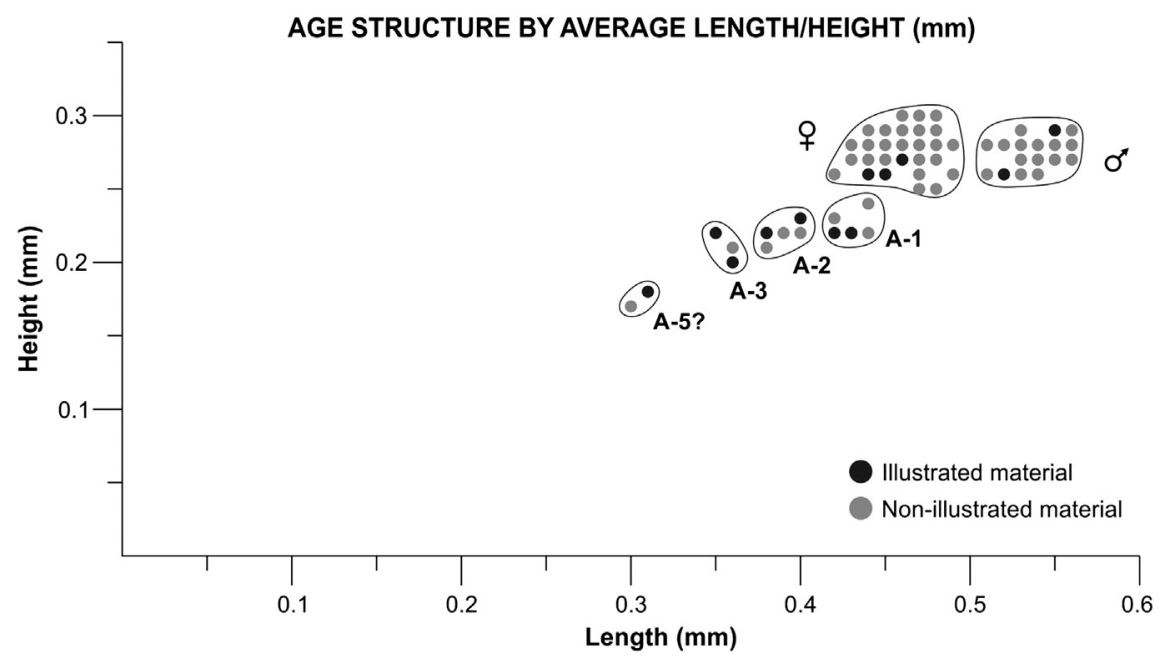

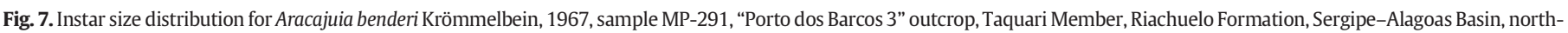
eastern Brazil. 
have been established based on this species: Zone Amphicytherura benderi (coded as OSE-1) and Subzone Amphicytherura benderi (coded as OSE1.6). The present study confirms the re-validation by Musacchio and Simeoni (2008) of the genus Aracajuia, which was considered to be a synonym of Amphicytherura by Viviers et al. (2000). Therefore, both the zone and the subzone are now renamed as Aracajuia benderi (Fig. 8).

Although not formally established in the Neuquén Basin, several assemblage and composite assemblage zones are described from its Valanginian-Hauterivian interval (Vaca Muerta, Chachao and Agrio formations). These informal zones include Aracajuia cf. valanginiana fauna, Aracajuia colchesterensis fauna, Cytherelloidea agrioensis-Aracajuia? sp. EM assemblage zone, Aracajuia theloides fauna and Aracajuia? lestai fauna (Musacchio and Simeoni, 2008). After the present review of the genus Aracajuia, this last one is renamed as Aracajuia lestai fauna.

\section{Paleozoogeography}

The first occurrences of Aracajuia are from South Africa, possibly during the Tithonian of the Knysna region (Dingle, 1984). By the late Valanginian (Berriasian?), it spread to the Neuquén Basin of Argentina, while still present in the Algoa and Outeniqua basins of South Africa. It remained in the Neuquén area until the end of the Hauterivian (early Barremian?) (Dingle, 1969a; Brenner and Oertli, 1976; McLachlan et al., 1976; Musacchio, 1978; Valicenti and Stephens, 1984; Musacchio and Simeoni, 2008) (Fig. 9A).

Beginning in the early Aptian, Aracajuia spread to Morocco (Essaouira and Middle High Atlas basins) (Andreu-Boussut, 1991; Andreu, 1992), possibly from Argentina. The group then underwent great speciation, which resulted by the Albian in a diverse group of new species occurring throughout the South American, African, Levantine and Indian coasts (Outeniqua and Natal-Zululand basins, South Africa; Potiguar and Sergipe-Alagoas basins, Brazil; Gabon Basin, Gabon; Lebanon; Abu Dhabi, United Arab Emirates; Khazduni Basin, Iran; Bab Basin, Oman; Gulf of Aden Basin, Somalia; Jaffa Basin, Israel; Cauvery Basin, India) (Krömmelbein, 1966, 1967, 1975; Jain, 1976; Bertels, 1977; Grosdidier, 1979; Dingle, 1982, 1984; Rosenfeld and Raab, 1984; Dingle, 1996; Luger, 2003; Andreu et al., 2008) (Fig. 9B). Most of these occurrences disappeared at the end of the Albian, with only those at Morocco and South Africa reaching the Late Cretaceous (Dingle, 1984; Gebhardt, 1999) (Fig. 10A).

The latest records of Aracajuia are from the Cenomanian-Santonian. During these stages, new species originated in North Africa and the Middle East (Western Desert Basin, Egypt; Essaouira and West High Atlas basins, Morocco; Douleb and Djebel Chemla, Tunisia; Wadi Sirhan Basin, Jordan; Jaffa Basin and Mount Carmel, Israel) (Bold, 1964; Gerry and Rosenfeld, 1973; Rosenfeld and Raab, 1974; Andreu-Boussut, 1991; Andreu et al., 2008; Ruault-Djerrab and Kechid-Benkherouf, 2011) (Fig. 9B). Specimens identified as Aracajuia sp. 5 and Amphicytherura aff. A. yakhiniensis were also observed in the Cenomanian-Coniacian of India (Jaisalmer Basin) (Jain, 1976; Andreu et al., 2008), believed to arrive from South Africa. At the end of the Turonian, the geographic distribution of Aracajuia became much reduced; still, the genus reached Laurasia (Räcknitzer Formation and Subhercynian Basin, Germany), arguably from the Levantine Coast. There it became extinct at the end of the Santonian (Gründel, 1970, 1974) (Figs. 9B, 10A).

The genus Amphicytherura was restricted to the Upper Cretaceous. It was first undoubtedly observed in the Cenomanian-Turonian of France, in the Aquitaine, l'Estéron and Provence basins, and the Turonian of the

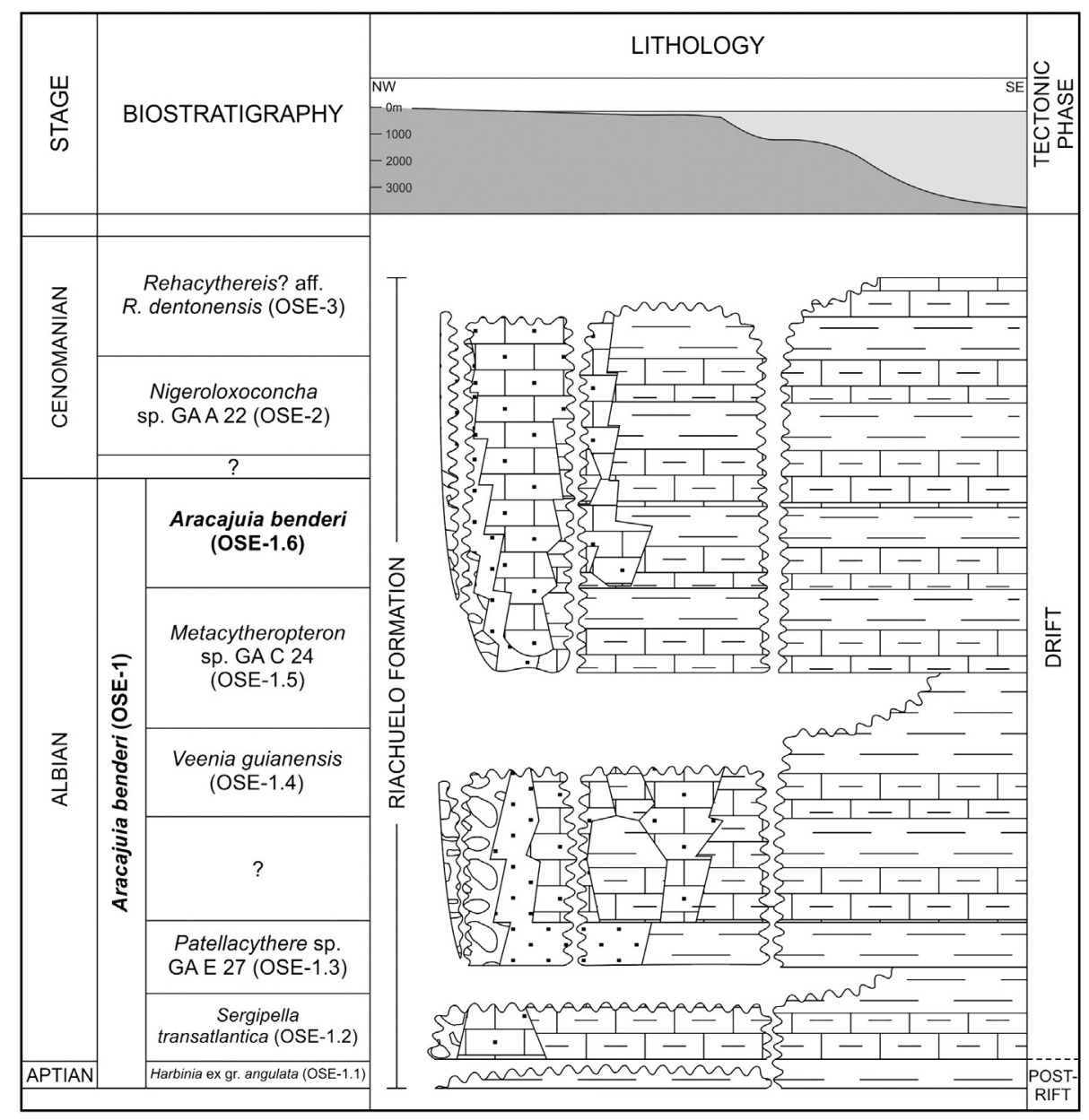

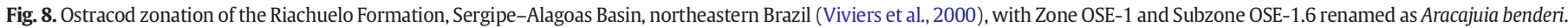




\section{(A) Tithonian-Barremian}

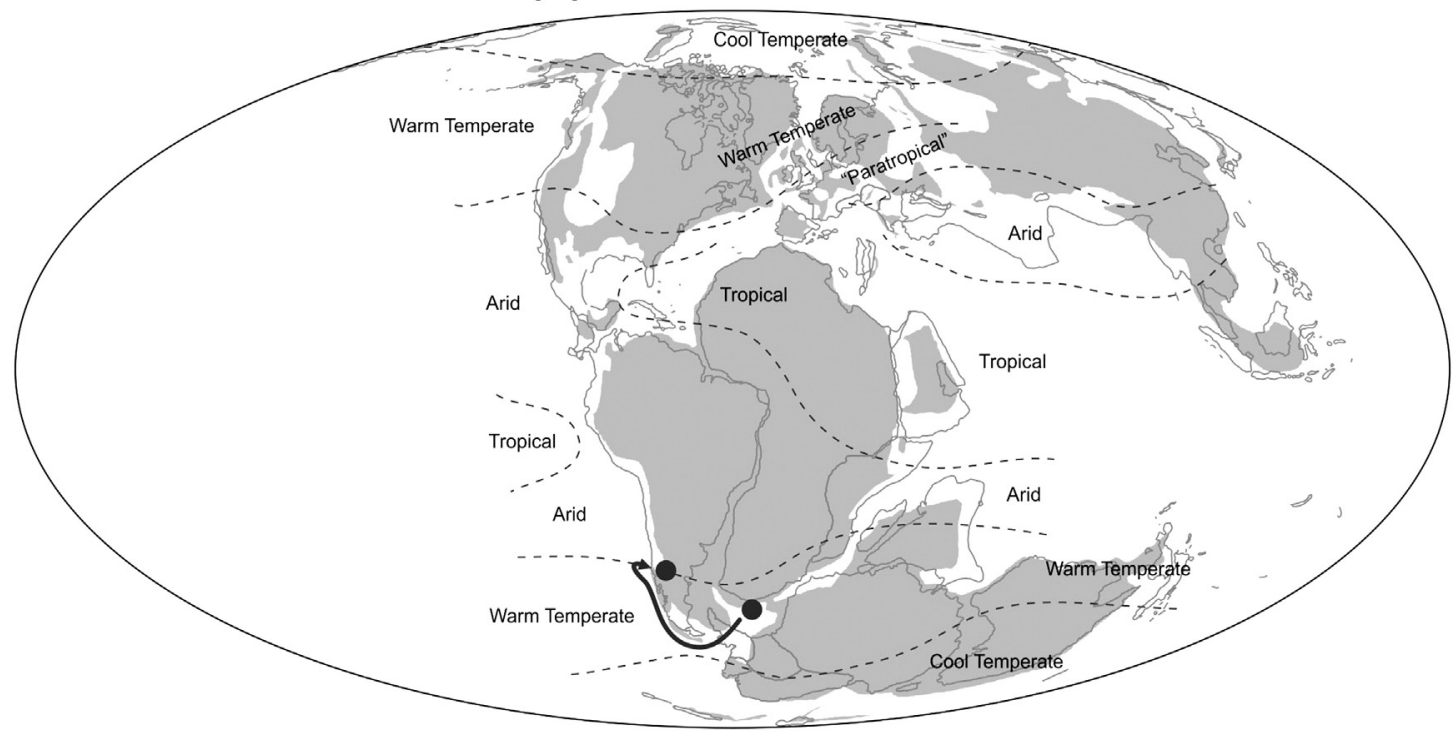

\section{(B) Barremian-Turonian}

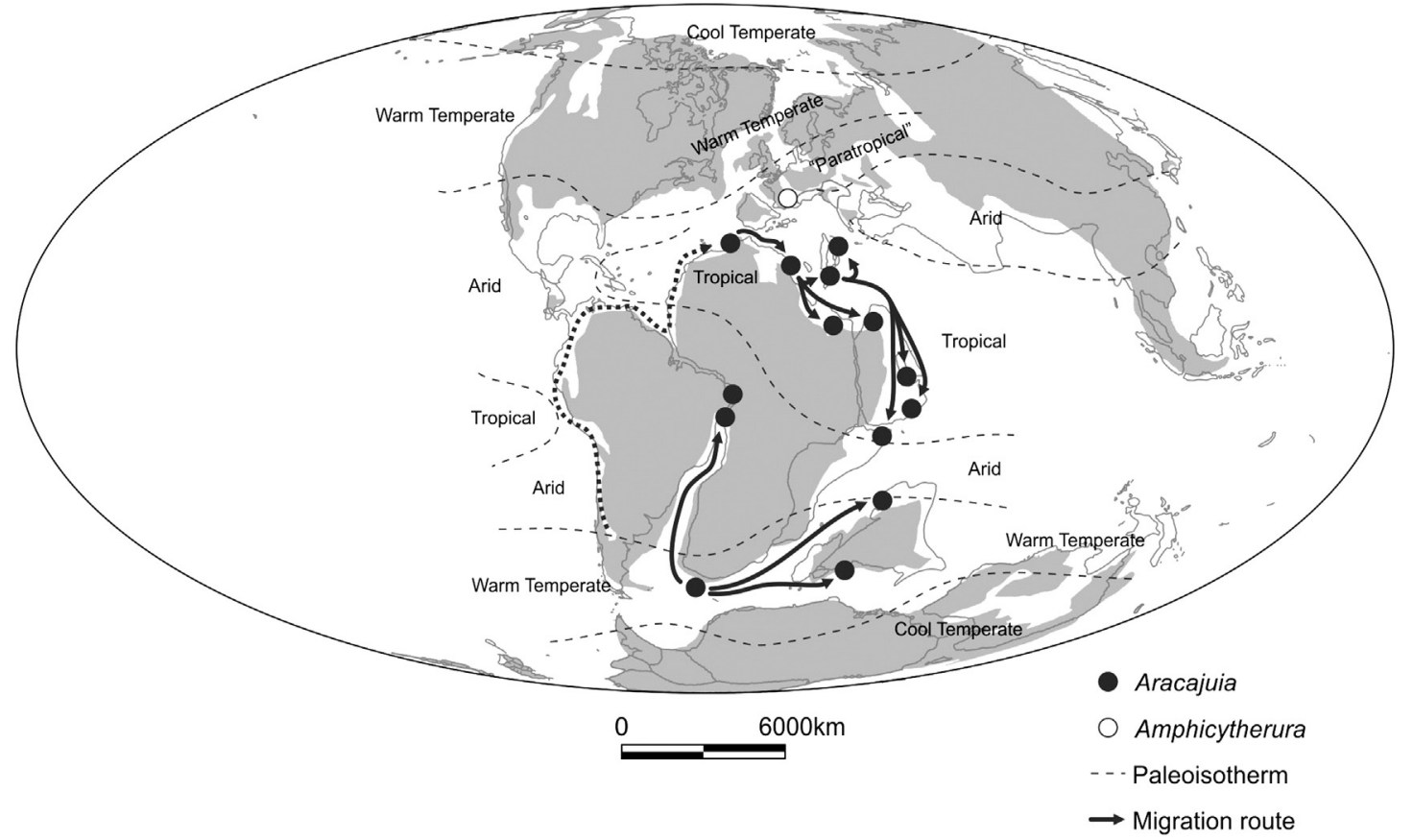

Fig. 9. Paleozoogeography and migration routes of Amphicytherura Butler and Jones, 1957 and Aracajuia Krömmelbein, 1967. A, Tithonian-Barremian; B, Barremian-Turonian.

Chalk Group, England. During the Santonian-Campanian, it was already present on both sides of the proto-North Atlantic, in the Paris (France) and North Sea basins (Netherlands and Belgium), the Schreibkreide (Germany) and Chalk (England) groups and Ukraine, but also in the East Texas, Arkla, Black Warrior, Mid-Gulf Coast and Atlantic Coast basins (United States) (Jones and Hinde, 1890; Israelsky, 1929; Alexander, 1936; Jennings, 1936; Alexander, 1939; Butler and Jones, 1957; Ljubimova et al., 1960; Benson and Tatro, 1964; Crane, 1965; Damotte, 1965; Deroo, 1966; Donze and Thomel, 1972; Colin, 1974; Babinot et al., 1985; Gohn, 1992; Puckett, 1992; Andreev et al., 1999; Puckett, 2005) (Fig. 10A).

Dinglecythere, the most chronologically and geographically restricted of the three genera analyzed herein, first appeared in the Coniacian of South Africa (Umzamba Formation), and spread to other regions
(Natal-Zululand Basin) during the Campanian (Dingle, 1969b, 1980, 1981, 1982, 1996). By the upper Campanian, the genus was present in the United States (Rosario Formation) (Holden, 1964) (Fig. 10A). The most certain path was straight from South Africa, despite the great distance and variation of paleoenvironments along migration routes (Scotese, 2000). Another possibility would be through modern Jamaica, where there are records of the genus (Puckett et al., 2012), but only from the subsequent Maastrichtian stage; anyway, all of the aforementioned occurrences are also known from the Maastrichtian.

During the Maastrichtian, Amphicytherura became widespread throughout Europe (Rügen Island, Germany; London Basin, England; North Sea Basin, Netherlands; and Russia), Jamaica (Central Inlier) and the United States (Black Warrior, Mid-Gulf Coast, Atlantic Coast, East Texas, South Georgia and Arkla basins) (Ljubimova et al., 1960; Kaye, 


\section{(A) Turonian-Maastrichtian}

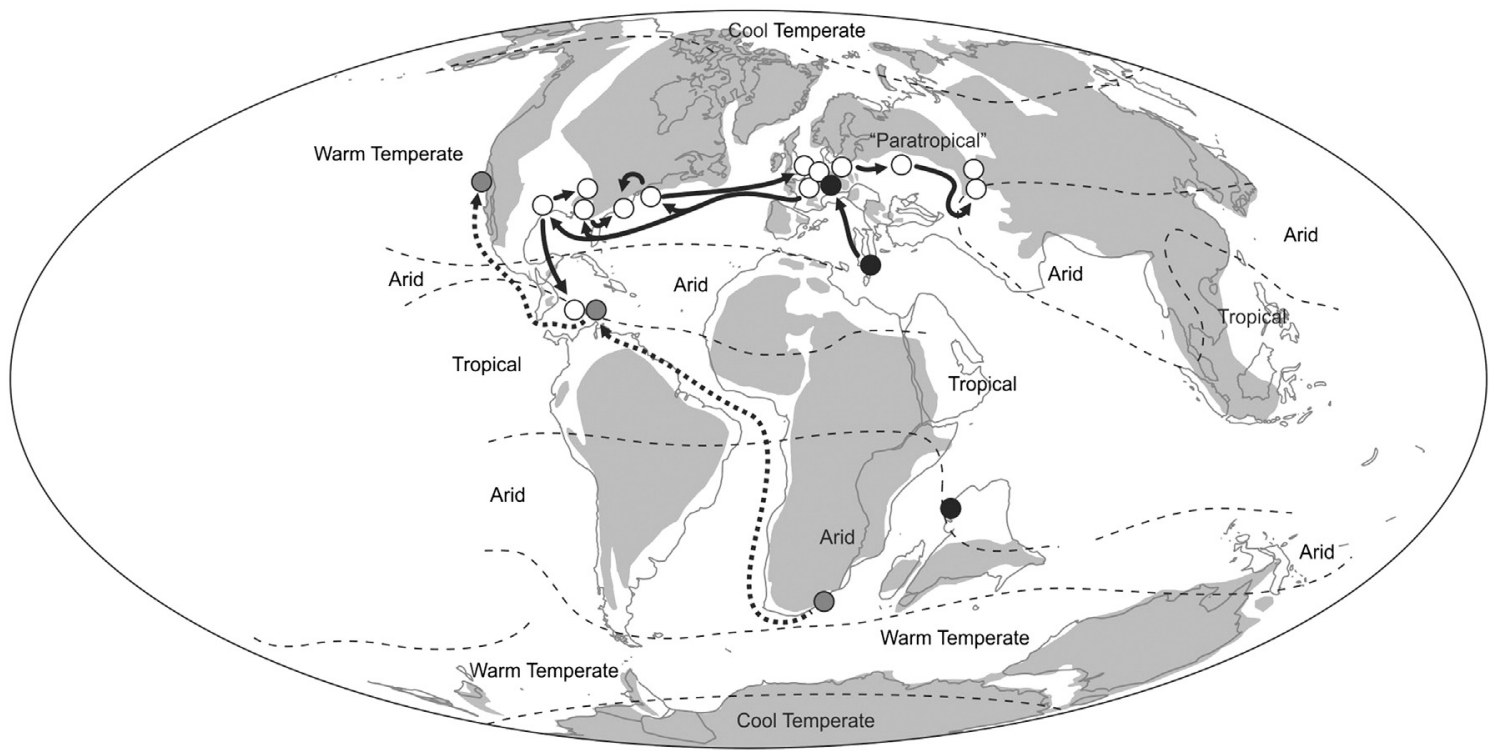

(B) Maastrichtian-Priabonian

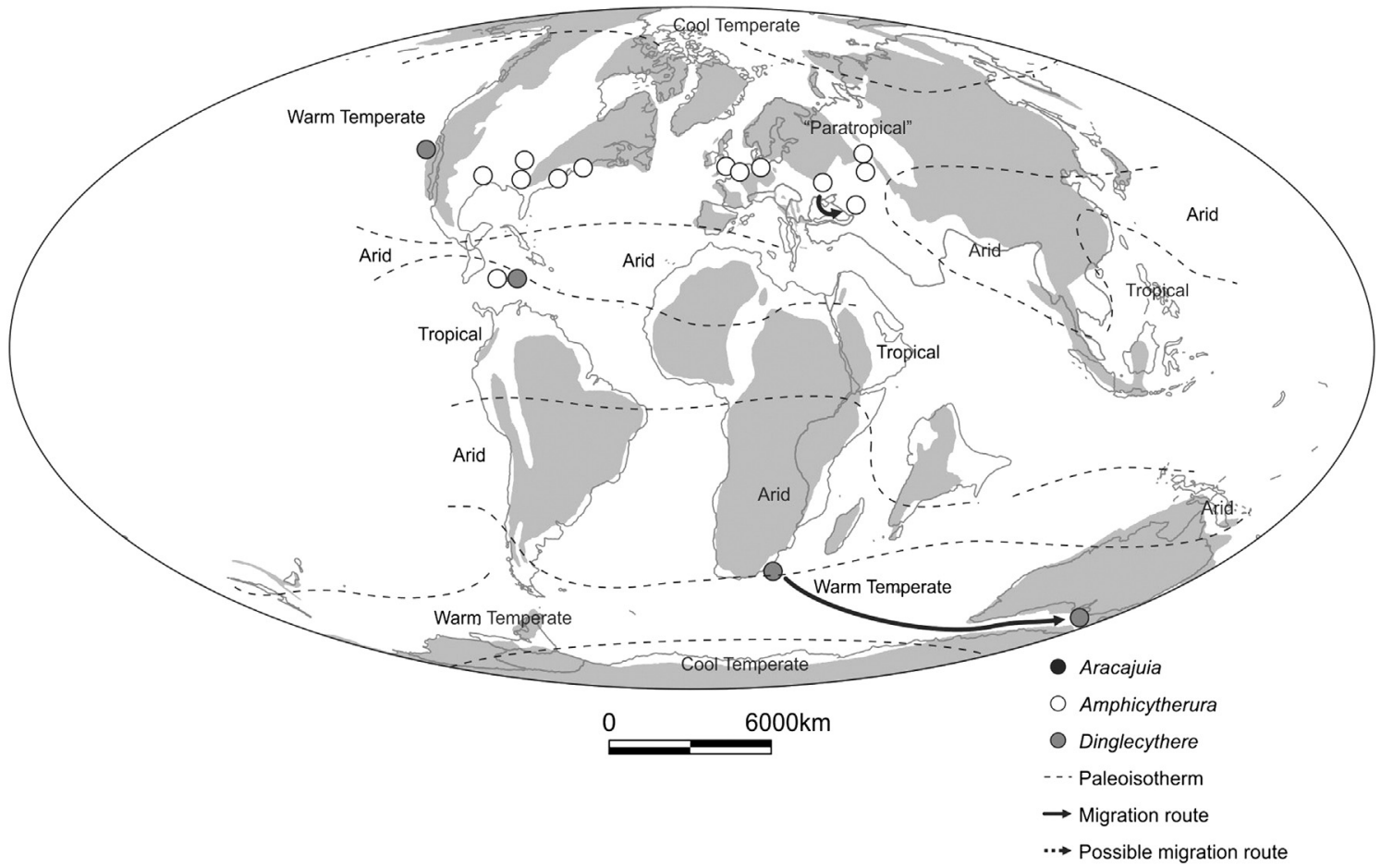

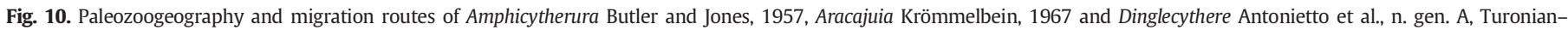
Maastrichtian; B, Maastrichtian-Priabonian.

1964; Deroo, 1966; Brouwers and Hazel, 1978; Smith, 1978; Gohn, 1992; Puckett, 1992; Gohn, 1997; Self-Trail and Gohn, 1997; Andreev et al., 1999; Puckett, 2005; Slipper, 2009; Puckett et al., 2012). However, during the Paleocene-Eocene, only three Amphicytherura species remained in the geological record, ranging from Eastern Europe (Pomeranian and Warsaw basins, Poland) to Western Asia (South Caspian Basin, Russia) (Kuznetsova, 1961; Szczechura, 1965). These localities were most probably colonized via Europe; all these species became absent from the fossil record at the Thanetian-Priabonian. One species of Dinglecythere was extant during the Paleocene-Eocene, restricted to the Priabonian of the Otway Basin (Australia) (McKenzie et al., 1993), possibly reaching this basin from South Africa, and disappearing at the end of this stage (Fig. 10B).

Amphicytherura, Aracajuia and Dinglecythere present distinct chronological and paleozoogeographical histories, although similar paleoecological niches. The distribution of Aracajuia is mostly linked to the evolution of Gondwana, where it occurred with similar levels of diversity along nearly all tropical, arid and warm-temperate coasts of the paleocontinent (Scotese, 2000). The few exceptions are the records in Germany, in "paratropical" areas of ancient Laurasia (Figs. 9, 10A). The maximum diversity of the genus occurred during the Albian. Amphicytherura was confined to Laurasia, in warm-temperate and 
"paratropical" waters along the North Atlantic coasts of Europe and North America and Western Asia (Figs. 9B, 10). The greater species richness of the genus occurred during the Maastrichtian, when it was widespread. Dinglecythere was usually found in warm-temperate to arid environments, and rarely in tropical waters close to the arid ones (Scotese, 2000), from southern-southeastern Gondwana to Western Laurasia. Its diversity and distribution peaked during the CampanianMaastrichtian (Fig. 10).

\section{Conclusion}

The purpose of the present study was to review the current taxonomic status of the genera Amphicytherura and Aracajuia, along with its type-species, Aracajuia benderi. According to the results presented here, Aracajuia can be distinguished from Amphicytherura by the ornamentation of the lateral surface, the shape of the central ridge and the lack of sexual dimorphism in the latter genus. Some Amphicytherura species lack a central ridge and possess a distinctive postero-central tubercle. Therefore, they are re-classified as Dinglecythere. Species previously assigned to Sondagella are not sufficiently different from those attributed to Aracajuia to sustain the separation of these two genera. This finding is consistent with the proposal to consider Sondagella a junior synonym of Aracajuia. Based on shared morphological traits, certain species of Amphicytherura are also re-assigned to Aracajuia.

Because Aracajuia benderi is the index fossil for the Zone Amphicytherura benderi (coded as OSE-1) and the homonymous subzone (OSE-1.6) from the late Aptian-Albian of the Sergipe-Alagoas Basin, the nomenclature of both zones is changed to Aracajuia benderi, based on the results of this taxonomic revision. Additional studies make it possible to trace the chronological, paleozoogeographical and paleoecological histories of Amphicytherura, Aracajuia and Dinglecythere. Aracajuia was mostly restricted to Gondwana, where it occurred along tropical, arid and warm-temperate coasts of the paleocontinent; a few species inhabited "paratropical" areas of Laurasia. This group's peak of diversity was during the Albian. Amphicytherura occurred throughout Laurasia, in the warmtemperate and "paratropical" waters along the North Atlantic coasts of Europe and North America, but also in Western Asia. This genus became widespread during the Maastrichtian. Dinglecythere, which reached its climax in the Campanian-Maastrichtian, was recorded from Southern Gondwana to Western Laurasia, in marginal tropical, arid and warmtemperate waters.

\section{Acknowledgements}

The authors are indebted to the Fundação Paleontológica Phoenix, Dr. Wagner Souza-Lima, Dr. Cynthia Lara de Castro Manso and the University of Brasilia (UnB) for providing fieldwork support. We thank the Brazilian National Agency of Petroleum, Natural Gas and Biofuels (ANP), Petróleo do Brasil S.A. (PETROBRAS) and the Technological and Scientific Ventures Foundation (FINATEC) for financial support via the OSTRAKi project. We are also grateful to professors Sara Ballent and Eduardo Musacchio, who will always be remembered, for their contributions to the present work and for access to specimens of Aracajuia valanginiana and Aracajuia colchesterensis from Argentina. M.Sc. L.S. Antonietto especially thanks Drs Gene Hunt (Smithsonian Institution, Washington, D.C., United States) and Giles Miller (Natural History Museum, London, United Kingdom) for providing logistical and scientific support during research visits to these institutions, and Drs Benjamin Sames, Ian Slipper and Ekaterina Tesakova for bibliographic support.

\section{References}

Alexander, C.I., 1933. Shell structure of the ostracode genus Cytheropteron, and fossil species from the Cretaceous of Texas. J. Paleontol. 7 (2), 181-214.

Alexander, C.I., 1936. Ostracoda of the genera Eucythere, Cytherura, Eucytherura, and Loxoconcha from the Cretaceous of Texas. J. Paleontol. 10 (8), 689-694.
Alexander, C.I., 1939. Common and significant species of Foraminifera and Ostracoda of the Brownstown, Ozan and Annona formations of southwestern Arkansas. Shrevep. Geol. Soc. Guideb. 14, 64-67.

Almeida, F.F.M., Carneiro, C.D.R., 1998. Origem e evolução da Serra do Mar. Rev. Bras. Geocienc. 28 (2), 135-150

Andreev, N., Kolpenskaya, N.N., Kupriyanova, N.V., Kukhtinov, D.A., Ljubimova, P., Neustrueva, I.Y., Nikolaeva, I.A., Sinitsa, S.M., Skoblo, V.M., Starozhilova, N.N., 1999. Prakticheskoye Rukovodstvo Po Mikrofaune, Tom 7: Ostrakod'i Mezozoya. VSEGEI, Saint Petersburg (in Russian).

Andreu, B., 1992. Associations d'ostracodes et paléoécologie du Crétacé (Barrémien à Turonien) le long d'une transversale Agadir-Nador (Maroc). Palaeogeogr. Palaeoclimatol. Palaeoecol. 99, 291-319.

Andreu, B., Colin, J., Singh, J., 2008. Cretaceous (Albian to Coniacian) Ostracodes from the subsurface of the Jaisalmer Basin, Rajasthan, India. Micropaleontology 53 (5), 345-370.

Andreu-Boussut, B., 1991. Les ostracodes du Crétacé Moyen (Barrémien à Turonien), le long d'une transversale Agadir-Nador (Maroc). Strata 2 (14), 1-765.

Babinot, J.F., Colin, J.P., Damotte, R., 1985. Crétacé supérieur. In: Oertli, H.J. (Ed.), Atlas de Ostracodes de France (Paléozoïque-Actuel). Mémoires Elf Aquitaine, vol. 9. Elf Aquitaine, Pau, pp. 211-255.

Ballent, S.C., 1990. Lower and middle Jurassic Ostracoda from Argentina. In: Whatley, R., Maybury, C. (Eds.), Ostracoda and Global Events. Chapman and Hall, London, pp. 211-220.

Ballent, S.C., 2009. Afinidades gondwánicas de los ostrácodos (Crustacea) marinos del Jurásico y Cretácico Inferior de la cuenca Neuquina. Rev. Asoc. Geol. Argent. 65 (2), 311-321.

Ballent, S.C., Whatley, R.C., 2006. The Mesozoic ostracod genus Arculicythere Grékoff: further evidence for the southern Gondwana seaway. Cret. Res. 27, 728-734.

Ballent, S.C., Whatley, R.C., 2009. Taxonomy and zoogeography of the Mesozoic Cytherurid ostracoda from West-central Argentina. Palaeontol. 52 (1), 193-218.

Ballent, S.C., Concheyro, A., Sagasti, G., 2006. Bioestratigrafía y paleoambiente de la Formación Agrio (Cretácico Inferior), en la Provincia de Mendoza, Cuenca Neuquina, Argentina. Rev. Geol. Chile 33 (1), 47-79.

Bartenstein, H., 1956. Zur Mikrofauna des englischen Hauterive. Senckenberg. Lethaea 37 (5/6), 509-533.

Bate, R.H., 1972. Upper Cretaceous Ostracoda from the Carnarvon Basin, Western Australia. Spec. Pap. Palaeontol. 10, 1-85.

Bengtson, P., 1983. The Cenomanian-Coniacian of Sergipe Basin, Brazil. Fossils Strata 12, $1-78$.

Benson, R.H., Kaesler, R.L., 1963. Recent marine and lagoonal ostracodes from the Estero de Tastiota region, Sonora, Mexico (northeastern Gulf of California). Univ. Kans. Paleontol. Contrib. Arthropoda 3, 1-34.

Benson, R.H. Tatro, J.O., 1964. Faunal description of Ostracoda of the Marlbrook Marl (Campanian), Arkansas. Univ. Kans. Paleontol. Contrib. Arthropoda 7, 1-32.

Bertels, A., 1977. Cretaceous Ostracoda - South Atlantic. Dev. Palaeontol. Stratigr. 6, 271-304.

Bold, W.A., 1964. Ostracoden aus der Oberkreide von Abu Rawash, Ägypten. Palaeontographica 123 (A), 111-136.

Bonnema, J.H., 1941. Ostracoden aus der Kreide des Untergrundes der nordöstlichen Niederlande. Natuurhistorisch Maandbl. 29 (91-95, 104-108, 115-118, 129-132; $30,8-10,21-24,26-29,40-43,56-60,70-72)$.

Brenner, P., Oertli, H.J., 1976. Lower Cretaceous ostracodes (Valanginian to Hauterivian) from the Sundays River Formation, Algoa Basin, South Africa. Bull. Cent. Rech. Pau SNPA 10 (2), 471-533.

Brouwers, E.M., Hazel, J.E., 1978. Ostracoda and correlation of the Severn Formation (Navarroan: Maestrichtian) of Maryland. Paleontol. Monogr. 1, 1-52.

Bueno, G.V., 2004. Diacronismo de eventos no rifte Sul-Atlântico. Bol. Geocienc. Petrobras 12 (2), 203-229.

Butler, E.A., Jones, D.E., 1957. Cretaceous ostracoda of Prothro and Rayburns Salt Domes, Bienville Parish, Louisiana. Bull. La. Geol. Surv. 32, 1-65.

Campos Neto, O.P.A., Lima, W.S., Cruz, F.E.G., 2007a. Bacia de Sergipe-Alagoas. Bol. Geocienc. Petrobras 15 (2), 405-415.

Campos Neto, M.C., Janasi, V.A., Basei, M.A.S., Siga Júnior, O., 2007b. Sistema de nappes Andrelândia, setor oriental: litoestratigrafia e posição estratigráfica. Rev. Bras. Geocienc. 37, 47-60.

Carvalho, M.A., Oliveira, D.C., Machado, L.G., Mendonça Filho, J.G., 2005. Sedimentação Albo-Aptiana de partículas vegetais (fitoclastos) em rochas do Membro Taquari, Formação Riachuelo, bacia de Sergipe, Brasil. Arq. Mus. Nac. 63 (3), 411-424.

Cesero, P., Ponte, F.C., Northfleet, A.A., Gonçalves, A., Netto, A.S.T., França, A.M.C., Penna, C.A.T., Silva, C.A.M., Ribeiro, E.M., Rosa, G.B., Lopes, J.A., Ribeiro, J.C., Neves, L.E., Silva, O.B., Araripe, P.T., Souza, U.P., 1997. Análise comparativa da paleogeologia dos litorais atlânticos brasileiro e africano. Bol. Geocienc. Petrobras 11 (1/2), 1-18.

Clarke, B., 1983. Die Cytheracea (Ostracoda) im Schreibkreide Richtprofil von LägerdorfKronsmoor-Hemmoor (Coniac bis Maastricht; Norddeutschland). Mitt. Geol. Palaontol. Inst. Univ. Hamburg 54, 65-168.

Colin, J.P., 1974. Contribution a l'étude des ostracodes du Crétacé Supérieur de Dordogne. Geobios 7 (1), 19-42.

Concheyro, A., Lescano, M., Caramés, A., Ballent, S., 2009. Micropaleontología de la Formación Agrio (Cretácico inferior) en distintos sectores de la Cuenca Neuquina. Rev. Asoc. Geol. Argent. 65 (2), 342-361.

Crane, M.J., 1965. Upper Cretaceous ostracodes of the Gulf Coast area. Micropaleontol. 11 (2), 191-254.

Damotte, R., 1965. Contribution a l'étude des ostracodes du Sénonien de Sens (Yonne): les Schizocytheridae, les Cytheridae et les Cytherellidae. Rev. Micropaleontol. 7 (4), 232-241.

Damotte, R., Babinot, J.F., Colin, J.P., 1981. Les Ostracodes du Crétacé Moyen Européen. Cretac. Res. 2, 287-306. 
Deroo, G., 1966. Cytheracea (Ostracodes) de Maastrichtien de Maastricht (Pays-Bas) et des régions voisines; résultats stratigraphiques et paléontologiques de leur étude. Med. Geol. Sticht. Ser. C 2 (2), 1-197.

Dias, J.L., 2004. Tectônica, estratigrafia e sedimentação no Andar Aptiano da margem leste brasileira. Bol. Geocienc. Petrobras 13 (1), 7-25.

Dingle, R.V., 1969a. Marine Neocomian Ostracoda from South-Africa. Trans. R. Soc. S. Afr. 38 (2), 139-163.

Dingle, R.V., 1969b. Upper Senonian ostracods from the coast of Pondoland, South Africa Trans. R. Soc. S. Afr. 38 (4), 347-385.

Dingle, R.V., 1971. Some Cretaceous ostracodal assemblages from the Agulhas Bank (South African Continental Margin). Trans. R. Soc. S. Afr. 39 (4), 393-419.

Dingle, R.V., 1980. Marine Santonian and Campanian ostracods from a borehole at Richards Bay, Zululand. Ann. S. Afr. Mus. 82 (1), 1-70.

Dingle, R.V., 1981. The Campanian and Maastrichtian Ostracoda of South-East Africa. Ann. S. Afr. Mus. 85 (1), 1-181

Dingle, R.V., 1982. Some aspects of Cretaceous Ostracod biostratigraphy of South Africa and relationships with other Gondwanide localities. Cret. Res. 3, 367-389.

Dingle, R.V., 1984. Mid-Cretaceous Ostracoda from Southern Africa and the Falkland Plateau. Ann. S. Afr. Mus. 93 (3), 97-211.

Dingle, R.V., 1996. Cretaceous Ostracoda of the SE Atlantic and SW Indian Ocean: a stratigraphical review and atlas. In: Jardiné, S., Klazs, I., Debenay, J.P. (Eds.), Géologie de l'Afrique et de l'Atlantique Sud. Mémoire, 16. Elf Aquitaine, Pau, pp. 1-17.

Dingle, R.V., 1999. Walvis Ridge barrier: its influence on palaeoenvironments and source rock generation deduced from ostracod distributions in the early South Atlantic Ocean. In: Cameron, N.R., Bate, R.H., Clure, V.S. (Eds.), The Oil and Gas Habitats of the South Atlantic, vol. 153. Geological Society Special Publication, London, pp. 293-302.

Do Carmo, D.A., Whatley, R., Queiroz Neto, J.V., Coimbra, J.C., 2008. On the validity of two Lower Cretaceous non-marine ostracode genera: biostratigraphic and paleogeographic implications. J. Paleontol. 82 (4), 790-799.

Do Carmo, D.A., Colin, J.P., Hidalgo, P.H.P., Meireles, R.P., Berbert-Born, M.L.C., Almeida, C.M., 2012. Reassessment of the genus Sergipella Krömmelbein, 1967 (Ostracoda, Trachyleberididae), uppermost Aptian-Albian of Brazil and West Africa: taxonomy and paleogeographic distribution. Rev. Micropaleontol. 55 (2012), 3-15.

Do Carmo, D.A., Coimbra, J.C., Whatley, R.C., Antonietto, L.S., Citon, R.T.P., 2013. Taxonomy of limnic Ostracoda (Crustacea) from the Alagamar Formation, Middle-Upper Aptian, Potiguar Basin, Northeastern Brazil. J. Paleontol. 87 (1), 91-104.

Donze, P., Thomel, G., 1972. Le Cénomanien de la Foux (Alpes de Haute-Provence). Biostratigraphie et faunes nouvelles d'ostracodes. Eclogae Geol. Helv. 65 (2), 369-389.

Feijó, F.J., 1994. Bacias de Sergipe e Alagoas. Bol. Geocienc. Petrobras 8 (1), 149-161.

Gebhardt, H., 1999. Cenomanian to Coniacian biogeography and migration of North and West African ostracods. Cret. Res. 20, 215-229.

Gerry, E., Rosenfeld, A., 1973. Amphicytherura distincta and Neocyprideis vandenboldi (Ostracoda), new species from the Cenomanian-Turonian of Israel. Rev. Esp. Micropaleontol. 5, 99-105.

Gohn, G.S., 1992. Distribution of selected Campanian and Maastrichtian Ostracoda in stratigraphic test holes of the New Jersey coastal plain. U.S. Geol. Surv. Open File Rep. 92-399, pp. 1-25.

Gohn, G.S., 1997. Data report: Cretaceous ostracode assemblages in the island beach core, New Jersey coastal plain. In: Miller, K.G., Snyder, S.W. (Eds.), Proceedings of the Ocean Drilling Program, Scientific Results, vol. 150. Friesens, Altona, pp. 287-292.

Grekoff, N., 1963. Contribution à l'étude des Ostracodes de Mésozoïque moyen (Bathonien-Valanginien) du Basin de Majunga, Madagascar. Rev. Inst. Fr. Pétrol. 18 (12), 1709-1783.

Grosdidier, E., 1979. Principaux ostracodes marins de l'intervalle Aptien-Turonien du Gabon (Afrique Occidentale). Bull. Centres Rech. Explor. Prod. Elf-Aquitaine 3 (1), 1-35.

Gründel, J., 1970. Die Ostracoden aus dem unteren Mittelturon (Racknitzer Schichten, OberKreide) Sachsens. Abh. Staatl. Mus. Mineral. Geol. Dresd. 16, 41-54.

Gründel, J., 1974. Die Ostracoden aus dem Salzbergmergel des Salzberges bei Quedlinburg (unter Ausschluss der Trachyleberididae). Abh. Staatl. Mus. Mineral. Geol. Dresd. 21, $101-118$.

Hanai, T., 1970. Studies on the ostracod Subfamily Schizocytherinae Mandelstam. J. Paleontol. 44 (4), 693-729.

Herrig, E., 1966. Ostracoden aus der Weißen Schreibkreide (Unter-Maastricht) der Insel Rügen. Paläontol. Abh. A 2 (4), 693-1024.

Holden, J.C., 1964. Upper Cretaceous Ostracods from California. Palaeontology 7 (3), 393-429.

Howe, H.V., Laurencich, L., 1958. Introduction to the Study of Cretaceous Ostracoda. Louisiana State University, Baton Rouge.

Israelsky, M.C., 1929. Upper Cretaceous Ostracoda of Arkansas. Bull. Geol. Surv. Ark. 2, $1-29$.

Jain, S.P., 1975. Cytheracea (Ostracoda) from the Ariyalur Formation (Upper Cretaceous) of South India. Bull. Indian Geol. Assoc. 8 (1), 41-70.

Jain, S.P., 1976. Ostracoda from the Dalmiapuram Formation (Lower Cretaceous), Tiruchirapalli District, Tamil Nadu. Bull. Indian Geol. Assoc. 9 (1), 33-42.

Jain, S.P., 1978. Further Ostracoda from the Kallakudi Limestone (Albian) Tiruchirapalli District Tamil Nadu, India. Neues Jb. Mineral. Geol. Paläontol. Monat 1978 (8), 502-512.

Jennings, P.H., 1936. A microfauna from the Monmouth and basal Rancocas groups of New Jersey. Bull. Am. Paleontol. 23 (78), 1-76.

Jones, T.R., Hinde, G.J., 1890. A Supplementary Monograph of the Cretaceous Entomostraca of England and Ireland. The Palaeontographical Society, London.

Kaye, P., 1964. Revision of British marine Cretaceous Ostracoda with notes on additional forms. Bull. Br. Mus. Nat. Hist. Geol. 10 (2), 37-79.

Kaye, P., 1965. Further Ostracoda from the British Lower Cretaceous. Senckenberg. Lethaea $46,73-82$.
Kaye, P., Barker, D., 1966. Ostracoda from the upper Tealby Clay (Lower Barremian) of South Lincolnshire. Paleontol. 9 (2), 20l-219l.

Kesling, R.V., 1951. Terminology of ostracod carapaces. Contrib. Mus. Paleontol. Univ. Mich. 1 (4), 93-171.

Krömmelbein, K., 1966. Preliminary remarks on some marine ostracodes from northeastern Brazil and West Africa. In: Hinte, J.E. (Ed.), Proceedings of the Second West African Micropaleontological Colloquium. Ibadan. E.J. Brill, Leiden, pp. 119-123.

Krömmelbein, K., 1967. Ostracoden aus der marinen "Küsten-Kreide" Brasiliens. 2: Sergipella transatlantica n. g., n. sp., und Aracajuia benderi n. g., n. sp., aus dem Ober Aptium/Albium. Senckenberg. Lethaea 48 (6), 525-533.

Krömmelbein, K., 1975. Remarks on marine Cretaceous ostracodes of Gondwanic distribution. Proc. Vth Afr. Colloq. Micropalaeontol. Enadimsa, Madrid, pp. 539-551.

Kuznetsova, Z., 1961. Ostrakody melovyh otlozheniy Severo Vostochnogo Azerbaydzhana i ih stratigraficheskoe znachenie. Azerneshr, Baku (in Russian).

Liebau, A., 2005. A revised classification of the higher taxa of the Ostracoda (Crustacea). Hydrobiology 538, 115-137.

Ljubimova, P.S., Kazmina, T.A., Reshetnikova, M.A., 1960. Ostrakody mezozoyskikh kaynozoyskikh otlozheniy zapadno-Sibirskoy nizmennosti. Tr. VNIGRI Novaya Seriya, 160 1-427 (in Russian).

Luger, P., 2003. Paleobiogeography of late Early Cretaceous to Early Paleocene marine Ostracoda in Arabia and North to Equatorial Africa. Palaeogeogr. Palaeoclimatol. Palaeoecol. 196, 319-342.

Luppold, F., 2001. Die Ostrakoden des kalkig entwickelten Unter-Hauterivium im östlichen Niedersachsischen Becken und seine Mikrofauna und Fazies. Paläontol. Z 75 (2), 127-150

Manso, C.L.C., Souza-Lima, W., 2003. O Equinóide Douvillaster Lambert, 1917 na Formação Riachuelo, bacia de Sergipe, Brasil. Rev. Bras. Paleontol. 5, 29-37.

Marsson, T., 1880. Die Cirripedien und Ostracoden der Weissen Schreibkreide der Inse Rügen. Mitt. Naturwissenschaftlichen Ver. Mitt. Naturw. Ver. Greifswald 12, 1-50.

McKenzie, K.G., Reyment, R.A., Reyment, E.R., 1993. Eocene Ostracoda from the Browns Creek Clays at Browns Creek and Castle Cove, Victoria, Australia. Rev. Esp. Paleontol. 8 (1), 75-116

McLachlan, I.R., McMillan, I.K., Brenner, P.W., 1976. Micropalaeontological study of the Cretaceous beds at Mbotyi and Minganza, Transkei, South Africa. Trans. Geol. Soc. S. Afr. 79, 325-334.

Musacchio, E.A. 1978. Ostracodos del Cretacico Inferior em el Grupo Mendoza, Provincia del Neuquen, Argentina. Actas VII Congr. Geol. Argent., vol. 2. Asociación Geológica Argentina, Buenos Aires, pp. 459-473.

Musacchio, E.A., Simeoni, M., 1995. Ostrácodos de Argentina y el diseño de las áreas oceánicas durante el Cretácico. Ext. Abstr. 1st Workshop Paleoceanogr. Emphas. Micropaleontol. Stratigr. CPGEO/IG-UFRGS, Porto Alegre, Brazil, pp. 63-71.

Musacchio, E.A., Simeoni, M., 1996. Biogeographic relationships of Lower Cretaceous calcareous microfossils from Patagonia: an approach to causal factors. S. Atl. Mesoz. Correl. News 5, 44-45.

Musacchio, E.A., Simeoni, M., 2008. Valanginian and Hauterivian marine ostracods from Patagonia (Argentina): correlations and palaeogeography. Rev. Micropaleontol. 51, 239-257.

Neale, J.W., 1960. Marine Lower Cretaceous Ostracoda from Yorkshire, England. Micropaleontol. 6 (2), 203-224

Ornellas, L.P., Fallavena, M.A., 1978. Cytherura purperae Ornellas et Fallavena, sp. nov., a living ostracoda from mixohaline environment, southern Brazil. Pesquisa 9, 121-157.

Pletsch, T., Erbacher, J., Holbourn, A.E.L., Kuhnt, W., Moullade, M., Oboh-Ikuenobede, F.E. Södinge, E., Wagner, T., 2001. Cretaceous separation of Africa and South America: the view from the West African margin (ODP Leg 159). J. S. Am. Earth Sci. 14 (2), 147-174.

Puckett, T.M., 1992. Distribution of ostracodes in the Upper Cretaceous (Late Santonian through Middle Maastrichtian) of Alabama and Mississippi. Trans. Gulf Coast Assoc. Geol. Soc. 42, 613-632.

Puckett, T.M., 2005. Santonian-Maastrichtian planktonic foraminiferal and ostracode biostratigraphy of the northern Gulf Coastal Plain, USA. Stratigraphy 2 (2), 117-146.

Puckett, T.M., Colin, J.P., Mitchell, S., 2012. New species and genera of Ostracoda from the Maastrichtian (Late Cretaceous) of Jamaica. Micropaleontol. 58 (5), 397-455.

Rosenfeld, A., Raab, M., 1974. Cenomanian-Turonian ostracodes from the Judea group in Israel. Bull. Geol. Soc. Israel 62, 1-64.

Rosenfeld, A., Raab, M., 1984. Lower Cretaceous ostracodes from Israel and Sinai. Isr. J. Earth Sci. 33 (3), 85-134

Rosenfeld, A., Gerry, E., Honigstein, A., 1988. Jurassic-Cretaceous non-marine Ostracods from Israel and palaeoenvironmental implications. In: Hanai, $\mathrm{T}$., Ikeya, $\mathrm{N}$., Ishizaki, K. (Eds.), Evolutionary Biology of Ostracoda: Its Fundamentals and Applications. Elsevier, Amsterdam, pp. 659-669.

Ruault-Djerrab, M., Kechid-Benkherouf, F., 2011. Micropaleontological study (foraminifera, ostracods) and characterization of the paleoenvironment of middle Cretaceous deposits (Djebel Chemla area, north-eastern Algeria). Arab. J. Geosci. 4, 1289-1299.

Santos, R.P., Bonhomme, M.G., 1993. Datação K/Ar de argilas associadas às mineralizações e aos processos diagenéticos, em relação com a história da abertura do Oceano Atlântico Sul. Rev. Bras. Geocienc. 23(1), 61-67.

Schaller, H., 1969. Revisão estratigráfica da bacia de Sergipe/Alagoas. Bol. Tec. Petrobrás 12 (1), 21-86.

Scotese, C.R., 2000. PALEOMAP Project. Updated at: http://www.scotese.com/ (accessed 25 april 2013).

Self-Trail, J.M., Gohn, G.S., 1997. Biostratigraphic data for the Cretaceous marine sediments in the USGS-St. George no. 1 core (DOR-211), Dorchester County, South Carolina. U.S Geol. Surv. Open File Rep. 96-684, pp. 1-29.

Slipper, I.J., 2009. Upper Cretaceous. In: Whittaker, J.E., Hart, M.B. (Eds.), Ostracods in British Stratigraphy. The Geological Society, London, pp. 345-372. 
Smith, J.K., 1978. Ostracoda of the Prairie Bluff Chalk, Upper Cretaceous, (Maestrichtian) and the Pine Barren Member of the Clayton Formation, Lower Paleocene (Danian) from the exposures along Alabama State Highway 263 in Lowndes County, Alabama. Trans. Gulf Coast Assoc. Geol. Soc. 28, 539-579.

Souza-Lima, W., Hamsi Junior, G.P., 2003. Bacias da margem continental. Phoenix $50,1-6$.

Souza-Lima, W., Andrade, E.J., Bengtson, P., Galm, P.C., 2002. A bacia de Sergipe-Alagoas: evolução geológica, estratigrafia e conteúdo fóssil, 1. Fund. Paleontol. Phoenix 1-34 (Ed. Espec.).

Stepanaytys, N.Y., 1967. Rannemelovyye ostrakody Tuarkyra (zapadnaya Turkmeniya) Paleontol. Zh. 2, 74-79 (in Russian).

Swain, F.M., 2002. Biostratigraphy of Cretaceous Ostracoda from Wells in South Carolina. Updated at: http://www.geo.umn.edu/people/profs/swain/ostra_scarolina.pdf (accessed 17 August 2012).

Sylvester-Bradley, P.C., 1948. The ostracode genus Cythereis. J. Paleontol. 22 (6), 792-797.
Sylvester-Bradley, P.C., Benson, R.H., 1973. Terminology for surface features in ornate ostracodes. Lethaia 4 (3), 249-286.

Szczechura, J., 1965. Cytheracea (Ostracoda) from the uppermost Cretaceous and lowermost Tertiary of Poland. Acta Palaeontol. Pol. 10 (4), 451-564.

Tsukagoshi, A., Ikeya, N., 1987. The ostracod genus Cythere O. F.Müller, 1785 and its species. Trans. Proc. Paleontol. Soc. Jpn. New Ser. 148, 197-222.

Valença, L.M.M., Neumann, V.H., Mabesoone, J.M., 2003. An overview on CallovianCenomanian intracratonic basins of Northeast Brazil: onshore stratigraphic record of the opening of the southern Atlantic. Geol. Acta 1 (3), 261-275.

Valicenti, V.H., Stephens, J.M., 1984. Ostracods from the Upper Valanginian and Upper Hauterivian of the Sundays River Formation, Algoa Basin, South Africa. Rev. Esp. Micropaleontol. 16, 171-239.

Viviers, M.C., Koutsoukos, E.A.M., Silva-Telles Júnior, A.C., Bengtson, P., 2000. Stratigraphy and biogeographic affinities of the late Aptian-Campanian ostracods of the Potiguar and Sergipe basins in northeastern Brazil. Cret. Res. 21, 407-455. 
Anexo III. Artigo intitulado Taxonomy of limnic Ostracoda (Crustacea) from the Alagamar Formation, middleupper Aptian, Potiguar basin, Northeastern Brazil, publicado no periódico Journal of Paleontology. 


\title{
TAXONOMY OF LIMNIC OSTRACODA (CRUSTACEA) FROM THE ALAGAMAR FORMATION, MIDDLE-UPPER APTIAN, POTIGUAR BASIN, NORTHEASTERN BRAZIL
}

\author{
DERMEVAL APARECIDO DO CARMO,${ }^{1}$ JOÃO CARLOS COIMBRA, ${ }^{2}$ ROBIN CHARLES WHATLEY, ${ }^{3}$ LUCAS \\ SILVEIRA ANTONIETTO, ${ }^{1}$ AND RAPHAEL TEIXEIRA DE PAIVA CITON ${ }^{1}$ \\ ${ }^{1}$ Instituto de Geociências, Universidade de Brasília, Brasília, Distrito Federal, 70910.900, Brazil, <derme@unb.br>, \&lt:antoniettols@gmail.com>, \\ $<$ raphaelciton@yahoo.com.br>; ${ }^{2}$ Departamento de Paleontologia e Estratigrafia, Instituto de Geociências, Universidade Federal do Rio Grande do \\ Sul, PO Box 15001, Porto Alegre, Rio Grande do Sul, 91501.970, Brazil, < joao.coimbra@ufrgs.br>; and ${ }^{3}$ Institute of Earth Sciences, University of \\ Wales, Aberystwyth, Wales, SY23DF, UK, <riw@aber.ac.uk1>
}

\begin{abstract}
Fifteen limnic ostracodes species have been recorded in the Alagamar Formation, Potiguar Basin: Cypridea araripensis Silva, 1978a; Cypridea? sp., Harbinia sinuata (Krömmelbein and Weber, 1971); Harbinia crepata n. sp., Harbinia dimorphica n. sp., Harbinia alta Antonietto et al., 2012; Paracypria? elongata n. sp., Ilyocyprimorpha berthoui (Colin and Dépêche, 1997); Ilyocypris? sp., Brasacypris subovatum n. sp., Candona? sp., Theriosynoecum colini $\mathrm{n}$. sp., T. guzzoi n. sp., T. silvai (Silva, 1978b) diagnosis emended by Do Carmo et al. (2004b); and Darwinula martinsi Silva, 1978c diagnosis emended by Do Carmo et al. (2004b). Nine of these species have also been recorded outside of the Potiguar Basin, either in other Cretaceous basins in Brazil or coeval strata in western Africa. Despite the controversy about dating the local Alagoas Stage and the relatively large range of the Zone Harbinia spp. 201-218, the material studied in this paper belongs to the interval corresponding to the well-defined palynological zone coded as P-270, which is mid-upper Aptian in age.
\end{abstract}

INTRODUCTION

$\mathrm{D}$ ESPITE THE endemism of many limnic lower Cretaceous Ostracoda species, this calcareous microfossil group has been quite important for constructing a useful biostratigraphic framework in the Brazilian marginal basins and in many other basins around the world. After the first taxonomic papers published by T. R. Jones (1860, 1897), only Swain (1946) studied the Brazilian Cretaceous limnic ostracodes during the first half of the twentieth century. Since then, many articles addressing the taxonomy of these microfossils in Cretaceous Brazilian paleolakes or paleolagoons have been added: Grekoff (1956), Pinto and Sanguinetti (1958, 1962, 1984), Moos (1959), Wicher (1959), Krömmelbein (1961, 1962, 1963, 1964a, 1964b, 1965a, 1965b, 1966, 1967), Grekoff and Krömmelbein (1967), Krömmelbein and Weber (1971), Moura (1972), Bate (1972, 1973), Silva (1978a, 1978b, 1978c), Gobbo-Rodrigues et al. (1999a, 1999b), Smith (1999, 2000), and Do Carmo et al. (2004a, 2004b, 2008).

The present study is the first to address the taxonomy of the lower Cretaceous ostracodes from the Potiguar Basin. The study examines 15 species recovered from cores collected by PETROBRAS (Brazilian Oil Company) from the Alagamar Formation (Fig. 1). Six new species are described here: Harbinia crepata n. sp., Harbinia dimorphica n. sp., Paracypria? elongata n. sp., Brasacypris subovatum n. sp., Theriosynoecum colini n. sp., and T. guzzoi n. sp. On the basis of this taxonomical support, an ongoing project by DAC using the stratigraphic distribution of this ostracode fauna is expected to permit a paleoecological study and biostratigraphic refinement of this section and provide new insights into its controversial paleodepositional setting.

The Alagamar Formation is dated as latest early Aptian-early Albian, therefore Alagoas Stage. It is mainly attributed to the gulf phase of the Potiguar Basin (Bertani et al., 1991; Araripe and Feijó, 1994) (Fig. 1). Most of this basin is located in the Rio Grande do Norte State and a small part is located in the Ceará State, both in Northeastern Brazil, covering $60,000 \mathrm{~km}^{2}$, including onshore and offshore areas. Its Cretaceous rocks, which possess important gas and oil reservoirs (Bertani et al., 1991), are divided into three major stratigraphic groups that have their boundaries marked by regional discontinuities: Areia Branca, Apodi, and Agulha (Araripe and Feijó, 1994; Pessoa Neto et al., 2007).

The Alagamar Formation is the upper unit of the Areia Branca Group, and its contact with the lower and upper formations is unconformable. It is divided into the Canto do Amaro, Upanema and Galinhos members and a carbonate sequence named the Ponta do Tubarão beds, coded as CPT (Araripe and Feijó, 1994) (Fig. 2). The Canto do Amaro and Upanema members are characterized by siliciclastic fluvial-deltaic deposits. The upper portion is characterized by the transitional shales of the Galinhos Member. The CPT is a median stratigraphic unity that is characterized by deposition under sabkha conditions (Pessoa Neto et al., 2007).

Four interval zones have been recognized in the Alagamar Formation based on extinctions of palynomorph species presented by Araripe and Feijó (1994) and coded as P-230, P260, P-270, and P-280. The lower and median portions of the Upanema Member are considered uppermost lower Aptian based on the zone P-230 extinction of Transitoripollis crisopolensis (Regali et al., 1974) diagnosis emended by Regali (1987b) and the zone P-260 local disappearance of Inaperturopollenites turbatus Balme, 1957 (Regali et al., 1974).

The upper portion of the Upanema Member, the Ponta do Tubarão beds and the lower and median portions of the Galinhos Member are mid-upper Aptian based on the extinction of Sergipea variverrucata Regali et al., 1974, diagnosis emended by Regali (1987b), the fossil index of the zone P-270. As indicated by Araripe and Feijó (1994), the upper portion of the Galinhos Member is lower Albian because of its stratigraphic position above the extinction of $S$. variverrucata and because it is included in the zone P-280 based on the local disappearance of Caytonipollenites? sp. 1.

The Zone Harbinia spp. 201-218 is based on an assemblage of similar ostracode species attributed to the genus Harbinia Tsao, 1959 diagnosis emended by Hou (1984) and characterizes 


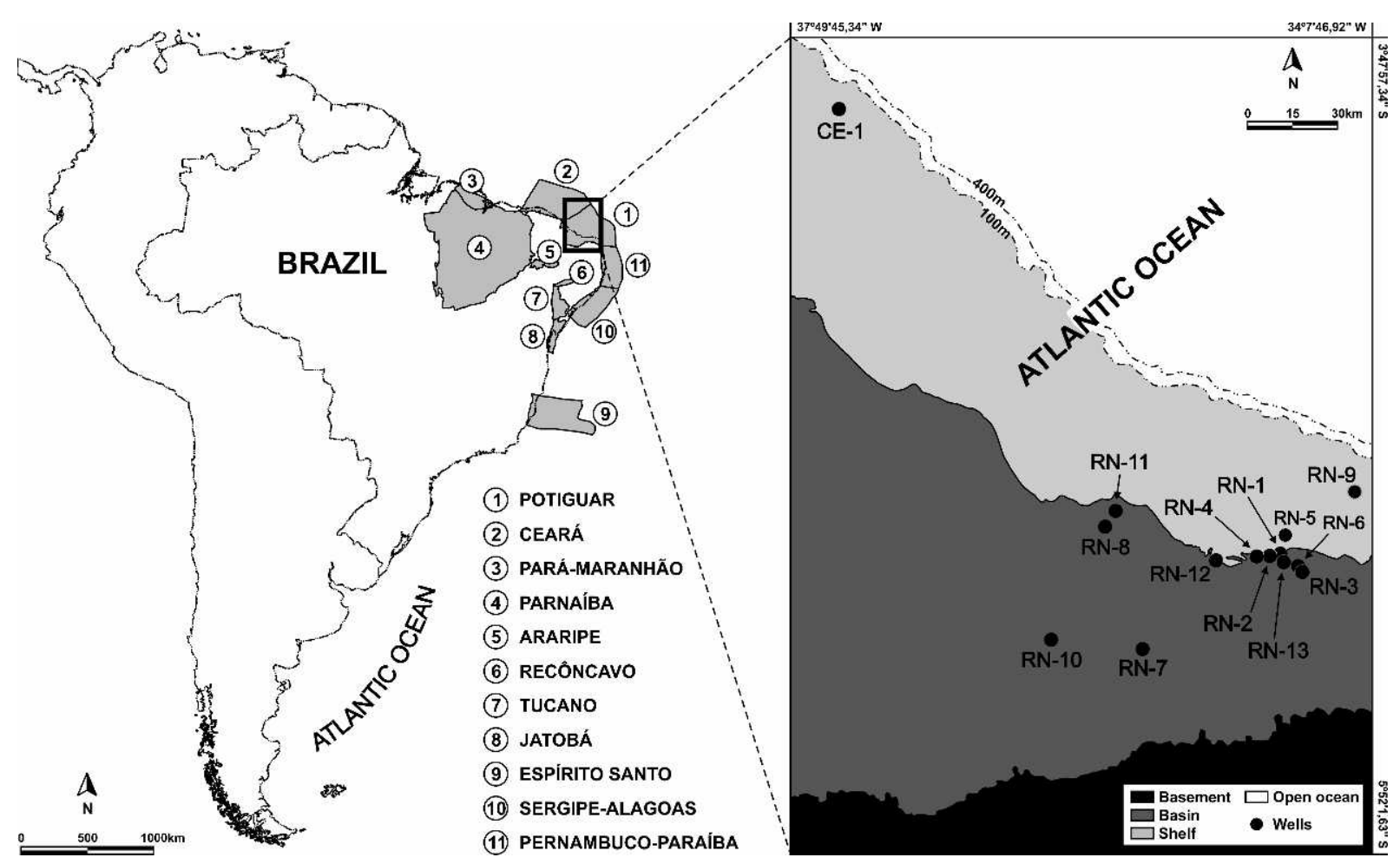

Figure 1-The Potiguar Basin in South America (Schenk et al., 1999) with the location of the wells in question.

the local Alagoas Stage (Schaller, 1969; Do Carmo et al., 2008). Regali and Viana (1989) suggest that this stage terminates in the early Albian; Viviers et al. (2000) date the end of this stage as Aptian, while Coimbra et al. (2002) place it in the late AptianAlbian. Because of this controversial dating of the end of the Alagoas Stage, it is important to point out that all of the ostracode occurrences mentioned in the present study paper correspond to the range accepted as belonging to the mid-upper Aptian zone P-270.

\section{MATERIAL AND METHODS}

One thousand four hundred twenty-two core samples from 14 wells drilled by PETROBRAS (the Brazilian Oil Company) in the Potiguar Basin were processed for mineralized microfossils (Table 1; Fig. 1). Only 312 samples yielded ostracodes, and few of them yielded additional microfossils, such as agglutinate foraminifers, small gastropods, conchostracans and fish denticles. The standard method for isolating calcareous and siliceous microfossils, using hydrogen peroxide at 35\% followed by sieving and microfossil picking, was applied. Gold-coated SEM images were taken at $10 \mathrm{kV}$ with a backscatter detector and secondary electron source. The samples recovered from the Ponta do Tubarão beds were also processed using classic palynological techniques in order to detect foraminifer linings and dinoflagellate cysts. These data, as well those based on ostracodes are being studied for paleoenvironmental application.

\section{SYSTEMATIC PALEONTOLOGY}

The illustrated ostracode species are housed in the Micropaleontology Museum of the "Universidade Federal do Rio Grande do Sul-UFRGS" (Porto Alegre, Brazil) under the MPO- catalogue prefix. Additional illustrated material is housed in the collections of the Museum of Geosciences, Laboratory of Micropaleontology, Institute of Geosciences, University of Brasília, Brazil, identified with the prefix CP-. The number of specimens is classified as follows: rare ( $1-5$ specimens), common (6-10 specimens), and abundant ( $>10$ specimens). The suprageneric classification follows Liebau (2005).

Order Podocopida Müller, 1894

Suborder Cypridocopina Jones, 1901

Superfamily CYPRIDOIDEA Baird, 1845

Family CyPrideIDAe Martin, 1940

Subfamily CyprideinAe Martin, 1940

Genus Cypridea Bosquet, 1852

Type species.-Cypris granulosa Sowerby, 1836, designated by Sylvester-Bradley (1947).

Remarks.-Do Carmo et al. (2008) featured an extensive discussion on the taxonomic status of Cypridea and presented an emended and summarized diagnosis for the genus, in accordance with Morkhoven (1963). Sames (2011), after an extensive review of North American species of Cypridea, presented a new diagnosis on the genus, which considered several genera in synonymy of Cypridea, but at the same time revalidating several subgenera admitted by Moore (1961). The present authors maintain the taxonomy by Morkhoven (1963), added to by Do Carmo et al. (2008).

\section{Cypridea ARARIPENSIS Silva, 1978a} Figure 3.1, 3.2

1978a Cypridea araripensis Silva, p. 1023, pl. 1, figs. 1-4.

1990 Cypridea araripensis Silva; Silva-Telles JR. AND Viana, 1990, pl. 2, fig. 5.

1997 Cypridea araripensis Silva; Colin AND DÉPÊCHE, p. 435, fig. 2.16 .

2002 Cypridea araripensis Silva; CoIMBRA, ARAI AND CARreño, p. 691, fig. 4.33.

Material.-Carapace MP-O-1596, length $1.06 \mathrm{~mm}$ and height $0.53 \mathrm{~mm}$; Brazil, Rio Grande do Norte State, well RN-7, at a depth of $775.30 \mathrm{~m}$. 


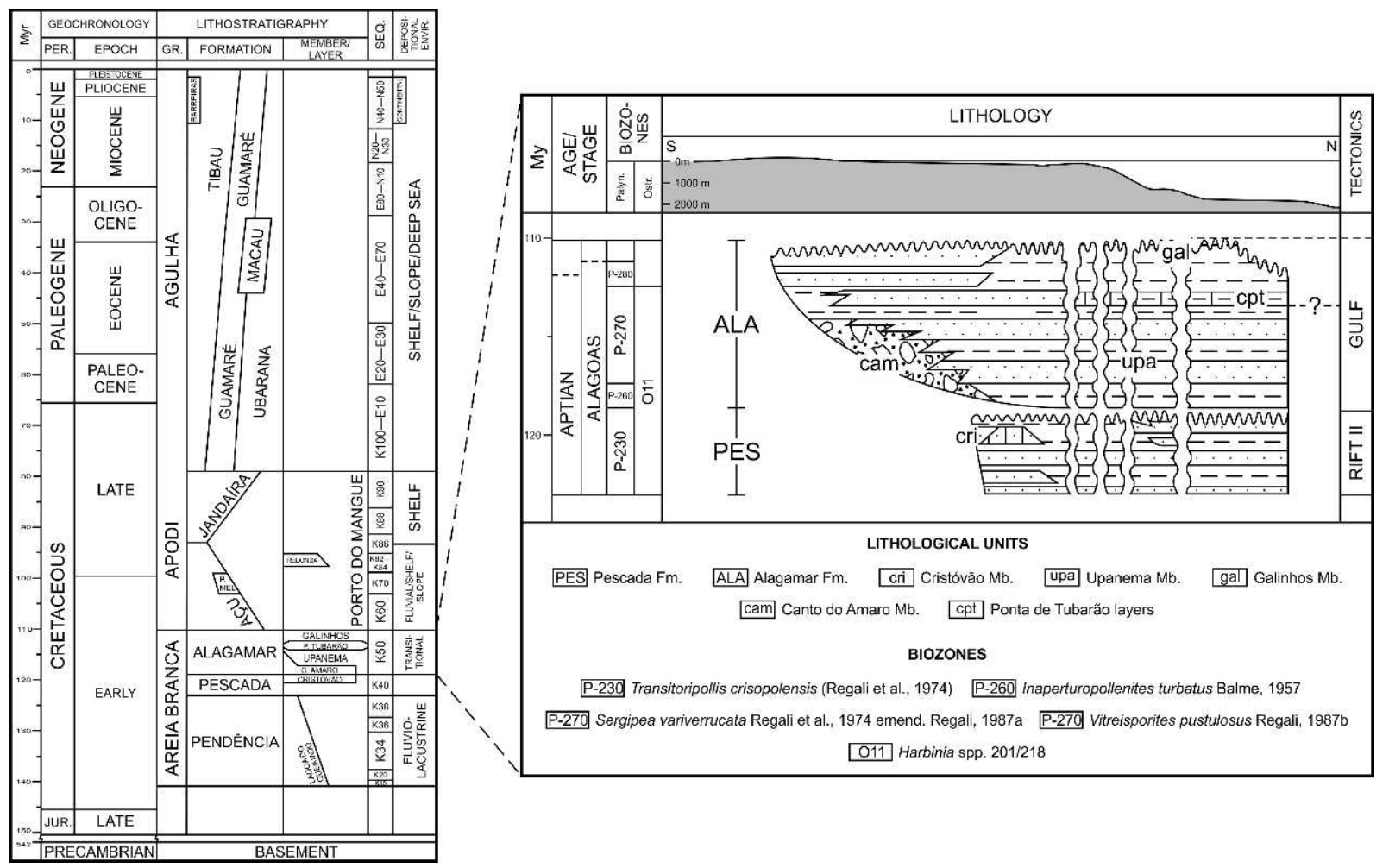

Figure 2-Lithostratigraphic unities of the Potiguar Basin with detail on the Alagoas Stage (Araripe and Feijó, 1994; Pessoa Neto et al., 2007).

Occurrence.-Brazil, Crato Member, Santana Formation, Araripe Basin (Silva, 1978a; Silva-Telles Jr. and Viana, 1990; Colin and Dépêche, 1997), interval dated as Aptian (Regali, 1990; Coimbra et al., 2002). Alagamar Formation, Potiguar Basin, midupper Aptian.

Remarks.-This species is easily identifiable by its typical ornamentation. However, all of recovered specimens are deformed. This species is abundant and quite well preserved in the Aptian Codó Formation, Parnaíba Basin, Northeastern Brazil.

\section{CYPRIDEA? sp. \\ Figure 3.3, 3.4}

Material. - Carapace MP-O-1597, length $1.10 \mathrm{~mm}$, height 0.67 mm, width $0.58 \mathrm{~mm}$; Brazil, Rio Grande do Norte State, well RN7 , at a depth of $775.30 \mathrm{~m}$.

Occurrence.-Alagamar Formation, Potiguar Basin, mid-upper Aptian.

Remarks.-Although abundant, Cypridea? sp. has poorly

TABLE 1 -Samples of the Potiguar Basin studied on the present work.

\begin{tabular}{lcc}
\hline \hline Wells & Number of samples & $\begin{array}{c}\text { Number of samples } \\
\text { with recovered fossil material }\end{array}$ \\
\hline RN-1 & 452 & 145 \\
RN-2 & 45 & 26 \\
RN-3 & 70 & 1 \\
RN-4 & 70 & 1 \\
RN-5 & 233 & 5 \\
RN-6 & 196 & 68 \\
RN-7 & 70 & 25 \\
RN-8 & 64 & 10 \\
RN-9 & 70 & 9 \\
RN-10 & 8 & 0 \\
RN-11 & 27 & 0 \\
RN-12 & 8 & 0 \\
RN-13 & 8 & 0 \\
CE-1 & 101 & 22 \\
Total & 1,422 & 312 \\
\hline
\end{tabular}

preserved carapaces that hinder accurate descriptions. It is a large species, with a sub-rectangular ovate carapace in lateral view, and in dorsal view, strongly convex and assymetrical. Surprisingly, the typical antero-ventral beak is somewhat dislocated upwards, which is uncommon in this genus.

Family CYPRIDIDAE Baird, 1845

Subfamily CyPRIDINAE Baird, 1845

Genus Harbinia Tsao, 1959

Type species.-Harbinia hapla Tsao, 1959, holotype Cat. No. 107 (pl. 14, fig. 5a, 5b).

Remarks.-As extensively discussed by Do Carmo et al. (2008), the genus Pattersoncypris Bate, 1972, comprising the sole species Pattersoncypris micropapillosa Bate, 1972 diagnosis emended by Smith (2000), is considered a junior synonym of Harbinia Tsao, 1959. In the same article, four subspecies of Hourcqia Krömmelbein, 1965a, described in Krömmelbein and Weber (1971), were transferred to Harbinia and elevated to species level: Hourcqia angulata angulata Krömmelbein and Weber, 1971 (Harbinia angulata); Hourcqia angulata salitrensis Krömmelbein and Weber, 1971 (Harbinia salitrensis); Hourcqia angulata sinuata Krömmelbein and Weber, 1971 (Harbinia sinuata); and Hourcqia angulata symmetrica Krömmelbein and Weber, 1971 (Harbinia symmetrica). Recently, a new approach on the taxonomic position of these five species was presented by Poropat and Colin (2012), revalidating Pattersoncypris to encompass Harbinia micropapillosa, Harbinia salitrensis and Harbinia sinuata, and proposing Kroemmelbeincypris Poropat and Colin, 2012 for Harbinia angulata and Harbinia symmetrica. As distinctive characters for the new genus, these authors emphasized the anteroventrally inclined posterior end to distinguish it from Harbinia, although this characteristic is not present in Harbinia symmetrica. Several other characteristics were considered in the description of Kroemmelbeincypris, such as overlap, outline and ornamentation pattern, but all of them are 


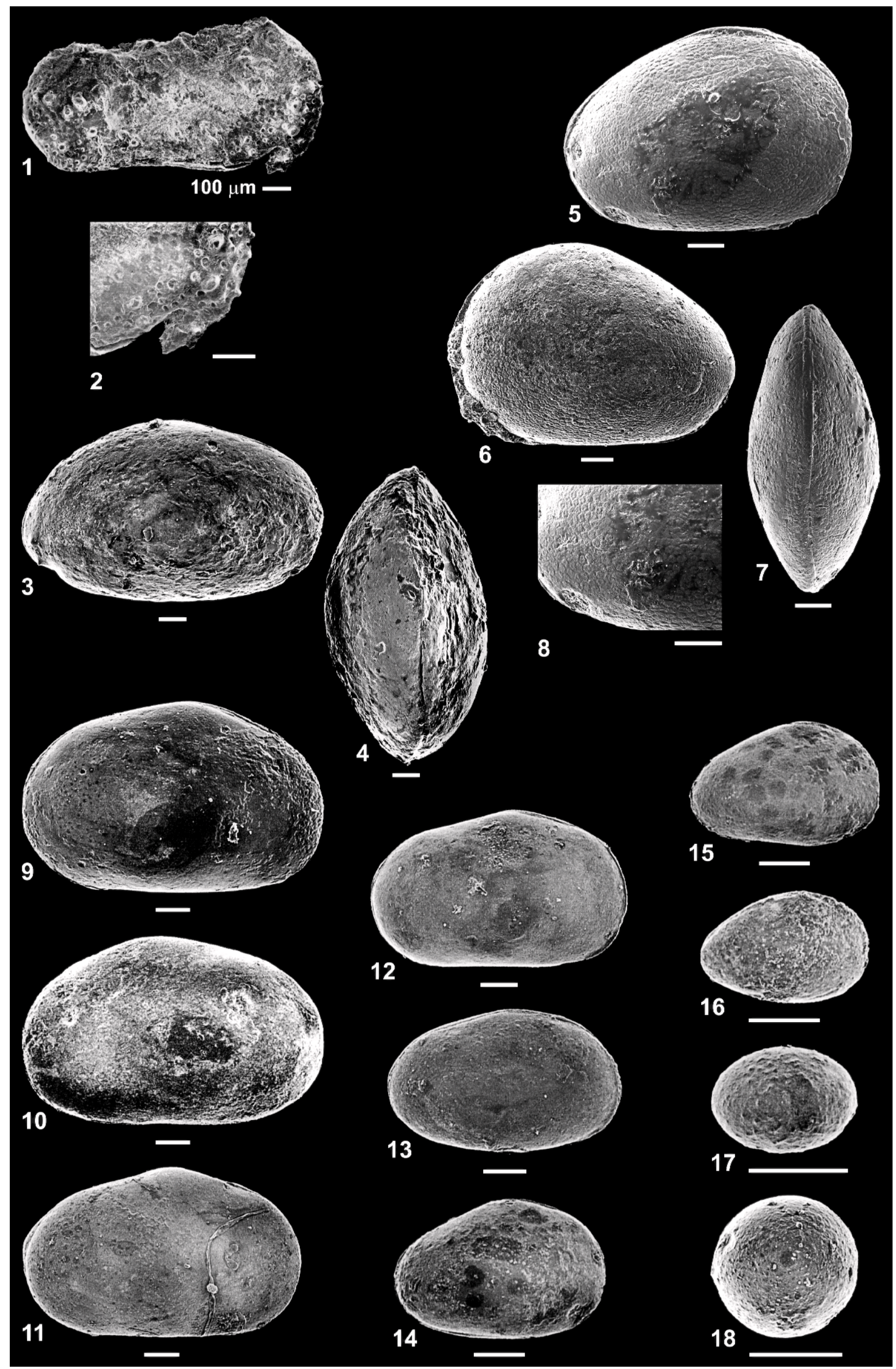


shared with Harbinia. It is possible that synonymy discussions in Harbinia and western genera will remain a polemic issue until a reassessment of type material from China is conducted.

HARBINIA SINUATA (Krömmelbein and Weber, 1971) Figure 4.1-4.27

1971 Hourcqia angulata sinuata KRÖMMELBEIN AND WEBER, pl. 6, fig. 24a-24c.

?1990 Hourcqia angulata ssp. Silva-Telles JR. And Viana, pl. 3, fig. 4.

non1991 Hourcqia angulata sinuata Krömmelbein and Weber; Andreu-Boussut, pl. 1, figs. 4-9.

2006 Harbinia sinuata (Krömmelbein and Weber); RAmos, Rossetti, AND PAz, p. 343, fig. 4I-4L.

2008 Harbinia sinuata (Krömmelbein and Weber); Do Carmo, Whatley, Queiroz Neto, and Coimbra, p. 795, fig. 6.10.

2012 Pattersoncypris sinuata (Krömmelbein and Weber); Poropat and Colin, p. 714, fig. 4.2.

Diagnosis.-Emended: the carapace is sub-ovate in the lateral view, with a well-developed dorsal hump and distinct concavity in the antero-dorsal margin. The external surface is smooth.

Description.-Emended: carapace large and sub-ovate in lateral view. Maximum height approximately central. Maximum length at mid-height. Left valve slightly larger than the right one, with weak overlap along the anterior and posterior margins. Dorsal margin with well-developed hump and small but conspicuous concavity anteriorly. Hinge line sub-rectilinear obliquely dipping to the posterior end. Ventral margin slightly concave medially. Anterior margin large and asymmetrically rounded. Posterior margin relatively small and narrowly rounded. Smooth external surface. Strongly convex in dorsal view, with maximum width at the postero-median region. Adductor muscle scars typical of Cyprididae, with two mandibular scars. Sexual dimorphism not observed.

Material.-Two adult carapaces: MP-O-1577, length $1.06 \mathrm{~mm}$, height $0.65 \mathrm{~mm}$, width $0.53 \mathrm{~mm}$; and CP-598, length $0.69 \mathrm{~mm}$, height $0.47 \mathrm{~mm}$, width $0.36 \mathrm{~mm}$. Seven juvenile carapaces: A-1 CP-599, length $0.55 \mathrm{~mm}$, height $0.37 \mathrm{~mm}$, width $0.28 \mathrm{~mm}$; A-2 CP-600, length $0.41 \mathrm{~mm}$, height $0.28 \mathrm{~mm}$, width $0.19 \mathrm{~mm}$; A-3 CP-601, length $0.33 \mathrm{~mm}$, height $0.24 \mathrm{~mm}$, width $0.16 \mathrm{~mm}$; A-4 CP-602, length $0.28 \mathrm{~mm}$, height $0.20 \mathrm{~mm}$, width $0.14 \mathrm{~mm}$; A-5 CP-603, length $0.25 \mathrm{~mm}$, height $0.18 \mathrm{~mm}$, width $0.13 \mathrm{~mm}$; A-6 CP-604, length $0.20 \mathrm{~mm}$, height $0.14 \mathrm{~mm}$, width $0.11 \mathrm{~mm}$; and A7 CP-605, length $0.15 \mathrm{~mm}$, height $0.10 \mathrm{~mm}$, width $0.07 \mathrm{~mm}$. Egg, CP-606, diameter $0.08 \mathrm{~mm}$. Brazil, Ceará State, Potiguar Basin, well CE-1, at a depth of $2080.20 \mathrm{~m}$.

Occurrence.-Brazil, Riachuelo Formation, Sergipe-Alagoas Basin (Krömmelbein and Weber, 1971), interval considered upper Aptian (Koutsoukos et al., 1991; Feijó, 1994). Romualdo Member, Santana Formation, Araripe Basin (Silva-Telles Jr. and Viana, 1990), interval considered Aptian-Albian (Regali, 1990, Coimbra et al., 2002). Alagamar Formation, Potiguar Basin, mid-upper Aptian.

Remarks.-The specimen MP-O-1577 is possibly a gerontic instar. The holotype dimensions of Harbinia sinuata designated by Krömmelbein and Weber (1971) is clearly an adult given the adult range in length between 0.69 and $0.78 \mathrm{~mm}$. This possible gerontic from Alagamar Formation, Potiguar Basin, is close in size to specimens recovered by Ramos et al. (2006) from Codo Formation, Grajaú Basin.

\section{Harbinia ALta Antonietto et al., 2012}

Figure 3.5-3.8

1971 Hourcqia angulata angulata KRÖMmELBEIN AND WeBer, p. 50, pl. 6, fig. 23a-23c.

1989 Hourcqia angulata angulata Krömmelbein and Weber; Viana, Brito and Silva-Telles Jr., p. 216, fig. 2a-2c.

1990 Hourcqia angulata angulata Krömmelbein and Weber; DéPÊCHe, Bérthou AND CAMPos, p. 304, pl. 1, fig. 1, 2.

1990 Hourcqia angulata angulata Krömmelbein and Weber; Silva-Telles JR. And Viana, pl. 3, fig. 3.

2006 Harbinia angulata (Krömmelbein and Weber); Ramos, Rosetti And Paz, p. 343, fig. 4e-4h.

2006 Harbinia sp.; Ramos, Rosetti and Paz, p. 346, fig. 4u-4y.

2012 Harbinia alta Antonietto, Gobbo, Do Carmo, Assine, Fernandes And Silva, p. 665, fig. 4.1-4.10.

Material. - Carapace CP-615, length $0.84 \mathrm{~mm}$, height $0.49 \mathrm{~mm}$ and width $0.39 \mathrm{~mm}$; Brazil, Rio Grande do Norte State, well RN1 at a depth of $1374.54 \mathrm{~m}$.

Occurrence.-Brazil, Ipubi and Romualdo members, Santana Formation, Araripe Basin (Silva-Telles Jr. and Viana, 1990; Antonietto et al., 2012), interval dated as Aptian-Albian (Regali, 1990; Coimbra et al., 2002). Codó Formation, Pará-Maranhão Basin, upper Aptian (Ramos et al., 2006; Soares et al., 2007). Alagamar Formation, Potiguar Basin, mid-upper Aptian.

Remarks.-According to Antonietto et al. (2012), Harbinia alta is easily identified because of its prominent dorsal hump and finely reticulated ornamentation.

\section{HARBINIA CREPATA new species}

Figure 3.9-3.18

1990 Gen. ind. sp. aff. 207; Silva-Telles JR. And Viana, pl. 2, figs. 1,3 .

Diagnosis.-Large and smooth. Subtriangular elongate in lateral view. The antero-dorsal hump is blunt for the genus. The left valve is slightly larger than the right. The overlap is slightly pronounced but is conspicuous antero-dorsally and posterodorsally.

Description.-Carapace large and subtriangular elongate in lateral view. Maximum height antero-medianly. Maximum length at mid-height. Left valve slightly larger than the right one; overlap slightly pronounced but conspicuous antero-dorsally and postero-dorsally. Antero-dorsal hump slightly prominent. Hinge line gently inclined to the posterior end. Posterior cardinal angle widely obtuse, but distinguishable. Ventral margin nearly straight. Anterior and posterior margins large and rounded, the posterior one somewhat narrower and truncate. Surface smooth. In dorsal view, valves inflated, with maximum width at the postero-median region. Sexual dimorphism not observed.

Etymology.-From the Latin crepare, meaning cracked with angle.

FigURE 3- Species from genera Cypridea Bosquet, 1852 diagnosis emended by Do Carmo et al. (2008) and Harbinia Tsao, 1959 diagnosis emended by Hou (1984); 1, 2, Cypridea araripensis Silva, 1978a, adult (MP-O-1596), carapace, right view and detail of the beak; 3, 4, Cypridea? sp., adult (MP-O-1597), carapace, right and dorsal views; 5-8, Harbinia alta Antonietto et al., 2012: 5-7, adult (MP-O-1588), carapace, right and left views and detail of the ornamentation; 8, adult (MP-O-1589), carapace, dorsal view; 9-18, Harbinia crepata $\mathrm{n}$. sp.: 9, 10, adult (MP-O-1579), carapace, right and left views; 11, juvenile A-1 (MP-O-1580), carapace right view; 12, juvenile A-2 (MP-O-1581), carapace right view; 13, juvenile A-3 (MP-O-1582), carapace right view; 14, juvenile A-4 (MP-O-1583), carapace right view; 15, juvenile A-5 (lost), carapace right view; 16, juvenile A-6 (MP-O-1584), carapace right view; 17, juvenile A7 (lost), carapace right view; 18, egg (lost). 


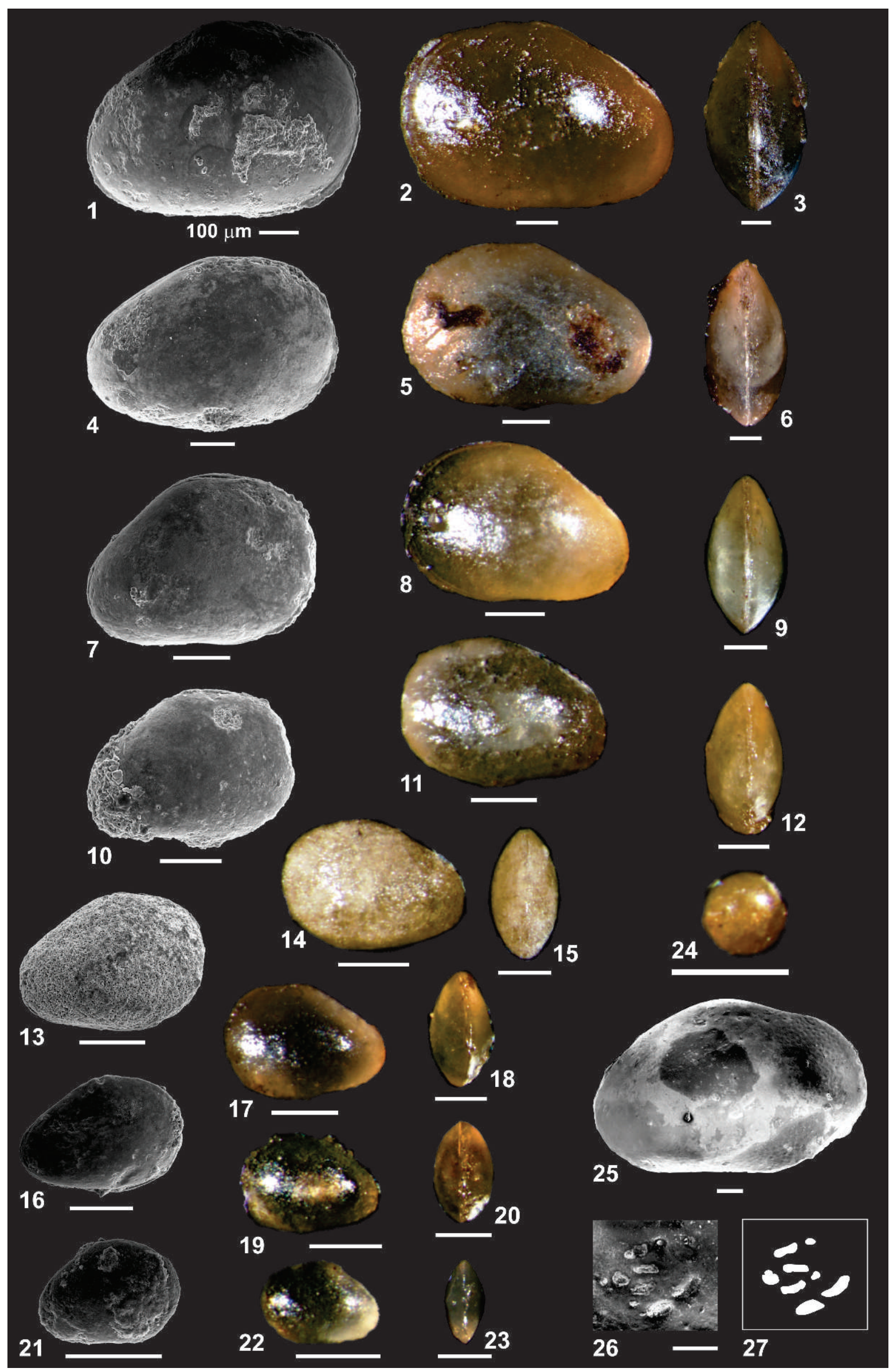


Material--Holotype, adult carapace MP-O-1579, length 0.88 $\mathrm{mm}$, height $0.56 \mathrm{~mm}$, width $0.41 \mathrm{~mm}$. Paratypes, five juveniles carapaces: A-1 MP-O-1580, length $0.80 \mathrm{~mm}$, height $0.44 \mathrm{~mm}$, width $0.37 \mathrm{~mm}$; A-2 MP-O-1581, length $0.70 \mathrm{~mm}$, height 0.43 $\mathrm{mm}$, width $0.32 \mathrm{~mm}$; A-3 MP-O-1582, length $0.55 \mathrm{~mm}$, height $0.33 \mathrm{~mm}$, width $0.24 \mathrm{~mm}$; A-4 MP-O-1583, length $0.42 \mathrm{~mm}$, height $0.28 \mathrm{~mm}$, width $0.22 \mathrm{~mm}$; and A-6 MP-O-1584, length $0.24 \mathrm{~mm}$, height $0.17 \mathrm{~mm}$, width $0.13 \mathrm{~mm}$. Unfortunately, two illustrated carapaces and a probable egg were lost during the SEM procedures: A-5, length $0.38 \mathrm{~mm}$, height $0.26 \mathrm{~mm}$; A-7, length $0.15 \mathrm{~mm}$, height $0.15 \mathrm{~mm}$; and egg, $0.16 \mathrm{~mm}$ diameter. The materials were recovered in Brazil, Ceará State, well CE-1, at a depth of $2079.50 \mathrm{~m}$.

Occurrence.-Brazil, Crato Member, Santana Formation, Araripe Basin (Silva-Telles Jr. and Viana, 1990), interval dated as Aptian (Regali, 1990; Coimbra et al., 2002). Alagamar Formation, Potiguar Basin, mid-upper Aptian.

Remarks.-Harbinia crepata n. sp. differs from Harbinia sinuata, Harbinia salitrensis (Krömmelbein and Weber, 1971) diagnosis emended by Antonietto et al. (2012) and Harbinia micropapillosa (Bate, 1972) diagnosis emended by Smith (2000) mainly by the subtriangular elongated outline and less inclined hinge line. Harbinia crepata is the only species studied here that occurs in monospecific assemblages.

\section{HARBINIA DIMORPHICA new species}

Figure 5.1-5.5

1979 Hourcqia? GA G 14; GrosDidier, pl. 12, fig. 66a-66c.

Diagnosis. - The carapace is large and subtriangular ovate in lateral view. The left valve overlaps the right valve throughout the free margin. The entire carapace is covered by smooth papillae that are somewhat similar to centrally concave pillows. There is well-developed sexual dimorphism, with the males being narrower and more elongate than females.

Description.-Carapace very large and subtriangular ovate in lateral view. Antero-median maximum height. Maximum length just below mid-height. Left valve larger than the right one, with conspicuous overlap throughout the free margin, but not along the hinge line. Antero-dorsal hump well defined. Hinge line straight obliquely dipping towards the posterior end. Ventral margin subrectilinear. Anterior and posterior margins rounded, posterior one more narrowly rounded. Surface ornamented by very small structures somewhat similar to centrally concave pillows, generally visible only under SEM. Strongly inflated in dorsal view, with the maximum width at the postero-median region. Internal features not observed. Pronounced sexual dimorphism, with males narrower and more elongate than females.

Etymology.-With reference to the well-defined sexual dimorphism of this species, uncommon in Harbinia.

Material.-Holotype, female carapace MP-O-1590, length 0.93 $\mathrm{mm}$, height $0.58 \mathrm{~mm}$, width $0.44 \mathrm{~mm}$. Paratypes, two adult carapaces: male MP-O-1591, length $1 \mathrm{~mm}$, height $0.56 \mathrm{~mm}$, width $0.42 \mathrm{~mm}$; and female MP-O-1592, length $0.93 \mathrm{~mm}$, height $0.58 \mathrm{~mm}$, width $0.44 \mathrm{~mm}$. The materials were recovered in Brazil, Rio Grande do Norte State, well RN-7, at a depth of $786.05 \mathrm{~m}$.

Occurrence.-Africa, Madiela Formation, Gabon Basin, upper Aptian (Grosdidier, 1979). Brazil, Alagamar Formation, Potiguar Basin, mid-upper Aptian.
Remarks.-This new species is somewhat similar to Harbinia hapla Tsao, 1959, which was described from the lower Cretaceous of China, but the two species differ mainly in outline, height and overlap.

\section{Genus BraSACYPRIS Krömmelbein, 1965b}

Type species.-Brasacypris ovum Krömmelbein, 1965.

Remarks.- In the original description, this genus was left as family Incertae. Here, Brasacypris is compared to Cyprinotus Brady, 1886, a member of Subfamily Cypridinae, from which it differs by a remarkably ovate lateral outline and more convex dorsal margin. Therefore, Brasacypris is tentatively attributed to the same suprageneric position as Cyprinotus.

\section{BRASACYPRIS SUBOVATUM new species}

Figure 5.10, 5.11

Diagnosis.-Large, sub-rectangular ovate in lateral view. The left valve overlaps the right throughout the free margin. The maximum width occurs two-thirds posteriorly.

Description.-Carapace very large and sub-rectangular ovate in lateral view. Maximum height one-third posteriorly. Maximum length approximately at mid-height. Left valve conspicuously larger than the right one; overlap pronounced along all throughout the free margin. Dorsal margin almost straight inclined slightly posteriorly. Ventral margin convex. Anterior margin broadly rounded. Posterior margin bluntly rounded. Surface smooth. In dorsal view, carapace strongly convex and somewhat fusiform; widest two-thirds posteriorly. Internal features and sexual dimorphism not observed.

Etymology.-Named for the resemblance of this species to Brasacypris ovum Krömmelbein, 1965, which was described from the lower Cretaceous of the nearby Reconcavo Basin, Bahia State, Northeastern Brazil.

Material.-Holotype, adult carapace MP-O-1593, length 1.34 $\mathrm{mm}$, height $0.84 \mathrm{~mm}$, width $0.69 \mathrm{~mm}$. Paratypes, two adult carapaces: MP-O-1594, a deformed specimen with length 1.38 $\mathrm{mm}$ and height $0.85 \mathrm{~mm}$; and MP-O-1595, length $1.30 \mathrm{~mm}$, height $0.81 \mathrm{~mm}$, and width $0.67 \mathrm{~mm}$. MP-O-1593 and MP-O1594 were recovered in Brazil, Rio Grande do Norte State, well $\mathrm{RN}-7$, at a depth of $788 \mathrm{~m}$; MP-O-1595 is from Brazil, Ceará State, CE-1 well, at a depth of $2079.20 \mathrm{~m}$.

Occurrence.-Brazil, Alagamar Formation, Potiguar Basin, mid-upper Aptian.

Remarks.-Brasacypris subovatum n. sp. somewhat resembles Brasacypris ovum Krömmelbein, 1965b but differs by the more sub-rectangular outline in lateral view, the less backwardly inclined dorsal margin, and the more delicate overlap along the free margin, especially along the ventral portion.

Family CANDONIDAE Kaufmann, 1900

Subfamily Paracypridinae Sars, 1923

Tribe Thalassocypridini Hartmann and Puri, 1974

Genus Paracypria Sars, 1910

Type species.-Paracypris tenuis Sars, 1905

Remarks.-Assigning fossil species to the genus Paracypria can be difficult because of the significant external similarity to other genera and the poor preservation of the internal morphology. Considering that these traits are usual among Mesozoic

Figure 4-Harbinia sinuata (Krömmelbein and Weber, 1971); 1-3, adult (CP-598), carapace, right, left and dorsal views; 4-6, juvenile A-1 (CP-599), carapace, right, left and dorsal views; 7-9, juvenile A-2 (CP-600), carapace, right, left and dorsal views; 10-12, juvenile A-3 (CP-601), carapace, right, left and dorsal views; 13-15, juvenile A-4 (CP-602), carapace, right, left and dorsal views; 16-18: juvenile A-5 (CP-603), carapace, right, left and dorsal views; 19, 20, juvenile A-6 (CP-604), carapace, left and dorsal views; 21-23, juvenile A-7 (CP-605), carapace, right, left and dorsal views; 24, egg (CP-606); 25-27, adult (MPO-1577), carapace right view, detail of the central muscle scars on the SEM and drawing. 


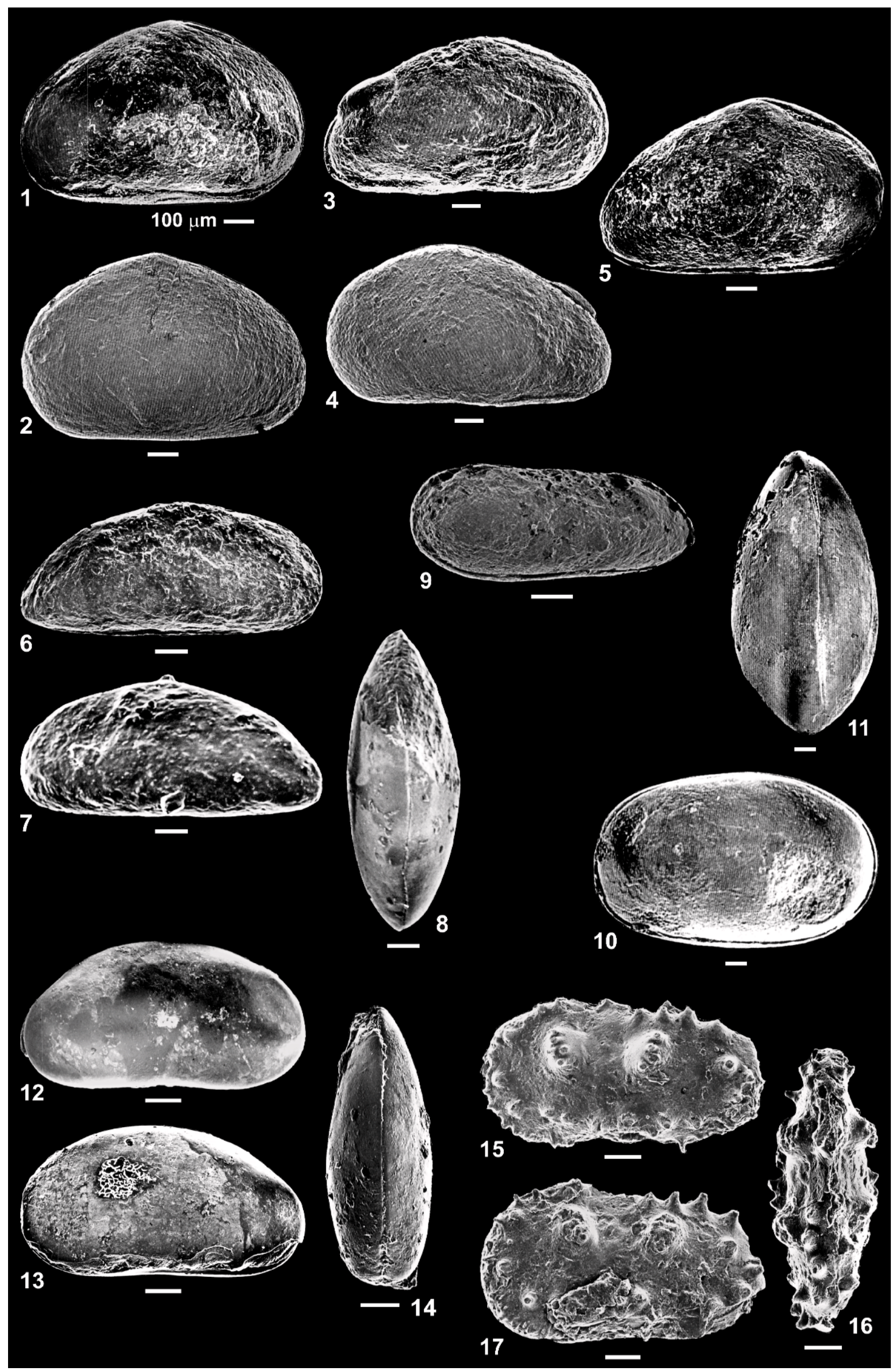


ostracode fossils, many Cretaceous species have been only tentatively attributed to Paracypria. For a more detailed discussion on Recent and fossil material, see Benson et al. (1961), Maddocks (1992), and Maddocks et al. (1993).

\section{PARACYPRIA? ELONGATA new species}

Figure 5.6-5.8

Diagnosis.-The carapace is large and elongate in lateral view. The maximum height occurs at mid-length. The maximum length occurs along the ventral margin. The left valve conspicuously overlaps the right ventrally and posteriorly. The surface is smooth.

Description.-Carapace large and elongate in lateral view. Maximum height at mid-length. Maximum length along the ventral margin. Left valve larger than the right one; overlap well defined ventrally and posteriorly. Dorsal margin evenly arched. Ventral margin sub-rectilinear. The anterior end is higher than the posterior and narrowly rounded, with the posterior end somewhat tapered. Smooth external surface. Somewhat tumid and subelliptical in dorsal view. Maximum width approximately at midlength. Internal duplicature with numerous short and straight radial pore-canals. Sexual dimorphism not observed.

Etymology.-With reference to the elongate outline of the carapace in lateral view.

Material.-Holotype, adult carapace MP-O-1600, length 0.93 $\mathrm{mm}$, height $0.43 \mathrm{~mm}$, width $0.29 \mathrm{~mm}$. Paratypes, one adult or A-1 carapace, MP-O-1601, length $0.91 \mathrm{~mm}$, height $0.41 \mathrm{~mm}$, width $0.34 \mathrm{~mm}$. The materials were recovered in Brazil, Rio Grande do Norte State, well RN-7, at a depth of $788 \mathrm{~m}$.

Occurrence.-Brazil, Alagamar Formation, Potiguar Basin, mid-upper Aptian.

Remarks.-Although the validity of Paracypria Sars, 1910 has been discussed at least since Rome (1962), some species were attributed to this genus during the 2000s. Harding (1962) proposed a new description for Paracypria and considered Dolerocypria Tressler, 1937, Thalassocypris Hartmann, 1955, and Thalassocypria Hartmann, 1957 to be junior synonyms. Maddocks (1992) noted that the Tribe Thalassocypridini is taxonomically problematical because of the difficulty of establishing diagnostic characteristics that permit a clear generic distinction. However, this new species is tentatively identified as Paracypria in the current paper, largely because of its outline, size, overlap pattern and smooth lateral surface.

\section{Subfamily CANDOninae Kaufmann, 1900 Genus CANDona Baird, 1845}

Type species.-Cypris candida Mueller, 1776.

Remarks. - Although it is beyond the scope of this paper, it is important to consider that Candona presents many similarities to its allied genus Candoniella Schneider, 1956, which is considered by many authors to be a junior synonym of that genus (e.g., Deying and Neale, 1991).

CANDONA? sp.

Figure 5.12-5.14

Material.-Carapace MP-O-1602, length $0.80 \mathrm{~mm}$, height 0.42 $\mathrm{mm}$, width $0.32 \mathrm{~mm}$; carapace MP-O-1603, $0.72 \mathrm{~mm}$, height 0.40 $\mathrm{mm}$, width $0.26 \mathrm{~mm}$; Brazil, Rio Grande do Norte State, well CE1 , at a depth of $2081.80 \mathrm{~m}$.

Occurrence.-Brazil, Alagamar Formation, Potiguar Basin, mid-upper Aptian.

Remarks.-Although abundant, most of the material of Candona? sp. is poorly preserved, and the internal features are not visible. Therefore, it is difficult to confidently assign this species to any genus of the Family Candonidae. The sub-reniform lateral outline, mid-posterior height, slightly concave ventral margin and smooth surface are features that resemble both Candona and its allied genus Candoniella Schneider, 1956.

Family ILYOCYPRIDIDAE Kaufmann, 1900

Subfamily ILYOCYPRIDINAE Kaufmann, 1900

Genus ILYOCYPRIMORPHA Mandelstam, 1956

Type species.-Ilyocyprimorpha palustris Mandelstam, 1956.

Remarks.-Ilyocyprimorpha Mandelstam, 1956 differs from Neuquenocypris Musacchio, 1973 by the presence of only one antero-median sulcus in lateral view, and an anterior crescentshaped flattened tooth in the hinge of the left valve. By contrast, Neuquenocypris has two sulci in lateral view, while its hinge is adont (see Musacchio and Simeoni, 1991).

\section{ILYOCYPRIMORPHA BERTHOUI (Colin and Dépêche, 1997)} Figure 5.15-5.17

1997 Neuquenocypris berthoui CoLIN AND DÉPÊCHE, p. 435, fig. 2.1.

1997 Neuquenocypris cf. berthoui Colin and Dépêche; Colın AND DÉPÊCHE, p. 443, fig. 6.10.

Material.-Female carapace MP-O-1604, length $0.81 \mathrm{~mm}$, height $0.49 \mathrm{~mm}$, width $0.24 \mathrm{~mm}$. A male carapace (MP-O-1589, length $0.77 \mathrm{~mm}$, height $0.42 \mathrm{~mm}$, width $0.21 \mathrm{~mm}$ ) was lost after SEM procedures. These materials were recovered in Brazil, Rio Grande do Norte State, well RN-7, at a depth of $775.60 \mathrm{~m}$.

Occurrence.-Africa, Bongor, Doba and Doseo basins within the Republic of Chad, Aptian/Albian (Colin and Dépêche, 1997). Brazil, Crato Member, Santana Formation, Araripe Basin, Aptian (Regali, 1990; Colin and Dépêche, 1997; Coimbra et al., 2002).

Alagamar Formation, Potiguar Basin, mid-upper Aptian.

Remarks.-This species resembles Ilyocyprimorpha palustris Mandelstam 1956, which was described from the Early Cretaceous of Mongolia. This species differs from Ilyocyprimorpha palustris mainly in that it is smaller, has a more subrectangular outline in lateral view, presents a lateral surface without reticulation and with a slightly different distribution of spines, and has conspicuous sexual dimorphism.

Genus ILYOCYPRIS Brady and Norman, 1889

Type species. Cypris gibba Ramdohr, 1808.

Remarks.-Ilyocypris is a very well-defined genus, known since the Jurassic and with major diversification along the Cenozoic. It resembles the Neuquenocypris Musacchio, 1973 from the Cretaceous, but with the right valve smaller than the left one, along with a more conspicuous pair of sulci, as discussed by Musacchio and Simeoni (1991).

Figure 5- Species from genera Harbinia Tsao, 1959 diagnosis emended by Hou (1984), Paracypria Sars, 1910, Darwinula Brady and Robertson, 1885 diagnosis emended by Rossetti and Martens (1998), Brasacypris Krömmelbein, 1965b, Candona Baird, 1845 and Ilyocyprimorpha Mandelstam, 1956; 1-5, Harbinia dimorphica n. sp.: 1, 2, female, holotype (MP-O-1590), adult carapace, right and left views; 3, 4, male, paratype (MP-O-1591), adult carapace, right and left views; 5, female, paratype (MP-O-1592), adult carapace, right view; 6-8, Paracypria? elongata n. sp.: 6, 7, holotype (MP-O-1600), adult carapace, right and left views; 8, paratype (MP-O-1601), adult carapace, dorsal view; 9, Darwinula martinsi Silva, 1978c diagnosis emended by Do Carmo et al. (2004b), juvenile A-1 (MP-O-1605), carapace right view; 10, 11, Brasacypris subovatum n. sp., holotype (MP-O-1593), adult carapace, right and dorsal views; 12-14, Candona? sp.: 12, 13, juvenile? (MP-O-1602), carapace, right and left views; 14, juvenile? (MP-O-1603), dorsal view; 15-17, Ilyocyprimorpha berthoui (Colin and Dépêche, 1997): 15, 16, male? (MP-O-1589, lost), adult carapace, left and dorsal views; 17, female? (MP-O-1604), adult carapace, left view. 


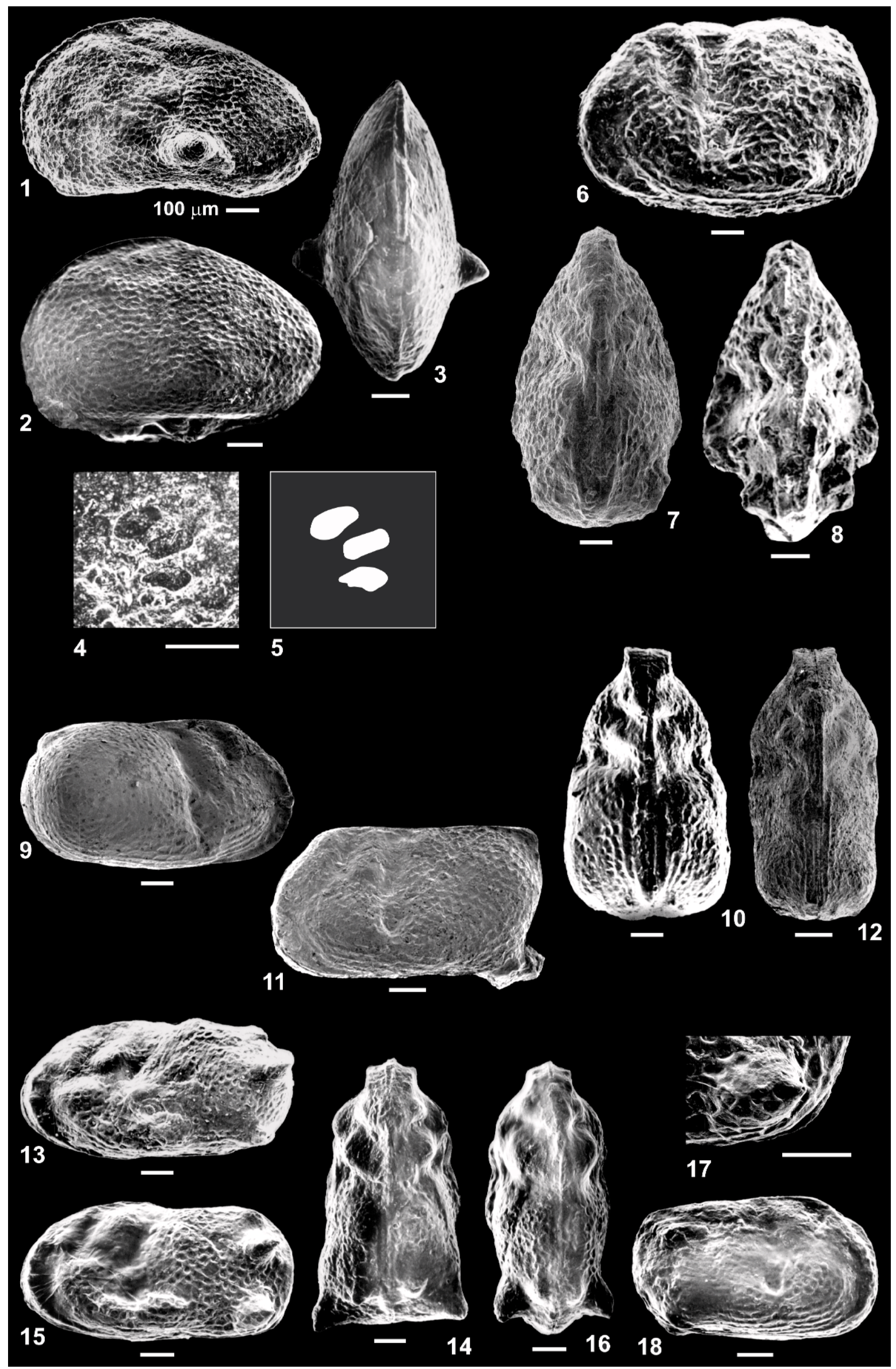


ILYOCYPRIS? sp.

Figure 6.1-6.5

1990 Hourcqia? sp. 1; Silva-Telles JR. and Viana, pl. 2, figs. 9, 10.

Material.-Adult carapace MP-O-1573, length $0.91 \mathrm{~mm}$, height $0.54 \mathrm{~mm}$, width $0.64 \mathrm{~mm}$. Juvenile carapace MP-O1574 , length $0.85 \mathrm{~mm}$, height $0.55 \mathrm{~mm}$, width $0.54 \mathrm{~mm}$. Juvenile carapace MP-O-1575, length $0.81 \mathrm{~mm}$, height $0.57 \mathrm{~mm}$, width $0.37 \mathrm{~mm}$. Fragment of a juvenile valve MP-O-1576 (with the central muscle scars). This material was recovered in Brazil, Rio Grande do Norte State, well RN-7, at a depth of $786.05 \mathrm{~m}$.

Occurrence.-Brazil, Crato Member, Santana Formation, Araripe Basin (Silva-Telles Jr. and Viana, 1990), interval dated as Aptian (Regali, 1990; Coimbra et al., 2002). Alagamar Formation, Potiguar Basin, mid-upper Aptian.

Remarks.-Although the material in question is abundant, all of the specimens have some degree of deformation, which hinders an accurate description of this species. However, some important features of the best preserved specimens make it possible to attribute these ostracodes with some confidence to the genus Ilyocypris. Typical antero-dorsal double sulci are present but are not conspicuous. The entire surface is covered by delicate reticulations, as is common in many species of this worldwide freshwater genus. The central muscle scars are poorly preserved but are consistent with Ilyocyprididae.

Suborder Cytherocopina Gründel, 1967

Infraorder ARCHAEOCYTHERININA Liebau, 1991

Superfamily LiMNOCYTHEROIDEA Liebau, 2005

Family TIMIARIASEVIIDAE Mandelstam, 1960

Genus Theriosynoecum (Branson, 1935) Branson, 1936

Type species.-Morrisonia wyomingensis Branson, 1935.

Remarks.-This paper follows Colin and Danielopol (1978), Do Carmo et al. (1999, 2004b), and Sames (2011), which consider Dryelba and Bisulcocypris to be junior synonyms of Theriosynoecum.

\section{Theriosynoecum SiLVAi (Silva, 1978b)}

Figure 6.9-6.12

1978b Bisulcocypris silvai SILvA, p. 1014, pl. 1, figs. 1-4.

1978b Bisulcocypris munizi SiLva, p. 1016, pl. 1, figs. 5-8.

1997 Theriosynoecum munizi (Silva); CoLIN AND DÉPÊCHE, p. 435 figs. 2.7, 2.8, 2.10-2.12.

1997 Theriosynoecum silvai (Silva); Colin AND DÉPÊCHe, p. 435 , figs. $2.4,2.6,2.9,2.15$, p. 439 , figs. 4.6, 4.7.

2002 Theriosynoecum silvai (Silva); CoIMBra, ArAI AND CARreÑo, p. 691, figs. 4.34, 4.35 .

2002 Theriosynoecum silvai (Silva); CoImBra, ArAI AND CARreño, p. 691, figs. 4.36, 4.37.

2004b Theriosynoecum silvai (Silva); Do CARMo, Raphael, Vilhena and Tomassi, p. 154, fig. 3.1-3.20.

Material.-Female carapace MP-O-1565, length $0.85 \mathrm{~mm}$, height $0.46 \mathrm{~mm}$, width $0.49 \mathrm{~mm}$. Male carapace MP-O-1567, length $0.75 \mathrm{~mm}$, height $0.41 \mathrm{~mm}$, width $0.40 \mathrm{~mm}$. Male carapace
MP-O-1568, length $0.74 \mathrm{~mm}$, height $0.40 \mathrm{~mm}$, width $0.36 \mathrm{~mm}$. This material was recovered in Brazil, Rio Grande do Norte State, well RN-7, at a depth of $786.05 \mathrm{~m}$.

Occurrence.-Africa, Bongor, Doba, and Doseo basins within the Republic of Chad, dated as Aptian-Albian (Colin and Dépêche, 1997). Brazil, Crato Member, Santana Formation, Araripe Basin (Silva, 1978b), interval dated as Aptian by Regali (1990), and Coimbra et al. (2002). Alagamar Formation, Potiguar Basin, mid-upper Aptian.

Remarks.-The holotype has been lost, and neotypes were proposed by Do Carmo et al. (2004b) based on material collected at the type-locality.

\section{TherIOSYNOECUM COLINI new species} Figure 6.13-6.18

1997 Theriosynoecum NC 36; Colin AND DÉPÊCHE, p. 439, figs. 4.10, 4.12.

Diagnosis.-Medium-sized, sub-rectangular, and elongate in lateral view. The anterior margin is peripherally compressed. Surface is gently but conspicuously reticulate and nodular. The three posterior nodes are generally well defined, and are in a vertical line. A crescentic reticulate ridge is well defined below the double and deep sulci.

Description.-Medium-sized carapace, sub-rectangular and elongate in lateral view. Maximum height just anterior to the mid-length. Maximum length approximately at mid-height. Dorsal and ventral margins subparallel. Dorsal margin somewhat obscured by the posterior inflation and ornamentation. Anterior end narrowly rounded, with a smooth ridge running subparallel to it. Posterior margin somewhat obtusely rounded. Surface gently but conspicuously reticulate and nodular, with two anterior subcentral sulci and a reticulate crescentic-shaped ventro-median ridge, right below the sulci. Anterior subcentral sulci inclined forward, with the posterior one deeper and larger. Four generally well-defined rounded or spinose hollow nodes, three of which arranged in a posterior vertical line, and one at the ventro-median region. In dorsal view, somewhat cuneiform, with a compressed apex at the anterior end. Strong sexual dimorphism, with males smaller and much less inflated than females.

Etymology.--In honor of Jean-Paul Colin who has devoted his professional life to the study of Ostracoda and with great enthusiasm has motivated new generations of ostracodologists.

Material.-Holotype, female carapace MP-O-1562, length 0.85 $\mathrm{mm}$, height $0.45 \mathrm{~mm}$, width $0.48 \mathrm{~mm}$. Paratypes, one male carapace MP-O-1563, length $0.81 \mathrm{~mm}$, height $0.45 \mathrm{~mm}$, width $0.39 \mathrm{~mm}$; and one juvenile carapace MP-O-1564, length 0.69 $\mathrm{mm}$, height $0.40 \mathrm{~mm}$, width $0.36 \mathrm{~mm}$. The materials came from Brazil, Rio Grande do Norte State, well RN-7, at a depth of $786.05 \mathrm{~m}$

Occurrence.-Africa, the Bongor, Doba, and Doseo basins within the Republic of Chad, Aptian/Albian (Colin and Dépêche, 1997). Brazil, Alagamar Formation, Potiguar Basin, mid-upper Aptian.

Remarks.-This species differs from T. guzzoi n. sp. mainly by the more elongate outline in lateral view, the position of the

FiguRE 6 - Species from genera Ilyocypris Brady and Norman, 1889 and Theriosynoecum (Branson, 1935) Branson, 1936. 1-5, Ilyocypris? sp.: 1, adult (MPO-1573), carapace right view; 2, juvenile carapace without lateral nodes (MP-O-1574), right view; 3, juvenile carapace with lateral nodes (MP-O-1575), dorsal view; 4, 5, juvenile (MP-O-1576), detail of the central muscle scars and drawing; 6-8, Theriosynoecum guzzoi n. sp.: 6, 7, female, holotype (MP-O-1570), adult carapace, left and dorsal views; 8, male, paratype (MP-O-1572), adult carapace, dorsal view; 9-12, T. silvai (Silva, 1978b) diagnosis emended by Do Carmo et al. (2004b): 9, 10, female (MP-O-1565), adult carapace, right and dorsal views; 11, male (MP-O-1567), adult carapace, left view; 12, male (MP-O-1568), adult, carapace dorsal view; 13-18, T. colini $\mathrm{n}$. sp.; 13, 14, female, holotype (MP-O-1562), adult carapace, left and dorsal views; 15-17, male, paratype (MP-O-1563), adult carapace, left and right views and detail of the posterior node; 18, juvenile, paratype (MP-O-1564), adult carapace, right view. 
greatest width, the presence of four generally conspicuous hollow nodes, forwardly inclined sulci and more delicate reticulation.

\section{THERIOSYNOECUM GUZZOI new species} Figure 6.6-6.8

Diagnosis.-Large, sub-quadrate to sub-rectangular in lateral view. The anterior margin is peripherally compressed. Surface reticulated, with a well-defined crescentic ventro-lateral ridge. Anterior subcentral sulci deep and straight. The dorsal view is sagittate, more conspicuously so in the male carapace.

Description.-Carapace large and subquadrate to sub-rectangular in lateral view. Maximum height just posterior to midlength. Maximum length at mid-height. Dorsal margin subrectilinear and obscured by the inflation posteriorly. Ventral margin slightly convex. Anterior end obliquely rounded. Posterior margin obtusely rounded. Surface reticulate laterally and striate ventrally. A large crescentic and reticulate ridge is conspicuously developed ventro-laterally. Two anterior subcentral sulci deep and straight, with the posterior sulcus deeper and extending to the ventro-lateral ridge. Sagittate in dorsal view. Strong sexual dimorphism, with the males being significantly smaller and more typically sagittate in the dorsal view.

Etymology.- In honor of Jarbas V. Guzzo who collaborated supervising the first author during early studies on limnic Ostracoda from Brazil.

Material.-Holotype, female carapace MP-O-1570, length 0.93 $\mathrm{mm}$, height $0.61 \mathrm{~mm}$, width $0.58 \mathrm{~mm}$. Paratypes, one female MP$\mathrm{O}-1571$, length 0.91 , height 0.57 , width $0.60 \mathrm{~mm}$; and one male MP-O-1572, length $0.78 \mathrm{~mm}$, height $0.41 \mathrm{~mm}$, width $0.48 \mathrm{~mm}$.

Type locality.-Brazil, Rio Grande do Norte State, from well RN-1 at a depth of $1365.15 \mathrm{~m}$. All of specimen types were recorded from the same sample. Type horizon, Alagamar Formation, Potiguar Basin, mid-upper Aptian.

Occurrence.-Brazil, Alagamar Formation, Potiguar Basin, mid-upper Aptian.

Remarks.-See discussion of T. colini.

Suborder Darwinulocopina Sohn, 1988

Superfamily DarwinUloIDEA Brady and Norman, 1889 Family DARWINULIDAE Brady and Norman, 1889 Genus Darwinula Brady and Robertson, 1885

Type species.-Polycheles stevensoni Brady and Robertson, 1870.

Remarks.-Since some new genera have been erected for darwinulids based mainly on soft parts, this paper follows the diagnosis of Darwinula emended by Rossetti and Martens (1998).

\section{DARWINULA MARTINSI Silva, 1978c}

Figure 5.9

1978c Darwinula martinsi Silva, p. 1028, pl. 1, figs. 1, 2.

1990 Darwinula cf. martinsi Silva; Silva-Telles JR. AND VIANA, pl. 2, fig. 4.

1997 Darwinula martinsi Silva; Colın AND DÉPÊCHE, p. 435, fig. 2.18.

2004a Darwinula martinsi Silva; Do CARMO, TOMASSI AND Oliveira, p. 145, fig. 4.9.

2004b Darwinula martinsi Silva; Do Carmo, Rafael, Vilhena AND ToMAssi, p. 156, fig. 3.21-3.27.

Material.-Carapace MP-O-1605. This specimen is somewhat deformed and poorly preserved, and the following measures are only approximate: length $0.69 \mathrm{~mm}$ and height $0.32 \mathrm{~mm}$.

Occurrence.-Brazil, Crato Member and base of the Ipubi Member, Santana Formation, Araripe basin (Silva, 1978c; SilvaTelles Jr. and Viana, 1990; Colin and Dépêche, 1997), interval dated as Aptian by Regali (1990) and Coimbra et al. (2002). Alagamar Formation, Potiguar Basin, mid-upper Aptian.
Remarks. - The holotype was lost and neotypes proposed by Do Carmo et al. (2004b) based on material collected in the original type locality. Compared to the neotypes in Do Carmo et al. (2004b), MP-O-1605 is probably a juvenile from instar A-1.

\section{CONCLUSIONS}

This study analyzed 1,422 samples from 14 wells drilled at Potiguar Basin, Northeastern Brazil, and the new data on taxonomy presented herein substantially improves the current understanding of the diversity and distribution of limnic ostracodes from the Cretaceous of Brazil. Fifteen species were discussed: Cypridea araripensis; Cypridea? sp.; Harbinia sinuata; Harbinia alta; Harbinia crepata n? sp.; Harbinia dimorphica n. sp.; Brasacypris subovatum n. sp.; Paracypria? elongata n. sp.; Ilyocyprimorpha berthoui; Theriosynoecum silvai diagnosis emended by Do Carmo et al. (2004b); T. colini n. sp.; T. guzzoi n. sp.; Darwinula martinsi diagnosis emended by Do Carmo et al. (2004b); and Candona? sp; and Ilyocypris? sp. Nine of the 15 species have also been recorded outside of the Potiguar Basin: C. araripensis and D. martinsi (Araripe basin, Brazil); Harbinia sinuata and Candona? sp. (Araripe and Alagoas basins, Brazil); Harbinia alta (Araripe, Alagoas and Espírito Santo basins, Brazil); Harbinia dimorphica (Gabão basin, Africa); and I. berthoui, T. colini and T. silvai (Araripe basin, Brazil; Doba, Doseo and Bongor basins, Africa). Therefore, these species are important for future studies of the correlation between West African and Brazilian marginal basins and for oil exploration, given that the Aptian of these basins is composed by source rocks and/or reservoir intervals. Despite the controversial chronostratigraphic range of the Alagoas Stage, all records of the ostracode species in this study correspond to the range accepted to belong to the palynological Zone Sergipea variverrucata, which is from the mid-upper Aptian.

\section{ACKNOWLEDGMENTS}

The authors are grateful to "Petróleo do Brasil S.A" (PETROBRAS) for providing the material for study and to EMBRAPA Genetic Resources and Biotechnology (CENARGEN) for SEM services. We also thank the reviewers, as well as R. L. Pinto, for the great intellectual contribution to the present work. DAC gratefully acknowledges the National Council for Scientific and Technological Development (CNPq, grant number 300499/99-0), and the Technological and Scientific Ventures Foundation (FINATEC) for financial support of his participation in the 15th International Symposium on Ostracoda. JCC gratefully acknowledges the CNPq (grant number 300703/2009$0)$. LSA acknowledges FINATEC for fellowship support.

\section{REFERENCES}

Andreu-Boussut, B. 1991. Les ostracodes du Crétacé Moyen (Barremien à Turonien), le long d'une Transversale Agadir-Nador. Actes du Laboratoire de Géologie Sedimentaire et Paleontologie de 1'Université Paul-Sabatier, 2: $1-762$.

Antonietto, L. S., S. R. Gobbo, D. A. Do Carmo, M. L. Assine, M. A. M. C. C. Fernandes, and J. E. L. Silva. 2012. Taxonomy, ontogeny and paleoecology of two species of Harbinia Tsao, 1959 (Crustacea, Ostracoda) from the Santana Formation, lower Cretaceous, Northeastern Brazil. Journal of Paleontology, 86:660-669.

Araripe, P. T. and F. J. Feijó. 1994. Bacia Potiguar. Boletim Técnico da Petrobras, 8:127-141.

BAIRD, W. 1845. Arrangement of British Entomostraca, with a list of species, particularly noticing those which have as yet been discovered within the bounds of the club. History of the Berwickshire Naturalists' Club, 2:145158.

Balme, B. E. 1957. Spores and Pollen Grains from the Mesozoic of Western Australia. CSIRO, Division of Coal Research, North Ryde, 48 p.

Bate, R. H. 1972. Phosphatized ostracodes with appendages from the Lower Cretaceous of Brazil. Palaeontology, 15:379-393. 
Bate, R. H. 1973. On Pattersoncypris micropapillosa Bate. Stereo-Atlas of Ostracod shells, 1:101-108.

Benson, R. H., J. M. Berdan, W. A. Bold, T. Hanai, I. Hessland, H. V. Howe, R. V. Kensling, S. A. Levinson, R. A. Reyment, R. C. Moore, H. W. Scott, R. H. Shaver, I. G. Sohn, L. E. Stover, F. M. Swain, and P. SylvesterBRAdLey. 1961. Systematic descriptions, p. Q99-Q421. In R. C. Moore and C. W. Pitrat (eds.), Treatise on Invertebrate Paleontology, Pt. Q. Arthropoda 3. Geological Society of America and University of Kansas Press, Lawrence.

Bertani, R. J., I. G. Costa, And R. M. D. Matos. 1991. Evolução tectonosedimentar, estilo estrutural e hábitat do petróleo na bacia Potiguar, p. 291310. In G. P. Raja Gabaglia and E. J. Milani (eds.), Origem e Evolução de Bacias Sedimentares. Gávea Press, Rio de Janeiro.

Bosquet, J. 1852. Description des Entomostracés fossiles des Terrains tertiaires de la France et de la Belgique. Mémoires de l'Académie Royales des Sciences, Lettres et Beaux Arts de Belgique, 24:1-142.

Brady, G. S. 1886. Notes on Entomostraca collected by Mr. A. Haly in Ceylon. The Journal of the Linnean Society, Zoology, 19:293-316.

Brady, G. S. AND D. Norman. 1889. A monograph of the marine and freshwater Ostracoda of the North Atlantic and of northwestern Europe. I. Podocopa. Science Proceeding of Royal Dublin Society, 4(2):63-270.

Brady, G. S. and D. RoberTson. 1870. The Ostracoda and Foraminifera of tidal rivers. With an analysis and descriptions of the British Ostracoda. Annals and Magazine of the Natural History, 4(31):1-33.

Brady, G. S. AND D. Robertson. 1885. Genus Darwinula. In T. R. Jones (ed.), On the Ostracoda of the Purbeck Formation; With Notes on the Wealden Species. Geological Society of London Quarterly Journal, 41(3):346.

Branson, C. C. 1935. Fresh-water invertebrates from the Morrison (Jurassic?) of Wyoming. Journal of Paleontology, 9:514-522.

Branson, C. C. 1936. New name for a Morrison ostracode genus. Journal of Paleontology, 10:323

Coimbra, J. C., M. Arai, And A. L. Carreño. 2002. Biostratigraphy of Lower Cretaceous microfossils from the Araripe basin, Northeastern Brazil. Geobios, 35:687-698

Colin, J. P. and D. L. Danielopol. 1978. New data on the systematics of the Limnocytheridae (Ostracoda, Cytheracea). Geobios, 11:563-567.

Colin, J. P. AND F. DÉPÊCHE. 1997. Faunes d'ostracodes lacustres des bassins intra-cratoniques d'âge Albo-Aptian en Afrique de l'Ouest (Cameroun, Tchad) et au Brésil: Considérations d'ordre paléoécologiques et paléobiogéographiques. African Geoscience Review, 4:431-450.

DéPÊCHe, F., P. Y. BÉRthou, AND D. A. CAMpos. 1990. Quelques observations sur les faunes d'ostracodes du Cretácé du Bassin d'Araripe (NE du Brésil). 1st Simpósio sobre a Bacia do Araripe e Bacias Interiores do Nordeste, Crato, Proceedings, 293-308.

Deying, S. and J. W. Neale. 1991. Plio/Pleistocene Candonidae (freshwater Ostracoda) from boreholes in The Nanning Area, Guangxi Province, Southern China. Journal of Micropalaeontology, 9:159-166.

Do Carmo, D. A., H. Z. Tomassi, and S. B. S. G. De Oliveira. 2004a Taxonomia e distribuição estratigráfica dos ostracodes da Formação Quiricó, Grupo Areado (Cretáceo Inferior), bacia Sanfranciscana, Brasil. Revista Brasileira de Paleontologia, 7:139-149.

Do Carmo, D. A., R. M. L. Rafael, R. M. Vilhena, and H. Z. Tomassi. 2004b. Redescrição de Theriosynoecum silvai e Darwinula martinsi, Membro Crato (Formação Santana), Cretáceo inferior, bacia do Araripe, NE, Brasil. Revista Brasileira de Paleontologia, 7:151-158.

Do Carmo, D. A., R. Whatley, J. V. Queiroz Neto, and J. C. Coimbra. 2008. On the validity of two Lower Cretaceous non-marine ostracode genera: biostratigraphic and paleogeographic implications. Journal of Paleontology, 82:790-799

Do Carmo, D. A., Y. T. Sanguinetti, J. C. Coimbra, and E. M. Guimarães. 1999. Paleoecologia dos ostracodes não-marinhos do Cretáceo Inferior da bacia Potiguar, RN, Brasil. 5th Simpósio sobre o Cretáceo do Brasil and 1st Simpósio sobre el Cretácico de América del Sur, Serra Negra, Bulletin, p. 383-391.

FeıJó, F. J. 1994. Bacias de Sergipe e Alagoas. Boletim de Geociências da Petrobras, 8:149-161.

Gobbo-Rodrigues, S. R., S. Petri, and R. J. Bertini. 1999a. Ocorrências de ostracodes da Formação Adamantina do Grupo Bauru, Cretáceo Superior da bacia do Paraná e possibilidades de correlação com depósitos isócronos argentinos. Parte I-Família Ilyocyprididae. Acta Geologica Leopoldensia, 23:3-13

Gobbo-Rodrigues, S. R., S. Petri, and R. J. Bertini. 1999b. Ocorrências de ostracodes da Formação Adamantina do Grupo Bauru, Cretáceo Superior da bacia do Paraná e possibilidades de correlação com depósitos isócronos argentinos. Parte II-Família Limnocytheridae. Revista da Universidade de Guarulhos, 4:5-12.

GreKofF, N. 1956. Guide pratrique pour la Détermination des ostracodes postpaléozoïques. Institut Français du Pétrole, 95:16-17.

Grekoff, N. AND K. KRÖMMELbein. 1967. Etude comparée des ostracodes mésozoïques continentaux des bassins atlantiques: série de Cocobeach,
Gabon et série de Bahia, Brésil. Revue de L'Institut Français du Pétrole, 1: 307-1353.

Grosdidier, E. 1979. Principaux ostracodes marins de l'intervalle AptienTuronien du Gabon (Afrique Occidentale). Extrait du Bulletin du Centre de Recherche et Exploration Elf-Aquitaine, 3:1-35.

HARDING, J. P. 1962. Mungava munda and four other new species of ostracod crustaceans from fish stomachs. Natural History of Rennell Island, British Solomon Islands, 4:51-62.

Hartmann, G. 1955. Neue marine Ostracoda der Familie Cypridae und der Subfamilie Cytherideinae der Familie Cytheridae aus Brasilien. Zoologischer Anzeiger, 154:109-127.

Hartmann, G. 1957. Zur Kenntnis der Mangrove-Estero-Gebietes von El Salvador und seiner Ostracoden-Fauna. II. Systematischer Teil. Kieler Meeresforschungen, 13:134-154

Hou, Y. 1984. Problems concerning the classification of the genera Harbinia, Sinocypris, Quadracypris and Nanxiongium (Ostracoda). Acta Micropaleontologica Sinica, 9:17-34.

Hou, Y.-T., B.-R. Huang, L.-Y. Geng, Y.-P. Li, H.-G. Shan, Z.-G. CaI, AND Y.-P. SHI. 1988. On the change of the author's names of new genera and species in the monograph "Early Tertiary ostracode fauna from the coastal region of Bohai" (1978). Acta Micropaleontologica Sinica, 5:1-215.

JoNES, T. R. 1860. Fossil entomostraca from Montserrate (Brazil). Quarterly Journal of the Geological Society of London, 16:266-268.

JonES, T. R. 1897. On some fossil Entomostraca from South America. Geological Magazine, New Series, Decade, 4:289-293.

Koutsoukos, E. A. M., M. R. Mello, Azambuja Filho, N. C. M. B. Hart, and J. R. Maxwell. 1991. The upper Aptian-Albian succession of the Sergipe Basin, Brazil: an integrated paleoenvironmental assessment. Bulletin of the American Association of Petroleum Geologists, 75:479-498.

KRÖMmelbein, K. 1961. Über dimorphism bei Arten der Ostracoden-Gattung Paracypridea Swain (Cyprideinae) aus dem NE-Brasilianischen "Wealden." Senckenbergiana Lethaea, 42:353-375.

Krömmelbein, K. 1962. Zur Taxionomie und Biochronologie stratigraphische wichtiger ostracoden-arten aus der oberjurassisch?-unterkretazischen Bahia-Serie (Wealden-Fazies) NE-Brasiliens. Senckenbergiana Lethaea, 43: 437-528.

Krömmelbein, K. 1963. Ilhasina n. g. und Salvadoriella n. g., zwei neue Ostracoden Gattungen aus der Bahia-Serie (nicht-mariner Oberjura?Unterkreide, NE-Brasilien). Senckenbergiana Lethaea, 171:375-390.

Krömmelbein, K. 1964a. Neue Arten der Ostracoden-Gattung Paracypridea Swain aus der Bahia Serie des Reconcavo Bahiano (Oberjura?- Unterkreide, Wealden-Fazies, NE-Brazilien. Boletim Paranaense de Geografia, 10:139 160 .

Krömmelbein, K. 1964b. Ostracoden aus der marinen "Kusten-Kreide" Brasiliens: Brachycythere (Brachycythere) sapucarienses n. sp., aus dem Turonium. Senckenberginiana Lethaea, 45:489-495.

KRÖMmelbein, K. 1965a. Ostracoden aus der nicht-marine Unter-Kreide ("Westafrikanischer Wealden") des Congo-Küsttenbeckens. Meyniana, 15: 59-74.

Krömmelbein, K. 1965b. Neue, für Vergleiche mit West-Afrika wichtige Ostracoden-Arten der brasilianischen Bahia Serie (Ober-Jura?/Unter-Kreide in Wealden-Fazies). Sennckenbergiana Lethaea, 46a:177-213.

Krömmelbein, K. 1966. Preliminary remarks on some Marine Cretaceous ostracodes from North-Eastern Brazil and West Africa. Second West African Micropaleontological Colloquium, Proceedings, Ibadan, 1:119123

Krömmelbein, K. 1967. Ostracoden aus der mariner "Küstern Kreide" Brasiliens. 2: Sergipella transatlantica n. g., n. sp. und Aracajuia benderi n. g. n. sp. aus dem Ober-Aptium/Albium. Senckenbergiana Lethaea, 48: $525-533$.

Krömmelbein, K. and R. Weber. 1971. Ostracoden des "Nordost-Brasilianischen Wealden." Geologisches Jahrbuch, 115:1-93.

LiEBAU, A. 2005. A revised classification of the higher taxa of the Ostracoda (Crustacea).Hydrobiologia, 538:115-137.

Maddocks, R. 1992. Anchialine Cyprididae (Ostracoda) from the Galapagos Islands, with a review of the Subfamily Paracypridinae. Zoological Journal of the Linnean Society, 104:1-29.

Maddocks, R., T. M. Iliffe, and S. Sarbu. 1993. Anchialine podocopid Ostracoda of New Caledonia, p. 439-452. In K. G. McKenzie and P. J. Jones (eds.), Ostracoda in the Earth and Life Sciences. Balkema, London.

Mandelstam, M. I. 1956. The Genus Iliocyprimorpha Mandelstam, gen. nov., p. 110-111. In M. I. Mandelstam, G. F. Schneyder, and I. E. Zanina (eds.), New Families and Genera of Invertebrates. All-Union Scientific Research Geological Institute, Papers in Palaeontology. (In Russian)

Moos, B. 1959. Ein beitrag zur altersdeutung des Recôncavo, Bahia (Brasilien). Geologisches Jahrbuch, 77:35-58.

Morkhoven, F. P. C. M. 1963. Post Paleozoic Ostracoda-Their Morphology, Taxonomy and Economic Use, Pt. 2. Elsevier, New York, 408 p.

MouRA, J. A. 1972. Algumas espécies e subespécies novas de ostracodes da bacia Recôncavo/Tucano. Boletim Técnico da PetrobraS, 15:245-263. 
Mueller, O. F. 1776. Zoologiae Danice Prodamus, Seu Animalium Daniae et Norvegiae Indigenarum Characteres, Nomina et Synonyma Imprimis Popularium. Lipsiae et Havniae, Copenhagen, 282 p.

Musacchio, E. A. 1973. Charophytas y ostrácodos no marinos del Grupo Neuquén (Cretácico Superior) en algunos afloramentos de las Provincias de Río Negro y Neuquén, República Argentina. Revista del Museo de la Plata (Nueva Serie), Sección Paleontologia, 48:1-32.

Musacchio, E. A. And M. Simeoni. 1991. Taxonomy of some Cretaceous nonmarine ostracods of palaeobiogeographical interest. Neues Jahrbuch für Geologie und Paläontologie Abhandlugen, 180:349-389.

Pessoa Neto, O. C., U. M. Soares, J. G. F. Da Silva, E. H. Roesner, C. P. Florencio, and C. A. V. De Souza. 2007. Bacia Potiguar. Boletim de Geociências da Petrobras, 15:357-369.

Pinto, I. D. And Y. T. SAnguinetti. 1958. Bisulcocypris: a new Mesozoic genus and preliminary notes about its relation with Metacypris and allied forms. Boletim da Sociedade Brasileira de Geologia, 7:75-90.

Pinto, I. D. And Y. T. SAnguinetti. 1962. A complete revision of the genera Bisulcocypris and Theriosynoecum (Ostracoda) with the world geographical and stratigraphical distribution (including Metacypris, Elphidium, Gomphocythere and Cytheridella). Publicação Especial da Escola de Geologia de Porto Alegre, 4:1-165.

Pinto, I. D. And Y. T. Sanguinetti. 1984. Mesozoic genus Theriosynoecum Branson, 1936 and validity of related genera. Anais da Academia Brasileira de Ciências, 56:207-215.

Poropat, S. F. and Colin, J. P. 2012. Reassesment of the Early Cretaceous non-marine ostracod genera Hourcqia Krömmelbein, 1965 and Pattersoncypris Bate, 1972 with the description of a new genus, Kroemmelbeincypris. Journal of Paleontology, 86:700-720.

RamDohr, F. A. 1808. Ueber die gattung Cypris Mueller und drei zu derselben ghörige neue arten. Der Gesellschaft naturforschender Freunde zu Berlin Magazin fur die neuesten Entdeckungen in der gesammten Naturkunde, 2: 83-93.

Ramos, M. I. F., D. F. Rossetti, and J. D. S. Paz. 2006. Caracterização e significado paleoambiental da fauna de ostracodes da Formação Codó (Neoaptiano), leste da bacia de Grajaú, MA, Brasil. Revista Brasileira de Paleontologia, 9:339-348.

Regali, M. S. P. 1987a. Palinomorfos do Barremiano/Albiano BrasileirosParte II. 10th Congresso Brasileiro de Paleontologia, Rio de Janeiro, Proceedings, 2:647-667.

Regali, M. S. P. 1987b. O gênero Sergipea e a sua estratigrafia no Eocretáceo do Brasil. Tenth Congresso Brasileiro de Paleontologia, Rio de Janeiro, Proceedings, 2:615-623.

Regali, M. S. P. 1990. Biocronoestratigrafia e paleoambiente do Eocretáceo das bacias do Araripe (CE) e Rio do Peixe (PB), NE-Brazil. 1st Simpósio Sobre a Bacia do Araripe e Bacias Interiores do Nordeste, Crato, Proceedings, 163-172.

Regali, M. S. P. and C. F. Viana. 1989. Sedimentos do NeojurássicoEocretáceo do Brasil: Idade e Correlação com a Escala Internacional. PETROBRAS/SEDES, Rio de Janeiro, $95 \mathrm{p}$.

Regali, M. S. P., N. Uesugui, and A. S. SAntos. 1974. Palinologia dos sedimentos Meso-Cenozóicos do Brasil. Boletim Técnico da Petrobras, 17: 177-191.

Rome, R. 1962. Ostracodes. Résultats scientifiques de l'exploration hydrobiologique du lac Tanganika, (1946-1947), 3:1-305.

Rossetti, G. And K. Martens. 1998. Taxonomic revision of the Recent and Holocene representatives of the Family Darwinulidae (Crustacea, Ostracoda), with a description of three new genera. Bulletin de L'Institut Royal des Sciences Naturelles de Belgique, Biologie, 68:55-110.

SAmEs, B. 2011. Early Cretaceous Theriosynoecum Branson 1936 in North America and Europe. Micropaleontology, 57:291-344.

SARs, G. O. 1905. Pacifische plankton-crustaceen. (Ergebnisse einer Reise nach dem Pacific, Schauinsland 1896-97). II. Brackwasser-Crustaceen von den Chatham inselm. Zoologisches Jahrbuch, Abteilung für Systematik, Geographie und Biologie, 21:371-414.

SARS, G. O. 1910. Zoological results of the Third Tanganika Expedition, conducted by Dr. W. A. Cunnington, F. Z. S., 1904-1905. Report on the Ostracoda. Proceedings of the Zoological Society of London, 48:732-760.

Schaller, H. 1969. Revisão estratigráfica da bacia de Sergipe/Alagoas. Boletim Técnico da Petrobras, 12:21-86.

Schenk, C. J., R. J. Viger, And C. P. Anderson. 1999. Maps Showing Geology, Oil and Gas Fields, and Geologic Provinces of the South America Region. U.S. Geological Survey Open-File Report 97-470D, 12 p.

SchneIder, G. F. 1956. Materialy po Paleontologii. Novye semeystvai rody: Ostracoda. Trudy Vsesoyuznogo Neftyanogo Nauchno-Issledovatelskogo Geologo-Razvedochnogo Instituta (VNIGRI), Novaya Seriya, Paleontologiya, 12:87-144, 306-323.

Silva, D. M. 1978a. Ostracodes da Formação Santana (Cretáceo InferiorGrupo Araripe), Nordeste do Brasil-II-Nova espécie do gênero Cypridea. 30th Congresso Brasileiro de Geologia, Recife, Annals, 2:1023-1027.

Silva, D. M. 1978b. Ostracodes da Formação Santana (Cretáceo InferiorGrupo Araripe), Nordeste do Brasil-I-Novas espécies do gênero Bisulcocypris. 30th Congresso Brasileiro de Geologia, Recife, Annals, 2:1014 1022

SILVA, D. M. 1978c. Ostracodes da Formação Santana (Cretáceo InferiorGrupo Araripe), Nordeste do Brasil-III-Nova espécie do gênero Darwinula Brady and Robertson, 1885. 30th Congresso Brasileiro de Geologia, Recife, Annals, 2:1028-1031.

Silva-Telles JR., A. C. And M. S. S. Viana. 1990. Paleoecologia dos ostrácodes da Formação Santana (bacia do Araripe): um estudo ontogenético de populações. 1st Simpósio sobre a bacia do, Araripe e bacias interiores do Nordeste, Crato, Proceedings, p. 309-328.

Sмith, R. J. 1999. Possible fossil ostracod (Crustacea) egg from the Cretaceous of Brasil. Journal of Micropaleontology, 18:81-87.

SMITH, R. J. 2000. Morphology and ontogeny of Cretaceous ostracods with preserved appendages from Brazil. Palaeontology, 43:63-98.

Soares, E. F., P. V. Zalán, J. J. P. Figueiredo, and I. Trosdtorf JR. 2007. Bacia do Pará-Maranhão. Boletim de Geociências da Petrobras, 15:321329.

Swain, F. M. 1946. Middle Mesozoic nonmarine Ostracoda from Brazil and New Mexico. Journal of Paleontology, 20:543-555.

Sylvester-Bradley, P. C. 1947. The shell structure and evolution of the Mesozoic genus Cypridea. Quarterly Journal of Geological Society, 103:79 .

Tressler, W. L. 1937. Ostracoda. Internationale Revue der gesamten Hydrobiologie und Hydrographie, 34:188-207.

Tsao, L. P. 1959. Harbinia Tsao, 1959, p. 48-49. In M. A. Nechayeva, Z. Y. Liu, D. Y. Su, Z. X. Shou, K. Z. Tian, and L. P. Tsao (eds.), Ostracodes of Lower Chalk Deposit of Valley Sunlyao. Monographs of the Institute of Geology, Series B (Stratigraphy and Paleontology), Geology Press, Beijing. (In Chinese)

Viana, M. S. S., P. M. Brito, and A. C. Silva-Telles JR. 1989. Paleontologia de uma camada de folhelhos pirobetuminosos do Membro Romualdo, Formação Santana, na mina Pedra Branca, Município de Nova Olinda, Ceará. 11th Congresso Brasileiro de Paleontologia, Curitiba, Annals, 1 207-217.

Viviers, M. C., E. A. M. Koutsoukos, A. C. Silva-Telles JR., And P. Bengtson. 2000. Stratigraphy and biogeographic affinities of the late Aptian-Campanian ostracods of the Potiguar and Sergipe basins in northeastern Brazil. Cretaceous Research, 21:407-455.

Wicher, C. A. 1959. Ein betrag zur Altersdeutung des Recôncavo, Bahia (Brasilien). Mit einem Anhang von Beata Moos. Geologisches Jahrbuch, $77: 35-58$.

\section{ACCEPTED 10 JUNE 2012}


Anexo IV. Manuscrito intitulado Biostratigraphic and paleozoogeographic review of the uppermost AlagoasAlbian Ostracods of Riachuelo Formation, Sergipe-Alagoas basin, Northeastern Brazil, aceito com correções pela Revista Brasileira de Paleontologia. 


\section{Revista Brasileira de Paleontologia}

2 messages

João Carlos Coimbra <revista.paleontologia@gmail.com>

Mon, May 18, 2015 at 6:27 PM

To: Lucas Antonietto <antoniettols@gmail.com>, Dermeval Carmo <delei1998@gmail.com>, Rodrigo Rodrigues

Adorno <rodrigo.adorno@cprm.gov.br>,mcviviers@petrobras.com.br

Prezados(as) Autores(as)

Ref.: MS intitulado "BIOSTRATIGRAPHIC AND PALEOZOOGEOGRAPHIC REVIEW OF THE UPPERMOST ALAGOAS-ALBIAN OSTRACODS OF RIACHUELO FORMATION, SERGIPE-ALAGOAS BASIN, NORTHEASTERN BRAZIL".

Estou encaminhando os pareceres dos dois consultores ad hoc. O MS foi recomendado para publicação após serem consideradas correções/sugestões propostas pelos revisores.

TODAS as sugestões/correções efetuadas pelos dois ad hocs devem ser observadas. Cada sugestão/correção não acatada deverá ser justificada individualmente.

Nessa etapa do processo editorial solicito especial atenção às normas da Revista Brasileira de Paleontologia, incluindo a formatação correta das referências bibliográficas e a revisão dos DOls.

É necessário, também, incluir os endereços de e-mail de cada um dos autores (veja normas).

O prazo para devolução desse artigo devidamente corrigido é de no máximo 2 (dois) meses. O aceite do MS só será dado após o recebimento da nova versão (que deverá ser enviada pelo autor correspondente) e da sua aprovação pelos editores.

Por favor, confirme o recebimento dessa mensagem e seus quatro anexos.

Att.

JCCoimbra

Editor 


\section{BIOSTRATIGRAPHIC AND PALEOZOOGEOGRAPHIC REVIEW OF THE UPPERMOST ALAGOAS-ALBIAN OSTRACODS OF RIACHUELO FORMATION, SERGIPE-ALAGOAS BASIN, NORTHEASTERN BRAZIL}

\section{LUCAS SILVEIRA ANTONIETTO}

Laboratory of Micropaleontology, Institute of Geosciences, University of Brasilia, Darcy Ribeiro Campus, Brasilia, Distrito Federal, Brazil.CEP 70919-970.

\section{DERMEVAL APARECIDO DO CARMO}

Laboratory of Micropaleontology, Institute of Geosciences, University of Brasilia, Darcy Ribeiro Campus, Brasilia, Distrito Federal, Brazil.CEP 70919-970.

\section{MARTA CLAUDIA VIVIERS}

PETROBRAS-CENPES/DIVEX, Cidade Universitária, Quadra 7, Ilha do Fundão, Rio de Janeiro, Rio de Janeiro, Brazil. CEP: 21949-900.

RODRIGO RODRIGUES ADÔRNO Geological Survey from Brazil-DEGEO/DIPALE-CPRM/REPO, Avenida Lauro Sodré, 2561, Porto Velho, Rondônia, Brazil. CEP 76801-581.

Abstract

A biostratigraphic and paleozoogeographic review of uppermost alagoas-Albian ostracods of the Riachuelo Formation, in the Sergipe-Alagoas basin, Brazil, was conducted. The studied material comprised 336 samples from several outcrops, along with well cores drilled by Petróleo Brasileiro S.A. (PETROBRAS). After taxonomic review, a new biozonation scheme 
was obtained for the Albian of the Formation, and the paleozoogeografical affinities of the Brazil-Central West Africa province were reviewed through comparison with results published in the current literature. Several changes were made to the previously established ostracod zones: the names of the subzones Pattersoncypris ex. gr. angulata, OSE-1.1, 'Patellacythere' sp. GA E 27, OSE-1.3, and Veenia guianensis, OSE-1.4, from the Aracajuia benderi Zone, OSE-1, were changed to Harbinia sinuata, Bythoceratina amsittenensis and Reticulocosta edrianae, respectively. The uppermost Albian Aracajuia antiqua Latest Occurrence Interval Zone, OSE-5, is proposed for the first time, following the reclassification of individuals of the Subzone Aracajuia benderi, OSE-1.6, from this species to Aracajuia antiqua. Paleozoogeographic analyses showed some faunal interchange with Tethyan provinces, beginning in the early Albian, at both specific and generic levels. Limited northward marine influxes across the Walvis ridge were also observed during this age, while larger scale southward migrations occurred in the early Cenomanian. The presence of Brachycytherinae species in the Brazil-Central West Africa province as early as the Aptian indicates a new zoogeographic origin for this subfamily, while explaining the occurrence of the group in both the Austral realm and part of the Tethyan realm during the Albian.

Keywords: Early Cretaceous, South Proto-Atlantic ocean, marine ostracods, Zone OSE-5, province interchange.

Palavras chave: Eocretáceo, proto-oceano Atlântico Sul, ostracodes marinhos, Zona OSE-5, intercâmbio entre províncias.

\section{INTRODUCTION}

The present work is a biostratigraphic and paleozoogeographic review of the uppermost 
alagoas-Albian ostracods of the Riachuelo Formation, in the Sergipe-Alagoas basin, northeastern Brazil. Its main objectives are to upgrade the biostratigraphic framework based on ostracods for the Albian of the basin and to re-evaluate the correlations between the ostracod biozones and those based on planktonic and benthic foraminifera and cephalopods. At the same time, we also seek to determine the relationships between the Brazil-Central West Africa ostracod province proposed by Tambareau (1982) with its counterparts worldwide, through comparison with previous works addressing the same issue.

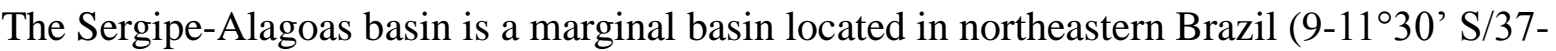
$\left.35^{\circ} 30^{\prime} \mathrm{W}\right)$. Its onshore portion is between 16 and $50 \mathrm{~km}$ long and $170 \mathrm{~km}$ wide, covering a total area of approximately $11000 \mathrm{~km}^{2}$ (Feijó, 1994), bounded by the Pernambuco-Paraíba to the northeast (Maragogi high) and the Jacuípe basin to the southwest (Itapuã fault) (Fig. 1). It has been the subject of several studies, mainly due to the amount of data acquired from efforts such as well and outcrop sampling, investigations of seismic lines and gravimetric and magnetic surveys. Most of these studies have focused on the oil- and gas-producing strata of the basin, i.e., its basement (Proterozoic), the Carmópolis oil field (Late Jurassic-Aptian) and the Calumbi Formation (Santonian-Cenozoic) (Marques, 1965; Souza-Lima et al., 2002; Campos Neto et al., 2007; Graddi et al., 2007).

Since the first studies on ostracods from the Sergipe-Alagoas basin conducted in the 1960s (Krömmelbein, 1962, 1964), the Riachuelo Formation has been at the heart of important discoveries. Viviers et al. (2000) established the first ostracod-based biostratigraphy of the basin (Fig. 2), integrating it with previous cephalopod and foraminifer data (Koutsoukos \& Bengtson, 1993) and, in this process, identifying several new species in the aforementioned formation. Do Carmo et al. (2008, 2012), Poropat \& Colin (2012), Do Carmo et al. (2013) and Antonietto et al. (2013) presented subsequent taxonomic updates of some of these species. 


\section{STUDY AREA}

The Sergipe-Alagoas basin was originally described by Schaller (1969) as a single basin. However, a later stratigraphic review by Feijó (1994) considered it to be two separate basins, the Sergipe basin and the Alagoas basin, separated by the Japoatã-Penedo high. Campos Neto et al. (2007) recently dismissed the Japoatã-Penedo high as a divisor between them, as it is not observable throughout the entire basin. It is noteworthy that the sedimentary deposits and tectonic style in the basin vary in the states of Sergipe and Alagoas, and they are therefore still considered to be separate sub-basins.

The basin consists of 23 formations, which are correlatable to the evolutionary stages of the formation and the expansion of the South Atlantic ocean: syneclise, pre-rift, rift, gulf and drift (Ponte \& Asmus, 1976; Feijó, 1994). In the beginning of the drift phase, initially restricted marine deposits evolved into open sea environments. The early Albian-late Cenomanian Riachuelo Formation was established during this phase, due to a transgression that allowed the sedimentation of openly marine sediments. There are three members of this formation: at the basin margins and grabens, deltaic fans were formed, and the coarse sediments they carried constitute the Angico Member. In lower sedimentation areas, the Maruim Member dominates, with carbonate ramps and dolomitized oolite/oncolite banks deposited under fluctuating sea level conditions. The Taquari Member, on the other hand, corresponds to calcareous mudstones and shale from lagoonal and slope environments. Two third-order sequences are observed in the formation, which are characterized by a highly organic clay basal interval and retrogradational stacking and are interpreted as transgressive systems. A third sequence, with predominantly calcareous deposits and a progradational pattern, is interpreted as a highstand system (Campos Neto et al., 2007).

\section{Regional settings}


The material studied in the present work comprised 147 samples collected from outcrops of the Riachuelo Formation, in the State of Sergipe, Brazil, during this period, plus 189 samples from cores drilled by Petróleo Brasileiro S.A. (PETROBRAS) (Figs. 1, 3), totaling 336 samples (Tab. 1). The UTM quadrant reference for coordinates is $24 \mathrm{~L}$, in the SAD69 default system. The majority of the outcrops (ESTRE, Fazenda Santa Bárbara, Porto dos Barcos 3, Penha, São José 1 and P384) is composed of alternate strata of the Taquari and Angico members. The Maruim Member is only present in the upper part of the Massapê outcrop. No lithology or GPS coordinates were provided by PETROBRAS for wells 1-CPB-1, 7-CP-252 and 1-US-1; however these wells were previously illustrated in maps by Viviers et al. (2000). Point ESTRE (713561 N, 8816808 E) in the Municipality of Rosário do Catete begins with marly mudstones that are rich in phytofossils, followed by interbedded carbonate/clay levels. Bioturbed creamy shales with abundant impregnations and fossil-rich siliceous concretions on the top make up the next strata. Immediately above it lie creamy-to-gray carbonate mudstones that are abundant in phytofossils, especially from angiosperms (Magnoliopsida?). In the same municipality, the Fazenda Santa Bárbara outcrop occurs (716635 N, 8821887 E), which is considered to be the type section of the Taquari Member of the Riachuelo Formation (Schaller, 1969). The analyzed section comprises reddish calciferous mudstones, with a fossil record consisting of gastropod shells (Family Turritellidae Loven, 1847) as well as possible brachiopods.

The Porto dos Barcos 3 location is situated in the municipality of Riachuelo (699059 N, 8814030 E). From the base to the top, this slightly saprolitic sequence shows levels of creamy calcareous siltstone, followed by alternating creamy and gray calciferous siltstones. Next, there is a layer of gray-to-yellowish mudstones that become very fossiliferous near the top. Over this mudstone, creamy calciferous siltstones are observed, and the outcrop ends with creamy micaceous mudstones. The fossil record of the outcrop includes echinoderm spines, 
gastropods and bivalves. Point Penha (692 726 N, 8812604 W), also located in Riachuelo, presents a sequence of yellow, calcareous fine sandstones with levels of brachiopod-coquina and sparse phytofossils at its base. This sequence is followed by gray calciferous shales, laminated calcareous siltstones and laminated fine sandstones. Abundant occurrences of bivalves and equinoides are also recorded in these strata.

In the same municipality, the São José 1 outcrop (693824 N, 8811279 W) presents the most complex lithology among the sampled sites. Basal siltstones with calcareous impregnations are superposed with yellow silty fine sandstones and calciferous yellow siltstones with limestone levels. After a non-observable interval, massive yellow sandstones are recorded, followed by limestones with abundant bivalves, cephalopods and bioturbations. Towards the top, marl levels with varying amounts of limestone occur, and above it, there are very fossiliferous solid limestones, immediately under a non-rhythmic intercalation of creamy laminated siltstone marls and mudstones, rich in turritelid fossils. The section ends with the deposition of creamy-to-yellowish, medium-to-thinly laminated calcareous sandstones, with many phytofossils.

Locality P384 (695625 N, 8814175 E), also in Riachuelo, comprises, from the base to the top, creamy calciferous laminated mudstones with bioturbation levels, rich in brachiopods, bivalves and phytoclasts; interbedded yellowish calciferous siltstones and creamy sandstones; and creamy calciferous laminated mudstones. The whole section is abundant in turritelid snails. Point Massapê (700764 N, 881233 L), located at the homonymous village in Riachuelo, is the only section addressed in the present work identified as part of the Maruim Member. The lithology of this extensive outcrop begins with yellow-creamy laminated calciferous and micaceous siltstones. Over these siltstones, fine-to-very fine yellowish calciferous/micaceous sandstones occur. These are followed by (in this order) intercalations of yellow-to-creamy siltstones and mudstones; gray greywacke with dark impregnations; and, finally, interposed 
levels of oolitic calcarenites and yellow sandstones with smoky quartz grains, sparse ooids and bioturbations.

\section{MATERIALS AND METHODS}

One-hundred and forty-two samples collected during fieldwork were tipped, prepared and packaged according to the methodology developed by the Laboratory of Micropaleontology of the University of Brasilia (LabMicro-UNB), Brazil. Sixty grams of each sample was prepared, and the remainder was packed in double plastic bags with catalogue-record sheets. This material is stored in a specific cabinet for prepared samples in the same laboratory. The sample contents separated for preparation were treated at the Laboratory of Micropaleontology as follows: first, they were treated with a solution containing $30 \%$ hydrogen peroxide $\left(\mathrm{H}_{2} \mathrm{O}_{2}\right)$, with the aim of fragmenting rock particles. Ethanol at $92 \mathrm{GL}$ was added to interrupt this reaction, after which separation of grains by size was performed, using mesh sieves of 630, 250, 160 and $80 \mu \mathrm{m}$. For samples MP-1430 to MP-1434, MP-1493, MP1494 and MP-1678, the $80 \mu \mathrm{m}$ sieve was replaced by a $90 \mu \mathrm{m}-56 \mu \mathrm{m}$ dual set.

The carapaces and valves of several species were studied at LabMicro-UnB and the Smithsonian National Museum of Natural History (NMNH), Washington D.C., United States. The analysis of the additional 189 previously processed samples from PETROBRAS was conducted at the “Centro de Pesquisas Leopoldo Américo Miguez de Mello” (CENPES). After taxonomic review of the ostracods present in the samples (see Antonietto et al., in prep.), a new biozonation scheme for the Albian of the Sergipe Alagoas basin was obtained. These ostracods were also used to review the paleozoogeografical affinities of the Sergipe-Alagoas basin with other basins during the Albian-early Cenomanian through comparison with previous results from the current literature on this topic. 


\section{RESULTS AND DISCUSSION}

The revision of the ostracod biostratigraphy of the Riachuelo Formation's Albian strata, as well as its taxonomy (Antonietto et al., in prep.), demonstrates the necessity of the present changes in range and nomenclature of the zones and subzones established by Viviers et al. (2000). New information to the Albian ostracodes zones was added, in order to improve application and resolution of the units. A new interval zone was also formalized in the uppermost Albian of the Riachuelo Formation, according to procedures detailed in Murphy \& Salvador (1999) This zone received a code name in the same model as the others established by Viviers et al. (2000) in the Sergipe-Alagoas basin - “O”, for ostracod, and “SE”, for Sergipe, followed by an hyfen and a number. A paleozoogeographic review is also performed in this work, expanding on the correlations with paleozoogeographic provinces in the northern and southern regions along the Proto-Atlantic ocean. Both reviews are presented in the sections below.

\section{Ostracod biostratigraphy}

According to Viviers et al. (2000), The Albian Stage in the Sergipe-Alagoas basin originally comprised one zone, Amphycytherura benderi, or OSE-1, later renamed Aracajuia benderi by Antonietto et al. (2013). This zone was subdivided into six subzones from bottom to top: Pattersoncypris ex. gr. angulate, OSE-1.1; Sergipella transatlantica, OSE-1.2, renamed as Sergipella viviersae Do Carmo et al., 2012 by Do Carmo et al. (2012); 'Patellacythere’ sp. GA E 27, OSE-1.3; Veenia guianensis Swain, 1976, OSE-1.4; Metacytheropteron aff. M. sp. GA C 24, OSE-1.5; and Amphycytherura benderi, OSE-1.6 - also Aracajuia benderi, after Antonietto et al. (2013). Between subzones OSE-1.3 and OSE-1.4, there was an interval where no zonation based on ostracods could be established, although a transition is observable in the planktonic (ending of Zone Ticinella bejaouensis, Subzone Ticinella bejaouensis) and 
benthic (ending of Zone Epistomina carpenteri, Subzone Osangularia schloenbachiPseudogaudryinella/ Spiroplectinata ex gr. dividens) foraminiferal faunas as well as between cephalopods (ending of Zone Douvilleiceras) (Fig. 2). After the present review of the Albian stratigraphy of the basin, several changes were made in previously established ostracod zones and subzones (Figs. 4, 5).

Aracajuia benderi Range Zone, coded as OSE-1

Definition. Stratigraphic interval corresponding to the local range of Aracajuia benderi Krömmelbein, 1967.

Characterization. From the base to the top, the following subzones are recognized: the Harbinia sinuata (Krömmelbein \& Weber, 1971), Sergipella viviersae, Bythoceratina amsittenensis Andreu-Boussut, 1991, Reticulocosta edrianae Antonietto et al. (in prep.) and Metacytheropteron aff. M. sp. GA C 24.

Stage. Uppermost Alagoas Stage-middle to upper Albian.

Stratotype. 1-US-1 well, City of Laranjeiras, Sergipe State, Brazil.

Observations. See Viviers et al. (2000) for a detailed discussion on the Zone OSE-1. The present work formalizes the taxonomic changes made to OSE-1 by Antonietto et al. (2013). A stratotype is also proposed for the zone for the first time.

Harbinia sinuata Latest Occurrence Interval Subzone, coded as OSE-1.1

Definition. Interval between the local first occurrence of Aracajuia benderi at the base, and the local last occurrence of Harbinia sinuata at the top.

Characterization. Interval containing a characteristic association of Harbinia sinuata, Aracajuia benderi, Sergipella viviersae and Gabonorygma sergipana Antonietto et al. (in prep.). 
Stratotype. 1-CPB-1 well, City of Carmópolis, Sergipe State, Brazil.

Stage. Uppermost Alagoas Stage.

Observations. See Viviers et al. (2000) for a detailed discussion on the Subzone OSE-1.1. This subzone was named and established using Pattersoncypris ex. gr. angulata (Krömmelbein \& Weber, 1971) as its fossil guide. However, Harbinia sinuata (Krömmelbein \& Weber, 1971) is more abundant in the studied samples (including the reviewed well material), which justifies its preference as a marker for the interval. A stratotype is also proposed for the subzone for the first time. Additionally, several species from Viviers et al. (2000), such as Ovocytheridea? aff. Ovocytheridea? sp. GA D 6, Pattersoncypris ex. gr. angulata, Conchoecia? sp. Se1 were not observed in the present review.

Sergipella viviersae Latest Occurrence Interval Subzone, coded as OSE-1.2

Definition. Lower and upper boundaries of the subzone defined by the last occurrences of Harbinia sinuata and Sergipella viviersae, respectively.

Characterization. Other species observed in this zone include Cytherella besrinensis (Bischoff, 1964) Cytherelloidea btaterensis Bischoff, 1964, Bairdoppilata pseudoseptentrionalis Mertens, 1956, Cetacella sp. 1, Paracypris eniotmetos Nicolaidis \& Piovesan, 2013, Harbinia symmetrica? (Krömmelbein \& Weber, 1971), Liasina sp. 1, Bythoceratina amsittenensis, Bythoceratina deltalata Antonietto et al. (in prep.), Bythoceratina reducta (Gründel, 1964), Patellacythere shimonensis (Rosenfeld \& Raab, 1983), Xestoleberis? sp. 1, Xestoleberis? sp. 2, Gabonorygma sergipana, Aracajuia antiqua (Rosenfeld \& Raab, 1983), Aracajuia benderi, Eocytheropteron sp. 1, Metacytheropteron aff. M. sp. GA C 24, Metacytheropteron minuta? (Swain, 1976) and Sergipella viviersae. Stratotype. São José 1 outcrop (693824 N, 8811279 W, 24L UTM quadrant reference, SAD69 default system), City of Riachuelo, Sergipe State, Brazil. 
Stage. Lowermost Albian.

Observations. See Viviers et al. (2000) for a detailed discussion on the Subzone OSE-1.2. The present work formalizes the taxonomic changes made to OSE-1.2 by Do Carmo et al. A stratotype is proposed for the subzone for the first time. (2012), while also designating a stratotype for this subzone. Conchoecia? sp. Se1 was not observed in the present review.

Bythoceratina amsittenensis Latest Occurrence Interval Subzone, coded as OSE-1.3

Definition. Interval between the last occurrences of Sergipella viviersae (bottom) and Bythoceratina amsittenensis (top).

Characterization. The ostracod assemblage of the subzone also comprises Cytherella besrinensis, Cytherelloidea btaterensis, Bairdoppilata pseudoseptentrionalis, Robsoniella falklandensis Dingle, 1984, Paracypris eniotmetos, Bythoceratina amsittenensis, Patellacythere parva? Weaver, 1982, Xestoleberis? sp. 2, Gabonorygma sergipana, Aracajuia benderi, Microceratina azazoulensis Andreu \& Colin, 2005, Microceratina? sp. 2 and Reticulocosta edrianae. Among species from Viviers et al. (2000) not observed in the Zone OSE-1.3 in the present review are Cytherella sp. Se4, Liasina sp. 1, Protoveenia guianensis (Swain, 1976), Sergipella aff. transatlantica Krömmelbein, 1967, Cetacella aff. C. sp. GA D 24 and Metacytheropteron aff. M. sp. GA C 24 occurs within the subzone.

Stratotype. Porto dos Barcos 3 outcrop (699059 N, 8814030 E, 24L UTM quadrant reference, SAD69 default system), City of Riachuelo, Sergipe State, Brazil.

Stage. Lower Albian.

Observations. The species which originally named this subzone, 'Patellacythere' sp. GA E 27, was found to actually belong to a group of species in the Family Bythocytheridae Sars, 1926 (Antonietto et al., in prep.). The figured specimen in Viviers et al. (2000) was reclassified as Patellacythere shimonensis, a species restricted to OSE-1.2, and most of the 
material assigned to this species in fact belonged to another taxon, Bythoceratina amsittenensis. This was particularly true for specimens occurring after the end of OSE-1.2. Therefore, Bythoceratina amsittenensis is considered to be the true OSE-1.3 marker. See Viviers et al. (2000) for more details in the discussion on this subzone.

Reticulocosta edrianae Latest Occurrence Interval Subzone, coded as OSE-1.4

Definition. Stratigraphic interval corresponding to the range between the latest occurrence of Bythoceratina amsittenensis at bottom and Reticulocosta edrianae at top.

Characterization. This subzone fauna also includes Cytherella besrinensis, Cytherelloidea btaterensis, Bairdoppilata pseudoseptentrionalis, Paracypris eniotmetos, Harbinia symmetrica?, Bythoceratina amsittenensis, Xestoleberis? sp. 2, Apatocythere? sp. 1, Gabonorygma sergipana, Neocythere tenuis (Kaye, 1965), Aracajuia benderi, Aracajuia fragilis (Piovesan \& Nicolaidis, 2013), Algeriana? sp. 1, Quasihermanites? sp. 1 and Reticulocosta edrianae.

Stratotype. Porto dos Barcos 3 outcrop (699059 N, 8814030 E, 24L UTM quadrant reference, SAD69 default system), City of Riachuelo, Sergipe State, Brazil.

Stage. Middle Albian.

Observations. The individuals identified as Veenia guianensis, the fossil guide for OSE-1.4, belong to Reticulocosta edrianae Antonietto et al. (in prep.), leading to the renaming of this subzone. Nevertheless, Veenia guianensis, now Protoveenia guianensis was also found in the present material, though not associated with Reticulocosta edrianae. Between subzones OSE1.3 and OSE-1.4, Viviers et al. (2000) observed an absence of any clear biozone marking species, and the interval between these subzones was left open for biozonation. The present work established the contact between the two zones, although it was not possible to determine when in time it occurred. Therefore, the authors chose to maintain along the top limits of 
OSE-1.3, Ticinella bejaouaensis Zone (Al2) of planktonic foraminifera and Douvilleiceras Zone of ammonites. Ovocytheridea? sp. Se1 from Viviers et al. (2000) was not observed in the present review.

Metacytheropteron aff. M. sp. GA C 24 Interval Subzone, coded as OSE-1.5

Definition. Subzone defined as the interval between the last occurrences of Reticulocosta edrianae and Metacytheropteron aff. M. sp. GA C 24.

Characterization. Metacytheropteron aff. M. sp. GA C 24 is associated with Conchoecia? sp. 1, Eucytherura sp. Se1, Metacytheropteron minuta?, Cetacella sp. 1, Paracypris eniotmetos, Gabonorygma sergipana and Aracajuia benderi.

Stratotype. 1-US-1 well, City of Laranjeiras, Sergipe State, Brazil.

Stage. Lowermost upper Albian.

Observations. See Viviers et al. (2000) for a detailed discussion on the Subzone OSE-1.5. A stratotype is proposed for the subzone for the first time.

Aracajuia antiqua Latest Occurrence Interval Zone, coded as OSE-5

Definition. Stratigraphic interval corresponding to the range between the latest occurrence of Aracajuia benderi and Metacytheropteron aff. M. sp. GA C 24 at bottom and Aracajuia antiqua at top.

Characterization. Other taxa present in this zone include Cytherella besrinensis, Cytherelloidea btaterensis, Bairdoppilata comanchensis (Alexander, 1929), Bairdoppilata sp. 1, Bairdoppilata sp. 2, Cetacella sp. 1, Paracypris eniotmetos, Xestoleberis? sp. 1, Gabonorygma sergipana, Neocythere pseudovanveeni (Gründel, 1966), Aracajuia benderi, Eocytheropteron? sp. 1, Microceratina azazoulensis, Protoveenia guianensis and Brachycythere smithsoniana Antonietto et al. (in prep.) 
Stratotype. Massapê outcrop (700764 N, 881233 L, 24L quadrant in the SAD69 system), in the city of Riachuelo, Sergipe State, Brazil.

Stage. uppermost Albian.

Observations. Individuals previously considered to be Aracajuia benderi in subzone OSE-1.6, at the top of Zone OSE-1 (Viviers et al., 2000), were reclassified as Aracajuia antiqua, creating an entirely new zone in the latest Albian of the Riachuelo Formation, the Aracajuia antiqua Latest Occurrence Interval Zone, after its guiding species, and coded as OSE-5. The OSE-5 Zone extends through the areas around the Massapê outcrop and the 1-US-1 well, between the cities of Riachuelo and Laranjeiras in Sergipe State. It is observable in the Massapê outcrop in all of the three members of the Riachuelo Formation, where it reaches 11m in thickness; in the 1-US-1 well, it goes almost 300 meters deep (Fig. 4). Although its lower limit is established based in two species, Aracajuia benderi and Metacytheropteron aff. $M$. sp. GA C 24, these two disappear from the fossil record within a slightly different interval between them.

\section{Paleozoogeography}

Original attempts to establish relationships based on the composition of taxa between the Albian ostracodofaunas of the Riachuelo Formation and coeval lithologic units from western Africa indicated great similarity between the latter units and the Madiéla Formation in the Gabon basin, Gabon (Krömmelbein, 1966, 1975; Krömmelbein \& Wenger, 1966; Bertels, 1977; Grosdidier, 1979; Koutsoukos \& Silva-Telles, Jr., 1993). Tambareau (1982) even suggested the existence of a "Central Brazil-West Africa” biological province. This correlation was later expanded by Koutsoukos \& Dias-Britto (1987) and Piovesan et al. (2013), who observed the co-occurrence of ostracod species and genera of the Riachuelo Formation in other Brazilian shore units, such as the northeastern-most Potiguar and the 
southeastern Campos and Santos basins.

Dias-Brito (2000), based on the occurrence of phytonellids (calcispheres), established the notion of the "Megatethys", or the "Mid Cretaceous Tethyan Realm”. According to this concept, the global distribution of pithonellids defined a realm occupying both hemispheres, approximately between latitudes $40^{\circ} \mathrm{N}$ and $40^{\circ} \mathrm{S}$, in the Albian-Turonian time interval. This Megatethys ocean reached its maximum extension in the late Albian, when warm water reached temperate regions and initially tropical organisms made brief incursions into highlatitude areas. The southern limit of this Tethyan arm was coincident with the Walvis Ridge, an effective low topographic barrier at that time.

The first evidence of faunal similarity between the Riachuelo Formation and strata outside of the central South Atlantic ocean was provided by Colin \& Andreu (1990), who were also working with halocypridid ostracods. These authors found the formations in eastern Brazil and western Africa to be strongly correlated with those from the North Atlantic ocean, from areas such as the Agadir basin in Morocco (Andreu-Boussut, 1991), the Jura Mountains in Switzerland (Charollais et al., 1977), southern England (Kaye, 1965), the Persian Gulf and Israel (Rosenfeld \& Raab, 1983). This observation was partly confirmed by Piovesan et al. (2013), following a review by Andreu (2002), who identified some genera distributed along the Brazilian coast (including the Sergipe-Alagoas basin) and lithologic units in Morocco. Reyment (1980) and Dingle (1999) studied the role of the proto-Walvis ridge as a geographical barrier between the central and southernmost Atlantic ostracodofaunas during the Berriasian-Santonian. After a taxonomic review of several Cretaceous stages of the Sergipe-Alagoas basin, Viviers et al. (2000) summarized the relationships of the Riachuelo Formation with strata in several Early-Late Cretaceous realms along the Proto-Atlantic ocean. These correlations were made based in part on the chronologic and geographic distribution of the ostracod genera Conchoecia Dana, 1849, Amphicytherura Butler \& Jones, 1957 and 
Veenia Butler \& Jones, 1957. A significant faunal renewal was recorded approximately in the middle Cenomanian, with the first appearance in the basin of genera such as Brachycythere Alexander, 1933 and Paracypris Sars, 1866.

Present results corroborate previous assumptions herein summarized about the paleozoogeography of the Riachuelo Formation ostracods, both at specific and generic levels. Although the majority of the species identified are endemic to this province, some interchange is observed with Tethyan faunas beginning in the early Albian (Fig. 6). Species such as Protoveenia guianensis and Bairdoppilata comanchensis are shared with North-Central American shores (Protoveenia guianensis is also found in Africa), while Conchoecia? sp. 1, Cytherella besrinensis, Cytherelloidea btaterensis, Bythoceratina amsittenensis, Patellacythere shimonensis and Aracajuia antiqua appear in both Brazil-Central West Africa and the Levantine region in the Middle East (Israel and Lebanon). Bairdoppilata pseudoseptentrionalis, Bythoceratina reducta, Neocythere pseudovanveeni and Neocythere tenuis co-occur in the Riachuelo Formation and some of the southern-to-western European basins in England, France and Germany. Two species shared with realms south of the Walvis ridge, Microceratina azazoulensis and Robsoniella falklandensis, probably originated in Brazil-Central West Africa, where they surged in the middle Albian. These species reached the former regions during the Cenomanian.

The exchange of genera between the provinces appears to follow the same pattern observed at the specific level. Genera such as Cytherella Jones, 1849, Cytherelloidea Alexander, 1929, Bairdoppilata Coryell et al., 1935, Paracypris, Bythoceratina Hornibrook, 1952 and Patellacythere Gründel \& Kozur, 1971 are both geographically and chronologically cosmopolitan. However, some other species present a more limited distribution, at least during the Early Cretaceous, and seem to indicate, through their origins, greater paleozoogeographical proximity with the Tethysyan realm, such as Gabonorygma Antonietto 
et al. (in prep.) (Christensen, 1965), Neocythere Mertens, 1956, Protoveenia (Damotte, 1961) (Swain, 1976), Reticulocosta Gründel, 1974, Robsoniella Kuznetsova, 1956 (Gramm \& Kuznetsova, 1970) and Microceratina Swanson, 1980 (Colin et al., 2005). Sergipella Krömmelbein, 1967 is the only endemic genus of the region, according to the occurrences summarized in Do Carmo et al. (2012).

The genus Aracajuia Krömmelbein, 1967 originated in the Austral province during the Berriasian, prior to becoming very common in this realm during the Hauterivian. However, this genus showed its peak diversity and abundance at the end of the Early Cretaceous (Barremian-Albian), along the shores of Brazil-Central West Africa and the South Mediterranean, extending to the Middle East (Antonietto et al., 2013). According to Dingle (1999), limited northward marine influxes across the Walvis ridge are postulated for the middle Aptian age, while large-scale southward migrations of marine ostracods from the northern sector occurred in early Cenomanian and/or Turonian times. This observation is confirmed by the occurrences of Aracajuia in the early-late Albian of the Sergipe Alagoas basin.

Brachycythere appeared to have originated during the Albian, somewhere close to the limits of the North American and African regions of the Tethysian realm (Colin \& Babinot, 1996; Puckett, 2002), although occurrences in India (Austral realm) have also been reported for the same age (Andreu et al., 2008). The presence of Brachycythere smithsoniana in the BrazilCentral West African province dates from the late Aptian (Grosdidier, 1979), much earlier than the previous earliest record for the Brazil-Central West Africa province, of Brachycythere sapucariensis Krömmelbein, 1964 from the Cenomanian (Viviers et al., 2000). Therefore, it relocates the geographic origin of the Subfamily Brachycytherinae Puri, 1954 southwards, as it helps to explain the occurrences of the group in both the Austral realm and part of the Tethyan realm during the Albian. 


\section{CONCLUSION}

The present review of the ostracod biostratigraphy and paleozoogeography of the uppermost Alagoas and Albian stages of the Riachuelo Formation resulted in changes in previously established zones and subzones. It also allowed a major expansion of the correlations with paleozoogeographic provinces along the Proto-Atlantic ocean. Subzones that are currently being changed include OSE-1.1, now defined by Harbinia sinuata; OSE-1.3, henceforth marked by Bythoceratina amsittenensis; OSE-1.4, whose guide species was reclassified as Reticulocosta edrianae, and its earlier limit was redefined as the end of OSE-1.3; and OSE-5, a new zone created in detriment to OSE-1.6 and based on Aracajuia antiqua.

Although the majority of the species from the basin are endemic to this bioprovince, some interchange is observed with Tethyan faunas, beginning in the early Albian, ranging from North-Central American shores to the Levantine region in the Middle East. Species shared with realms south of the Walvis ridge probably originated in Brazil-Central West Africa in the middle Albian and reached the former regions during the Cenomanian. The exchange of genera between the provinces appears to follow the same pattern observed at the specific level, except for the genus Aracajuia, which emigrated from the southernmost Proto-Atlantic during the Barremian, reaching the central Proto-Atlantic at the end of the Early Cretaceous. Sergipella is the only endemic genus of the region. The presence of Brachycytherine ostracods in Brazil-Central West Africa as early as the late Aptian relocates the geographic origin of this subfamily southwards, while also helping to explain the ocurrences of the group in both the Austral realm and part of the Tethyan realm during the Albian.

\section{ACKNOWLEDGEMENTS}

The authors wish to thank CNPq, associated with the "Serviço de Compras Internacionais" of 
the University of Brasilia, for the acquisition of our scanning electron microscope (SEM). We are also grateful to the University of Brasilia (UnB) for financial support the visit to PETROBRAS, and CENPES for technical support with core sample slides (J.V. Queiroz Neto and J.L.Grillo) and SEM photography (R.S.M. da Costa) during this visit. Many thanks go to the “Agência Nacional do Petróleo, Gás Natural e Biocombustíveis” (ANP), PETROBRAS and the "Fundação de Empreendimentos Científicos e Tecnológicos” (FINATEC) for financial support to field work in the Sergipe-Alagoas basin, through the OSTRAKi project. L.S. Antonietto wishes to thank the “Coordenação de Aperfeiçoamento de Pessoal de Nível Superior" (CAPES) for granting support through the "Programa de Doutorado Sandwich no Exterior" (PDSE), which allowed the realization of most of the work in the Smithsonian NMNH from July 2013 to July 2014, and the board of the Institute of Geosciences, University of Brasilia, for all of their cooperation throughout the process. He is also very grateful to FINATEC for financial support provided to the same student to attend the $4^{\text {th }}$ International Palaeontological Congress held in Mendoza, Argentina. Last, but not least, he thanks the NMNH Paleobiology Department staff members, Dr. G. Hunt and C.E. Sanford, for all of their help (and great, joyful moments) during his stay at Washington, D.C., United States.

\section{REFERENCES}

Andreu, B. 2002. Cretaceous ostracode biochronology of Morocco. Eclogae Geologicae Helvetiae, 95:133-152. doi:10.5169/seals-168951

Andreu, B.; Colin, J.P. \& Singh, J. 2008. Cretaceous (Albian to Coniacian) Ostracodes from the subsurface of the Jaisalmer basin, Rajasthan, India. Micropaleontology, 53:345-370. doi: 10.2113/gsmicropal.53.5.345

Andreu-Boussut, B. 1991. Les ostracodes du Crétacé moyen (Barrémien à Turonien), le long d'une transversale Agadir-Nador (Maroc). Strata, 2:1-765. 
Antonietto, L.S.; Abrahão, A.; Do Carmo, D.A. \& Meireles, R.P. 2013. Taxonomy, biostratigraphy and paleozoogeography of Amphicytherura Butler and Jones, Aracajuia Krömmelbein and Dinglecythere Antonietto et al., n. gen. (Crustacea, Ostracoda). Marine Micropaleontology, 105:1-17. doi:10.1016/j.marmicro.2013.09.002

Bertels, A. 1977. Cretaceous Ostracoda - South Atlantic. In: F.M. Swain (ed.) Developments in Palaeontology and Stratigraphy, 6 - Stratigraphic micropaleontology of Atlantic basin and borderlands, Amsterdam, Elsevier, p. 271-304.

Campos Neto, O.P.A.; Souza-Lima, W. \& Cruz, F.E.G. 2007. Bacia de Sergipe-Alagoas. Boletim de Geociências da PETROBRAS, 15:405-415.

Charollais. J., Moullade, M., Oertli, H.J. \& Rapin, F. 1977. Découverte de microfaunes de l’albien moyen et supérieur dans la Vallée de Joux (Jura vaudois, Suisse). Géobios, 10:683695. doi:10.1016/S0016-6995(77)80047-8

Christensen, O.B. 1965. The Ostracod Genus Dicrorygma Poag 1962 from Upper Jurassic and Lower Cretaceous. Danmarks Geologiske Undersøgelse - II Rjekke, 90:3-23.

Colin, J.P. \& Andreu, B.1990. Cretaceous Halocypridid Ostracoda. In: R. Whatley \& C. Maybury (eds.) Ostracoda and Global Events, London, Chapman \& Hall, p. 515-526. Colin, J.P. \& Babinot, J.F. 1996. Preliminary account of ostracodes from the Aptian-Albian of Venezuela: palaeobiogeographic implications. In: M.C. Keen (ed.) Proceedings of the 2nd European Ostracodologists Meeting, London, British Micropalaeontological Society, p. 29-34. Colin, J.P.; Andreu, B.; Dejax, J. \& Gèze, R. 2005. Sur l’origine du genre Microceratina Swanson, 1980 (Ostracoda, Eucytherurinae) et sa présence téthysienne dès le Jurassique supérieur. Revue de Micropaléontologie, 48:15-24. doi:10.1016/j.revmic.2004.12.005 Dias-Brito, D. 2000. Global stratigraphy, palaeobiogeography and palaeoecology of AlbianMaastrichtian pithonellid calcispheres: impact on Tethys configuration. Cretaceous Research, 21:315-349. doi:10.1006/cres.2000.0196 
Dingle, R.V. 1999. Walvis Ridge barrier: its influence on palaeoenvironments and source rock generation deduced from ostracod distributions in the early South Atlantic ocean. In: N.R. Cameron, R.H. Bate \& V.S. Clure (eds.) Special Publication, 153 - The Oil and Gas Habitats of the South Atlantic, London, Geological Society of London, p. 293-302.

Do Carmo, D.A.; Coimbra, J.C.; Whatley, R.C.; Antonietto, L.S. \& Citon, R.T.P. 2013. Taxonomy of limnic Ostracoda (Crustacea) from the Alagamar Formation, middle-upper Aptian, Potiguar basin, Northeastern Brazil. Journal of Paleontology, 87:91-104. doi:10.1666/11-108R.1

Do Carmo, D.A.; Colin, J.P.; Hidalgo, P.H.P.; Meireles, R.P.; Berbert-Born, M.L.C. \& Almeida, C.M. 2012. Reassessment of the genus Sergipella Krömmelbein, 1967 (Ostracoda, Trachyleberididae), uppermost Aptian-Albian of Brazil and West Africa: Taxonomy and paleogeographic distribution. Revue de Micropaléontologie, 55:3-15.

doi:10.1016/j.revmic.2011.12.002

Do Carmo, D.A.; Whatley, R.; Queiroz Neto, J.V. \& Coimbra, J.C. 2008. On the validity of two Lower Cretaceous non-marine ostracode genera: biostratigraphic and paleogeographic implications. Journal of Paleontology, 82:790-799. doi:10.1666/07-008.1

Feijó, F.J. 1994. Bacias de Sergipe e Alagoas. Boletim de Geociencias da PETROBRÁS, 8:149-161.

Graddi, J.C.S.V.; Campos Neto, O.P.A. \& Caixeta, J.M. 2007. Bacia de Jacuípe. Boletim de Geociências da PETROBRAS, 15:417-421.

Gramm, M.N. \& Kuznetsova, Z.V. 1970. Sistematicheskoye polozheniye roda Robsoniella (Ostracoda). Paleontologicheskii Zhurnal, 3:89-94.

Grosdidier, E. 1979. Principaux ostracodes marins de l'intervalle Aptien-Turonien du Gabon (Afrique Occidentale). Bulletin des Centres de Recherche Exploration-Production du Pétrole, 3:1-33. 
Kaye, P. 1965. Some new british Albian Ostracoda. Bulletin of the British Museum (Natural History) - Geology, 11:215-253.

Koutsoukos, E.A.M. \& Bengtson, P. 1993. Towards an integrated biostratigraphy of the upper Aptian-Maastrichtian of the Sergipe basin, Brazil. Documents des Laboratoires de Géologie de Lyon, 125:241-262.

Koutsoukos, E.A.M. \& Dias-Brito, D. 1987. Paleobatimetria da margem continental do Brasil durante o Albiano. Revista Brasileira de Geociências, 17:86-91. doi:10.5327/z0375-7536 Koutsoukos, E.A.M. \& Silva-Telles Jr., A.C. 1993. Stratigraphic and palaeoenvironmental distributions of mid-Cretaceous Ostracoda from the Sergipe basin, NE Brazil, and their biogeographic affinities with NW Africa. In: K.G. McKenzie \& P.J. Jones (eds.) Ostracoda in the Earth and Life Sciences, Rotterdam, Balkema, p. 664.

Krömmelbein, K. \& Wenger. R. 1966. Sur quelques analogies remarquables dans les microfaunes Crétacées du Gabon et du Brésil oriental (Bahia et Sergipe). In: D. Reyre (ed.) Bassins sédimentaires du littoral Africain. Symposium, 1ère partie: littoral Atlantique, Paris, Association des Services géologiques africains, p. 193-196.

Krömmelbein, K. 1962. Zur Taxonomie und Biochronologie stratigraphisch wichtiger Ostracoden-Arten aus der oberjurassich?-unterkretazischen Bahia-Serie (Wealden-Fazies) NE-Brasiliens. Senckenbergiana Lethae, 43:437-527.

Krömmelbein, K. 1964. Ostracoden aus der marinen “Küsten-Kreide” Brasiliens. 1: Brachycythere (Brachycythere) sapucariensis n. sp. Aus dem Turonium. Senckenbergiana Lethae, 45:489-495.

Krömmelbein, K. 1966. Preliminary remarks on some marine ostracodes from northeastern Brazil and West Africa. In: J.E. Hinte (ed.) Proceedings of the Second West African Micropaleontological Colloquium, Leiden, E.J. Brill, p. 119-123.

Krömmelbein, K. 1975. Remarks on marine Cretaceous ostracodes of Gondwanic distribution. 


\section{In: AFRICAN COLLOQUIUM ON MICROPALAEONTOLOGY, 5, 1972. Proceedings,}

Madrid, Enadimsa, p. 539-551.

Marques, R.C. 1965. Campo petrolífero de Carmópolis: histórico da descoberta - geologia do campo - perspectivas econômicas. Boletim Técnico da PETROBRÁS, 8:307-328.

Murphy, M.A. \& Salvador, A. 1999. International Stratigraphic Guide — An abridged version. Episodes, 22:255-271.

Piovesan, E.K.; Nicolaidis, D.D.; Fauth, G. \& Viviers, M.C. 2013. Ostracodes from the Aptian-Santonian of the Santos, Campos and Espírito Santo basins, Brazil. Journal of South American Earth Sciences, 48:240-254. doi:10.1016/j.jsames.2013.09.012

Ponte, F.C. \& Asmus, H.E. 1976. The Brazilian marginal basins: current state of knowledge. Anais da Academia Brasileira de Ciências - Suplemento, 48:215-289.

Poropat, S.F. \& Colin, J.P. 2012. Reassessment of the Early Cretaceous non-marine ostracod genera Hourcqia Krömmelbein, 1965 and Pattersoncypris Bate, 1972 with the description of a new genus, Kroemmelbeincypris. Journal of Paleontology, 86:700-720. doi:10.1666/11140R.1

Puckett, T.M. 2002. Systematics and paleobiogeography of brachycytherine Ostracoda. Micropaleontology, 48:1-87.

Reyment, R.A. 1980. Paleo-oceanology and paleobiogeography of the Cretaceous South Atlantic Ocean. Oceanologica Acta, 3:127-133.

Rosenfeld, A. \& Raab, M., 1983. Lower Cretaceous ostracodes from Israel and Sinai. Israel Journal of Earth Sciences, 33:85-134.

Schaller, H. 1969. Revisão estratigráfica da bacia de Sergipe-Alagoas. Boletim Técnico da PETROBRÁS, 12:21-86.

Souza-Lima, W.; Andrade, E.J.; Bengston, P. \& Galm, P.C. 2002. A bacia de Sergipe-Alagoas: evolução geológica, estratigrafia e conteúdo fóssil. Phoenix, Edição Especial, 1:1-34. 
Swain, F.M. 1976. Lower and Middle? Cretaceous Ostracoda from the Atlantic Ocean off Guiana and off West Africa. Journal of Paleontology, 50:734-753.

Tambareau, Y. 1982. Les Ostracodes et l’histoire géologique de l’Atlantique Sud au Crétacé. Bulletin des Centres de Recherche et Exploration-Production Elf-Aquitaine, 6:1-37.

Viviers, M.C.; Koutsoukos, E.A.M.; Silva-Telles, Jr. A.C. \& Bengtson, P. 2000. Stratigraphy and biogeographic affinities of the late Aptian-Campanian ostracods of the Potiguar and Sergipe basins in northeastern Brazil. Cretaceous Research, 21:407-455.

doi:10.1006/cres.2000.0205

Figure 1. Location of the Sergipe-Alagoas basin in South America (A) and Brazil (B), along with the outcrops and wells studied in the present work (C).

Figure 2. Biostratigraphy of the Albian and early Cenomanian sections of the Sergipe-Alagoas basin, Brazi, based in ostracodes, foraminifers and cephalopods (Koutsoukos \& Bengtson, 1993; Viviers et al., 2000).

Figure 3. Lithology of sampled Riachuelo Formation outcrops in the Sergipe-Alagoas basin, Brazil.

Figure 4. Reviewed ostracod biostratigraphy of the Sergipe-Alagoas basin, along with the temporal distribution of its late Aptian-Albian species.

Figure 5. Biostratigraphy of the outcrops and wells from the Sergipe-Alagoas basin studied in the present work. 
Figure 6. Paleozoogeography of species with occurrences in the Riachuelo

Formation, Sergipe-Alagoas basin, Brazil, and coeval lithologies worldwide during the Albian and Early Cenomanian.

Table 1. Sampled depths from wells ceded by PETROBRAS S.A studied in the present work. 


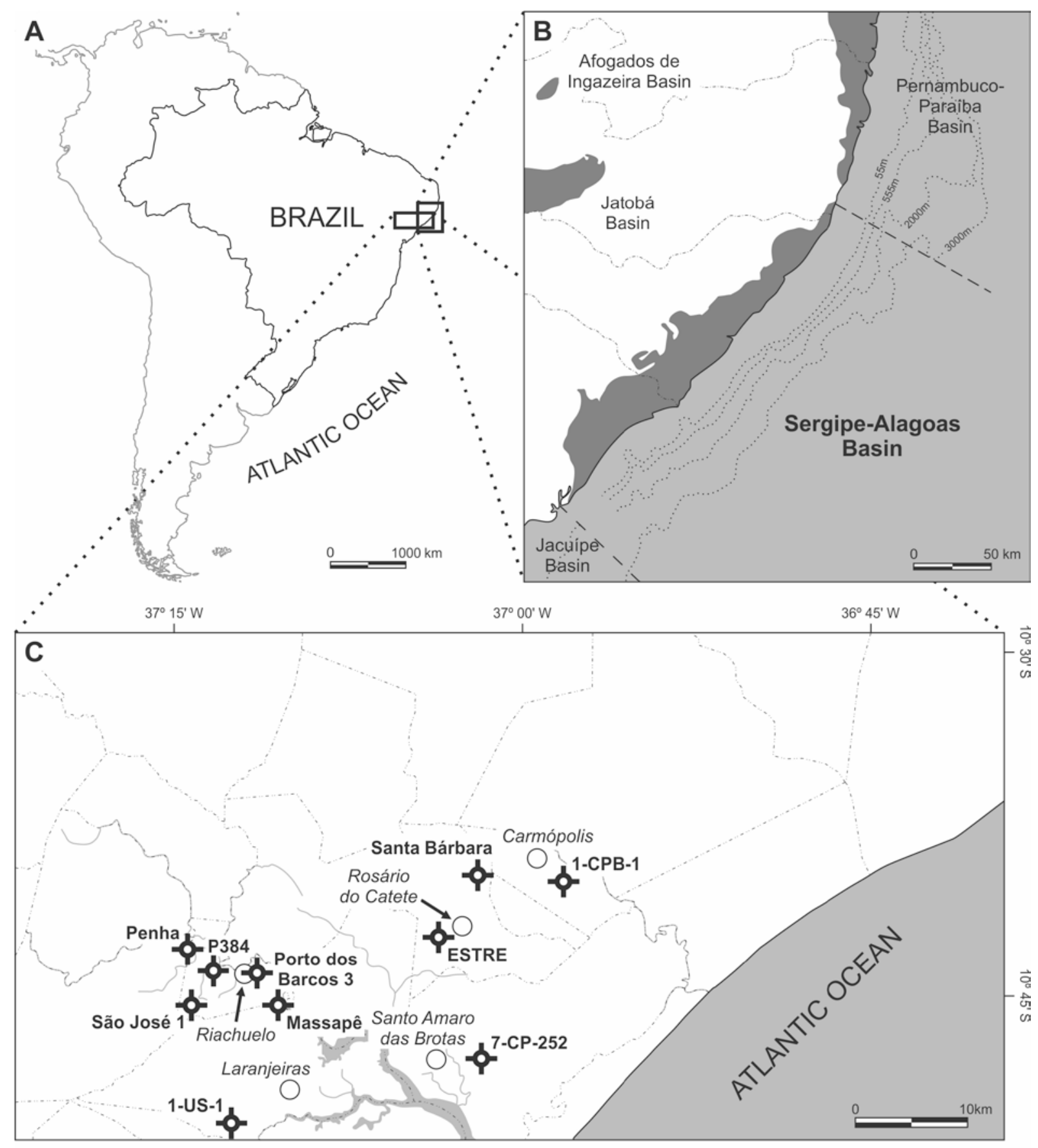




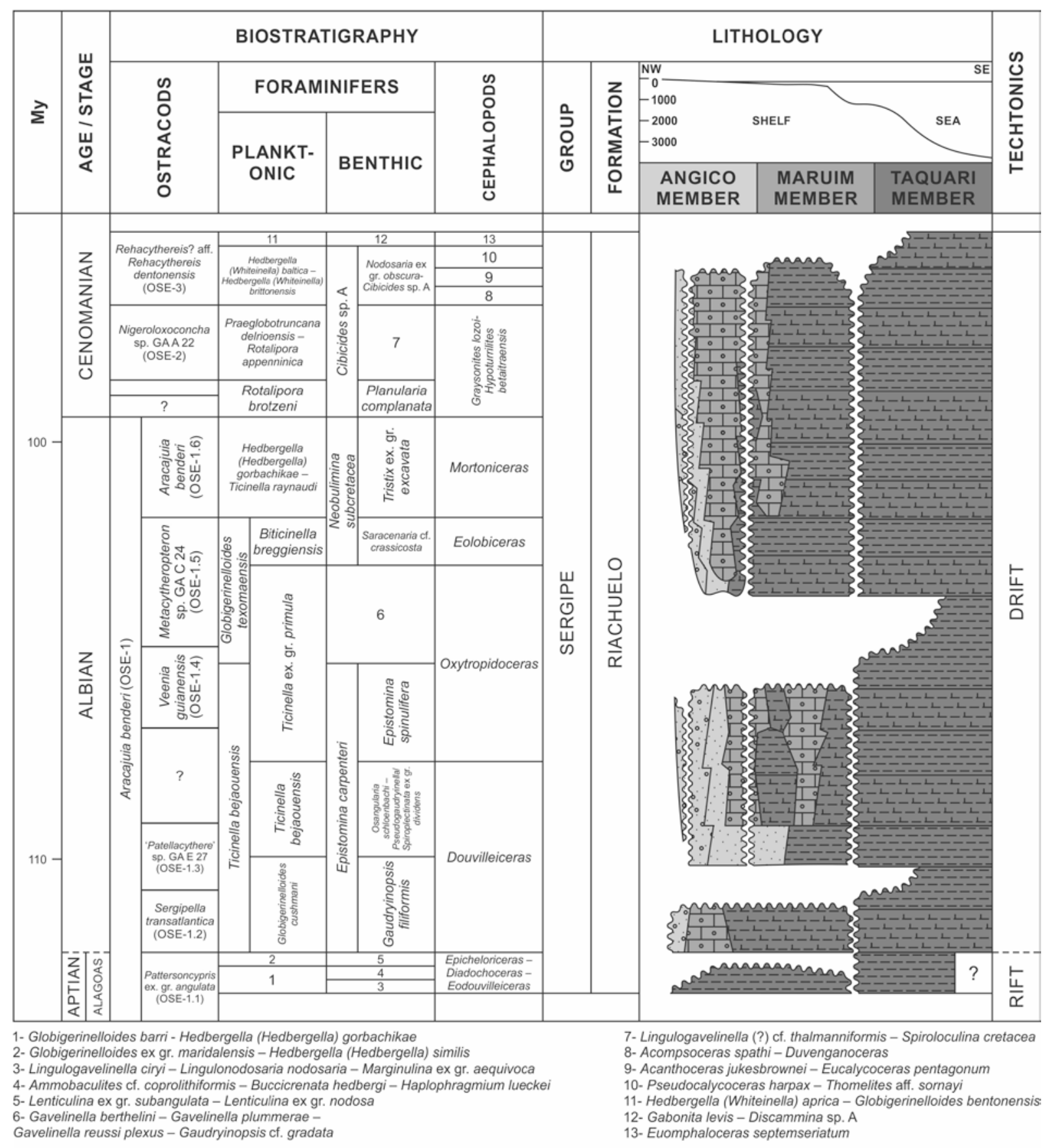




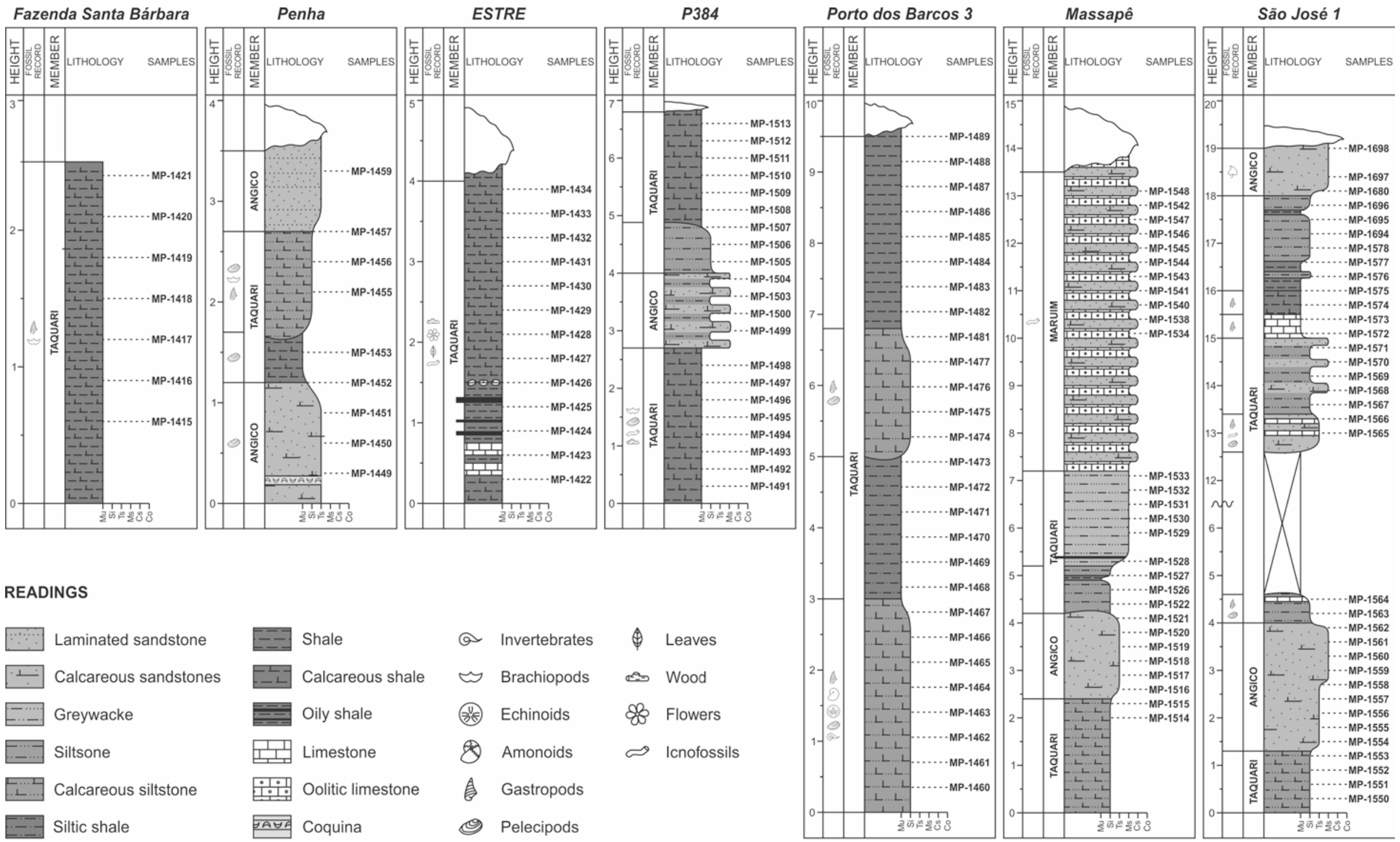




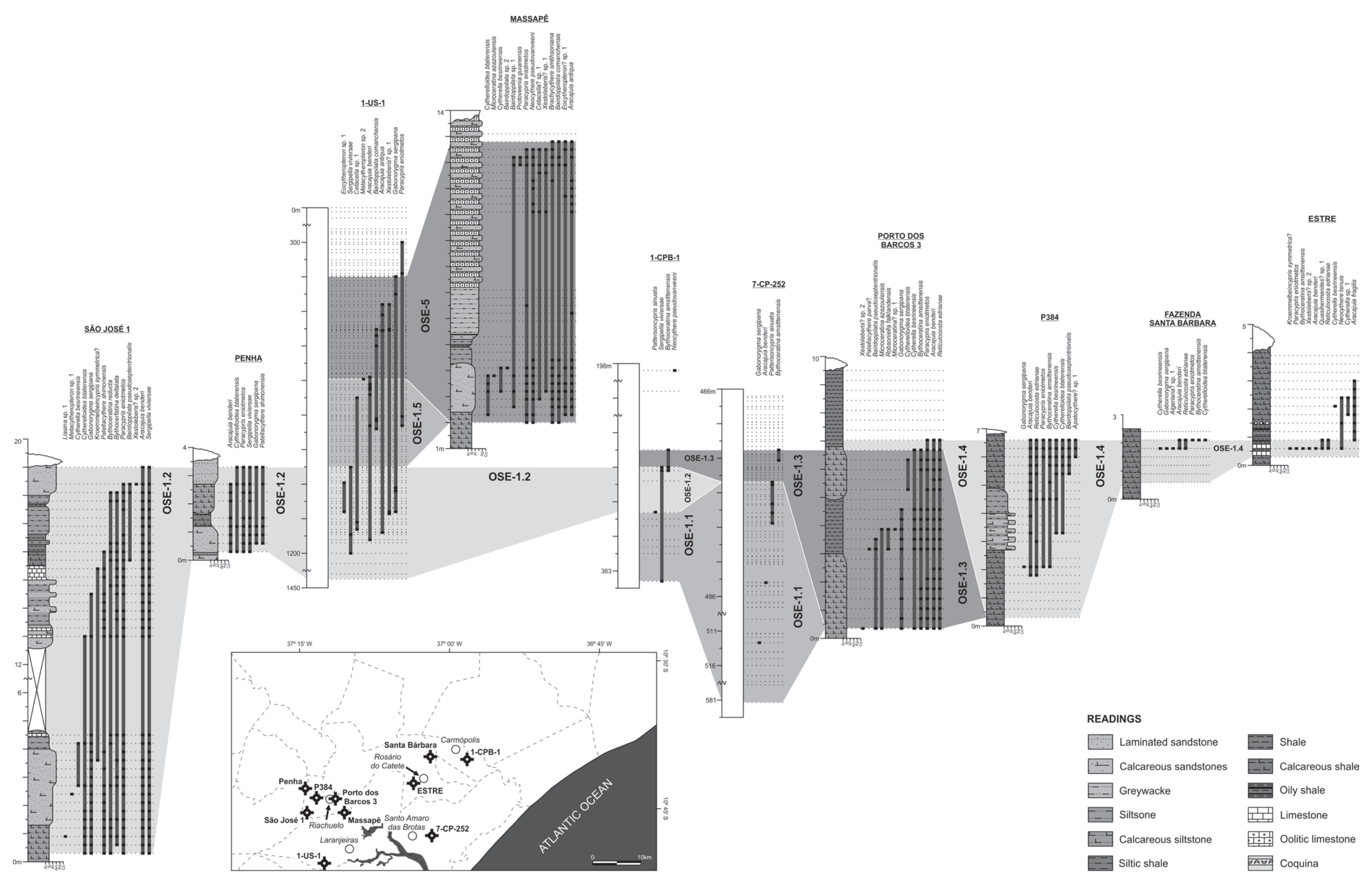




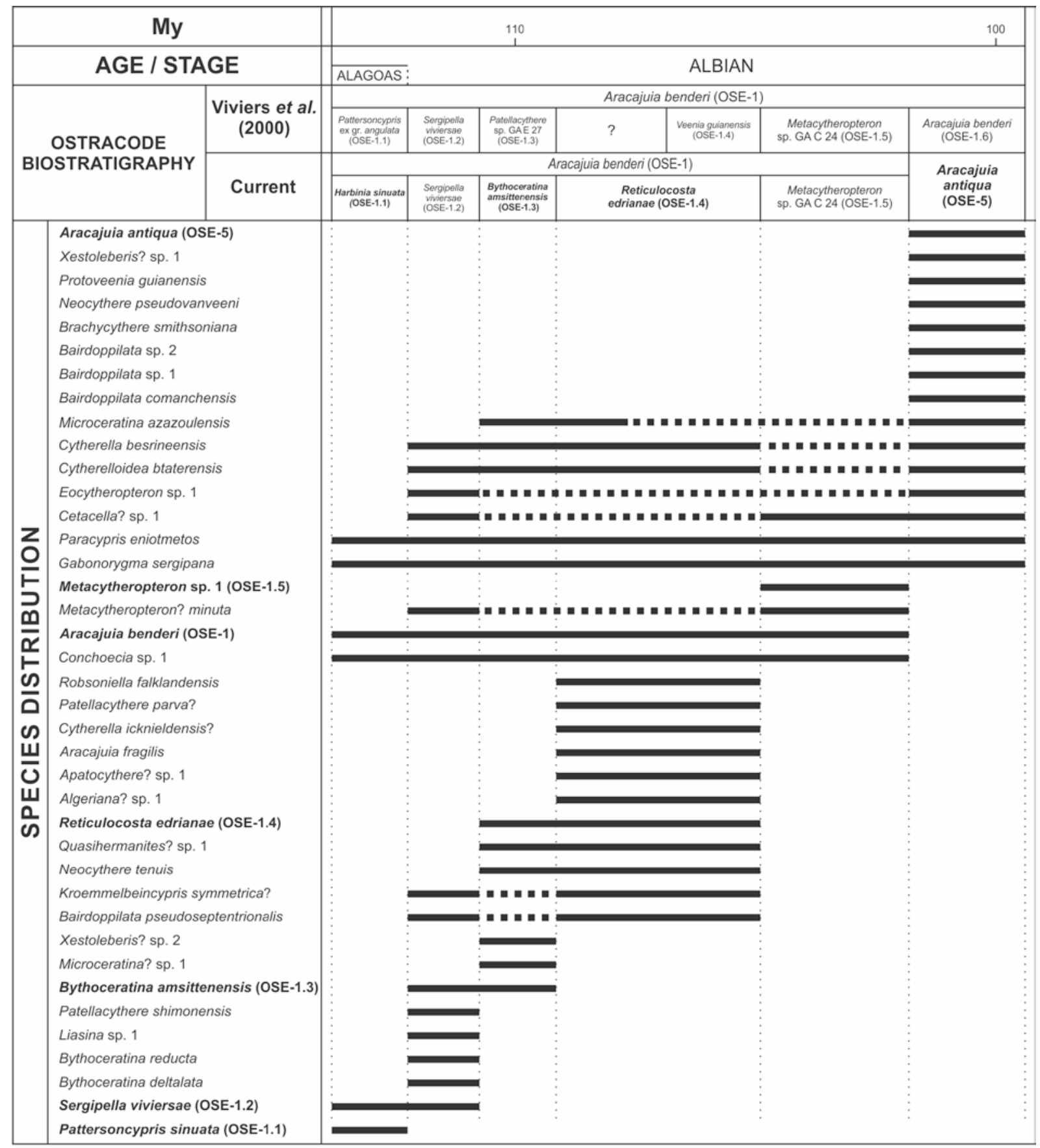


Early Albian (112 Ma)
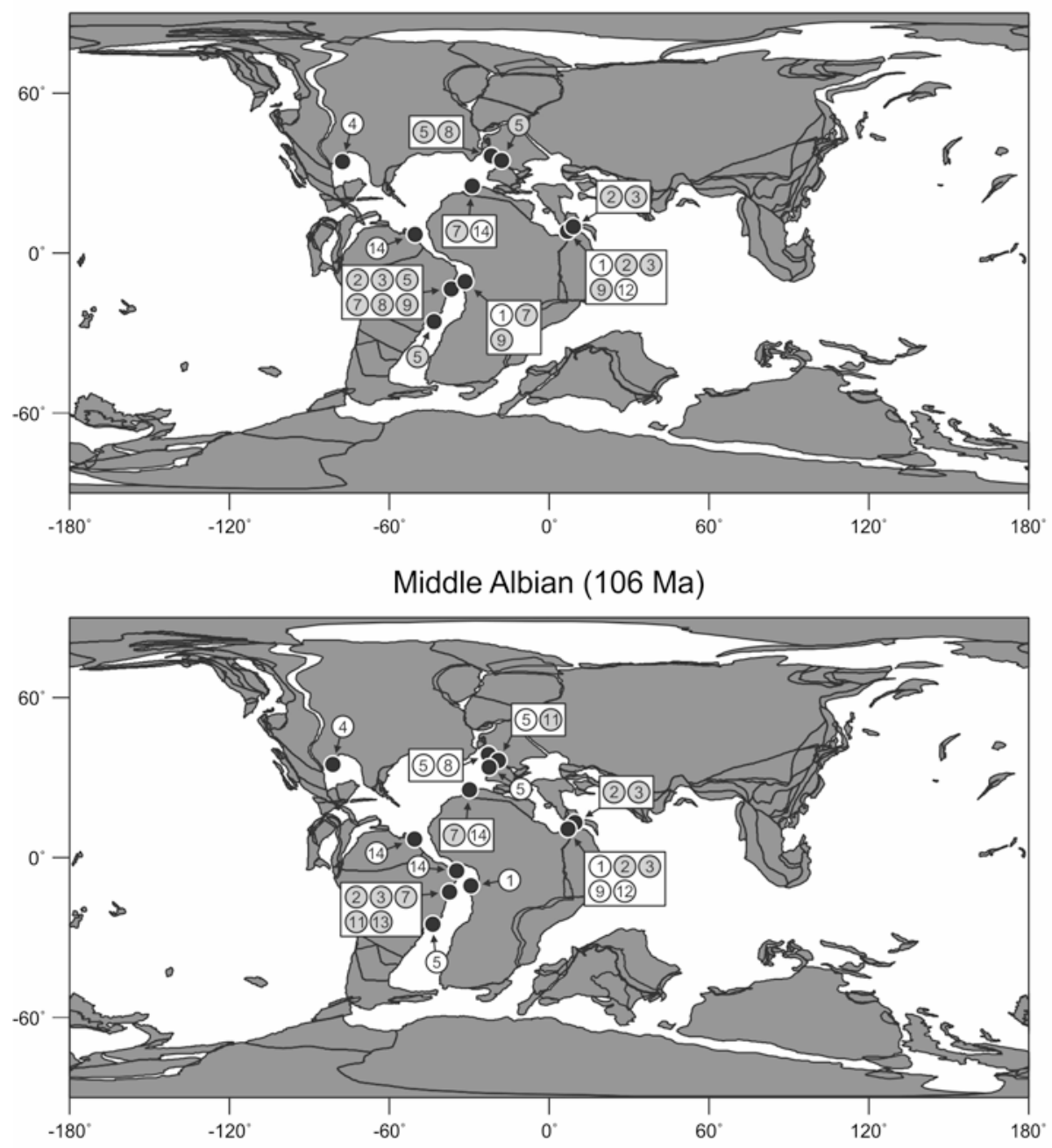

Late Albian (100 Ma)

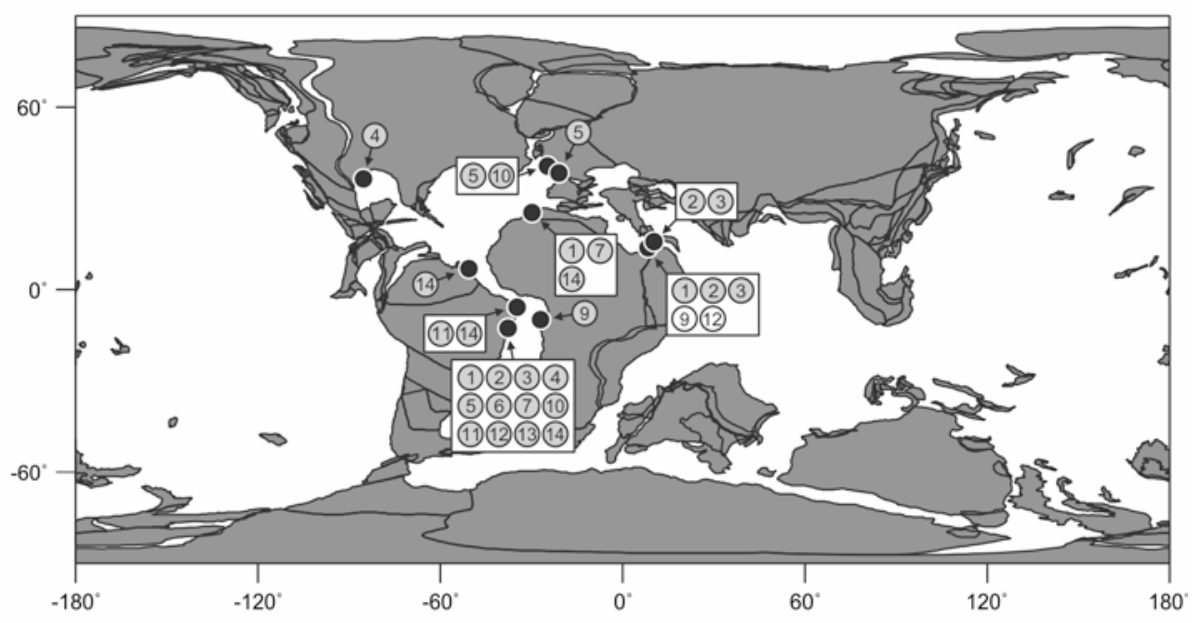

Early Cenomanian (97 Ma)

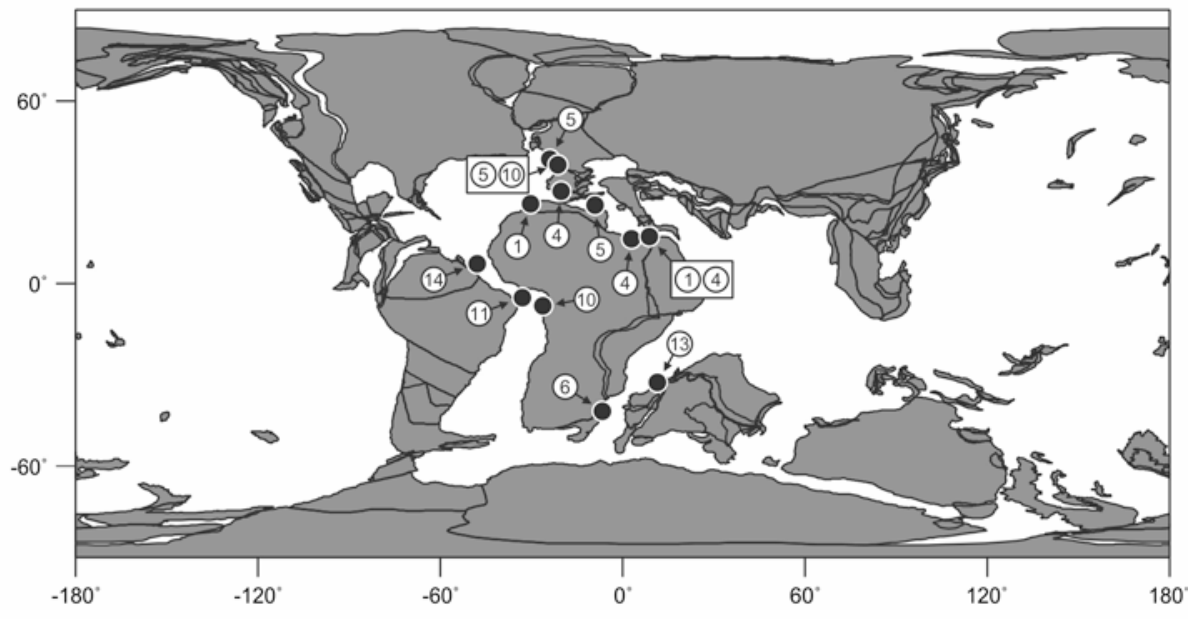
80

(1) Conchoecia sp. 1

(3) Cytherelloidea btaterensis

(5) Bairdoppilata pseudoseptentrionalis (7) Bythoceratina amsittenensis

(9) Patellacythere shimonensis

(2) Cytherella besrineensis (4) Bairdoppilata comanchensis (6) Robsoniella falklandensis (8) Bythoceratina reducta (10) Neocythere pseudovanveeni (12) Aracajuia antiqua (14) Protoveenia guianensis 


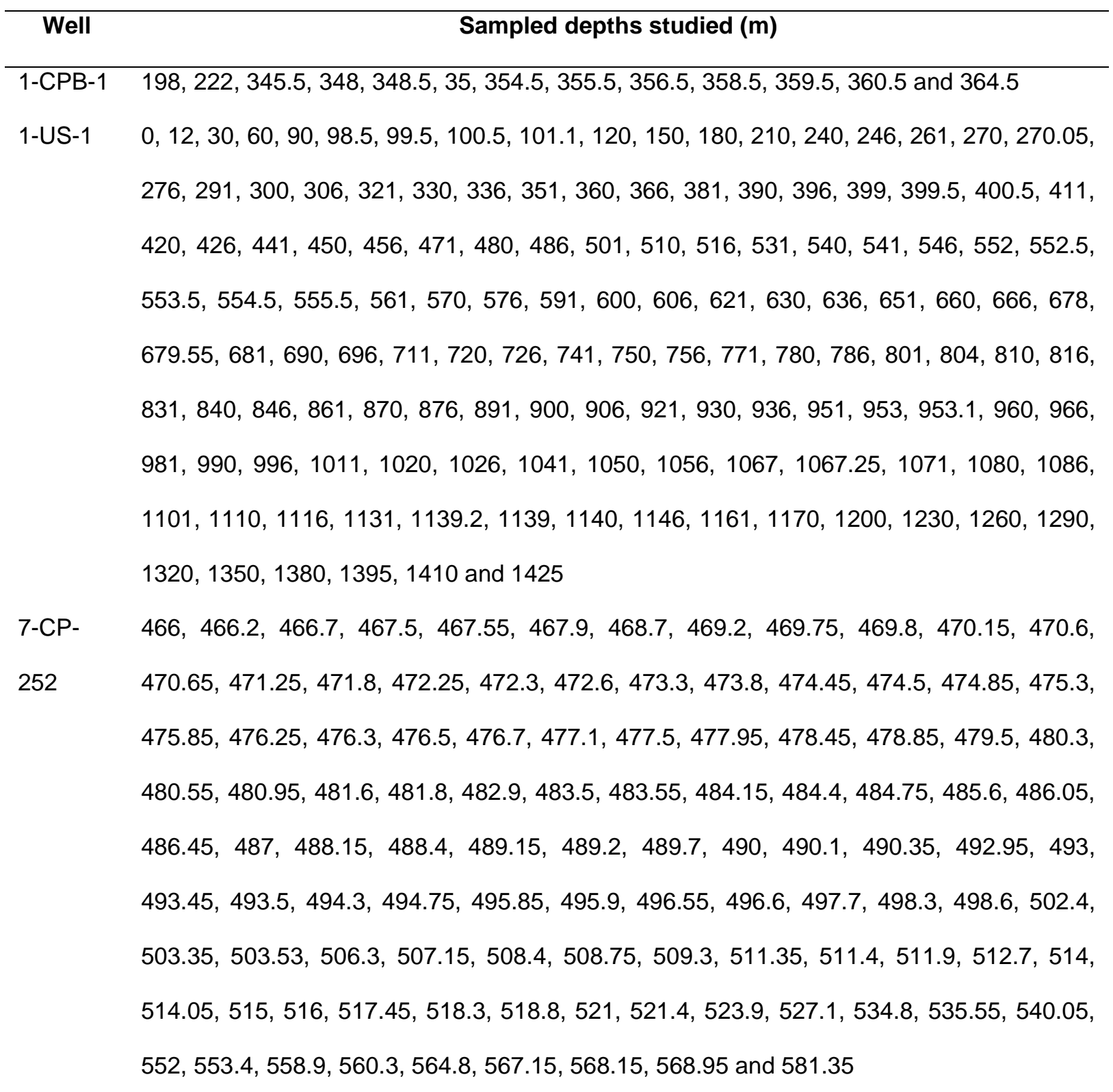


Anexo V. Resumo intitulado Taxonomic, biostratigraphic e palaeozoogeographic aspects of Amphicytherura Butler \& Jones, 1957 e Aracajuia Krömmelbein, 1967 (Cytheridae, Schizocytherinae), apresentado no $17^{\text {th }}$ International Symposium on Ostracoda (ISO), realizado em Roma, Itália. 
Naturalista sicil., S. IV, XXXVII (1), 2013, pp. 39-40

\author{
LuCAS AntonietTo, ANNa ABrahão, \\ DeRMeVAl APARECIDO DO CARMO \& RiCARDO MEIRELES
}

\begin{abstract}
TAXONOMIC, BIOSTRATIGRAPHIC AND PALAEOZOOGEOGRAPHIC ASPECTS OF AMPHICYTHERURA BUTLER \& JONES, 1957 AND ARACAJUIA KRÖMMELBEIN, 1967 (Cytheridae Schizocytherinae)
\end{abstract}

The present work is based on a population of Aracajuia benderi Krömmelbein, 1967 isolated from the sample MP-291, collected at "Porto dos Barcos 3" outcrop (type-locality of the genus Aracajuia Krömmelbein, 1967) (KrömmelbeIn, 1967), Taquarí Member, Riachuelo Formation, SergipeAlagoas basin, northeastern Brazil. Our purpose is to reevaluate the taxonomic status of the genera Amphicytherura Butler \& Jones, 1957, Sondagella Dingle, 1969 (originally a subgenus of Amphicytherura) and specially Aracajuia, along with its type-species, Aracajuia benderi. The authors also intend to review most of the palaeozoogeography and stratigraphic distribution of these genera, so as to infer migration pathway histories for their species.

Following the taxonomic review, the genera Amphicytherura and Aracajuia received new diagnoses. Some species currently assembled to Amphicytherura actually do not resemble its type-species, Amphicytherura dubia (Israelsky, 1929) (BUTLER \& JONES, 1957); therefore, they should be placed in other existing genera, or possible new ones. Sondagella, due to its similarities to Aracajuia, and according to the principle of priority, was put into synonymy with the last.

Aracajuia benderi, which is the type-species of Aracajuia (Krömmelbein, 1967), was also re-diagnosed and re-described, based on SEM photography. Specimens attributed to this species had their height and length measured, and the results were used to analyse the ontogenetic development of the species. The occurrence of Aracajuia benderi is considered a stratigraphic marker of late Aptian-Albian sequences in the Sergipe-Alagoas basin 
(VIVIERS et al., 2000). A zone and a subzone were established based on this species, although both originally were named Amphicytherura benderi. The present authors propose a new combination to name these zones, Aracajuia benderi n. comb.

Although morphologically similar, Amphicytherura and Aracajuia present very distinct evolutionary histories. Occurrences of Aracajuia are mostly linked to the evolution of Gondwana, where it was observed in similar levels of diversity throughout tropical/arid and possibly warm temperate coasts of the palaeocontinent. Few exceptions were the occurrences in "paratropical" areas of ancient European portions of Laurasia. Its greatest diversity occurred during the Albian. The genus Amphicytherura is restricted to the Upper Cretacous and Paleocene. It was observed in warm temperate and possibly "paratropical" waters along the North Atlantic coasts of Europe and North America. The specific abundance of the genus peaked in the Maastrichtian, but Amphicytherura was still represented in the Paleocene-Eocene, when it ranged from Eastern Europe to Western Asia. Species currently placed in Amphicytherura which might belong to other genera or possible new ones were not considered in the present paleoecological analysis, and should be addressed properly elsewhere.

Acknowledgments - The first author thanks Eni S.P.A. (Rome, Italy) for making possible his participation to ISO17 through a Young Researcher Grant.

\section{REFERENCES}

ButLer E.A. \& Jones D.E., 1957. Cretaceous ostracoda of Prothro and Rayburns Salt Domes, Bienville Parish, Louisiana. Bulletin of the Louisiana Geological Survey, 32: 1-65.

KrÖMmelbeIN K., 1967. Ostracoden aus der marinen "Küsten-Kreide" Brasiliens. 2: Sergipella transatlantica n. g., n. sp., und Aracajuia benderi n. g., n. sp., aus dem Ober Aptium/Albium. Senckenbergiana lethaea, 48: 525-533.

Viviers M.C., Koutsoukos E.A.M., Silva-Telles Júnior A.C. \& Bengtson P., 2000. Stratigraphy and biogeographic affinities of the late Aptian-Campanian ostracods of the Potiguar and Sergipe basins in northeastern Brazil. Cretaceous Research, 21: 407-455.

Authors' Addresses - L. Antonietto, D.A. Do CARmo, Micropaleontology Lab, Institute of Geosciences, University of Brasilia, Darcy Ribeiro Campus, 70919-970 Brasilia (Brazil); e-mail: antoniettols@gmail.com; derme@unb.br; A. ABRAHÃO, Departament of Botanics, Institute of Biology, University of Campinas, Cidade Universitária Zeferino Vaz, Monteiro Lobato Street, 255, P.O. Box: 6109, 13083-862, Campinas (Brazil); e:mail: anna.abrahao@gmail.com; R. MEIRELEs, Research Center in Biodiversity and Genetic Resources, Associate Lab, Department of Biology, University of the Azores, 9501-801, Ponta Delgada (Portugal); e-mail: ricomeireles@gmail.com. 
Anexo VI. Resumo intitulado Insights on taxonomy, paleozoogeography and biostratigraphy of Albian Ostracoda (Crustacea) from the Sergipe-Alagoas basin, Brazil, apresentado no $4^{\text {th }}$ International Palaeontological Congress (IPC), realizado em Mendoza, Argentina. 


\title{
INSIGHTS ON TAXONOMY, PALEOZOOGEOGRAPHY AND BIOSTRATIGRAPHY OF ALBIAN OSTRACODA (CRUSTACEA) FROM THE SERGIPE-ALAGOAS BASIN, BRAZIL
}

\author{
Antonietto, L.S. ${ }^{1,2}$, Do Carmo, D.A. ${ }^{1} \&$ Hunt, G. ${ }^{2}$ \\ 1. Micropaleontology Lab, Institute of Geosciences, University of Brasilia, Darcy Ribeiro Campus, Brasilia, Distrito \\ Federal, Brazil, P.O. Box: 04465, ZIP: 70.910-900. antoniettols@gmail.com. \\ 2. Department of Paleobiology, National Museum of Natural History, Smithsonian Institution, \\ $10^{\text {th }}$ Street \& Constitution Avenue NW, Washington, District of Columbia, P.O. Box: 37012, MRC: 121, ZIP: \\ 20560-0121.
}

The Sergipe-Alagoas basin has one of the most complete, exposed lithological successions of the Cretaceous period in the continental margin of Brazil. It captures several phases of the evolution of the South Atlantic ocean, including rift, gulf and drift. The Aptian-Albian Riachuelo Formation belongs to its gulf phase and it is subdivided into three interbedded members: Angico, Taquari and Maruim. Previous studies of this formation and those adjacent led to a finely dated biostratigraphy of the unit. Herein, the main objective is to expand knowledge about the biodiversity, paleozoogeography and biostratigraphy of the Albian of the Sergipe-Alagoas basin, while reviewing the status of some of its zones and subzones. Thirty-four species were recovered from the present samples: Cytherella besrineensis (Bischoff, 1964), Cytherella sp. 1, Cytherelloidea btaterensis Bischoff, 1964, Cytherelloidea knaptonensis Kaye, 1963, Bairdoppilata comanchensis (Alexander, 1929), Bairdoppilata pseudoseptentrionalis Mertens, 1956, Bairdoppilata sp. 1, Robsoniella sp. 1, Paracypris eniotmetos Nicolaidis \& Piovesan, 2013, Kroemmelbeincypris symmetrica? (Krömmelbein \& Weber, 1971), Liasina sp. 1, Bythoceratina amsittenensis Andreu-Boussut, 1991, Bythoceratina reducta (Gründel, 1964), Bythoceratina sp. 1, Bythoceratina sp. 2, Patellacythere parva? Weaver, 1982, Phodeucythere? sp. 1, Asciocythere? sp. 1, Dicrorygmini sp. 1, Neocythere pseudovanveeni (Gründel, 1966), Neocythere tenuis Kaye, 1965, Aracajuia antiqua? Rosenfeld \& Raab, 1983, Aracajuia benderi Krömmelbein, 1967, Metacytheropteron sp. 1, Microceratina sp. 1, Microceratina? sp. 2, Quasihermanites? sp. 1, Protoveenia? sp. 1, Reticulocosta sp. 1, Brachycythere sp. 1, Algeriana? sp. 1, Sergipella viviersae Do Carmo et al., 2012, Isocythereis sp. 1, Gen. et sp. indet. 1 and Gen. et sp. indet. 2. Several species are shared with faunas from Europe, the Middle East, North America and West Africa, indicating that the ostracodes from the SergipeAlagoas basin share closer affinities with these distant faunas than with those in closer proximity in the Proto-South Atlantic region, such as the southernmost parts of South America and Africa. Several factors 
could explain these patterns of faunal similarity, including differences in ecological settings between the areas of the Proto-South Atlantic ocean at north (arid-tropical) and south (warm temperate) of the Walvis ridge. Taxonomic studies also indicate the Subzone Veenia guianensis, in the Zone Aracajuia benderi, should have its name changed, although it still depends on an ongoing review. The recently found higher diversity of the genus Bythoceratina, compared to previous materials from the basin, might also lead to name changes in the Subzone 'Patellacythere’ sp. GA E 27. 